ine 



\section{Science of Fishing}

The Most Practical Book on Fishing Ever Published "

Tells How to Catcn Fish; For Those Who Have Caught Them, as Well as

Those Who Never Have

LAKE BROOKS

Published by

A. R. HARDING, Publisher

Columbus, Ohio 
NINTH REVISED EDITION-1933 Printed in U. S. A.

SH 4 41

- $\mathrm{H}_{3}$ $1933 x$

Copyright 1912

Rv A. R. HARDING 


\section{CONTENTS.}

Chapter.

PAGE

I. Remarks on the "Gentle Art" . . . . . 15

II. Rods . . . . . . . . . . . . . 21

III. Reels . . . . . . . . . . . . . 38

IV. Hooks, Lines and Leaders . . . . . . 51

V. Flies . . . . . . . . . . . 65

VI. Artificial Baits . . . . . . . . . . 72

VII. Landing Nets, Gaffs, Tackle Boxes, Etc. . . 83

VIII. Bait Casting . . . . . . . . . . . 95

IX. Fly Casting . . . . . . . . . . . 103

X. Surf-Casting, Trolling, Stiıl Fishing, Etc. . 112

XI. Use of Natural Baits . . . . . . . . 121

XII. Handling the Hooked Fish . . . . . . 130

XIII. Fishing For Black Bass . . . . . . . 135

XIV. Fishing For Trout and Salmon . . . . . 143

XV. Pike, Pickerel, Muskellunge, and Pike-Perch . 157

XVI. Sunfish, Carp, Catfish, and Suckers . . . 167

XVII. Fishing For Tarpon and Tuna . . . . . 184

XVIII. Fishing For Other Sea Fish . . . . . . 190

XIX. Making, Repairing, and Caring For Tackle . 201

XX. General Information and Advice . . . . 222

XXI. Commercial Fishing . . . . . . . . 230

XXII. Distribution of Fish-Good Places . . 249 



\section{ILLUSTRATIONS.}

PAGE

A Catch of Salmon and Trout from the Miramichi River, New Brunswick . . . . . . Frontispiece

A Large Specimen of the Northern Pike . . . . . 17

Construction of Split Bamboo and Solid Wood Rods . 23

Various Styles of Line Guides . . . . . . . . 25

Various Styles of Rod Tips . . . . . . . . . 27

Rod Handles . . . . . . . . . . . . . . . 28

Three-Piece Bait-Casting Rod, and Three-Piece Steel

Bait-Casting Rod . . . . . . . . . . . 30

Fly Rod and Bait Rod . . . . . . . . . 32

A Salmon Fly Rod . . . . . . . . . . . 34

A Two-Piece Split Bamboo Salt-Water Rod, and a

Solid Wood Rod with Removable Butt . . . . 35

Agate Tip for Salt-Water Rod . . . . . . . . 36

Single Action Click Reel, Rubber, with Protected Bal-

ance Handle . . . . . . . . . . . . 39

Single Action Reel with Revolving Side Plate and

Expert Click Reel . . . . . . . . . . 40

Salmon Reel . . . . . . . . . . . . . . 41

Multiplying Reel, for Bait-Casting . . . . . . . 42

The Anti-Back-Lash Casting Reel . . . . . . . 44

Redifor Reel with Automatic Spooler . . . . . 45

The Marhoff Level-Winding Reel . . . . . . . 46

An Automatic Reel - the Y. \& E. . . . . . . . 47

An Automatic Reel in Action - The Martin . . . 48

Tarpon and Tuna Reel . . . . . . . . . . 49

Wood Reel, for Trolling and Salt Water Fishing . . 50

Various Patterns of Fish Hooks . . . . . . . 52 
Barbless Hooks

PAGE

Fish Hooks in Exact Sizes

Weedless Hooks

The Van Vleck Tarpon Hook . . . . . . . . 57

Sizes of Twisted Linen Lines . . . . . . . . 58

Sizes of Braided, Enameled, Silk Lines . . . . 59

Sizes of Tapered Silk Lines . . ‘ . . . . . . . 60

A Gut Leader and a Leader Box . . . . . . . 61

A Steel Wire Leader with Swivel ard Coupler . . . 63

Floating or Dry Flies, for Trout . . . . . . . 67

Salmon Flies . . . . . . . . . . . . . 68

Buck Tail Bass Fly . . . . . . . . . . . 70

The Roamer Bait . . . . . . . . . . . 72

The Nemo Bait . . . . . . . . . . . . . 73

The Booster Bait and the Fish Nipple . . . . . 74

The Pearl Minnow . . . . . . . . . . . . 74

Phantom Minnow, Shakespear and Dowagiac Minnows, Coaxer Bait, and Pearl Wobbler . . . . 75

The Little Wonder Bait . . . . . . . . . . 76

The Champion Bait . . . . . . . . . . . 76

Muskellunge Spoon and Two-Hook Casting Spoon . 77

The Lifelike Minnow Bait . . . . . . . . 78

A Spoon Bait with Fly Hook . . . . . . . . 78

Baits for Salt-Water Fish . . . . . . . . . 79

Fluted Casting Baits or Spoons . . . . . . . 81

A Landing Net for Use While Wading Streams . . 84

Folding Pattern Landing Nets . . . . . . . . 85

A Pocket Landing Net . . . . . . . . . . 86

Marble's Clincher Gaff . . . . . . . . . . 87

Gaff Hooks . . . . . . . . . . . . 88

A Creel or Fish Basket . . . . . . . . . . 89

A Chain Fish Stringer . . . . . . . . . . 90

A Glass Minnow Trap . . . . . . . . . . 91

A "Lead In" for a Glass Jar Trap . . . . . . . 92 
PAGE

A Metal Tackle Box . . . . . . . . . . 93

The Fruits of Bait Casting . . . . . . . . . 96

Diagram Showing Bait Side Cast . . . . . 98

Thumbing the Reel . . . . . . . . . . 99

Spooling the Line . . . . . . . . . . . 100

A Soft Rubber Butt Cap . . . . . . . . . 101

Results of Fly Casting . . . . . . . . . 106

A Catch of Pike and Suckers from Otter Tail Co.,

Minnesota, Killed with Spears . . . . . . 115

A Fish Spear . . . . . . . . . . . . 117

Eel or Sucker Spear . . . . . . . . . . 118

A Pickerel Trap, for Ice Fishing . . . . . . 119

Sunfish, a Two Hours' Catch Near Madison, Wis. . . 123

Hooks Baited with Worm and Hopper . . . . . 124

Hook Baited with Minnow . . . . . . . . . 125

Some Natural Bait Hooks . . . . . . . . . 127

Small Mouthed and Large Mouthed Black Bass . . 137

Steelhead Trout, Brook Trout, and Lake Trout . . 146

A Thirteen Pound Rainbow Trout Taken on a Spinner . 149

Atlantic Salmon and Quinnat Salmon . . . . . 154

Pike, Eastern Pickerel, Muskellunge, and Pike Perch . 160

Difference in Scales of Pike, Pickerel, and Muskellunge . 162

Common Sunfish . . . . . . . . . . . 168

White Perch and Yellow Perch . . . . . . 171

The Common Carp . . . . . . . . . . . 174

Common Catfish or Bullhead . . . . . . . 177

Catfish from Ross County, Ohio . . . . . . 179

The White Sucker . . . . . . . . . . 181

The Tuna . . . . . . . . . . . . . . . 185

Tarpon, Bluefish, and Kingfish . . . . . . . 187

Jewfish, or Black Sea Bass, From the Pacific . . . 191

Barracuda, Squeateague or Weakfish, and Spanish,

Mackerel . . . . . . . . . . . 193

Striped Bass and Sea Bass . . . . . . . . 196 
Red Drum or Channel Bass . . . . . . . . . 197

Sheephead . . . . . . . . . . . . . . . 199

Diagram Showing Measurements for a Bait Rod . . 203

Regulation Methods of Wrapping a Rod . . . . 210

Another Way to Wrap a Fishing Rod . . . . 212

Construction of Separate Handles . . . . . . . 213

Leader Knots . . . . . . . . . . . . 215

More Leader Knots . . . . . . . . . . 217

Hook and Leader Tying . . . . . . . . . . 218

Net Knots and Needles . . . . . . . . . 220

Tying the Net, and Use of Gauge Stick . . . . . 221

A Catch of Croppies from Huffman Lake, Indiana . 223

Interior of a Herring Saltery . . . . . . . . 235

Interior of a Salmon Cannery . . . . . . . . 240

Map Showing the General Distribution of North American Fish . . . . . . . . . . . 


\section{PREFACE.}

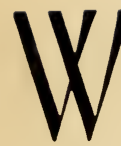

HEN planning this work the difficulty of thoroughly covering the broad subject forming the title of the book was foreseen, and the average angler would probably have considered it impossible to get a comprehensive work of this nature into such a small volume. Without a desire to boast, and especially since you have not yet had a chance to express your opinion on the work, I feel justified in thinking that I have succeeded beautifully in this. But in order to tell everything I had in view, as expressed in the chapters which follow, I found it necessary to get right to the point, and avoid all superfluities, and the little anecdotes which usually relieve the monotony of such a work, but I believe that the general reader will like it better so, since he will get in one book what is usually comprised in two.

The author is a practical angler - not an expert in each branch, it is true-but well acquainted with each. Most of the writing is based on my own experience, but in descriptions of certain fishes and their habits, I have been obliged to refer sometimes to the works of others. In such cases all statements of a doubtful character have been eliminated.

It has been my object throughout to inspire the reader with a desire for cleaner and better sport, that he may get from his chosen recreation all the pleasure that there is in it. To this end I have dwelt fondly on fly-fishing and bait-rasting, and the instruments used for these branches 
Red Dru g, for I consider them the cleanest, most satisShee ${ }^{2}$, and most pleasant styles of fishing. Some might Dia ${ }^{\circ}$ ook on it this way, as a little story that I heard just R ently will illustrate.

An old colored woman wanted to purchase one of the late pattern artificial baits, and the dealer, knowing that she did not know how to use a bait of this kind proceeded to explain. "Now see here," he said, "you can't use this like you do an ordinary baited hook; you must keep it moving all the time - wiggle it." And she replied, "Aw gwan; take yo wiggle; I don't want no wiggle. I wants a bait that I can fro out, and sit still and fish." And so it may be with others.

And now I leave you to peruse this work, and I trust that you will enjoy it; that it may help you to make better catches of nicer fish; and perhaps, if you are an amateur, even teach you better and more enjoyable ways of fishing. 


\section{SCIENCE OF FISHING.}

\section{CHAPTER I.}

\section{Remarks on The "Gentle Art."}

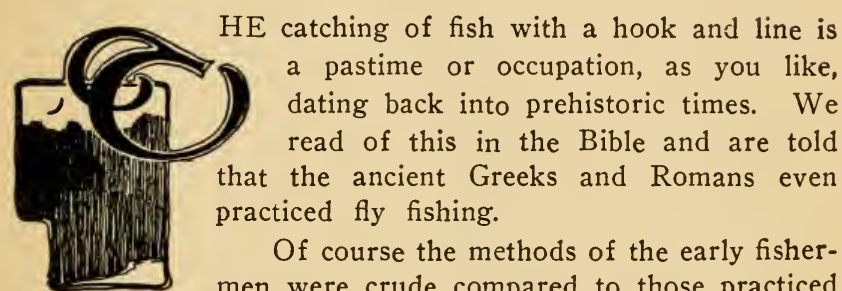

men were crude compared to those practiced at the present day, even though they did fish with the artificial fly, for the beautiful rods, reels, lines and other paraphernalia of the present day angler were unknown then. There is no doubt whatever that the first fishing done by mankind was not for sport, but to procure the wherewithal to satisfy the cravings of the inner man. Doubtless our remote, savage ancestors picked up fish that were cast up on the beach and as everything in the line of flesh was food, they soon learned that fish were good to eat. Then they devised means of capturing the finny denizens of the deep, perhaps using crude nets of bark, strips of hide, and like materials, perhaps also making pound nets or traps of rushes; and when they learned that fish would bite at dainty morsels thrown into the water, they doubtless resorted to hair lines and bone hooks. Lines of horsehair were the only kind in use in ancient times, and even down to the days of "Sir" Izaak Walton, in the first half of the sev- 
inteenth century, perhaps much later. Anyway we know that not many years ago it was quite common to see a horsehair line used for trout fishing, and such lines may even yet be in use in rural districts.

Catching fish with hook and line therefore is an ancient sport, but it is also a modern one for there is no more delightful pastime to be had. It leads one into the country, if not into the wilds, away from the haunts of man quite often, and always to the quiet places where Mother Nature reigns. There the enthusiastic angler gives no heed to the rapidly passing time, as he casts his flies first to this and then to that likely looking spot, where his close study of the habits of the fish have taught him that a gamey bass or trout may lurk. And then the rise and the strike, the mad rushes and acrobatic leaps of the hooked prize, as it vainly tries to break the line or shake the stinging hook from its mouth! But the steady tension of the bended rod and the scientific methods of the angler are too much for him and he is eventually reeled in, fighting all the way; the landing net is slipped under him and he is lifted bodily from his beloved waters.

Or perhaps the fisherman is a bait-casting enthusiast. With his short, stiff rod he sends his many hooked artificial bait, resembling nothing in nature, out many rods over the quiet waters, in much the same way that we, when barefoot boys, threw apples from a stick. With unerring accuracy he places the bait onto the very spot of water he had in view, commencing to reel in the line as soon as the bait strikes the water. His method is certainly scientific, but will hardly appeal to the fly-fisherman. But he enjoys it more than any other form of sport, and it yields fish, and big ones, too.

But there are many who like to fish who are not enthusiasts. They fish on holidays, on Saturday afternoons, sometimes between Saturday and Monday, and sometimes 


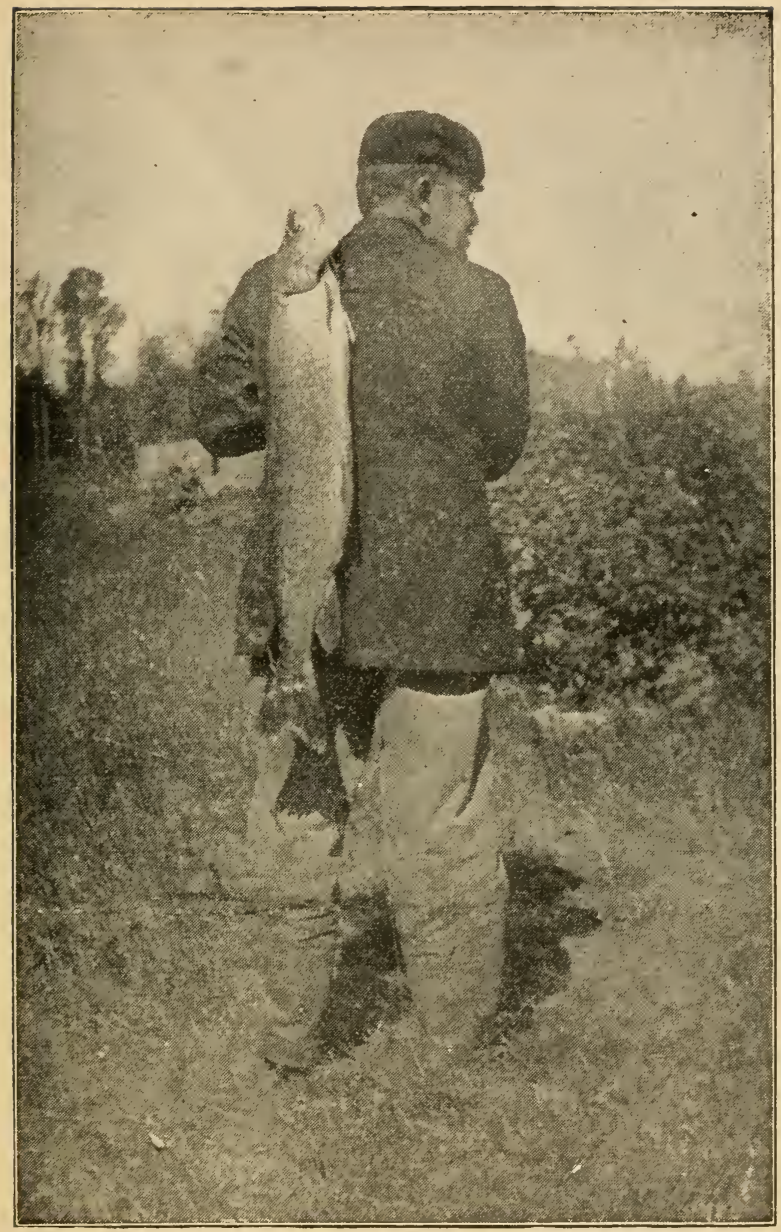

A Large Specimen of the Northern Pike. 
when they should be at work. It is the rest, the quiet, the fresh air, and a mess of fish that they are after, usually, but many like the fishing for itself and to them there is as much pleasure in hauling a surprised and protesting carp or bullhead from his watery home as can be secured from any other form of sport. Let us not despise still-fishing, as it is called, for it is the sport of the man or woman who wants fish, and it yields fish too, in many cases more than the artistic methods of the fly-caster or the strenuous methods of the bait-caster. There is scarcely a person who cannot enjoy a day's fishing for "sunnies" with a cane pole and can of worms, and how many are there who have not, when a boy, spent many a day idling on the river's bank, watching the cork float; and then remember if you can the pleasures you experienced when the cork did its acrobatic feat and dived beneath the water, how you pulled the rod from its rests and hauled the flapping prize on shore, swinging it far overhead lest it fall off into the water and escape! And sometimes when you drew the fish to the surface but the hook failed to catch, how greatly magnified that fish appeared to be as he turned over and you got a fleeting picture of his gleaming side! Nobody could have made you believe that the small fish that you caught a few minutes later was the same one that you had lost - it was much larger than that one. And you believed you were perfectly honest and truthful in your story of "the big one that got away."

But regardless of your purpose, whether for sport or fish, it is fish that you want to take home with you, and what you want to know is how to get them. There is much in knowing what tackle to use and how to use it; in knowing the habits of the fish, what they feed on, and where they may be found. Let the old hands say what they like about learning from experience-we know it is the best way - but it is a fact too evident to be disputed that if the novice can read a good work on fishing, he can learn 
much that would require years of experience to teach him. New methods of fishing are taking the place of the old and new kinds of tackle is being invented almost every day, and unless one is satisfied with his "luck" and content to fish in the same locality with which he has become familiar, he should not depend on observation and experience alone. The purpose of this book is to teach you how to catch fish.

It is my aim to give most attention to the common fishes, those that are well distributed throughout the country and are considered of most importance, either because they offer the most sport, or because of their value as food-fishes. The black bass in particular, being the finest game fish of the fresh waters, and being distributed over a very large part of North America is a fish of the utmost importance. As a game fish, the speckled trout comes next, being one of the fighting kind and found only in the clear cold waters. Its distribution is even wider than that of the black bass. Then there is the savage muskellunge, the fresh water shark of the North; it is important because of its size and fighting proclivities. Even the most common fishes of the central and eastern sections are of importance, because of their abundance and the fact that they are found in the thickly settled portions of the country and are therefore valued by those who cannot go far from home to fish, and those who prefer the quiet baitfishing. Such fish are the carp, sucker, catfish and the various kinds of sunfish.

Fishing will offer sport to the outdoor lovers long after the game birds and animals have become so rare that they no longer will be sought by sportsmen, if that time ever comes. The conservation of the fish supply only needs the support of the public, for if nature is given a chance she will keep up the supply. Laws protecting the more valuable fish for a part of each year, and prohibiting the use of unsportsmanlike methods of fishing should be encouraged and supported by the public, instead of being broken as is too 
often the case by fishing during closed season, using dynamite which kills hundreds of small fish, fishing with seines, and like methods. The public can do much towards preserving the fish supply, in fact the whole matter rests with the people. Let us each one do our part well.

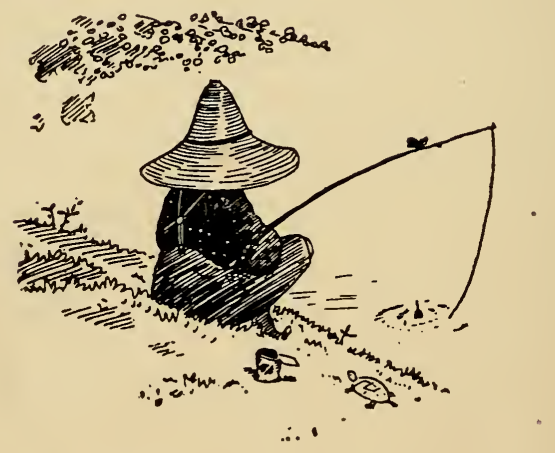




\section{CHAPTER II.}

\section{Rods.}

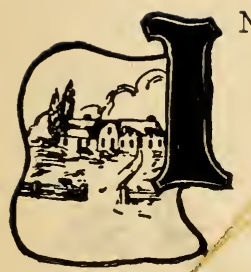

$\mathrm{N}$ all the angler's outfit there is no other article so important as the rod, and when a true angler has found one that is just right for his particular kind of fishing he cares for it as tenderly as the sportsman gunner cares for his fine, high-priced firearms, and has a greater regard for it. This is but natural, and a fine fishing rod, especially the light and resilient fly-rod, cannot fairly be compared with a firearm, or other sporting equipment. A gun in the hands of a hunter becomes only the means by which the end is attained, but the fishing rod in the hands of the angler is something more - it is, when in use, as a part of himself, seemingly like an extension of his arm, and he uses it as though it were a portion of that member, and not a separate and inanimate article.

Of course there are rods and rods, from the beautiful four ounce fly rod costing a whole pocketful of money to the humble cane rod used in still fishing and costing only a few cents. Naturally the choice of rod depends on the style of fishing that it is needed for and the kind of fish that it is expected to take.

Many kinds of native woods have been experimented with but for light rods nothing has been found equal to the woods imported for this purpose, and commonly used. Of all solid wood rods those made of lancewood are most common in this country. They are cheaper than others and the wood is lighter than bethabara and greenheart, also softer, 
but it is a very good wood. Greenheart is an excellent wood, more pliant than lancewood and also harder and heavier. It is not used in this sountry as much as lancewood, and it is said that for some reason good greenheart cannot be imported, or if it is, it gets bad here in our climate. Of this I do not know, but greenheart is the favorite rod wood in England and the English greenheart rods are fine ones, though heavier than the American rods, usually. Bethabara is a fine wood but is not so common. It is more resilient than either of the others. The wood is dark colored and very hard and close grained. It is very strong and springy and makes excellent rods. Another wood used by a Canadian firm is called kaliki. This is a native wood, coming from British Columbia. It is said to make very good rods.

Those who use solid wood rods are divided into as many classes as there are kinds of wood and each defends valiantly the wood of his choice, but the users of wood rods are in the minority. The largest number of anglers in this country pin their faith to the built-up rod of Calcutta bamboo. These rods have each section made of six triangular strips of bamboo, fitted perfectly their entire length and glued together so that they form a six-sided strip, with the hard outside part of the bamboo on the outside of the stick. After gluing the wood is wound tightly with a cord and when dry the ferrules are fitted and the sticks are wound at close intervals with silk thread. This makes a rod much stronger than any solid wood rod and it is exceedingly springy and casts accurately. But it will be seen that such a rod, if faithfully made requires a lot of labor and this naturally makes it expensive. Carefully made, of first class materials it makes the best kind of rod for any kind of fishing that money can buy, but if poorly constructed or made of second grade material it is likely to prove less worthy than the solid wood rod. For this reason it is advised that when the purchaser can afford to pay well for a rod he get the split 
Rods.

bamboo, but if he cannot put plenty of money into it he will be wise to select a solid wood rod, for he is more likely to get a good greenheart or lancewood rod at from three to five dollars than a good split bamboo at twice as much.

The illustration showing the construction of a split bamboo rod and the cross section of bamboo and wood rods shows plainly why a built up rod, if well made, is stronger than a solid wood rod. In the bamboo rod the grain parallels the center on every side. For this reason it must have equal strength and backbone, and the same action, no matter which way it is turned. In addition to this the material composing it is harder and stronger than any wood. The solid wood rod has the grain running directly across the strip, all in
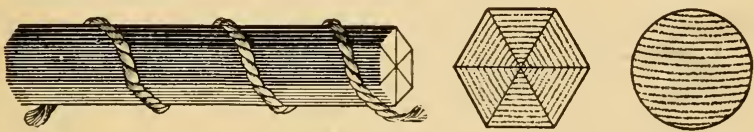

Construction of Split Bamboo and Solid Wood Rods.

the same direction as shown. It is bound to be unequal in action as the rod is turned, and less strong than the bamboo. One New York City firm is making rods of what is called steel vine. They claim it to be a very strong material and the rods are built up of six strips, the same as the bamboo, but are rounded afterwards instead of being left in the hexagonal form.

The only other rod material of importance is steel. Steel rods are in general use and quite popular for bait fishing. Steel is especially well liked for the short rods made for the new style bait-casting. The greatest advantage of the steel rod is that it does not warp or set, but always hangs true. Steel rods are of course hollow but for all of that they are heavier than other rods, usually. They will stand more abuse than any cther rod. 
For fresh water fishing there are two distinct types of rod, namely, the bait rod and the fly rod. Their difference is in length and weight and the position of the reel seat. Bait rods are shorter, stiffer, and heavier than fly rods, and have the reel seat above the handle where the spool of the reel can be controlled in casting, for bait-casting is done from the reel, that is, the weight of the bait or its momentum, draws the line from the reel. The fly rod has the reel seat below the hand grasp, for in fly-casting the line is not cast from the reel but is drawn off and controlled by hand. With the reel below the hand the rod balances nicer and is less tiring.

Bait and fly rods usually consist of three sections. The first is call the butt section, the next the second joint, and the smallest piece is usually called the tip, but as there is a line guide on the end of this piece called a tip also this is likely to cause confusion. The English people call the smallest section the "top."

These sections are fitted with ferrules so that they may be fastened together. These are of two pieces known respectively as the male and female ferrules. The male ferrule is the smaller and fits into the other. The end of the male ferrule is solid so that water cannot reach the wood, and the female ferrule, at the bottom, has a metal floor for the same purpose. Some rods have tapered dowels in the ferrules but this is not generally considered a good idea and is going out of use. The ferrules are made of brass, usually nickel plated, or of German silver. The English give the ferrules a dark color by oxidizing, which is a good idea. In a well made rod the ferrules should fit over the wood which should not be cut down for the purpose, and they should be cemented to the wood but not pinned, as they are sometimes. The base of the ferrule is wound with silk thread and the most improved styles are split at the base (split ferrules) or cut into long points (serrated ferrules), and the wrapping is put 


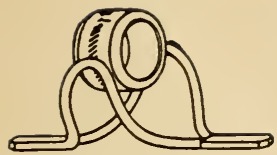

agate CASTING
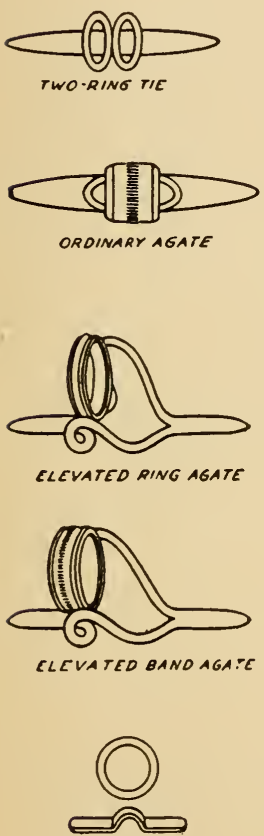

RING ANO AEEPEA

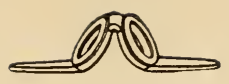

Side and top view

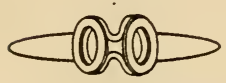

SOLOERLESS TWO-RING

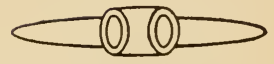

COMMON TIE

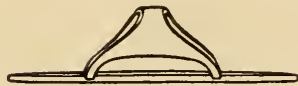

side view

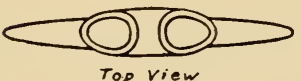

Top view

ANTI-FRICTION RAISED TIE
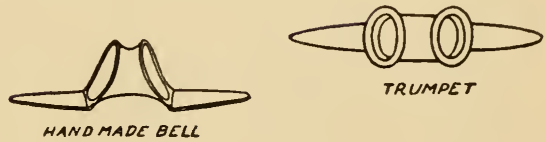

TRUMPET
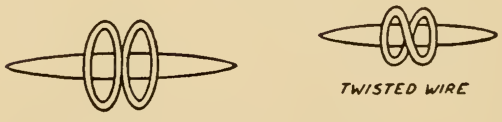

TWISTED WIRE

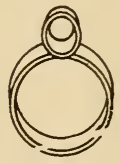

STANDING RING

GLR MAN SILVER CASTING
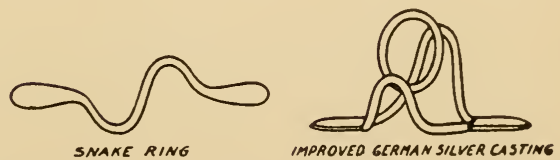

Various Styles of Line Guides. 
over these cuts. The highest grade have a rib around the edge of the female ferrule, called a welt.

As mentioned before the rods are wound at intervals with fine silk thread. This is to strengthen and stiffen the rod. The line guides are also fastened on by wrapping.

Line guides are made in many patterns and the illustration given here shows the most common kinds. For fly rods the ring and keeper guides are used much, especially on the cheaper grades, but small, light standing guides, especially the snake guides are better, as the line runs more freely and casts better. Many fishermen have the first guide, the one next the reel, of agate, or to be exact, a metal guide with an agate lining. Agate is very hard and smooth, does not wear the enamel off the line and in turn is not worn by the friction of the line. Offering less resistance to the line it enables the user to cast farther.

The end guide on the end of the tip joint, which as I explained before is also called a tip, should be a simple ring on a fly rod, but is best if lined with agate as it will cast better and will not harm the line. Those that are bent to one side so that they offer no resistance to the line are best. It is not necessary or advisable to have the other guides of agate on a fly rod, but on a bait-casting rod this is advised if you care to go to the expense. Anyway on a bait-casting rod it is generally conceded best to have large guides and tip, while on a fly rod they should be small and light.

The part of the butt section that is held in the hand is called the grip, grasp or handle. On a solid wood rod it is usually a part of the butt joint, simply an enlargement, and may be plain wood, cork or celluloid, and many are wound with hard twine or split cane. They are all good and the angler may take his choice though most of them choose cork, especially for a fly rod, as it will not slip 

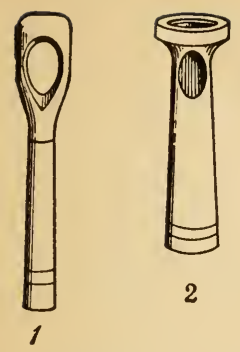

2
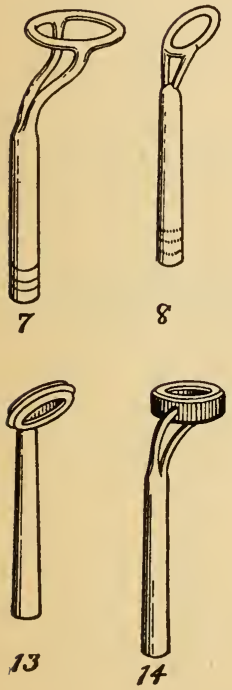
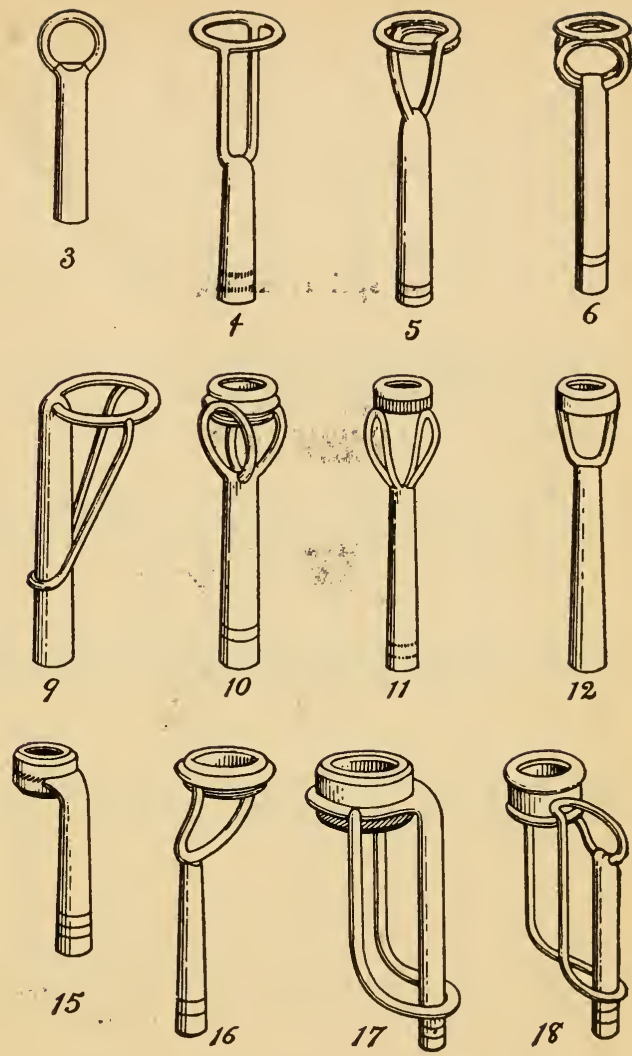

VARIOUS STYLES OF ROD TIPS.

1-Nickel, Double-Hole ; 2-Single-Hole Tube ; 3-German Silver, One-Ring; 4-Stirrup Casting; 5-Spiral Casting; 6Three-Ring ; 7 -Offset Stirrup ; 8-Light Casting; 9 -German Silver Helper Casting; 10-Three Ring Adamant; 11-Lightweight Agate ; 12-Hand-Made Stirrup Agate; 13-Narrow Agate Angle ; 14-Agate Casting ; 15-Agate Offset or Fly ; 16Offset Agate Casting; 17-Special Agate Casting ; 18-Adamant Casting. 
and is not likely to cramp the hand, also is very light and durable.

As stated before the reel seat of a fly rod is located below the grip and that of a bait rod above. The reel seat is usually of metal to match the ferrules and has two raised ribs to hold the reel from slipping. At one end is a fixed

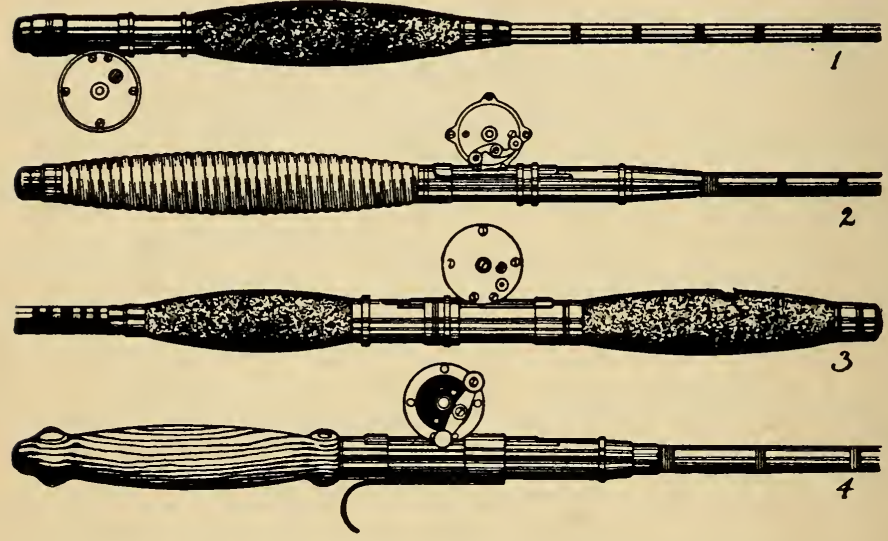

ROD HANDLES.

1-Cork Grip Fly Rod; 2-Cane-Wound Grip Bait Rod; 3Double Cork Grip, Bait-Casting Rod; 4-Casting rod with Shaped Wood Grip and Finger-Hook Reel Band.

band under which the end of the reel base is slipped and a movable band is drawn over the other end of the base to fasten it in place. On some reel seats the band locks in place by means of grooves. Some rods have a place bedded in the wood for the reel base, and have the bands only instead of the metal reel seat, and this is preferred by many. This is the Britisher's idea. 
The butt of the American rods is finished with a metal cap, but the English rods have a large rubber knob or button on the end of the butt and this adds much to the appearance of the rod.

All wood or split bamboo rods must be varnished to keep the water from penetrating the wood. Steel rods are enameled.

To catch bottom feeding fish, such as carp, bullheads, suckers, perch, and other fish of that kind, all that is needed is a long cane pole, and it is better for that kind of fishing than any other rod. No reel is needed, for the line is tied directly to the rod. Other rods may be used though for this kind of work, and a jointed rod is always more convenient for carrying. A nice four-piece Calcutta bamboo rod, about sixteen feet long, may be purchased for a dollar or a little more perhaps, in our eastern cities, and better ones up to two and a half dollars. These have line guides and reel bands. Jointed cane rods of ten or twelve feet may be purchased for fifty cents. Or you can buy a jointed plain wood rod, and if you like you may buy the trimmings and make the rod yourself, as explained elsewhere in this book.

For fishing with minnow bait for bass and such fish a three-piece bait rod is used. This has always been a favorite style of fishing for such game fish as take the live minnow or small frog. For this use the Henshall pattern rod has always been a favorite. This may be of steel, of split and glued bamboo, or of solid wood such as lancewood, greenheart or bethabara.

The Henshall bass rod is eight feet, three inches long, and weighs eight ounces with solid metal reel seat, and seven and one-half ounces when made with reel bands only, which was the way Dr. Henshall preferred it. The standard rod of this style was made of three pieces, the butt of white ash and the other two joints of lancewood. Another rod favored by this great fisherman and originated by him was of 
split bamboo, eight feet, one inch in length and of a weight of six and a half ounces. The steel rod is eight feet, six inches long and weighs ten ounces. All fishing tackle dealers sell such rods.

In late years the casting of artificial baits with a short, stiff rod, by the overhead cast, has become a very popular way of fishing for bass and such fish. The bait-casting rod for this kind of work shoúld be between four and a half and six feet long, but the best length seems to be about five
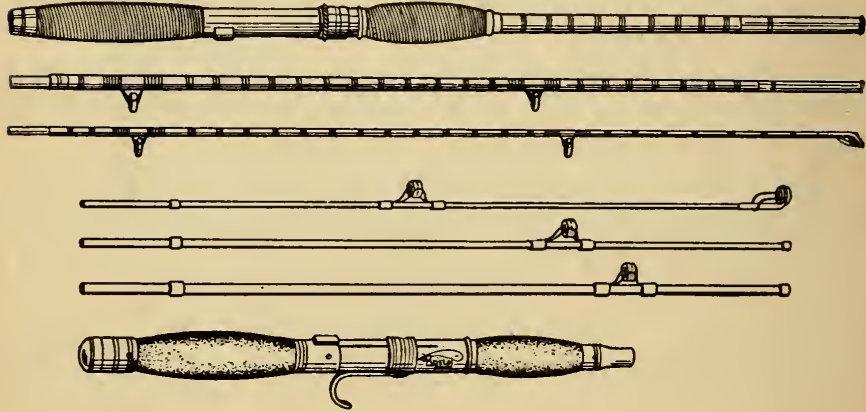

Three-Piece Bait-Casting Rod and Three-Piece Steel Bait-Casting Rod with Detachable Handle.

feet. The rule is to use a short rod for the heavy artificial baits and for the lighter lures a longer rod may be used, but a long rod of seven or eight feet could not be used for this kind of casting.

The material of the bait-casting rod may be either solid wood, steel, or split bamboo. Some anglers prefer the solid wood rod, others like the steel rod best, and many swear by the split bamboo.

The rod may be of one, two or three pieces. A onepiece rod is best in real use but too unhandy in transpor- 
plates should be rounded and smooth so that they will not wear the enamel from the line.

There is another form of single action click reel which has no side plates, simply a pair of rims held together by

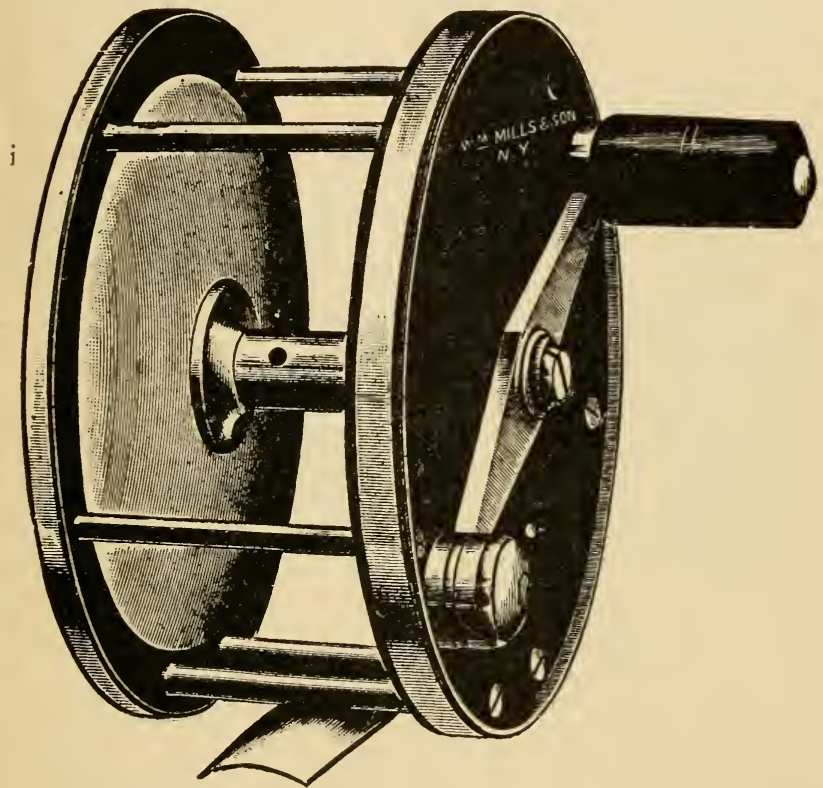

Salmon Reel.

(About three-fourths size.)

the pillars and a post up the left side to which the spool is attached. The handle is attached direct to the other end of the spool. The "Expert," "Featherweight" and "Ideal" reels are of this pattern. They are very good and are used considerably for fly fishing. 
A single action reel for trout or bass fishing should be of the size said to hold eighty or 100 yards of line. These will hold only about half that much size $\mathrm{E}$ enamel line, and while it is seldom if ever that more than thirty-five yards are needed for bass or trout, it is better if the spool is well filled up, but not crowded. The more line you have on the spool the faster it will pick up the slack.

For salmon very large single action reels are used.

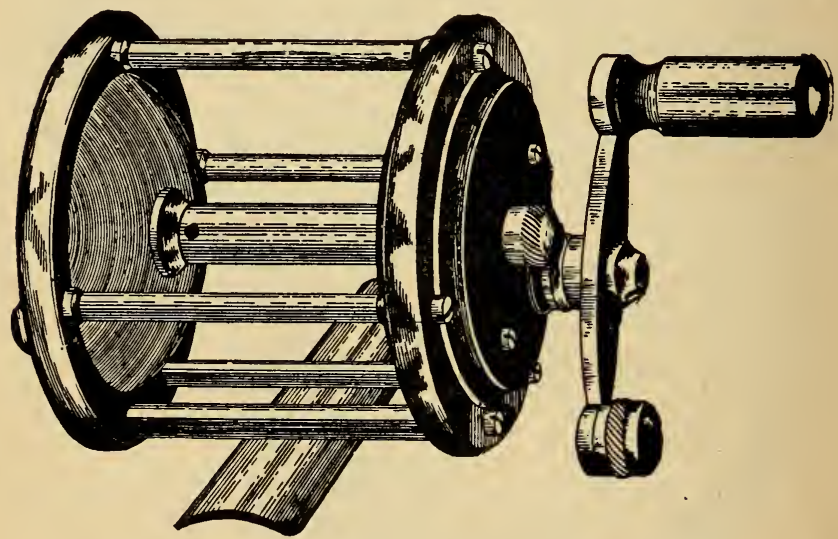

Multiplying Reel, for Bait-Casting.

They will measure from three and a half to four and a fourth inches in diameter and will hold several hundred yards of heavy enameled line.

The multiplying reel has double side plates at the handle end and the handle is not attached to the spool or the central shaft, but is set to one side and is connected with the spool by means of cog gearing. A double multiplying reel turns the spool twice to one turn of the handle, and a quad- 
ruple multiplier turns the spool four times to one revolution of the handle. The object of this is not only that they will wind up line faster, but that they may run more freely, for multiplying reels are used in bait-casting and the momentum of the bait must draw out the line from the reel. They are made long in proportion to their diameter, for the running of the spool must be controlled by pressure of the thumb when casting, and the narrow kind would not allow this. When winding in line it must be guided by the hand so that it winds evenly on the spool.

These reels all have balance handles. All of them are fitted with sliding click and some of them with a drag. The drag is to make the reel run harder and tire the fish.

The best reels are made as carefully as a watch, of the best German silver and steel, the bearings made very hard to make them run easily and resist wear, and some are jeweled or have ball-bearings. These fine reels come very high, from ten to sixty dollars, but if one does much fishing, and can stand the initial cost, they are well worth the money, for they will never wear out and are a source of continuous joy to the owner. They are the kind that are used in the bait-casting tournaments and the longest casts have been made with them.

This description applies to reels of the standard design, but in late years special reels to do away with the thumbing operation, always difficult for the amateur, have been invented. These are called "self-thumbing" reels. This device is entirely concealed inside the reel and consists of simple weights attached to the flanges of the spool. They are said to work very well and enable the amateur to cast a bait as well as the experienced fishermen, without letting the spool overrun and make a "backlash," as a tangle of this kind is called.

Another fine reel brought out in recent years fs known as the anti-backlash casting-reel, and it is intended to govern 
automatically the rendering of the line, and is said to do so to perfection. This reel requires no thumbing. This is accomplished with only a fraction of an ounce additional weight to the reel and with a device so simple that it is hardly worthy to be called a mechanism. The braking effect is adjustable in a moment, entirely without the use of tools,

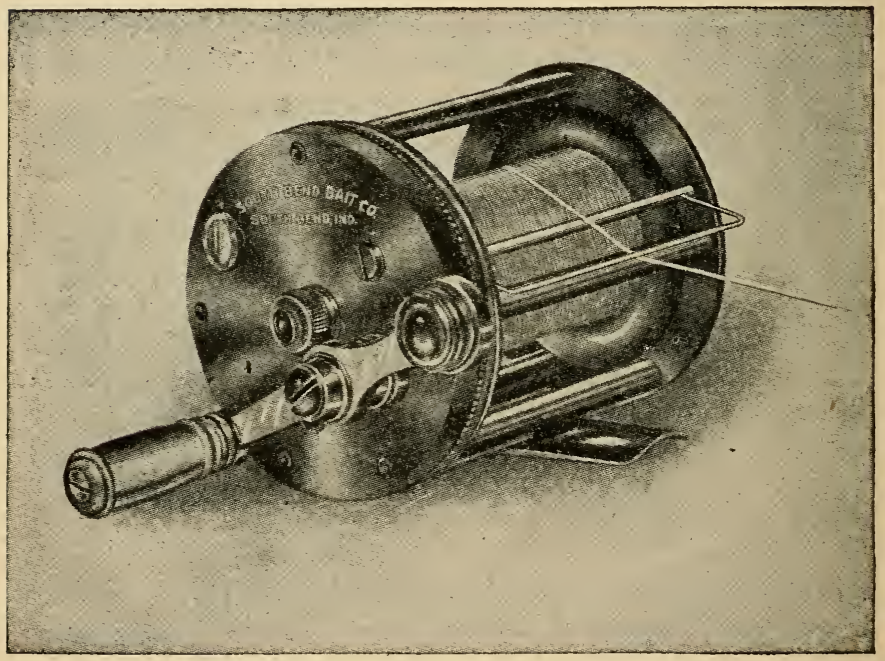

The Anti-Back-Lash Casting Reel.

to suit any weight bait. If desired, a half turn of the adjusting screw releases the brake and the reel can then $b$ : used and thumbed as an ordinary reel.

Then there are "free spool" reels which automatically free the spool from the gearing as the bait is cast, allowing the spool to run without turning the handle of the reel, thus allowing of long casts, It is somewhat on the principle of 
the coaster brake on a bicycle. The first movement of the handle in reeling in line again engages the gear and turns the spool.

Another invention that is a great help to the beginner is the even spooler, a device to attach to a reel to make it wind the line evenly from end to end of the spool without attention from the angler. This consists of a pulley with an arch over it as a line guide, traveling back and forth on a spindle, which is threaded right and left. The pulley travels to one end of the spool, automatically slips into the other thread and travels back again, laying the line evenly on the spool.

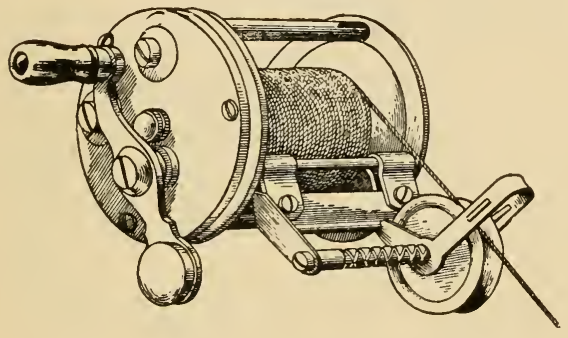

Redifor Reel with Automatic Spooler.

There are several reels made by the Shakespear people that have a level winding arrangement built into the reel itself, but the independent even-spoolers can be attached to almost any reel.

There is also a reel that may be taken apart in a few seconds without tools and by having separate spools with lines wound, same may be inserted and used in case a line breaks or tangles badly.

Some time ago there was placed on the market a reel and rod handle combined which winds the line in a crisscross style. It is known as the Gyratory reel. It can only 
be used with the handle supplied with it as it is not made to be fastened in a reel seat. The object is to so wind the line that it will not cut in (one round wedged between others.) It consists of a simple spool on a spindle, the spindle projecting through the rod handle and the reel handle attached to the spindle. The reel is one of the free-spool kind and no part moves when casting except the spool itself. It is the wobbling motion of the spool that cross-winds the line.

The old and experienced bait-casters frown on all of these improvements and denounce them. They are experts

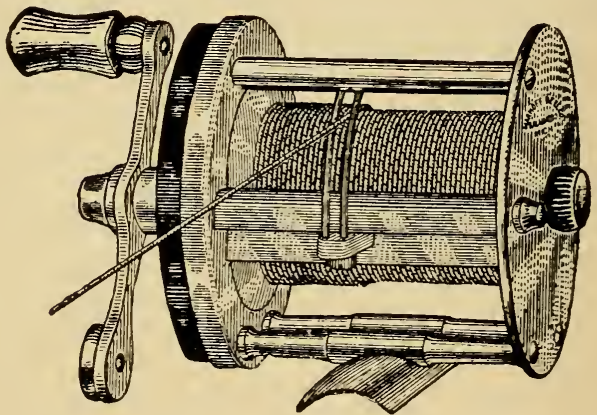

The Marhoff Level-Winding Reel.

in thumbing the reel and are so used to spooling the line that they can do it nicely without giving it a thought. But for the beginners there is no question that they are a great convenience. It requires a lot of time and patience to learn to properly thumb the reel and many amateurs become discouraged and go back to still-fishing, because they do not have the time and patience to learn. But with these improvements they never have to learn to master this delicate accomplishment unless they want to. The experts say that they do not give the fish a chance; that they rob fishing of its pleasures 
by makin $\xi$ it too easy. It would do so for them, but not for the man who can only devote a day now and then to fishing - they add to his pleasure.

The expert fishermen are quite often opposed to the automatic reel for the same reason; it does not give the fish a chance and makes fishing easy. But properly used the automatic reel is one of the finest things ever designed for the fly fisherman; it is no good for bait-casting, but may be used for still-fishing. To my mind it is as sportsmanlike as

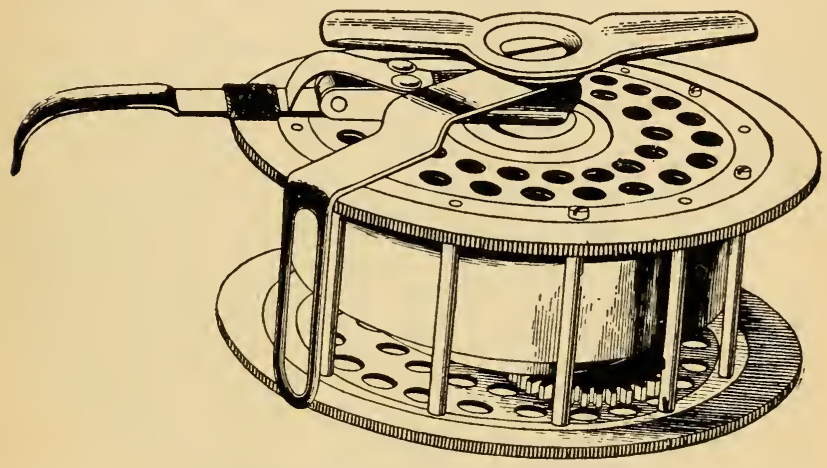

An Automatic Reel - the Y. \& E.

the hammerless or repeating gun and I can see no reason why anybody should draw the line at improvements in fishing reels. In fly fishing the angler need not use the reel to play the fish if he does not care to do so, but handle the line by hand and pick up the slack with the reel. A pressure of the little finger on the lever causes the reel to rapidly wind in line. It is really intended to co-operate with the spring of the rod to automatically and instantly take up all slack of the line and keep a constant strain on the fish. It is not in- 
tended to reel the fish in. The reel may be used for fly fishing either above or below the hand, but works hest below the hand, as it balances the rod and makes it hardle better. The reel should be of the smallest and lightest for light fly rods. It is said that the automatic reel is an excellent one for salmon fishing, but, of course, the largest sizes must be used for this.

All automatic reels are made on the same principle and turn the spool by means of a long coiled or wound spring.

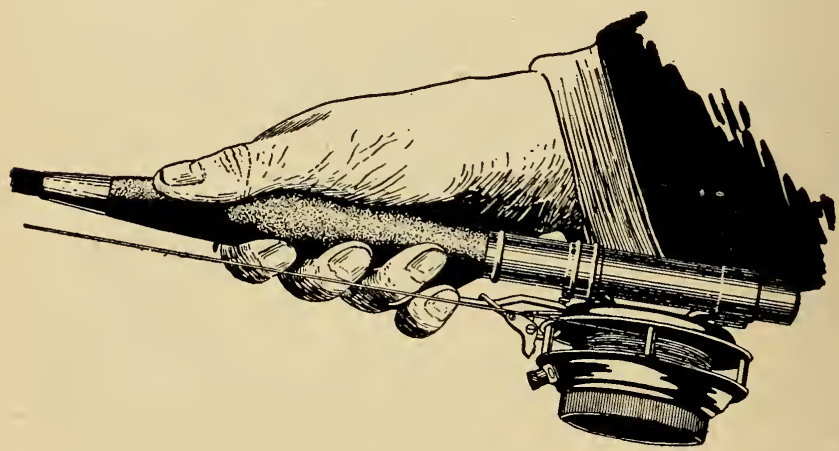

An Automatic Reel in Use - the Martin.

The tension of the spring may be regulated to suit the rod and the kind of fish that are sought. It should not be made too strong if the rod is a light one.

Reels for salt-water fishing are made similar to baitcasting reels, but are shorter in proportion to their diameter and are much larger. A reel for surf fishing should hold two hundred yards of line, or more. The best are made of German silver and rubber and have a "throw-off" to make them free-spool, for casting. The reel should be equipped with a leather brake, which is a piece of leather attached to 
one of the pillars and is pressed against the line on the spool to check the rush of a fish. The greatest objection to a leather brake is that it wears the line rapidly. What is better is the handle drag, which is a balance handle so made that it acts as a brake, and is fitted to the reel in place of the

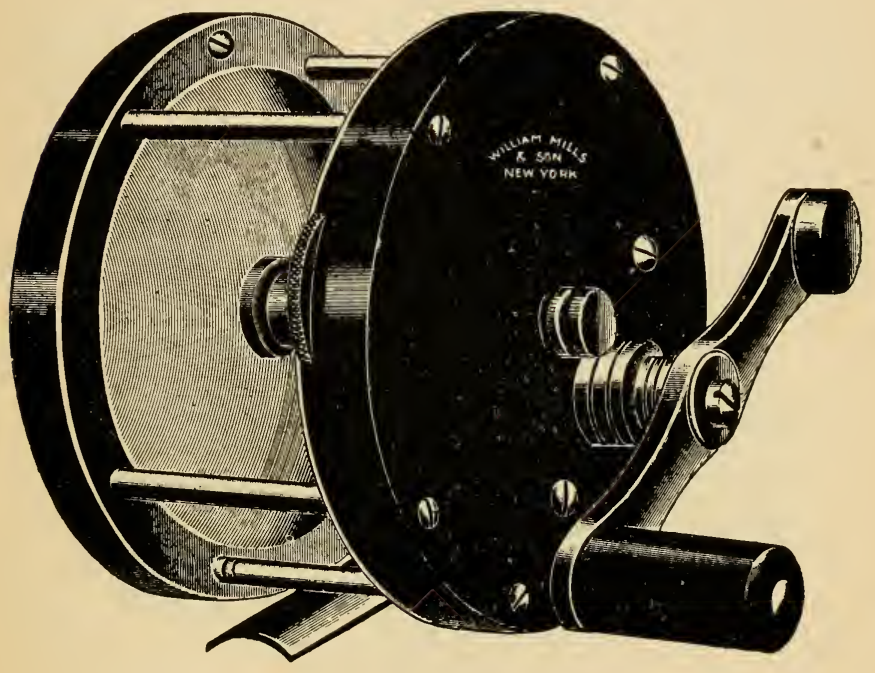

Tarpon and Tuna Reel.

(A little more than one-half size.)

regular handle. The center of the handle consists of a large disc holding six screws around the edge. By turning these screws any degree of drag may be obtained. In using them the angler does not let go of the handle but holds it stationary and the fish must draw out the line against the tension for which the drag is adjusted. The handle remains 
stationary, but when the fish gets tired and slacks the line the handle may be turned and the slack reeled in. It prevents breaking of rod tips and lines and the loss of fish.

One firm, a large manufacturer of salt-water reels, fit their tarpon and tuna reels with an adjustable drag of their own which holds against the fish continually, when it runs, at the tension to which it was adjusted. The drag does not alter the appearance of the reel and the handle does not revolve when the line is drawn out.

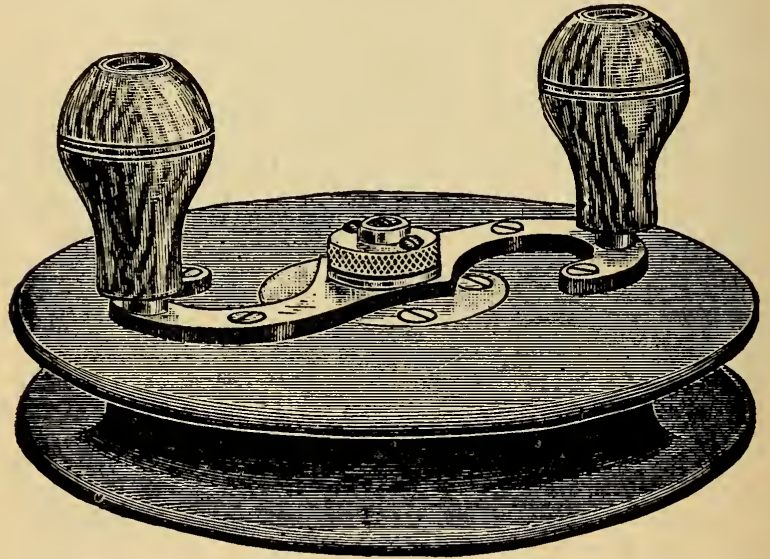

Wood Reel, for Trolling and Salt Water Fishing.

Reels for tarpon and tuna fishing are of the largest size, some of them being four and a half inches in diameter and holding 600 yards of line.

A simple wood reel of large size is sometimes used for troiling with a copper wire line, for muskellunge, lake trout and other fresh-water fish. Many salt-water anglers also use them - those who fish from the piers and in the surf. They are made in five: six, and seven inch sizes. 


\section{CHAPTER IV.}

\section{Hooks, Lines and Leaders.}

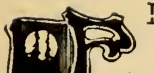

ISH HOOKS have been in use from prehistoric times, but what they were like in these early days, or what they were made of we do not know. But hooks of metal were in use in early Bible times and bronze fish hooks have been found in the ruins of the ancient city of Pompeii. The fish hook of today the carefully shaped and tempered article-originated in England in the early days of the Eighteenth Century. At that time there were certain fishing centers on the various rivers and the several dealers in fishing goods each had their hooks made by local workmen, after a given pattern. These hooks were named after the towns where they were made, and the same patterns are made today, as well as others of American patterns, which were also named after the place of manufacture, or the place where first used.

Of the old English patterns we have such as the Aberdeen, Limerick, Kendall, Carlisle, etc., and some of our later hooks are the Virginia, Cincinnati Bass, and others that suggest their origin by their names. As will be noted by referring to the illustration which shows a few patterns only (there are hundreds of patterns), all differ in some way, either in length of shank, style of bend, side bend, or shape of point. Each angler has his favorite style of hook for each kind of fishing, and while some are better than others there is not as much difference in catching and holding qualities as some imagine.

There are two distinct styles of point and barb; the spear point and the hollow point. The latter is preferable 

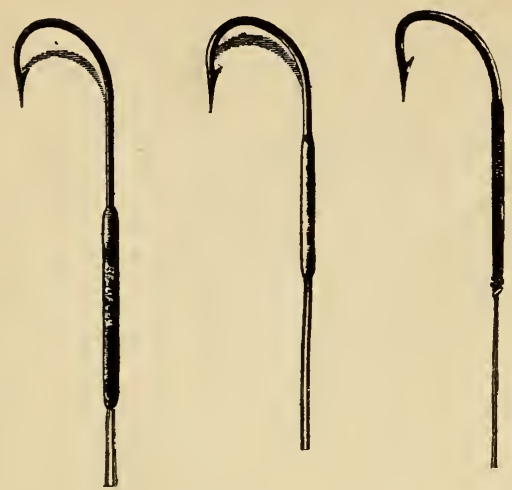

Carlisle

Cincinnati

Pennell Bass
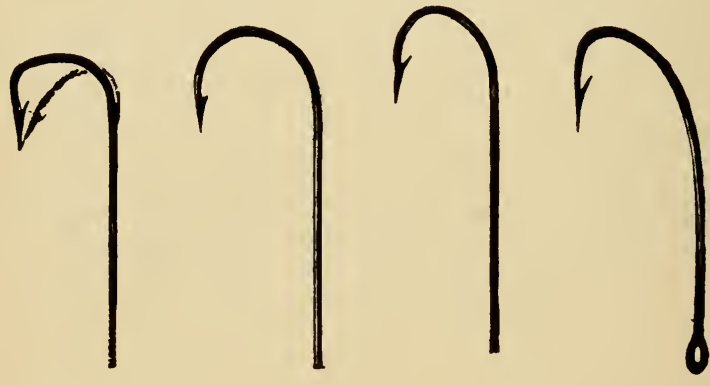

Sneck. Kendal

Aberdeen

New York Trout

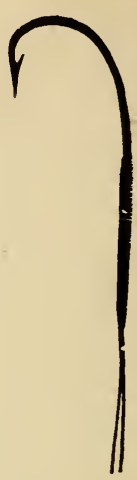

Sprodt

Limerick

Various Patterns of Fish Hooks. 
and is used on all first-class hooks. Cheap ringed hooks that sell for five cents a hundred or thereabouts, all have spear points and are formed entirely by machinery. They will do for such fishing as chubs, sunfish, catfish, suckers, and that kind, but they are not as strong as the hand-forged hook and heavier and larger ones must be used. A hollow point hook has the inside of the point, between the extreme point of hook and point of barb filed out to a nice curve and the hook below the barb is also shaped by filing or grinding. The cheap ringed hooks are invariably japanned black, but the good hooks are blued or bronzed.

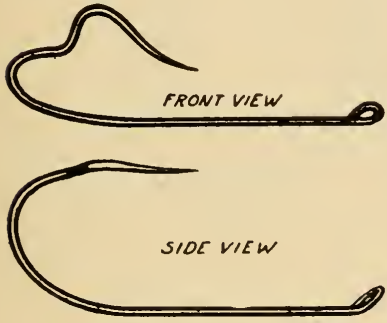

WILLIAMS
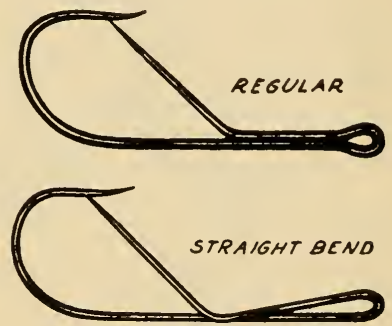

EDGAR

Barbless Hooks.

The length of shank makes this difference; it weakens the hook if too long, allowing it to spring and let the fish slip off, but it also enables the angler to extract it readily without getting his fingers in the fish's mouth. They also save bait when using worms, as the bait slips up the shank of the hook and is less mutilated by the fish. The longest shanked hook is the Carlisle. It is rather weak and not good for heavy fish; also has a strong side bend which few anglers approve of.

The end of the shank may be finished in several ways; it may be ringed, by turning the end of the wire so that it 


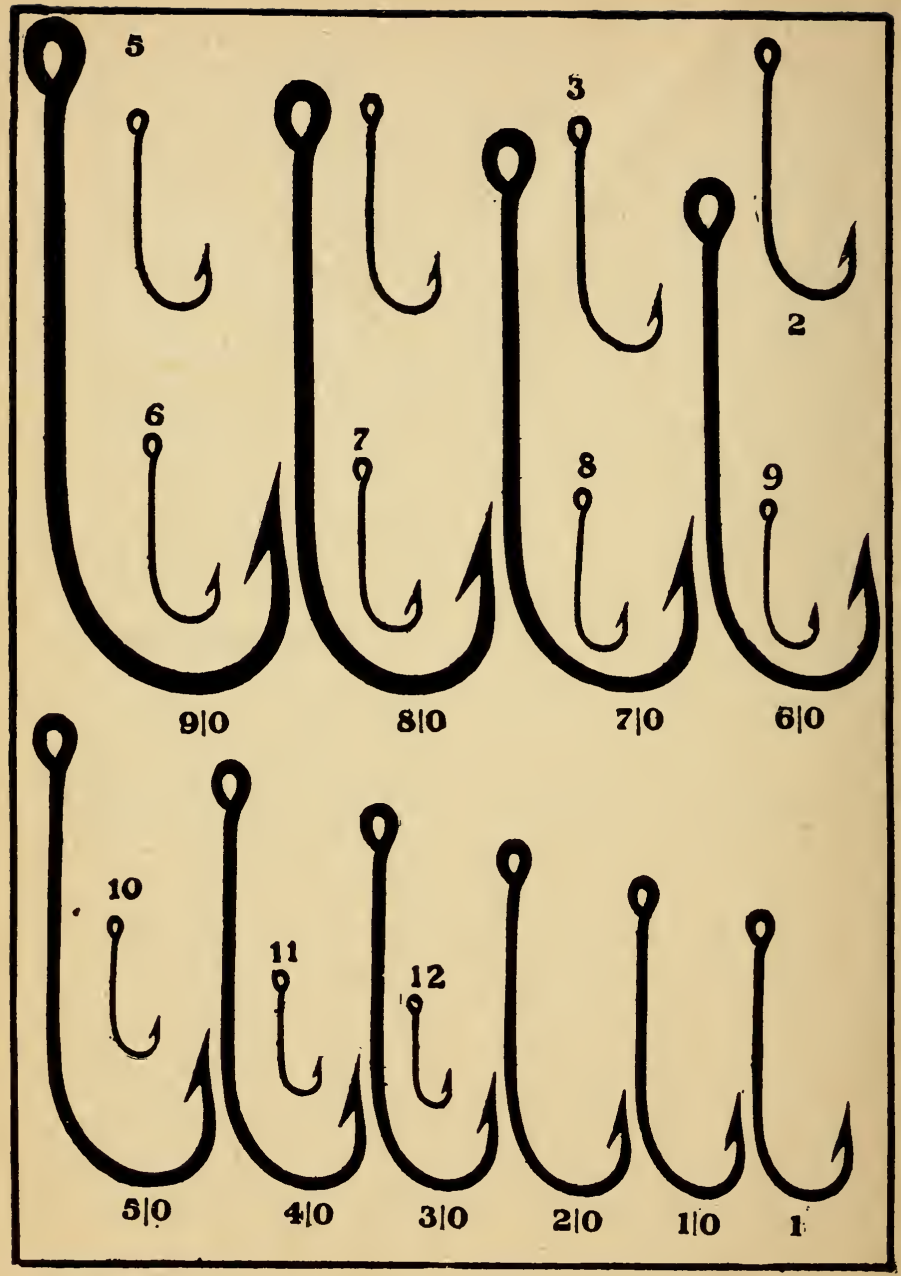

Fish Hooks in Exact Sizes-Kirby Pattern. Ringed. 
forms an eye; it may be tapered and marked with little cuts; or it may be flattened out at the end. The marked hooks are used for snelling with silkworm gut and for making flies with snells. The gut is thoroughly softened by soaking in water, and is laid along the shank of the hook and bound on by winding tightly with fine silk thread. The winding is then shellaced.

Ringed hooks are used for what are called "eyed flies" and are tied to the end of the leader by certain knots which are described elsewhere. They are also used for common fishing by tying direct to the line. The flatted end hooks may be used either way, with gut or to the line itself.

One style of hook is known as the Pennell. The eye or ring of this hook is turned over towards the point and this makes a fine shape and one of the very best of hooks. The shanks are tapered, the hooks finely tempered and finished in bronze. Another very popular hook, especially for the smaller kinds of rish, is the Sneck pattern, also called Kendall-Sneck, or Sneck-Kendall. They are finely tempered and blued. The O'Shaughnessy is also a favorite, especially for sea-fishing.

For tarpon, tuna and other very large and powerful fish the Van Vleck hook is the kind most used. These hooks are eyed and the eye is formed by flattening the end and punching. The point and barb also differs from the regulation pattern. The Improved Van Vleck has a double barb and it is set on the outside of the point instead of the inside. The smallest of these hooks is numbered 8 and this one is about the same size as the No. 1 or No. 1-0 of the other hooks. Sizes 7 and 8 are for black bass. The Captiva is a tarpon hook similar to the plain Van Vleck.

There are several styles of hooks which have no barbs. One is the Williams Barbless hook, which has a peculiar bend to prevent the fish from shaking it out. This hook is said to be a very good one and is liked because it does not 
injure the fish as much as a barbed hook, so that the small ones may be returned to the water none the worse for the catching. The other barbless hook is the Edgar, which has a tongue to prevent the fish from getting off.

Many hooks have been designed for bass and for other surface feeding fish, with weed guards, to prevent the hook catching weeds and grass. Some of these are good and do their work well, but others are so constructed that they turn over quite often when the fish takes the bait and thus prevent the hook from catching. Some of the best kinds are
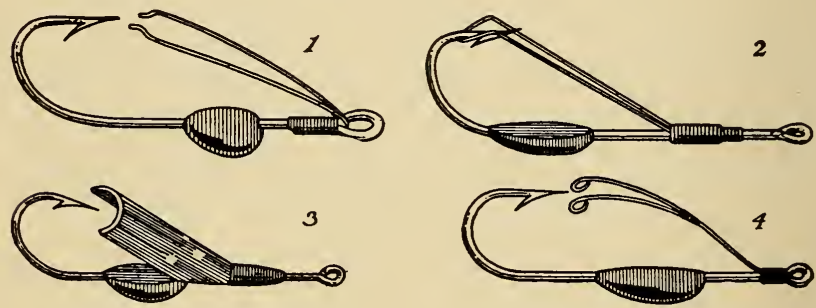

WEEDLESS HOOKS.

1-La Salle; 2-Henzel; 3-Cooper's Weedless Porker; 4Jamison.

shown in the illustration. It will be noted that they are all weighted; this is to make them ride point up. Quite a novel idea is shown in the Doddridge Automatic Weedless hook, which is weedless only while being drawn forward, the tension of the line tripping the weed guards up to the point of the hook and the guards dropping down out of the way the instant the line is slacked.

There are also double hooks, made by forming hooks on both ends of a piece of wire and bending it in the middle. This form is not used much but nearly all artificial baits are furnished with one or more treble hooks, which are made 
by soldering a single and a double hook together so that it forms three hooks on the same shank, each standing out in a different direction from the shank. These are sometimes used plain and sometimes covered with a bunch of feathers or deer hair, to conceal them and ward off weeds and grass.

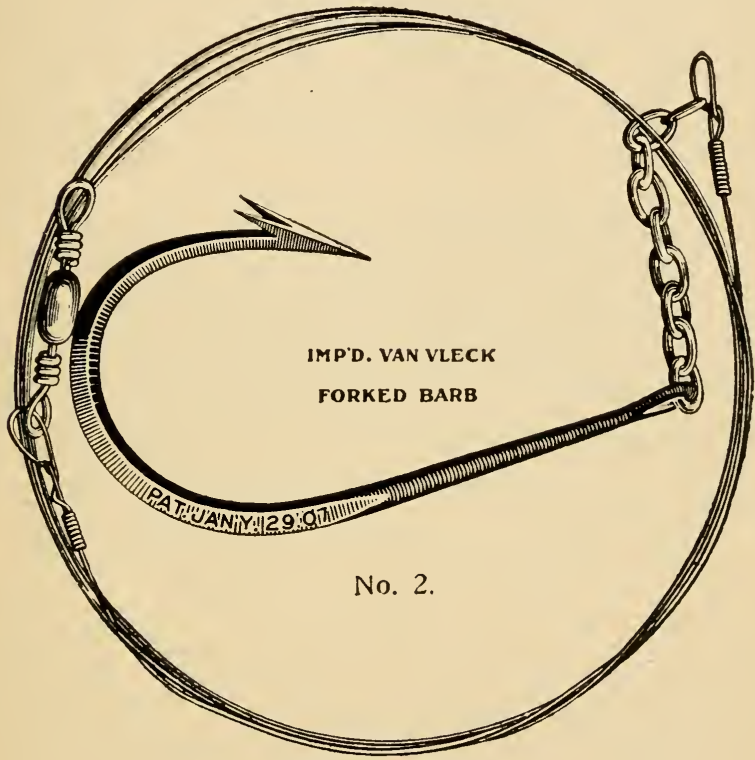

The Van Vleck Tarpon Hook.

As with hooks, so also it is with lines. There are many kinds and each has its use. For instance there are lines of cotton, twisted and braided, both braided and twisted linen lines, soft braided silk lines, oiled or waterproof braided silk '.ines, and enameled silk lines. 
Twisted cotton lines are used only for catching catfis ] and such bottom feeding fish. Braided cotton lines are used for the same purposes; also for ocean fishing and for trolling. Braided and twisted linen lines are very strong and are used for all kinds of salt-water fishing and lake trolling.

The sizes of twisted linen Cuttyhunk lines are shown here, the numbers showing the number of threads of which they are made. Each thread is tested to stand a strain of two pounds, so a thirty-thread line will stand a strain of sixty pounds; a nine-thread line will stand a strain of eighteen pounds, etc. These lines are very hard and smooth.

Number of Threads.

30

24

21

18

15

12

9

Sizes of Twisted Linen Lines.

Some of those made by the Kingfisher people are waterproof, and all of them make excellent lines for all-around fishing. A No. 6 Cuttyhunk linen line is no larger than an ordinary thread, but will stand a strain of twelve pounds.

A line that is excellent for trolling and also good for salt-water fishing is made by braiding silk over a linen center. It is a very strong line but rather stiff and rough for casting. Pure silk lines are not durable when used in salt-water.

The plain undressed silk lines are the kind for baitcasting. They are numbered differently but the sizes are a 
trifle larger than the twisted linen lines of the same strength. A soft undressed braided silk line about the same diameter as a No. 9 twisted linen line will stand a strain of sixteen pounds, and the linen line will stand eighteen. This size is generally known as $G$, but different brands of line are numbered differently and you must know this before you order a line of this kind. This, and the $\mathrm{E}$ size, which is larger, are the sizes most used for bait-casting for black bass.

The oiled silk lines are made for general all-around fishing, but are not specially adapted for any particular use. They make durable and useful lines for the average fisher-

\section{Size $H$

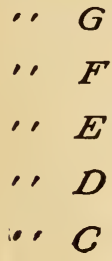

Sizes of Braided Enameled Silk Lines.

man, as they can be used for fishing with worm, for bottom fishing, trolling, etc.

For fly casting there is only one kind and that is the enameled silk line. Here is where quality counts and the finest are none too good. These lines are covered with a flexible enamel and not only covered but saturated with it as well. It makes the lines very smooth and increases their weight, both of which are desirable qualities for fly casting. It must be stiff enough to run nicely through the guides without drooping enough to bind, but must not by any means be stiffer than this - some of them are too stiff and none are too pliable. The enamel must be of the best so that it 
will not break, wear off or get sticky. The sizes used mostly for fly-casting for trout and bass are sizes $E$ and $F$. The $E$ size is used most, but for a very light rod the $F$ size should be chosen. For salmon the size $\mathrm{C}$ is right.

The fine enameled silk lines have the dressing applied in a vacuum at a high temperature. It requires six months to enamel and finish one of these lines. When buying such a line double it sharply and pinch and roll it between the

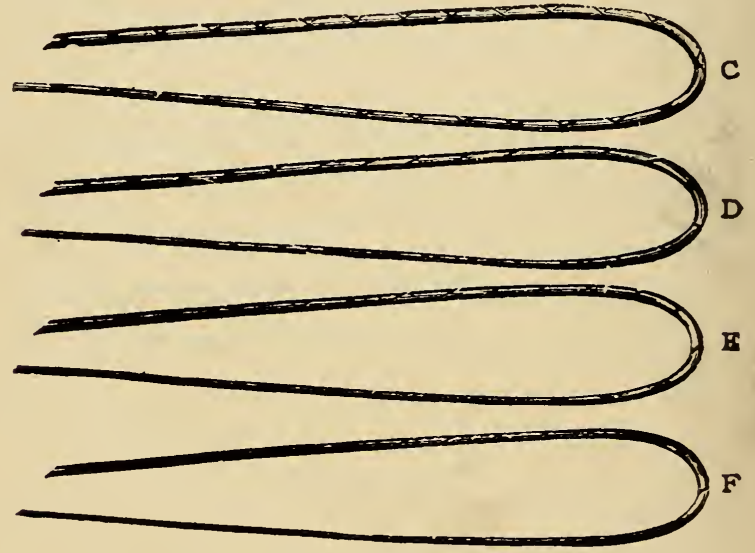

Sizes of Tapered Silk Lines.

thumb and finger; if it turns white or softens or weakens at the place it is not a first-class article. See also that the line is flexible, and not sticky to the touch.

Of these enameled lines there are two kinds, known as level and tapered lines. The level lines are of even thickness throughout, but the tapered lines are two or three sizes smaller towards one end, if a single taper, or at both ends if a double tapered line. Tapered lines are better for fly- 
casting, especially for use on lakes and still water; the heavy center pushes the lighter end out more readily, and the line falls more lightly. A double tapered line can be changed end about when one end gets bad.

A fishing line should be of a color that will not show

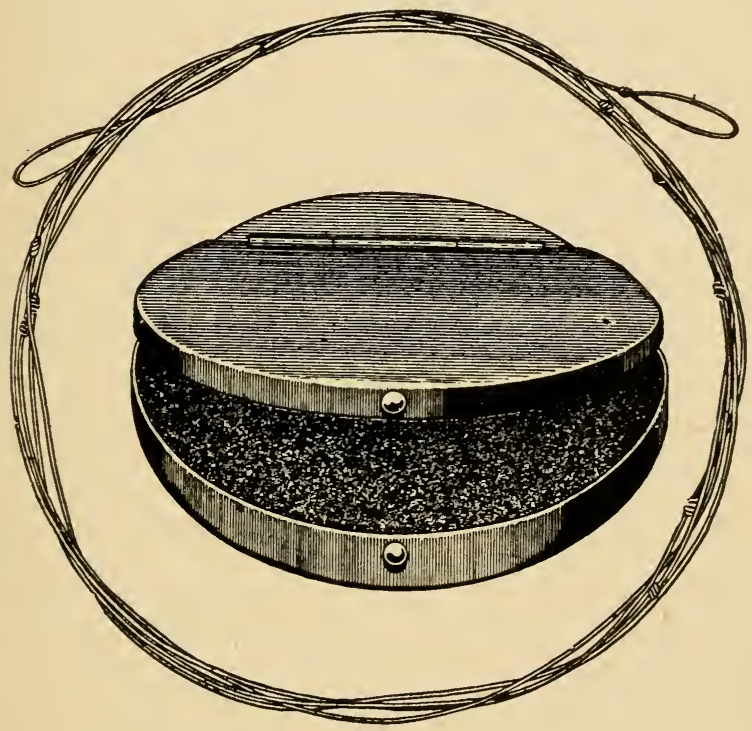

A Gut Leader and a Leader Box.

plainly in the water. For muddy or cloudy water it may be amber or tan color. The "pepper and salt" kind is good in grassy waters, so also are the green and yellow kinds. It should be remembered that the fish usually sees the line from below, outlined against the sky. 
For deep trolling wire lines are used. These may be a single strand of copper wire, but such are likely to get broken as they kink very easily. A line of braided copper wire is better. Lines of other metals, rust-proof, are also made for this purpose. Their advantage over other styles of line is that they require no sinker and sink to the proper depth of their own weight. They are used for muskellunge and lake trout, especially the latter, which are nearly always found in very deep water.

Leaders, for fly fishing and for use with bait at times are made of metal or of silkworm gut, depending on what use is to be made of them. Those for trout, bass and salmon are always made of silkworm gut.

This is really a product of the silkworm. Most of it comes from Murcia, Spain, but some comes from Italy. It is made from the substance that the silk is made from, but it is taken from the body of the worm before he spins his cocoon from which we make silk. This raw product is found in a little sack and sack and contents are drawn out into a thread a foot or more in length, and allowed to harden. The sack is then removed and a strand of silkworm gut remains; a hard, semi-transparent and very strong substance. It goes through a bleaching and polishing process before it is ready for use, and some of it is drawn through holes in metal plates, like wire, to make it an even thickness and of equal strength. Nearly all of the fine, light-weight gut is drawn this way. Undrawn gut is not treated this way.

The leaders are made by tying these pieces together into lengths of three, six, or nine feet, with loops at the ends for attaching line and snelled hook. There are single gut leaders for light fishing and double gut leaders for heavier work. The double or treble gut leaders are generally twisted. If more than one thickness of gut is used it is better twisted as twisting equalizes the strain. Six and nine-foot leaders are now made mostly of three-foot lengths looped together 
and the loops make good places to attach dropper flies without tying additional loops to the leader. The loops are shoved open, the end of the snell passed through, and the loops drawn tight again. There must be a knot on the end of the snell.

Single gut leaders only are used for trout fishing and unless the fish are very large the lighter weight will answer,

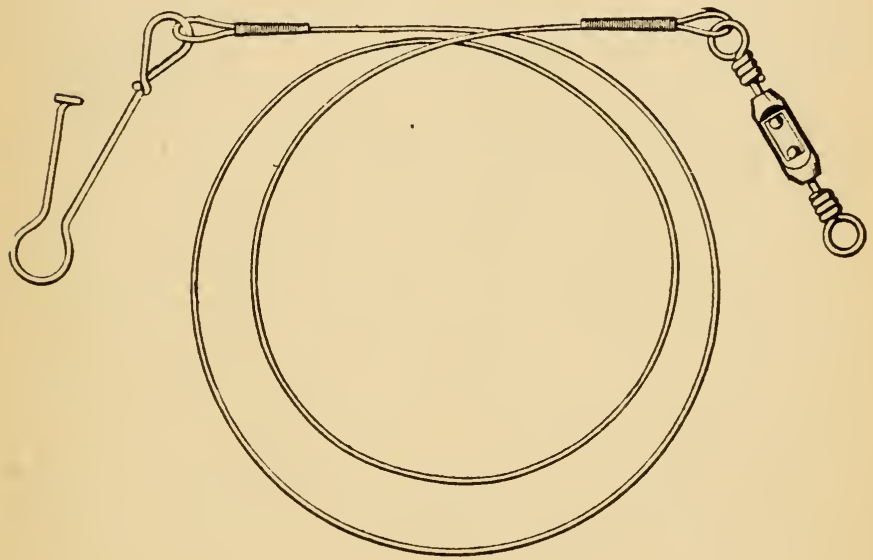

A Steel Wire Leader with Swivel and Coupler.

is really best, especially for lake fishing. For streams where there is always more or less motion to the water a heavier leader may be used, and as the leader is subjected to a greater strain in stream fishing it must be strong. It should be of even thickness from end to end, though for lake fishing they are sometimes tapered so that they fall more lightly on the water. Some leader makers, in order to get longer spaces 
between knots, use the light, inferior ends. As the strength of a chain is gauged by the strength of its weakest link, so also a leader is just as strong as its weakest spot; and of course there should be no weak spots. It should be round and transparent, of equal thickness throughout, and without kinks, frayed or split spots or blemishes of any kind.

For salmon the heaviest nine-foot single leaders should be used. For bass the leader should be three or six feet, heavy single, or light twisted double gut. An amateur needs a stronger leader than an expert.

Gut leaders are sometimes stained to a bluish or yellowish color, but it is doubtful whether this makes them any better or less conspicuous and many anglers believe that the coloring weakens the gut.

Wire leaders are made for trolling and sea fishing. They are usually made of steel wire, tinned and have swivels on the ends. Piano wire is sometimes used, also specially tempered steel, and phosphor bronze. One end should be fitted with a coupler for attaching the hook or bait. They are made in various lengths from six inches up to five feet. Twisted wire is also used for this purpose.

When going fishing the gut leaders should be carried in a small case or leader box between moist felt pads. This softens the leader and strengthens it. Never use a dry gut leader for fishing; soften it before you commence to fish. 


\section{CHAPTER V.}

\section{Flies.}

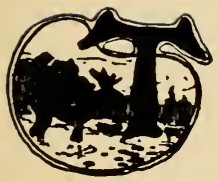

$\mathrm{HE}$ finest and most artistic branch of fishing is the taking of surface-feeding fish by means of the artificial fly. Fly fishing is not of recent origin. We find that this kind of sport was indulged in by the ancient Romans, but it was in England, hundreds of years later that it was developed to its present stand. It is the favorite method of nearly all trout anglers in this country, and is the kind of fishing also employed for the Atlantic salmon, and largely used for the capture of black bass and other fishes of less importance. As practiced in England it is far advanced over our comparatively crude methods used on this side of the water.

Artificial flies are not merely bright colored feathers tied in various combinations to suit the angler's fancy, as many believe, but each fly, with a few exceptions, is an imitation of some insect found on the streams at one time of the year or other, on which the fish feed, or an imitation of a caterpillar or other favorite food. A few, however, have been designed in imitation of othing living, and have proved good. Because a fish never saw a live insect of just such colors is no reason why he shouldn't bite at it.

There are three game fishes which feed largely on flies and the artificial flies have been designed purposely for the capture of these fishes; they are the trout, the black bass, and the salmon. Therefore we have trout flies, bass flies and salmon flies, and these answer for all kinds of fish that rise to a fly. 
About the only difference between trout and bass flies is the sizes; the same patterns and colors are used for each. The bass flies are sometimes used for large trout.

Flies are known as winged flies, hackles and palmers. The winged flies have one or two pairs of wings, a hackle to represent legs, a body and usually a tail. The hackle has a body and sometimes a tail, and always a hackle tied at the shoulder, but no wings. A palmer has a body with a hackle set in spirally the length of the body. It is made in imitation of a caterpillar. Many anglers call both of these latter "hackles."

The old way and the most common way yet of tying flies is to build the fly on a marked shank hook with a snell of silkworm gut attached, a loop at the end so that it may be quickly and easily attached to the leader. But the "eyed flies," that is flies tied to ringed or eyed hooks, especially to hooks of the Pennell pattern are becoming more and more popular each year. They are tied directly to the end of the leader, which has no loop in this case, by a knot which is explained elsewhere in this book, or they may be tied to a snell which is looped to the end of a leader. If the leader is well softened, and no leader should be used when dry, these eyed flies are as easily attached as the snelled ones. If snelled flies are selected they should have a short extra piece of gut tied into the fly and joined to the snell some distance above the hook. This is called a helper and makes the fly, or the snell rather, last twice as long, for it is at its junction with the hook that the snell breaks. By using eyed flies the leader loop is done away with, and the leader makes less commotion on the surface of the water when the fly is cast.

It is since the dry or floating flies came into such general use in England that the eyed fly has become so popular. The dry fies are very small ones, tied on very small hooks numbers 12,14 and even as small as 18 and 20 . The bodies of these flies are made of cork, or other material to cause 
them to float, and the leaders are of the finest gut, such delicate tackle that the uninitiated would think it too weak to catch minnows with, yet the largest trout and ouananiche are taken with them when properly handled. The object is to correctly imitate the flies that the fish are feeding on, in size, form and color, and to keep it on the surface of the w ite: 'ile a live fly. For these the looped snells would be bad, a; th: loops would nake as much disturbance of water as the fly itself. Dry flies are not yet much used in this country, but are arousing more interest among the fly fishermen each season.

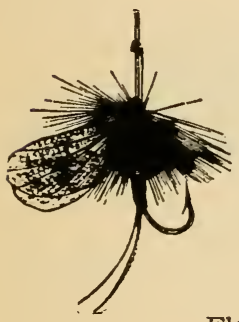

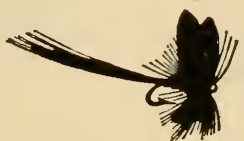

Fly on Hook No. I4.

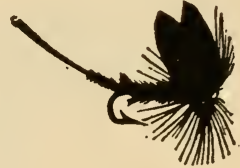

Fly on Hook No. I2.

Floating or Dry Flies, For Trout.

The ordinary trout flies are tied on numbers 6,8 and 10 hooks, as a rule. A No. 8 Sneck or Sproat hook is about right for general use. Midge flies as small as the English dry flies are also made in this country and these are very successful in small streams, where the fish are small and shy. They are of the more sombre colored patterns as a rule.

Bass flies are tied on much larger hooks and many believe that they would be better on smaller sizes. For the northern black bass they are usually tied on Nos. 2, 4 and 6 hooks, and No. 4 is most used. For southern waters, where the large mouth bass only are found, and they of very large size, flies are tied on Nos. $1 / 0,3 / 0$ and $5 / 0$ hooks. These 
large sizes are also used in combination with spinners and spoons, for trolling. Sproat hooks are the favorite style for bass flies.

Salmon flies are seldom if ever made to imitate a real live insect. They are tied on single hooks from No. $3 / 0$ to No. 8 , and on double hooks from No. 2 to No. 8 in size. Most salmon fishermen prefer the single hooks. Only the finest hooks are used for salmon flies; also the best materials obtainable for bodies, wings, etc. The best flies cost from twenty-five cents to seventy-five cents each. The first-class trcut flies cost from $\$ 1.00$ to $\$ 1.50$ per dozen; bass flies and
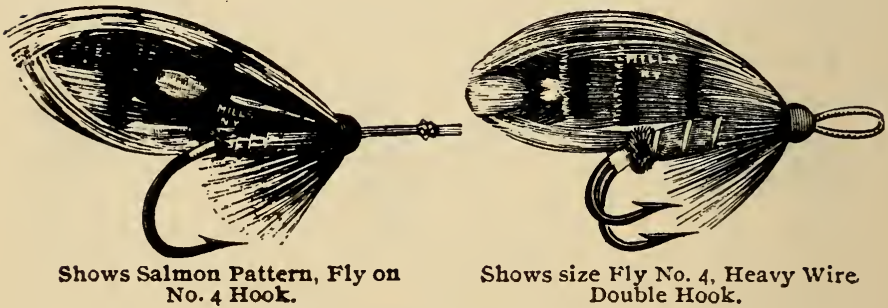

Shows size Fly No. 4, Heavy Wire Double Hook.

Salmon Flies.

the large size trout flies about $\$ 2.00$ or $\$ 2.50$ per dozen. Cheap ones made of dyed feathers, etc., may be bought at thirty-five to fifty cents per dozen.

Many anglers now make their own flies and it is pleasant work for winter evenings and bad days. Of materials, feathers of all colors and especially those of waterfowl are used; also fur of moles, mice and rabbits, whiskers of rabbits, silk floss and silk thread, tinsel (gold and silver), worsted yarn of various colors, mohair, seals fur, and for finishing, yarnish; also wax for the silk is needed. These materials as well as hooks and gut, may be purchased from any large dealer. I could not devote space here to telling 
how to make artificial flies, but can tell of the materials and colors for some of the most popular. If any angler desires to make his own flies, he should purchase an assortment, one of each, and keep them for patterns.

One of the most popular flies for both trout and bass is the Royal Coachman. It is made with a peacock herl body w.th a band of scarlet silk in the center, the wings of white feather and the hackle a soft rich brown.

The Coachman is made same as the Royal Coachman save that it does not have the scarlet silk center to body, and the body is thick and fluffy. The tag is of silver tinsel, and it has a grey speckled tail.

The Parmachenee Belle is an imitation of the anal fin of the brook trout, a killing bait for trout, especially for evening fishing, and good also for bass. It has a body of yellow silk, red and white wings, red hackle and red tail.

The Grizzly King is another one that is very good and much used. The body is made of green silk wound with silver tinsel; the wings are of pintail duck feather (gray and white speckled); red tail and grizzled hackle. The tag (tip of body next tail) is of gold tinsel.

The Silver Doctor is a gaudy fly, good for trout and bass, and usually costing much more than the other kinds. The body is silver tinsel with a winding of red silk. The tag is red and the tail of a golden pheasant hackle. The wings are made of wild turkey feather in under, wood duck on top and the remainder in mixed red and yellow fronds. The hackle is blue. It is the difficulty of getting materials for this fly that makes it so costly, and it is difficult to make, too.

The Professor is good for bass and trout. The body is of yellow silk wound with gold tinsel; tail of bright red (ibis); hackle, brown; wings of pintail duck.

The Montreal, also good for both fish, has a body of 
crimson silk wound with gold tinsel; wings brown (turkey's wing) ; scarlet hackle; tail, ibis; tag, gold tinsel.

The Ibis has ibis (red) wings, hackle and tail, and body of red mohair wound with gold tinsel.

The Brown Hackle has no wings, but the body is made of peacock herl and is draped with a heavy brown hackle.

The Gray Hackle has a body of green silk and a winding of silver tinsel. The hackle is heavy and gray.

I might go on and describe many others but do not think it necessary, for the fly tyer must have a pattern anyway unless he is well acquainted with the fly he wishes to make.

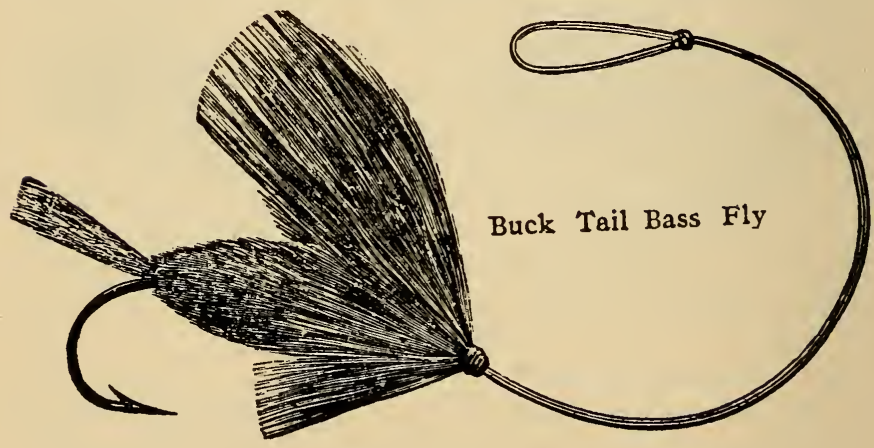

No doubt there is a whole lot of nonsense written and talked regarding fly-making and many anglers think the extreme care and careful selection of colors entirely unnecessary. Some think that the size and shape count for everything and others that it is all in the color. Some others say that neither is particular and that all that is needed is a small bunch of feathers or other material on the hook, just so the colors be bright or sombre as the day and condition of light requires. And to prove that they are right they will tie a piece of feather and a bit of worsted on a hook and 
eatch fish apparently as well as the most scientific angler. It probably depends much on the water, whether it is fished much, etc. In my opinion a fish, if hungry, seldom waits to see the color and form; if he did he would seldom rise to a fly for he would see the hook and leader also, and would notice that it did not appear very lifelike.

Flies are made for bass of deer hair and known as bucktail flies. Their ddvantage over flies of feathers and fur is that they do not mat when wet, but unless the hair is dyed they can only be made in gray and white or brown. Some of them are nicely shaped and others are only heavy hackles. Some of these flies are made with weed guards. These, of course, are large and might properly be classed with artificial baits. The Jamison fly has black head and red body; hackle of red hair and large wings of single red feathers; tail white. Some very large bass have been taken with it.

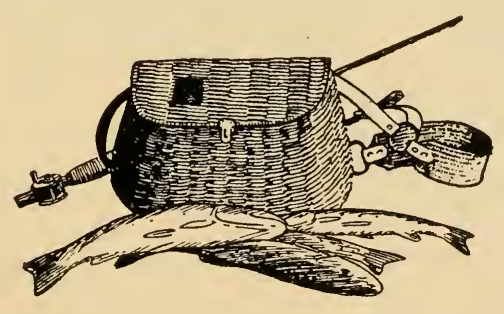




\section{CHAPTER VI.}

\section{Artificial Baits.}

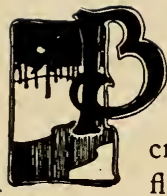

AITS of wood, metal, rubber, and other materials are much used by present-day anglers. Some of these resemble minnows, but as a rule they do not imitate any living creature, differing in this way from the artificial fly, but are probably mistaken by the fish for live creatures, anyway the fish attack them and some of these baits have proved very successful. Perhaps the oldest

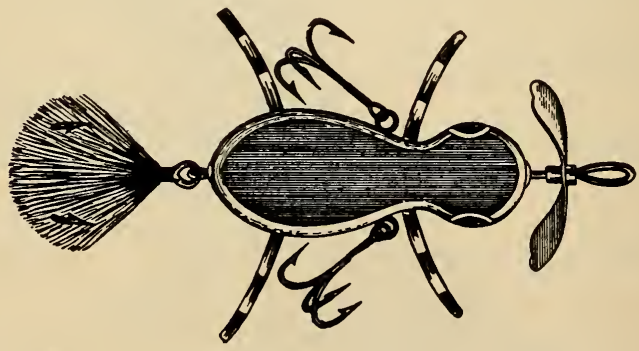

The Roamer Bait.

of all artificial baits is the phantom minnow, which is, unlike many of the later creations, an imitation of a real minnow, and the manufacturers really do try to make it look like a small fish. It is an old standard bait, but is not as successful as some of the later ones. They are usually made of silk, though one brand is made of porpoise hide. They have spinning wings attached to the head and are furnished with 
three treble hooks fastened to gut or gimp snells. One treble is just behind the head; another trails farther back on the body, and the third hangs just behind the minnow's tail, so that a fish can hardly strike the bait without getting caught on one of the hooks.

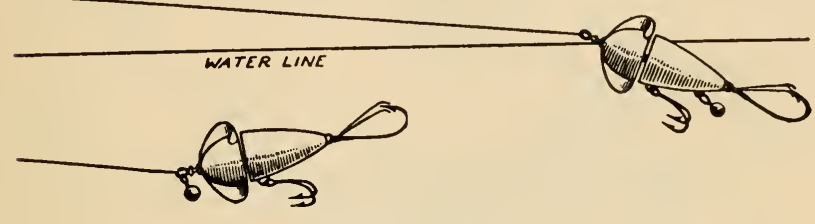

The Nemo Bait.

Then there are imitations of frogs, helgramites, mice, grasshoppers, crickets, grubs, worms, etc., usually made of rubber but these are not used as much as some of the later freaks and are not as good fish catchers, either, except, perhaps, the rubber frog, which is a very good bait.

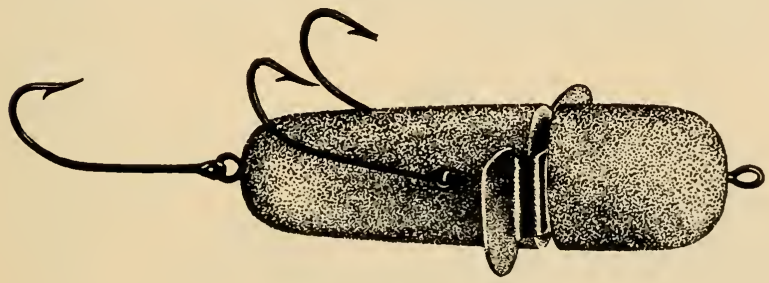

The Decker Bait.

The trolling spoon is one of the oldest and most successful of artificial baits and is adapted to the capture of all fresh-water game fish, as well as many kinds of ocean fish. The first trolling spoon was a real spoon, or rather the bowl of one, dessert size, with a hole in one end for the line and a 
single hook attached to the other end. It is the simplest form of spoon bait and none of the dozens that have been designed since have proved more successful. But very few of them are made this way now and most of them have a small ring at the small end of the spoon and it spins on a short section of heavy brass wire having a loop at one end for a treble
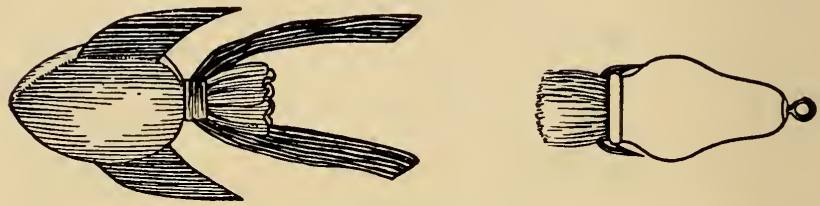

The Booster Bait and the Fish Nipple.

nook and at the other end a loop to which a brass or bronze swivel is fastened. Under the spoon is a short tube fitted loosely on the wire and sometimes a bead is placed over this for the spoon to revolve on. The hooks may be plain, but are more often covered with feathers or deer hair to conceal the hooks and act as weed guards. The spoon may be of

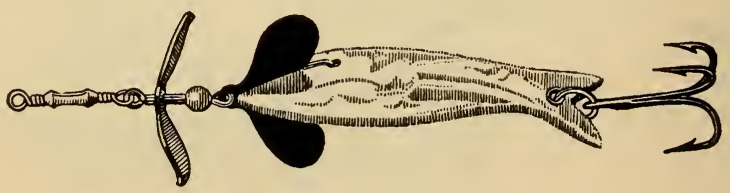

The Pearl Minnow.

ary kind of metal and is plated, painted or polished to make it more attractive, usually being one color on the inside and another color on the other. Spoons are also made of motherof-pearl, which is very attractive.

Tandem spoon baits are also made, one spoon being placed a short distance above the other. 

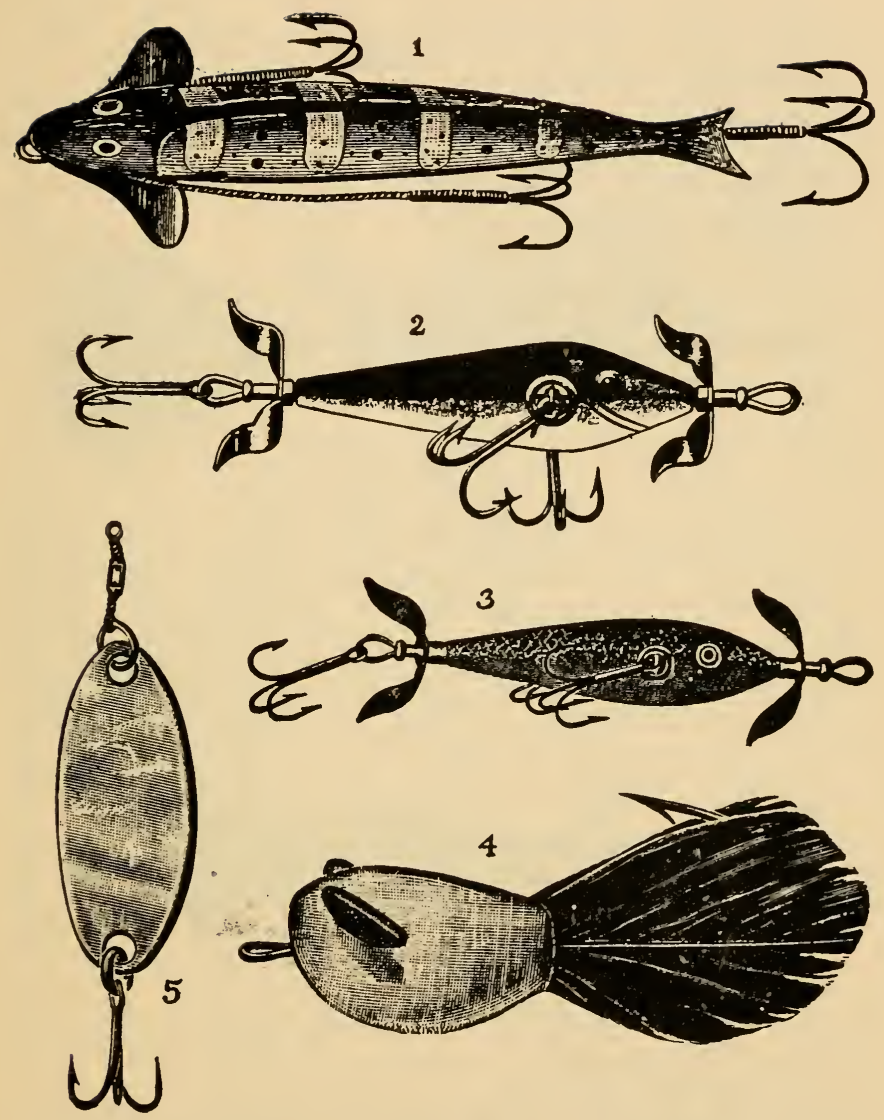

1-Phantom Minnow; 2-Shakespeare Minnow; 3-Dowagiac Minnow ; 4-Coaxer Bait; 5-Pearl Wobbler. 
The spoon may be of any of the standard shapes, and I think it makes little difference whether it is round, oblong or kidney shaped, smooth or fluted. The size is more im. portant and I think that the smaller ones catch the most fish. A spoon measuring about $1 \frac{5}{8}$ inch long will be best, in my opinion, for most fishing, although very large ones are used

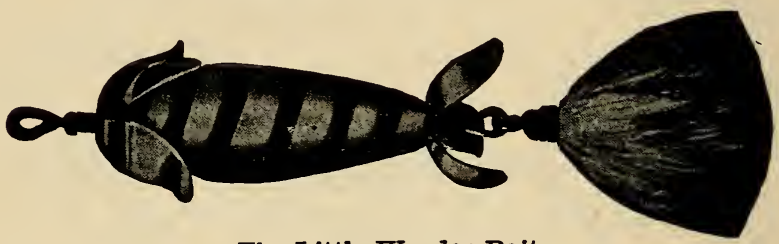

The Little Wonder Bait.

for muskellunge. The illustration showing a muskellunge spoon says "Cut $\frac{1}{2}$ size," but this is a mistake. The exact length of this spoon is $3 \frac{1}{4}$ inches. It makes no difference, to my mind, whether the hook is feathered or not, but a bucktail or feathered hook will catch fewer weeds. If a single hook is used, and I prefer that, it need not be draped, but if

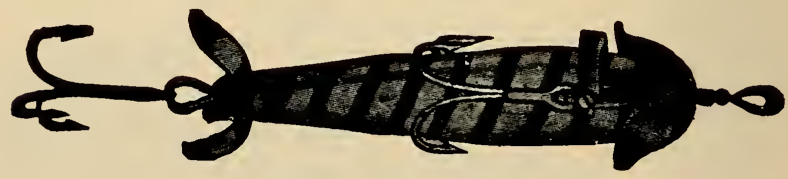

The Champion Bait.

it is the feathering, should not be heavy. There are also spoon baits with large fly hooks attached which are very popular for bass fishing.

The orily spinner that should be used for bass and trout is the small casting spoon, which is a very small spoon with a single undraped hook attached. A worm can be used on the 


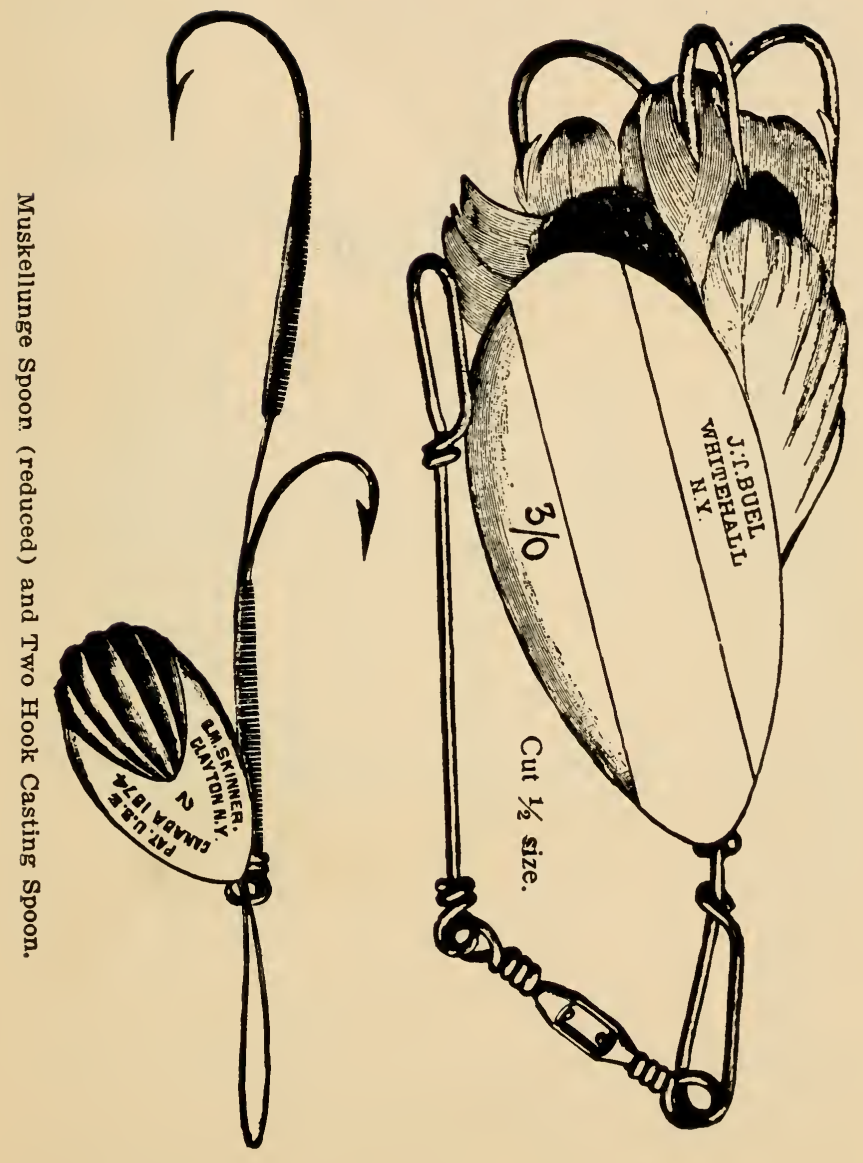


hook but it is unnecessary - the spoon alone is attractive enough. The double hook casting spoons are for use with live bait.

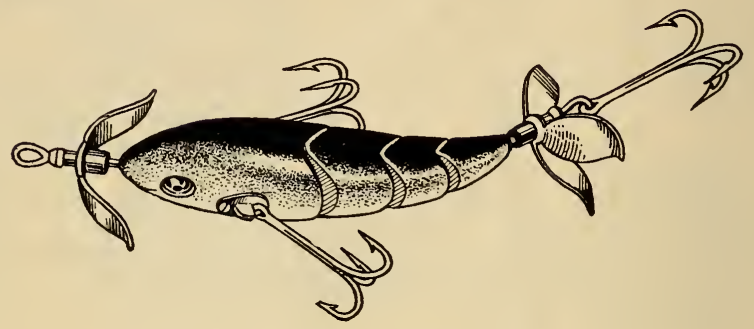

The Lifelike Minnow Bait.

A very good bait, attractive to all game fish, is the Pearl Wabbler. The darting movement of this spoon makes it very attractive. There are other spoons of metal made on

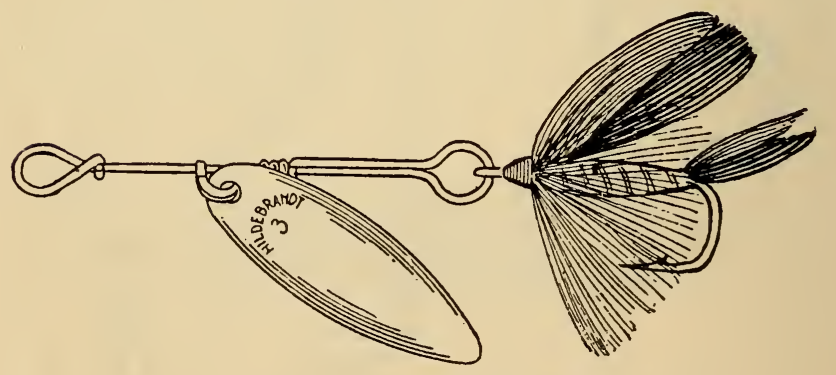

A Spoon Bait with Fiy Hook.

the same pattern. These are the same as the original trolling spoon except that they have treble hooks.

In addition to spoons there are also spinners which serve the same purpose. They are leaf-shaped blades attached by 

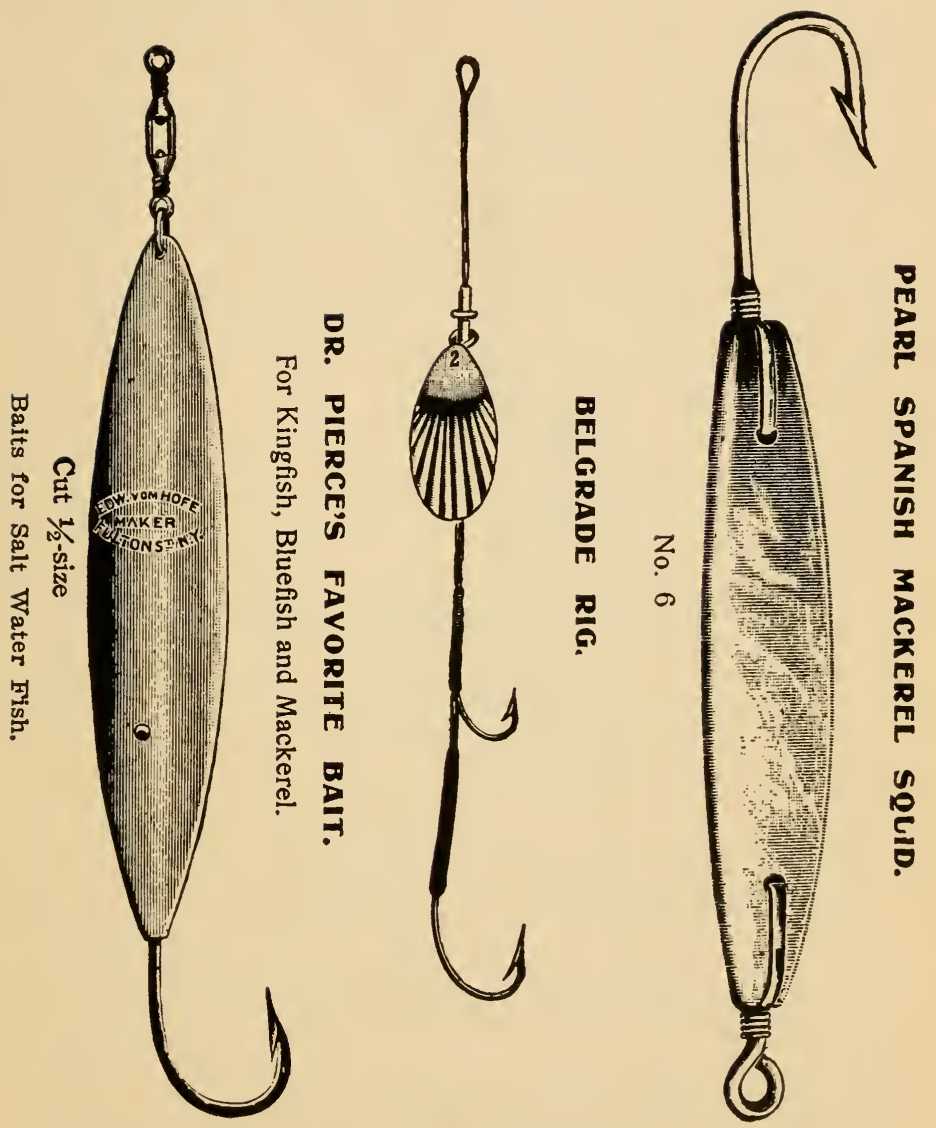
loops along the center line to a brass wire link and the lobes of the leaf being turned in opposite directions cause the blade to revolve rapidly when drawn through the water.

In late years since bait-casting has become so popular large numbers of artificial baits have been placed on the market. They are of every imaginable shape and combination of colors, and to describe all of them or to say which is best is impossible; indeed, I can say that there is no "best" bait, for the one that catches the most fish one day must take a back seat the next, and some other one will prove more tempting. Again, the bait that is good in some waters is not good in others.

Some time ago there was a warm controversy between the manufacturers of the Decker and the Coaxer baits, which ended in a fishing contest. The outcome could hardly be called decisive, but it was proved conclusively that they are both excellent baits for black bass.

There are many baits of the minnow form and I think they are all attractive at times. These are made in all colors, usually have a spinner at head and tail and three sets of treble hooks, the rear treble sometimes feathered. Some of these have weedless hooks and if the water is grassy or weedy it is best to use that kind, otherwise the plain ones are preferable. Some of these minnow baits have no spinners at all and some have only one or two gangs of hooks. There are large ones and small ones; fat ones and slim ones.

Some of these are surface baits and some are underwater baits. One known as the Wagtail Witch dives beneath the surface when reeled in rapidly, otherwise rides on the surface. The Nemo bait is both a surface or under-water bait, depending on where the weight is placed. The Roamer resembles a large bug and it is said to be a good bait. Some, such as the Moonlight Floating Baits, are luminous for use at night. There is a Pearl Minnow which is a combination 
of spoon and minnow bait, and so the list mounts up and each season there are many new ones added to the list.

One that is known as the Booster bait is on the bordes between the artificial and the natural baits. It is made of red, white and yellow cloth and is filled with substances said to attract fish by its taste or odor when wet. It has no hooks and is used same as a natural bait. Each bait will last for a day or a day and a half of fishing.

For salt-water fishing artificial baits are also used, but

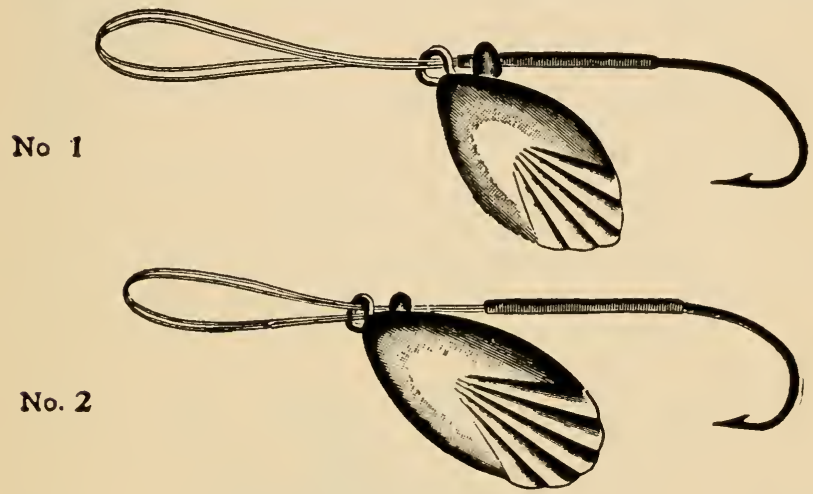

Fluted Casting Baits or Spoons.

they do not vary so much in form. They are usually some form of spoon or an imitation of a small squid or cuttlefish and called squids.

Squids are made of block tin, bone, cedar wood (weighted) and pearl. They are used for mackerel, weakfish, bluefish, etc.

Spoon baits for use in salt-water are of large size and usually have the hooks attached to the end of the spoon. The Wilson's, Sam's and Stewart spoons are the most 
popular. They are used for kingfish, barracuda, bluefish, yellowtail, tarpon, sea trout, mackerel, amberjack, etc.

There are also spinning baits for mackerel and weakfish and others for striped bass. These latter are to be baited. They are mounted on double hook rigs and are shaped like the spinners made for fresh-water fish, like a triangular, deeply lobed leaf, placed upside down.

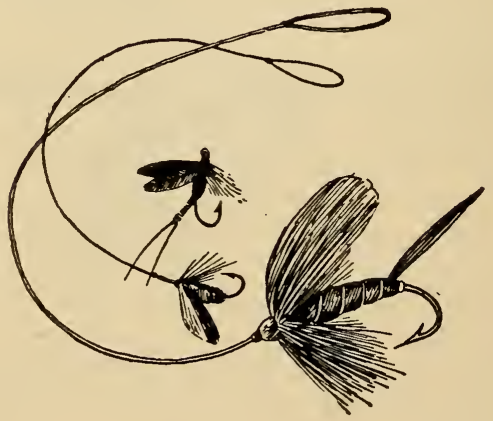




\section{CHAPTER VII.}

\section{Landing Nets, Gaffs, Tackle Boxes, Etc.}

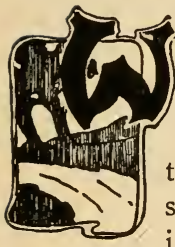

'IILE the rod, reel, line and hooks or artificial bait are the most necessary articles, and in many cases all that is really required for catching and landing an ordinary fish, there are other articles that are useful and sometimes can not safely be omitted. Of such is the landing net, for it is of great value for landing a heavy or lively fish. Many bass and trout fishermen do not use a landing net, but many of these fish are lost because of it and it is nearly always the big one that escapes in this way. For the more common fishes it is not so much needed as stronger tackle is used and there is less danger of it giving way.

Landing nets may be divided into two classes; those for use when fishing from the shore or from a boat and those for use when wading. For the first mentioned use a net with a handle of from two to four feet is needed. The long handle is best when the time comes to net the fish, but it is less convenient in carrying, therefore the longer handle should be selected for use from a boat and the shorter length when fishing from the shore, but for this latter it should never be less than two feet long.

The frame or ring of the net should be of steel or other rust-proof and strong metal. It may be either oval or round and need not be of large size.

The net should be made of strong twine and should be deep and have a square bottom. The whole net, frame and 
handle, should be strong, and especially where frame and handle meet.

For use when wading the streams the net should be of the same kind but should have a very short handle with a rubber cord to hang from the neck. This keeps the net up out of the way when fishing, but the elastic cord allows the angler to reach out to the length of his arm to net the fish.

Some of these nets have wooden frames and solid handles. Some have detachable handles and many fold up or collapse in one way or another, to make them more easily

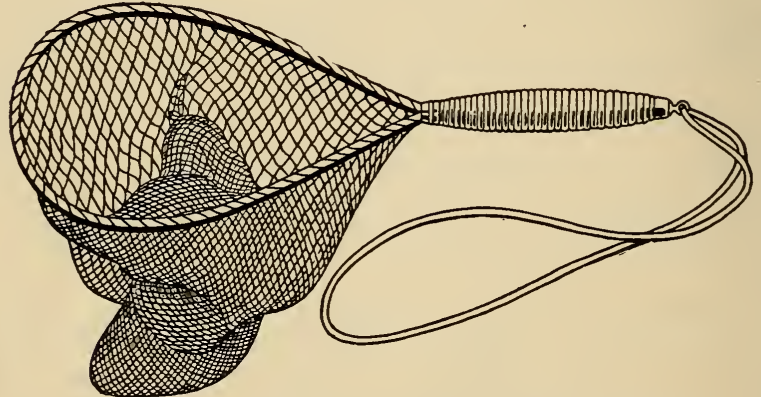

A Landing Net for use While Wading Streams.

transported. Some have hollow handles in which the frame may be placed when not in use; others have jointed handles. One may be coiled up into a very small size, but by far the greatest number of wading nets simply fold the handle into the net ring or frame. There are too many kinds and they cliffer too much to be described fully here, but one need only look through the catalogues of one of the large dealers in fishing tackle to see descriptions, and should have no trouble finding something to suit his requirements. Landing nets range in value from thirty or forty cents up to threee-fifty or 
thereabouts, depending on the style and quality. Some frames and handles are sold without nets, and the cost of a net must be added to them.

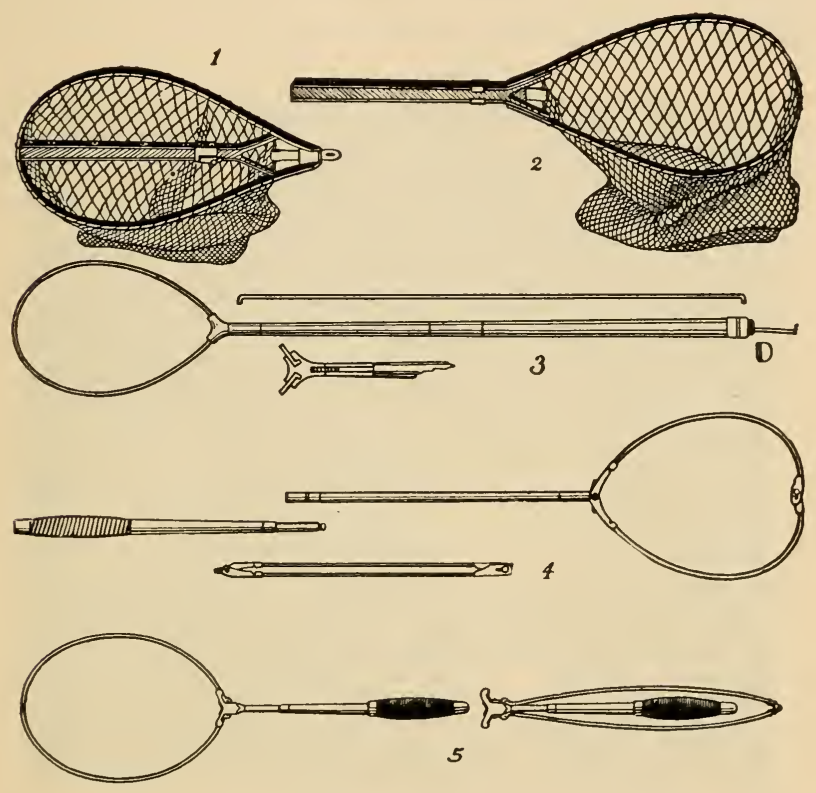

FOLDING PATTERN LANDING NETS.

1-Barnes, Folded; 2-Barnes, extended; 3-Dorsal Fin (head Springs out Straight and Slips into Handle) ; 4-Collapsing, Jointed Handle; 5-St. Lawrence.

Regarding the use of a landing net, like in most other things, there is a right and a wrong way. The proper way is to play the fish until he is fully exhausted and gives up fighting, then submerge the net and lead the fish over it. Never 
shove the net under the fish. The best thing then is to give him a little slack by lowering the rod and he will turn head down over the net, when it should be raised, lifting the fish from the water. If the fish is really exhausted this may be done with perfect safety, but if he is not you should not give

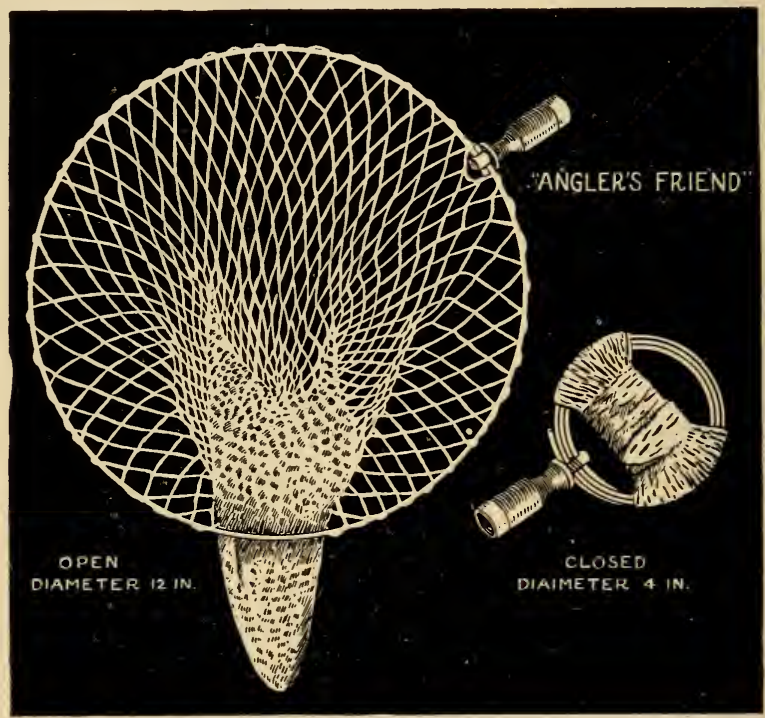

A Pocket Landing Net.

him any slack line or attempt to net him head first. But you should never attempt to land a fish as long as he is in a fighting humor - you always have plenty of time, so wear him out and land him in safety. Also never try to land a fish in swift water-lead him into a quiet place before you try netting him. 
It is only the smaller game fish that are landed with a net. Large fish such as pike, muskellunge, salmon, large trout and all kinds of sea fish are drawn out of the water
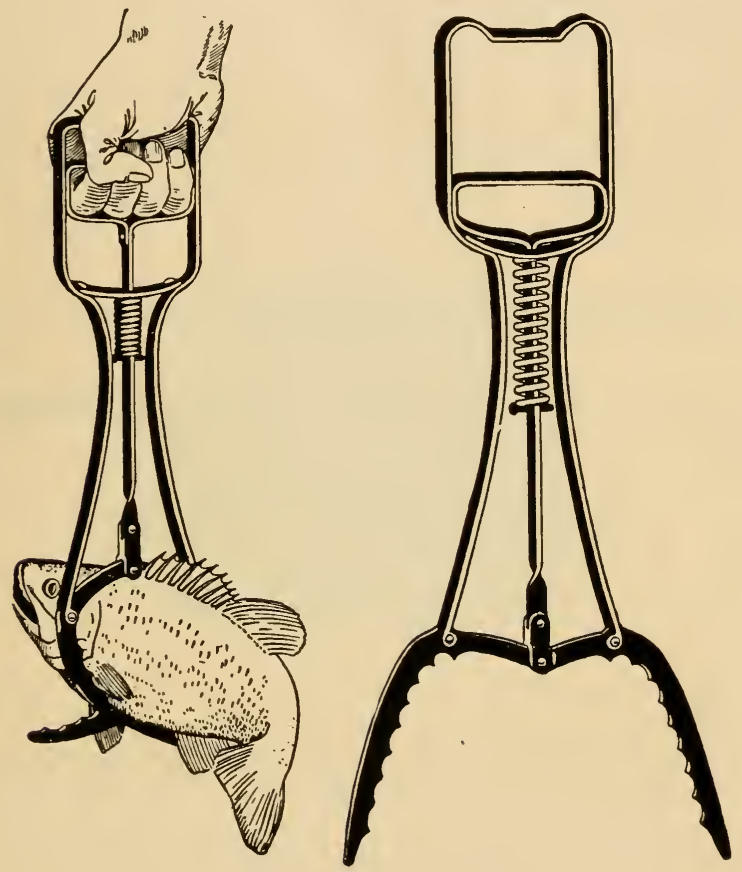

Marble's Clincher Gaff.

with a hook, known as a gaff, after they have been piayed to exhaustion. They are sharp steel hooks, two inches or more wide, depending on the size of fish they are to be used for, and have handles from one and one-half to eight feet long. 
Some of these hooks are made to lash onto a handle that is cut on the fishing grounds; others have the handle in short sections and screw together. For horse mackerel and other very large sea fish a combination of gaff and harpoon is used. The hook is barbed, and when hooked into the fish it detaches from the handle, the hook being fastened to a rope with wire leader, which is used to tow and land the fish with.

There are also what are known as automatic gaffs, fitted with barbed jaws which close on the fish when pressed against it. The Norlund is of this kind.

The Clincher gaff shown here needs no explanation, as

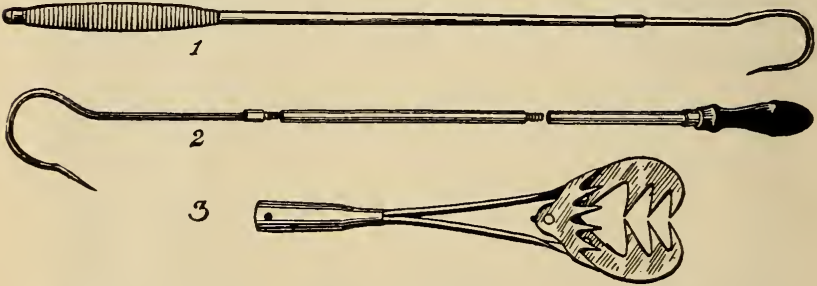

GAFF HOOKS.

1-Ordinary Gaff; 2-Ideal; 3-Norlund's.

the illustration shows how it is used. It can be used instead of a landing net for fish of medium size.

One thing that the fisherman must provide himself with is something in which to carry his catch. For fish of ordinary size, such as bass, trout, etc., that are taken when walking the shore or wading, and when the fish must be carried long distances, there is nothing so good as the willow creel, or basket. The various ruakes are so much alike that all that we need say regarding them is, get one large enough to hold a large fish without bending him. While some sportsmen are likely to look on the carrier of a large basket as a "fish hog," he need not be one simply because he has a large 
basket. It should hold the fish without crowding and should also hold the angler's lunch and some spare tackle. On the inside of the cover you can fasten a leather purse to hold your fly book, leader box, etc., and all through the large creel will be most satisfactory. There are also canvas creels but I do not know much about them.

The creel must be provided with a suitable shoulder strap. The part that goes over the shoulder may be webbing and the other parts of leather. It hangs on the left side when in use and the strap hangs over the left shoulder, ai-

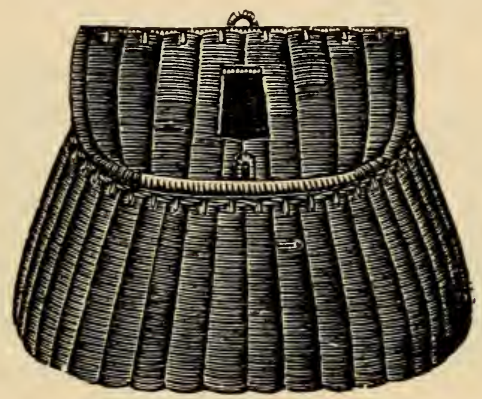

A Creel or Fish Basket.

lowing free use of the rod arm. The strap is held from slipping off by a narrow strap that passes around the chest, under the right arm.

For still fishing or use when fishing from a boat you can use either a fish bag, which is made of twine and about the size of a landing net, or a stringer made of twine or chain. The stringer has a needle at one end and a crossbar at the other and the fish are threaded on by passing the needle in the gills and out of the mouth. By fastening the stringer in the water the catch will live all day. The fish bag is used the same way, keeping the fish alive. 
If you are a live bait user you will want a minnow trap. There are several good glass traps which if baited with cracker crumbs and let down into suitable water for a day or a night will catch plenty of small fish for bait. They also catch crawfish sometimes. There is a device that can be fitted into the mouth of a common glass fruit jar and makes a very good minnow trap.

Some anglers prefer to use a net for catching minnows. One of the nicest of these works like an umbrella and occupies but small space when not in use. The net is also useful for catching crawfish.

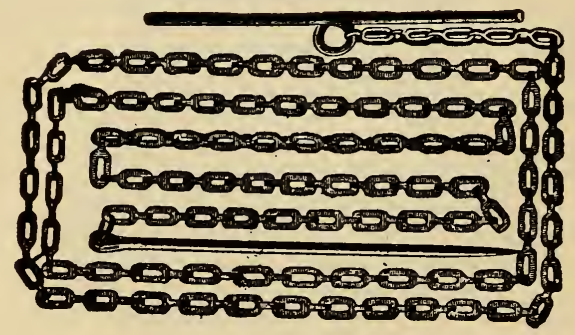

A Chain Fish Stringer.

If you have any fishing tackle worth mentioning you will want a tackle box in which to keep it and in which to carry it when going on a fishing trip or out on the water in a boat. Nothing is more annoying than to not be able to find some very much-needed article when getting ready for fishing and especially so if you are wanting to get an early start to the fishing place and have slept a little too long. Of course a prudent angler will not wait until morning to get his outfit together, but he wants it all together just the same, and you will want some means of carrying it all when going on a fishing trip. Then again you want it all together 
when you go out on the lake in a boat, for you may want to try some other bait, or you may want to quit the fly tackle and try bait-casting as the day advances.

Tackle boxes are made of leather, copper or japanned tin, and if you are of a mechanical turn you can make one yourself out of wood. Ordinarily they are made with compartments for reels, artificial baits, hooks, lines, and other articles that are likely to be needed. There are usually one or more trays that lift out. The leather and copper ones are best

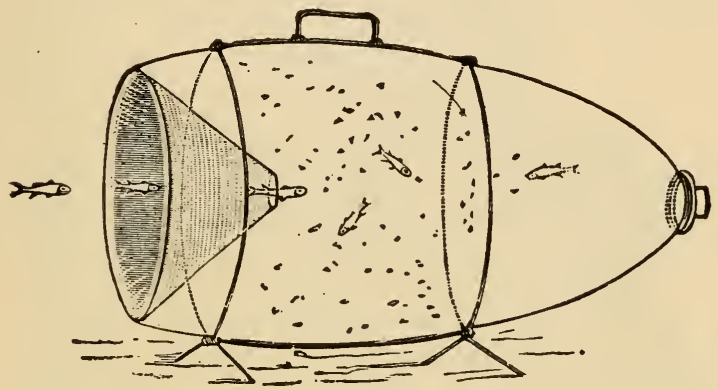

A Glass Minnow Trap.

but one can get just the kind he needs or the kind he can afford.

A fly fisherman must also have a fly book in which he can carry a stock of flies of various patterns. These are made of seal or Morocco leather, alligator, pigskin, and the cheaper ones of canvas. Here again one may purchase what he can afford, but the higher grades are always best. It is not necessary though that they hold a large number of flies for my experience is that a large variety is seldom needed and the majority of fly fishers do not use over a dozen patterns. I have even known fishermen to fish through an 
entire season using only two or three patterns of flies. But even though you do favor a few patterns only, you will want plenty of that kind and you want a convenient method of carrying them, so that you can pick out the very fly you want and separate it from the others with the least possible loss of time and temper.

Among the books most popular are the Jack Frost, the Cooper, the Mansfield, the Levison, the Orvis, and the Chubb. Modifications of the older styles are also made. In most of the old styles the flies are held by clips of some kind on pages like the page of a book. Some of them have serrated

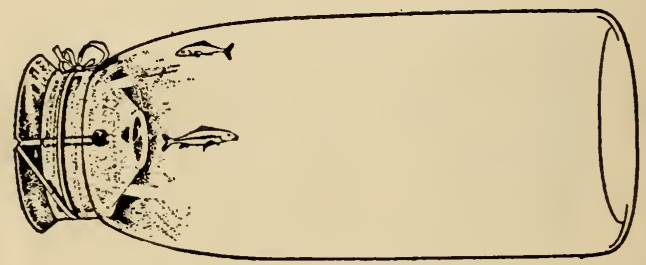

A "Lead in" that makes a Minnow Trap of an Ordinary Glass Jar.

edge strips of metal at the ends of the leaves to hold the hooks, and a coiled wire spring in the center to hold the snells straight. Others have the springs arranged longitudinally, a separate one for each fly snell, and they keep the snells stretched so that they dry straight and are always held securely, though easily removed. The Levison is of this kind. All of them have felt pads between the leaves to dry the flies after using.

The Mansfield has removable folders to hold the flies. This, like the loose leaf system is very convenient as the fisherman may carry just as many or a few flies as he likes 
Landing Nets, Gaffs, Tackle Boxes, Etc.

The Cooper fly book is one of the latest. It is of the loose leaf kind and has an envelope on each leaf for the flies. The envelopes each hold from three dozen to six dozen flies and they have celluloid windows at the top so that the flies are in full view. These envelopes are claimed to be moth proof. It also has a drying pad, a leader holder and a pocket for bait hooks.

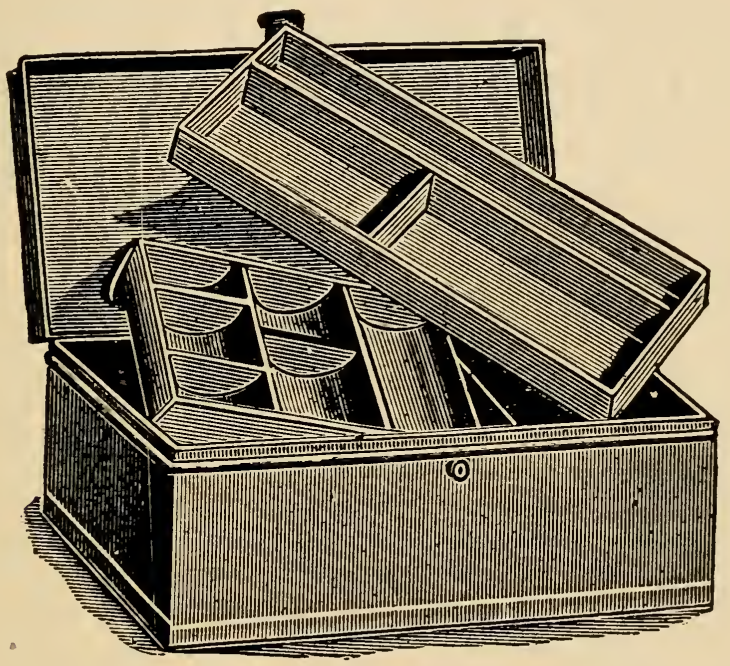

A Metal Tackle Box.

Another made on a somewhat similar plan is the Jack Frost. It has celluloid envelopes to hold the flies and the envelopes are held in place in the book by snap buttons. It has an aluminum box with moistening pads for leaders and for moistening the snells of the flies before using. A chain is also provided so that it will not be lost. 
Small, oblong, aluminum boxes may be had to carry leaders and snelled flies in for moistening. These have felt pads which are made wet and by placing the leaders and fly sne!ls under them they are softened and strengthened, which should always be done before they are used. But they should not be left between these damp pads after the day's fishing.

Eyed flies are carried in metal boxes or cases. These have either got clips to hold each fly separately or strips of cork in which the points of the hooks are held.

In case the fly book has no pads for moistening the leaders the angler should have a leader box for this purpose. These are flat, round boxes, about four inches in diameter, with hinged cover, and are fitted with felt pads for moistening. The boxes are made of aluminum, copper, or steel.

Two other articles that I want to mention before closing this chapter are the hook disgorger and the line releaser. The former is most useful in fishing for bottom feeding fish, which swallow the hook. It is an instrument so shaped that it fits into the curve of the hook and by its use a swallowed hook may be removed without difficulty, and without the usual surgical operation, which is not pleasant for a tenderhearted angler. The hook releaser is useful when fishing along wooded streams, and especially for fly casting. Its purpose is to release a hook that gets entangled on a branch that is out of reach of the hand. It is simply a hookshaped knife with a cord attached, and to use it, you fix it on the tip of the rod and hook it over the branch, then re move the rod and pull the cord, cutting the bransh to which the hook clings. 


\section{CHAPTER VIII.}

\section{Bait Casting}

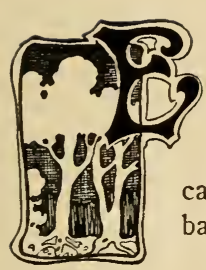

VERY angler has a favorite method of fishing; he may be a fly-caster, or he may be a still fisherman, but probably nire-tenths of present day anglers who fish for black bass, pickerel, etc., are baitcasters, using either live bait, or the artificial baits before described.

Except in places where deep water is found near the shore or bank, and when fishing from a boat, the angler knows that he will get the most fish by getting his bait out several rods from him, where the water is deeper, or where the fish, not being able to see him, have not become frightened. The way of the still fisher is to use a long cane rod, say fifteen or twenty feet long, and a line nearly as long as the rod. With this outfit he may be able to reach out thirty feet from shore. But neither the line nor the rod can be conveniently lengthened, and the length of the cast is limited to the combined length of rod and line, at the best. This is a serious handicap, for the best places are always out of reach, and as fishermen in general are ambitious, is it any wonder that the mode of casting the bait from the reel was discovered and perfected as it is today.

Formerly live baits, minnows, small frogs, helgramites, crawfish, etc., were much used, but now the artificial baits are gradually taking their place. This is not because the one method is unsportsmanlike, but because it is more convenient and more enjoyable to fish with an inanimate bait, and many denounce the use of live bait as cruelty. 


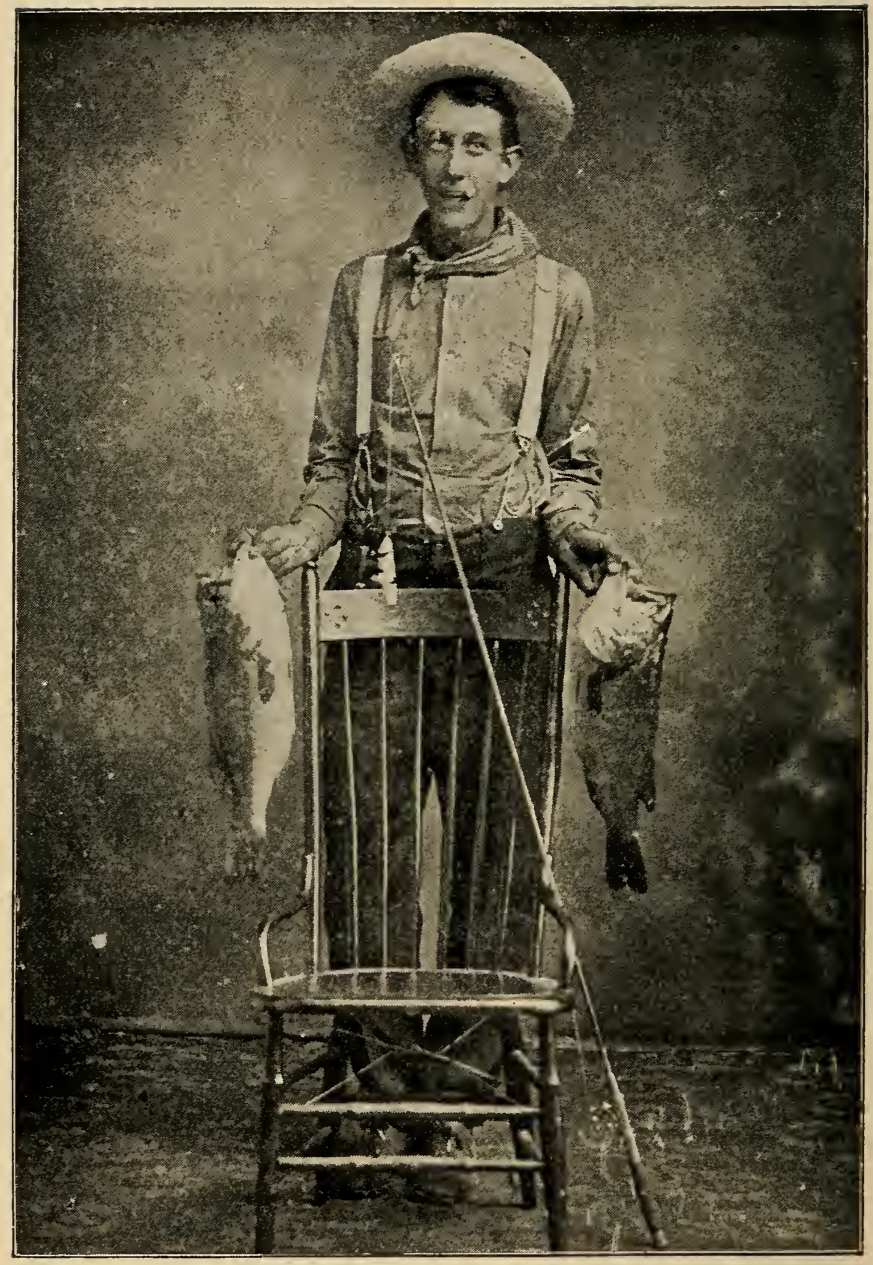

THE FRUITS OF BAIT CASTING.

Gust Melin, of Michigan with two Five-pound Small Mouths. 
Each of these styles of bait fishing requires a different mode of casting the lure, and as the live bait fishing is older than the other I will describe the old method of baitcasting first.

For this the bait rod is used, and it should be about eight or eight and a half feet in length. The reel, above the handle, is a quadruple multiplier, and when the rod is turned with reel seat up, the handle end of the reel is to the left. In casting the reel is kept on top, but as soon as the bait strikes the water the rod is shifted to the left hand and turned with the reel in under, which throws the handle to the right where it is convenient for the right hand, and the line runs freely in the guides, on the under side of the rod. The line is size $\mathrm{H}$, or No. 6, for bass, and for larger fish is size G, or No. 5 or larger, and must be of soft, undressed, braided silk. The longest casts can be made with the fine line, but the heavier line wears longer. The hook must be of a size to suit the fish sought, and should have a snell of strong gut or gimp, and is attached to the ine by means of a small swivel. No leader can be used for bait-casting.

For bait, the minnow is most commonly used. The way to hook bait will be described later.

We will suppose now that an angler is fishing from the shore of a wide stream, or perhaps wading the water, and he wishes to cast his bait to near the opposite shore, eighty or ninety or more feet distant. $\mathrm{He}$ reels in the line until the swivel is close up to the rod tip and the bait hangs only six or eight inches from the end of the rod. Then he grasps the rod in his right hand, with his thumb pressed firmly on the spool of the reel, the reel turned up, and pointing slightly to the left; then he turns so that his left shoulder points towards the place where the bait is to be cast to, $\mathrm{A}$ in the diagram, the angler facing $\mathrm{B}$, and he drops 
his elbow down to the hip and points his rod to the right, the bait down almost against the water. Then without turning his body he turns his head so that he can see the place he wants to cast to, (A) and with a steady sweeping movement he swings his right forearm across in front of his body, to the left, and upward, until the rod points upward at about a twenty-five degree angle and an angle of thirty degrees from the line of his shoulders; this is the end of the cast. Just before reaching this point the pressure on the reel spool is eased up, the thumb pressure almost removed, and the momentum of the bait drags the line from the reel, the bait traveling outward and upward for quite a distance, then curving downward to the water.

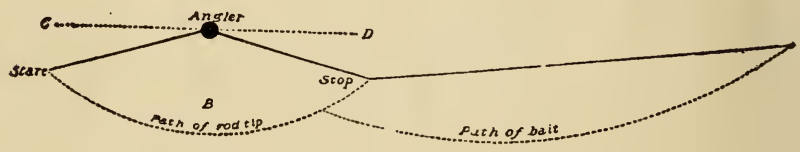

Diagram Sino:.nng Bait Side Cast.

But the pressure on the spool must not be entirely released, unless it is one of the self inumbing kind, or the reel will run so fast that it winds the line back the other way, bringing the bair up with a jerk and tangling the line. This is called a back-lash and the back-lashes cause the amateur more trouble than everything else combined. To learn to control this pressure so that it is not so hard that it hinders the spool in movement, and yet hard enough to prevent a back-iash, is the great secret of bait-casting. It takes months of practice usually, and some persons are so constituted that hey can never become good casters.

The movenient of the rod, already described, is simple enough and easily learned, but that it may be more easily understood I will try to describe it in another way. The rod 
is pointed downward and to the right, the angle being about thirty degrees from the line of the shoulders and it is swung across before you to the left, to a line of thirty degrees from the shoulder line on that side, at the same time swinging it upward by bending the elbow, and when it reaches the limit of its movement the butt should be level with the left shoulder. The butt has started at the right hip and traveled to the left shoulder, and the elbow has moved across the front of the body, but close to the body all of the time. The rod must not be swung too far or the bait will go to the left of the place you have in view.

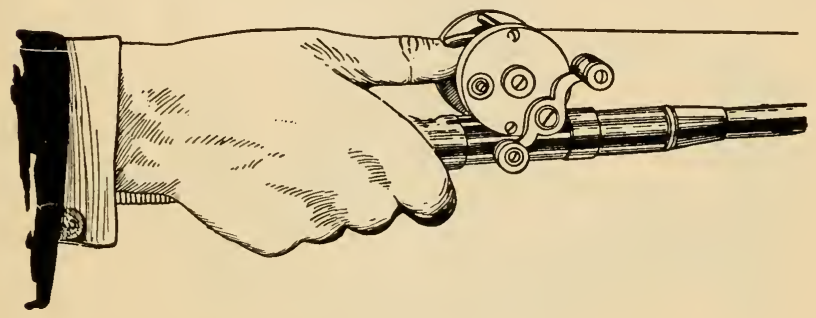

Thumbing the Reel.

The best casts are made by swinging the body somewhat along with the movement of the forearm and the entire movement must be steady, so that there is no jerk, and so that the end of the rod stops when the arm stops.

The instant the bait touches the water the pressure on the reel spool is increased so that the reel stops, and the bait is allowed to sink some distance beneath the surface. At the same time the rod is taken in the left hand so that the right hand is free to reel in the line. The line is reeled in a few yards, then a pause, then a few yards again. When it is brought in quite close it is all reeled in again and another cast made. When reeling in line, the line must be 
spooled with the thumb, or thumb and finger of the left hand, so that it lays evenly on the spool of the reel. If it winds more one place than another you cannot cast well as the thumbing of the reel will be more difficult. The common practice is to rest the butt of the rod against the body, holding the weight of the rod, and spooling the line with the left hand. There are rubber butt caps made to fit on the butt of the roa to keep it from slipping. Another way of spooling the line is by holding the rod in such a way that the left end of the reel rests in the palm of the left hand and the line is guided back and forth with the thumb. The even spooling devices are a great help here.

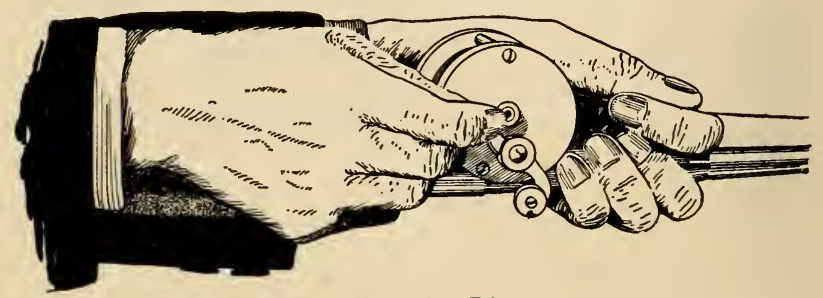

Spooling the Line.

Of course an angler who can cast only to the left is greatly handicapped, but it is just as easy to cast to the right. For this, the right forearm is swung across before the body until the hand is even with the left hip and the rod pointing downward to the left and the angle about thirty degrees from the shoulder line. Then the hand and rod is swept across to the right, and upward until the arm is fully extended and the angle of the rod is thirty degrees from the shoulder line, as before.

The other method of casting a bait is more modern and now a very popular style of fishing. It is known as the overhead cast, although the same outfit can be used for 
a side cast. The short bait-casting rod is used, reel and line the same as in the other method, but the reel is placed on the rod with the handle to the right and is kept on top of the rod all the time, and the guides are also on top. This is the outfit for frog casting, and either a regular snelled hook or one of the several frog harnesses described elsewhere can be used. But by far the larger number of anglers using this method, use one of the artificial baits before descrihed.

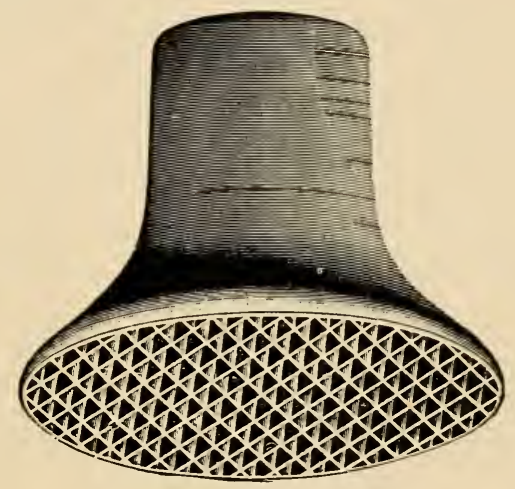

A Soft Rubber Butt Cap.

As before, the line is reeled in until the bait is close to thie end of the rod, about six or eight inches, and the rod is pointed forward towards the place where the angler wants to place the lure: the thumb pressing on the spool of the reel, which is on top but turned somewhat to the left; and the rod is then brought upward and backward until it points back over the right shoulder to a level or a little beyond; then with a quick movement bring your rod forward again to the original position, releasing the spool of the reel when the rod is in a vertical position so that the 
bait draws out the line, but not releasing it entirely. In making a cast of any kind from the reel, the thumb pressure must be increased as the bait gets farther away and the spool must be s,topped entirely just when the bait strikes the water. The best casters do not turn the rod so that the reel is exactly on top, but turned somewhat to the left, as the reel runs more freely in that position and the line does not cling to the rod but runs freely through the guides.

It is not necessary to try this out on the stream-you can practice it out in the field or any clear space, using a wooden plug without hooks instead of an artificial bait. Practice to cast accurately rather than far and you will have less trouble from back-lashes. Even in actual fishing accuracy counts for more than distance and casts of more than seventy-five feet are the exception, even with the expert.

In fishing by this method the amateur angler should use a surface bait, i. e., one that floats, as the frequent back-lashes and loss of time in shifting the rod, etc., allow an underwater bait to sink into the weeds and add to the angler's troubles. When he becomes more expert he may use the underwater bait, especially for running water, where there is a current, but in still water, and where there is a growth of grass or water lilies the surface bait is more satisfactory.

The end of the line near the bait gets the hardest wear, and it should be examined and tested frequently. If it shows signs of weakness cut off a few feet.

The reel must be kept well oiled and should be oiled every day, especially if a very light oil is used. The wearing qualities of your real and the free and easy running of the spool depend on its care. 


\section{CHAPTER IX.}

\section{Fly Casting.}

$\mathrm{HE}$ mode of casting the artificial fly is something very different from that employed in casting a bait, for in this the light tuft of feathers and the little hook could not be expected to draw the line out through the guides, therefore the weight of line must do the work. It also differs from bait-casting in that the line is not cast from the reel, but is drawn from the reel by hand before making the cast. The method of fishing with a fly is also just the reverse of bait fishing, as you shall see later.

Since the manner of handling the tackle is so different it naturally suggests that the tackle employed must differ also, and so it does. The light, slender fly rod described in chapter two is used, and you will remember that the fly rod has the reel seat placed below the hand grasps and that a different style of reel is used. This reel may be either a single action click reel of rubber with metal bands around the side plates, or one of aluminum or German silver. An automatic reel may be used if preferred for this kind of fishing and this is the choice of a large number of fishermen, but the smaller sizes should be selected as the larger ones are too heavy. The click reel should be attached with handle to the right.

The line should be thirty or thirty-five yards long and should be of the finest, enameled silk, size E for most use. but the $\mathrm{F}$ size is much used, especially for light rods. 
To the end of the line the gut leader is attached. It may be three feet long, with a single fly on the end (called a tail fly when used on end of leader); or it may be six feet long with a fly on the end and another (dropper fly) attached to the middle; or it may be nine feet long, with three flies, but this latter length is not used much for the ordinary fly fishing, as the knot catches in the tip when casting.

This is the outfit used for this, the fine art of fishing, and the modus operandi is as follows:

Grasping the rod in the right hand, reel down, and thumb extended on top of the grip, draw from the reel about twelve or fifteen feet of line, letting the slack fall to the ground at your feet, but holding onto the line with your left hand. Now point the rod out towards the place you want to cast to, say twenty-five or thirty feet away, and keeping the elbow close to the side, throw the tip of the rod upward to a vertical position, or perhaps back over the shoulder slightly, making this movement very quickly. If properly done the line shoots high up into the air and then stretches out behind, and just when it is fully stretched, make the forward cast, an easy, downward sweep of the rod, stopping it when it points out towards, but several yards above, the spot you want to cast to. As the line stretches out ahead of you at the end of this forward cast, release the line you have been holding and the momentum of the free line draws out the slack line that has been drawn from the reel.

To make the fly fall lightly on the water, and fall before the line does, elevate the tip of the rod gently just before the fly touches the water, also, to keep the fly from striking with a "spat," cast at a spot about a yard above the water.

The most difficult thing for the amateur to learn is just how long to pause after the back-cast before making 
the forward cast. This pause must be just long enough to let the line straighten out and pull gently on the rod tip. If you pause too long the line drops and strikes the ground or water, and if you make the forward cast before the line has straightened out you will snap the flies off the snell. An expert can feel the pull of the line on the rod tip, as the line straightens out behind, and the amateur can soon learn to wait for this. If you hear a sharp little snap behind you, you are not pausing long enough - you have made the forward cast before the line has straightened out.

Avoid throwing the rod too far past the perpendicular as you can never become a good caster as long as you do that. The rod should be carried little if any beyond the vertical line and the bend of the rod will usually be enough to give it some angle beyond. When your thumb on the grip points upward, stop. Also avoid a sudden stop at the termination of the forward cast, as it causes a double movement in the rod tip which spoils the cast, and do not release the line too quickly; it is better to wait until you feel a light pull, then release it.

But thirty feet is not a long cast and you may wonder how you are to reach more distant spots that you always thought could be reached by casting. To do so you simply make a second, a third, or even a fourth cast. With the length of your first cast out you draw a few yards more line from the reel and make another cast. It is made in the same manner as the first, except that with the longer line you must pause longer before making the forward cast. In fishing with an artificial bait we cast the longest distance possible and then reel in the bait. In fly fishing we fish the nearer water first and gradually lengthen the cast and reach other water, but even if you do not want to fish the nearer water, you must reach the extreme distance by a number of casts as described.

The beginner should learn first to cast accurately, and 


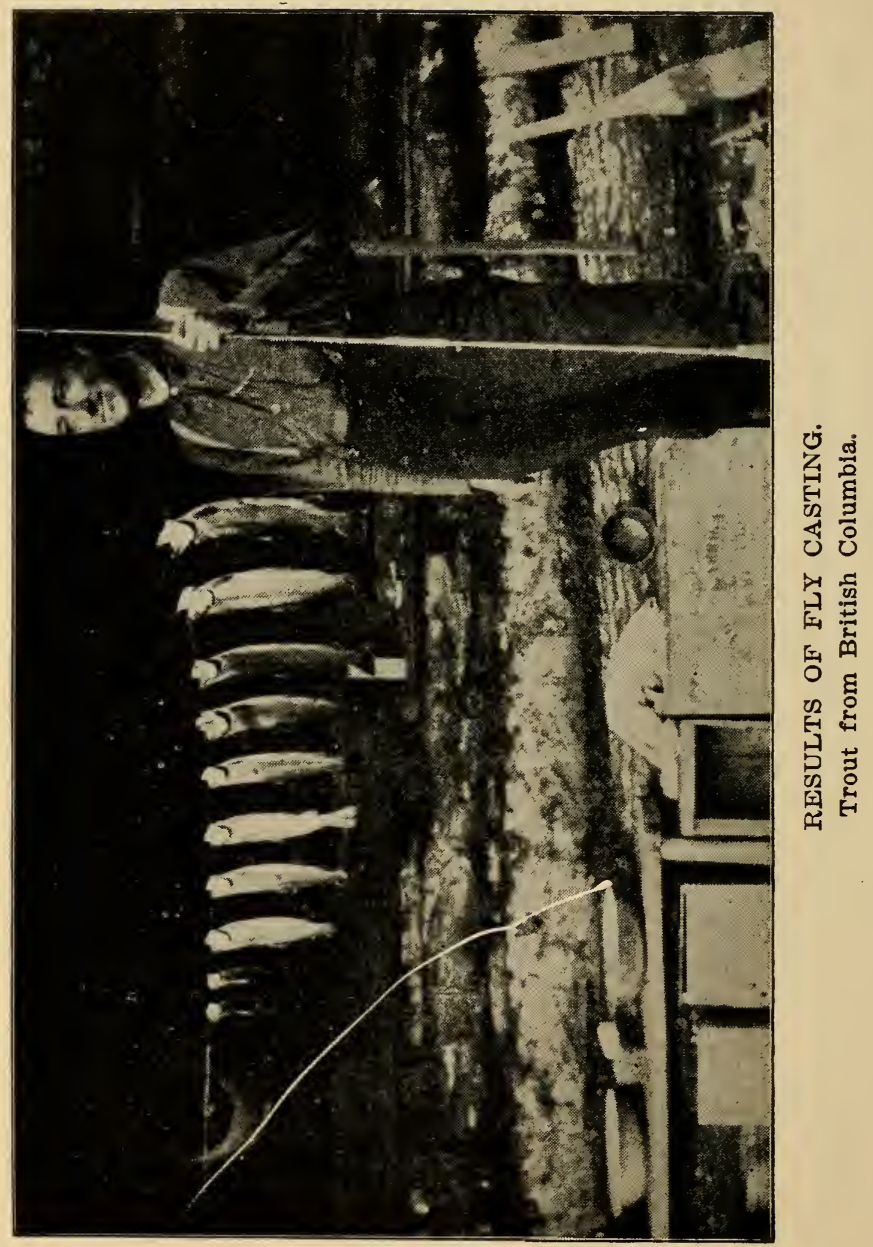


make the fly fall gently at the shorter distance, before trying to cast far. Even in fishing, accuracy and a light dropping of the fly count for more than distance, but both are points to strive for. When you have learned to cast easily at short distances you can try casting farther, and it is easier learned that way, also less likely to discourage the beginner.

You need not go fishing in order to learn casting - you can learn it out on any smooth, level piece of ground. Select a place where the ground is covered with short grass so that the line will not be injured. Place your hat on the grass, or a newspaper, weighted with little stones on the corners. You don't need a leader or fly, just the bare line, but you can tie some small white object on the end, like a bit of white string, so that you can easily see where the end of the line falls.

Remember, the rod used has much to do with the casting - in a way it is the rod that makes the cast, anyway the rod that has a lively spring - no suggestion of weakness or slow action - is the one that casts best. A long cast cannot be made with a very light rod, for with a light rod a light line must be used and the combination does not spell distance. The expensive rods are best, but the amateur should not buy an expensive rod to learn casting with; he can use one after he becomes expert with the cheaper one. The fact that in tournament work, all of the longest casts have been made with split bamboo rods is significant.

This is the overhead method of casting the fly, and all fly fishers use it more than the other ways but the method is frequently varied by the different fishermen. Some, when they finish the forward cast, straighten out the arm, giving more force to the movement, and some make the complete cast by giving the rod a sweeping movement somewhat on the line of a horseshoe, making the back-cast over the left shoulder and the forward cast from the right. some. 
what like a teamster cracks a long-lashed whip near the lead-team's ears.

In addition to the overhead cast there is the side cast, which is made in the same way except that the rod is swept out at a level or nearly so from one side or the other, instead of vertically, as in the overhead cast. This cast is useful in fishing under overhanging trees, but such long casts cannot be made in this way.

Another way to cast a fly a short distance, especially good when fishing small streams where the brush overhang, is to hold the fly between the thumb and first finger of the left hand, and, pointing the rod out towards where you want to cast to, pull back on the fly to bend the rod tip back, then release the fly and the spring of the rod sends it out the length of the line.

Still another way of casting a fly that is quite popular and especially good where trees interfere with the overhead cast is what is called the roll cast.

Some line is drawn from the reel, as in the other methods, enough so that when the rod is raised to the perpendicular or a little beyond, the line will still rest on the water. Raise the rod as mentioned, slowly, until it points straight upward or a little back over the shoulder, then pause an instant so that the line stops in its dragging motion, and make a quick snappy forward and downward cast. This throws a high curve in the line, which rolls forward, lifting the leader and fly from the water, up over the curve and out beyond to the length of the line. At the end of each cast a few yards of line should be drawn from the reel, before making another cast and the distance will be extended in this way each time. This is a very good cast for the angler to learn. The fly may also be cast to either side in the same way.

The kind of casting to practice depends much on the nature of the water where your fishing is done. If you fish 
lakes and wide streams you should learn to make long casts, and learn to drop the flies gently, especially for still waters. If you fish mountain streams where the trout lurk below boulders, under logs and similar small spots of water, accuracy casting rather than distance casting should be practiced, also practice casting under logs and bunches of brush, over branches of trees that hang near the water, etc. For this kind of water it will pay to learn the side cast and roll cast well. Also, learn to cast with either hand.

Whether to cast up stream or down stream is a question that every angler must settle for himself; there are weighty points both for and against either method. To get down to the bottom of the question, it is the sight of the angler that alarms the fish, sending a trout scurring and causing a bass to turn slightly and watch the angler, both refising to rise to the fly. Now a fish always lies with his head upstream, or with his nose to the current, and he can sce straight ahead, to both sides, and quite an angle back of the direct transverse, some say to an angle on both sides of thirty degrees from the body line. Therefore to be invisible, if standing out in the open, the angler must be behind the fish and inside of a section of the circumference of a circle comprising sixty degrees of same, with the fish for the center. From this vantage point the angler, if he does not splash or make too much commotion in the water, can approach quite close to a fish without being seen, and long casts are not needed. This is a great point in upstream fishing. Another is that the mud or sand stirred up by the angler floats away behind him, into the water that has already been fished, and this will not alarm any prospective catch. The points against upstream casting are that the fish will not see the fly if it falls a little short, that the current instantly sweeps the fly towards the angler, after the cast, and in case of a rise the angler sometimes cannot strike quickly enough, or rather cannot recover the slack 
quickly enough to set the hook, and the fish never hook themselves as they often do when fishing down stream, where the current keeps the line taut at all times. Then again it is more difficult to wade up stream, and on small trooks you cannot float the fly under overhanging brush as you can by fishing down stream. Therefore, to the question: Is it best to fish up stream or down stream? The answer is, it depends on the kind of water you are fishing. Casting across stream, if there is any current, is a bad way, as the current catches the line and makes the fly act very unlifelike, and the angler cannot manipulate the fly properly. Another trouble is that you must make long casts or the fish will see you.

You must never cast a fly from a high bank, a bridge, or any other place above the water's level, for the fish will surely see you. You must keep out of sight at all times, and the only satisfactory way to fish with a fly, on wide streams, is to wade the water. When wading you are down low and less likely to be seen, and there is more room for your line in casting. On small streams you can stay on the bank but keep as far away from the water as practicable.

Our American way of fishing with the artificial fly is to keep the fly partly submerged, especially for black bass. It is known as wet fly fishing in distinction from the English way of fishing with small floating flies, or dry flies. Our way is perfectly satisfactory for bass fishing, and in fishing waters where the fish are not sought much, but experiments have proven beyond all doubt that dry fly fishing is a more killing way in trout waters that have been hard fished, as many large fish may be caught where the wet fly fishers cannot get a rise. For dry fly fishing the tiny dry flies, with bodies of cork or some other buoyant material, and only one fly is used. It is attached to a ninefoot, very fine single gut leader, and a tapered line. The flies are of the eyed kind so that there will be no knot or 
loop in the leader near the fly, the object being to cause the fly to fall on the water as naturally and quietly as a live insect, to fall before the leader, and for the latter to make no commotion. The fly must remain on the surface of the water just like a real insect, and must retain a lifelike appearance and movement. The flies are dipped in an oily preparation to make them resist the water, and the line is rubbed with deer fat to make it float well. This method of fly fishing is being taken up in this country and is proving remarkably successful.

The method of casting the dry fly is exactly the same as casting the wet fly, except that the fly is not allowed to touch the water at the end of the cast but is retrieved while still ten or twenty feet above the water and the cast lengthened in this way, until the line reaches out to the place in view, when the fly is allowed to settle to the water.

Fly casting for salmon, with the two hand salmon rod is done in the same way as casting for trout and bass, except that both hands are used, and the hand that grasps the butt, usually the left, is used only as a pivot for the rod, and the movement of the rod is executed mainly with the right hand, which grasps the upper grip.

Fly fishing is the most refined, artistic, and sportsmanlike method of taking game fish - any kind of fish that will rise to a fiy - and is withal the most enjoyable. While, for some kinds of fish, it may not be as productive of results as some other kind of fishing, it is so much nicer in every way, so much more enjoyable, that it should be better understood by anglers in general. Black bass fishers especially, if not already acquainted with fly fishing, should give it some study. There are some anglers who do not even know that the black bass will take an artificial fly. For trout and salmon there is nothing like it, and there are other fishes also that will rise to a fly. 


\section{CHAPTER X.}

\section{Surf-Casting, Trolling, Still Fishing, Etc.}

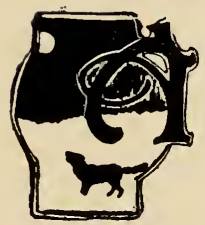

MODE of fishing practiced by salt-water anglers and much in vogue along the eastern coast is what is known as surf-casting. It is a sort of bait-casting from the beach into the ocean surf where certain fish such as channel bass and striped bass resort to feed on crabs, sea worms and certain shell fish that stay just at the edge of the deep water made by the waves in the sand. At a certain distance out this line will be found, a sudden deepening of the water, a cut of from a few inches to several feet deep. In this water is where the surf-casting is done, that is to say, the bait is cast to that place.

The rod for this kind of fishing was described elsewhere. It should be seven and a half to nine feet long if made with the plain, long butt, and somewhat longer if with spring butt. It should be of split bamboo and should weigh in the neighborhood of twenty ounces, the weight of course depending on the length. The line should be 150 or 200 yards long and made of twisted linen, about 12 or 18 thread size. The reel should be a double multiplier made specially for this kind of fishing, with a throw-off to make it a free-spool reel when casting, and it should have a handle drag or leather brake. To the end of the line a triangular swivel is fastened and to this a six-ounce pyramidical sinker and a short leader, a foot or a little more in length and made of six strands of gut, braided. The hook is a $9 / 0$ for red drum and striped bass. Shedder crab is ased mostly, for 
bait. The angler should also be provided with a rod belt, having a leather or rubber cup to hold the butt of the rod, and a beach rod holder, which is a tube shaped affair with a long spike on the bottom. It is stuck into the sand and used to hold the rod when baiting, etc., for rod and reel will be injured if thrown down on the sand. The belt with rod cup is to hold the butt of the rod while waiting for a strike, also to "pump" a large fish.

The casting is done from the reel, as in bait-casting, but the rod is handled with two hands and instead of making a direct overhead cast, the rod is swung at an angle of forty-five degrees, or thereabouts, from the vertical line. The weight of the sinker draws out the line in the same way that the bait draws the line out in bait-casting. The angler must be able to cast 100 feet or more for this kind of fishing.

The bait is cast out to the proper place where the heavy pyramid sinker anchors itself in the sand, and the angler reels in the slack line, stands the butt of his rod in the rod cup on his belt, and patiently waits for a bite. After waiting a few minutes, if he fails to get a strike, he reels the bait in a couple of yards closer and waits again. Occasionally he reels the entire line in to see that the bait is all right and not entangled in sea-weed, and makes another cast.

Trolling, is letting a revolving bait trail at the end of a long line behind a slowly moving boat. For this a hand line may be used, but it is much nicer to use a short, stiff rod and a multiplying reel. If a hand line is used it must be a strong one. A metal leader and swivel is advised, and the bait commonly used is the trolling spoon. Of course the proper weight and strength of tackle depends on the kind of fish sought. Muskellunge and pike require stout tackle, and the wire leader should always be used.

The wire leader cannot be cut by the fish and it also 
sinks the line to the proper depth. For very deep fishing, as for lake trout, a braided copper line is sometimes employed. This is used in connection with a short rod and the wooden reel before described. The large diameter of the wooden reel makes it espcially good for a wire line, as the line being stiff in comparison to other lines, winds more readily on the large wood reel.

In trolling. a common mistake is to go too fast; most of the fish are raught when moving slowly, about one and a 'nalf miles an nour. The bait is trolled at a distance of about 100 feet behind the boat.

For a trolling spoon, the rule is to use a bright spoon on a dark day or in dark waters, and a sombre colored spoon on bright days. As before mentioned, the smaller sizes seem to get the most strikes. The Archer spinner used with a minnow is also a good bait to use for trolling, especially for lake trout. More will be said of this later.

A bait-casting rod may be used for trolling, but if large fish are found where you fish it is best to have a large reel and a long line. For such large fish as muskellunge it is better tc use a light salt-water rod, about six feet long, as a rod is likely to get warped in trolling. If you do much fishing where such fish are found the rod will be generally useful. In case you do use a bait-casting rod, use it from the back of the boat, so that it projects straight out behind, and never use it out over the boat at right angles, as the strain on it is too severe.

Still fishing is the oldest and most common form of angling, and if we consider the number of devotees, it is the most popular. But this is not because it is a better way or that it yields more sport, but because it is so simple and easily mastered, and requires no elaborate or expensive tackle. A long cane rod with a light linen line of about the same length as the rod, a lead sinker of the proper weight, and some common ringed hooks are all that is needed. Such 


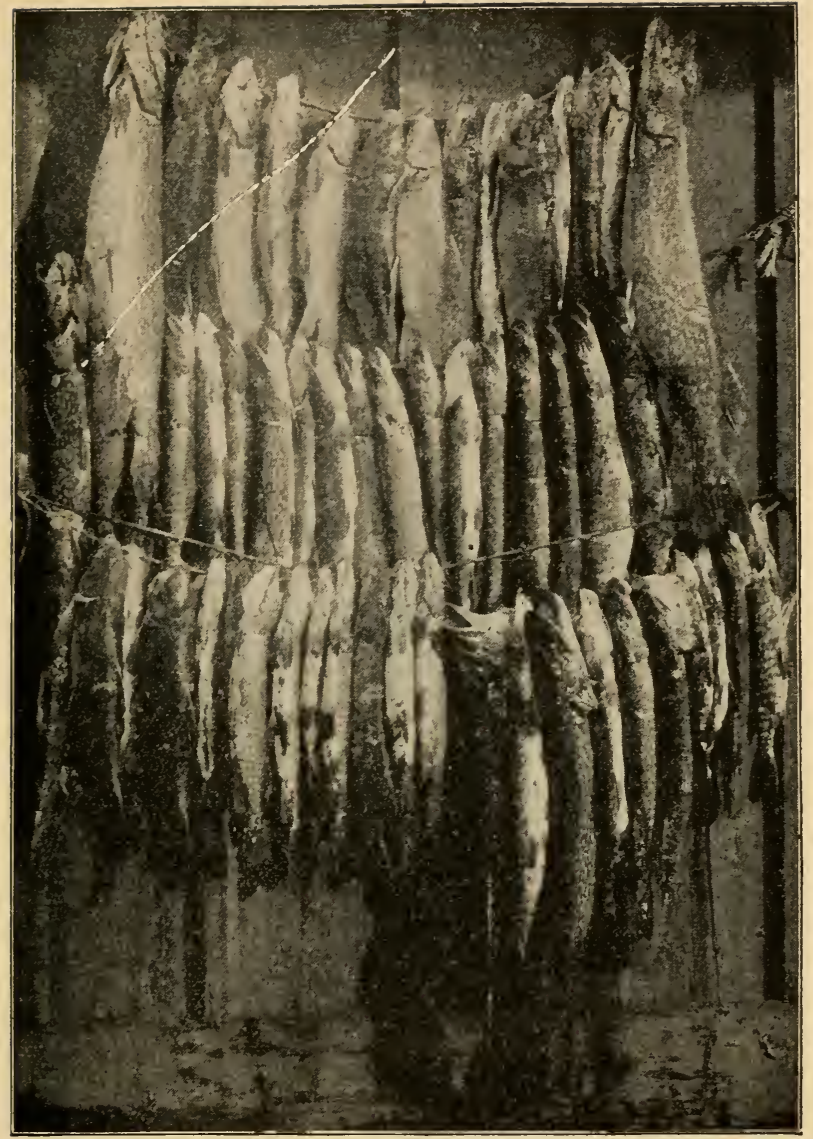

A Catch of Pike and Suckers from Otter Tail County, Minnesota, Killed with Spears. 
an outfit is easily handled as the hook is simply baited with an angleworm or other natural bait and thrown out into the stream as far as it will reach, providing, of course, that the best place for fishing lies in that cirection. If desired a cork, wood, or quill float may be used, and by having rod rests on the bank the angler may "set" his rod, then retire to a nice place farther up from the water where he can see the float and know by its movements when a fish is biting. The rod rests are crotched sticks stuck into the bank the one nearest the water being highest and the top forked, the other one having a hook, a short branch, near the projecting end, and the rod is placed in the fork of the one and under the hook of the other. When a fish bites he is hooked by a quick light jerk and drawn out of the water by a steady pull. The proper tackle to use for each kind of fish will be mentioned in the part devoted to that fish, farther on.

Still fishing may be done with a hand line if desired. The lines are simply cast out into the water and the end tied fast to a small branch or stick set in the bank.

Eels and catfish are sometimes taken at night by a line and bait, but no hook. The bait is a bunch of angleworms strung on a thread and wound into a ball. This is tied to the end of the line and let down to the bed of the stream from a boat. When a bite is felt the line is slowly drawn up to the surface and the catch lifted into the boat by a quick, steady lift.

Then there is the trot line method. A long, heavy line is fastened at the bank and a heavy stone is tied securely to the other end, then the line is taken into a boat and paid out as the boat is rowed across the stream. Where there is a current of any strength the boat is held at an angle against the current and rowed upstream, in a quartering direction, and the wash of the current against the side carries it straight across. When the end of the line is reached the stone is dropped overboard and the line is in position to re- 
Surf-Casting, Trolling, Still-Fishing, Etc. 117

ceive the hooks. Returning to the shore the fishermen then takes the line in hand and attaches first one baited hook and then another, several yards apart, by short lines, one and a half or two feet long. The hooks are always large, as big fish are caught this way. The fisherman pulls the boat along by means of the line and does not use the oars until he reaches the end of the line, when he rows back to shore. In looking at the hooks and removing the catch he simply raises the line near the bank, throws it across the bow of the boat, and draws the boat along hand over hand from one hook to

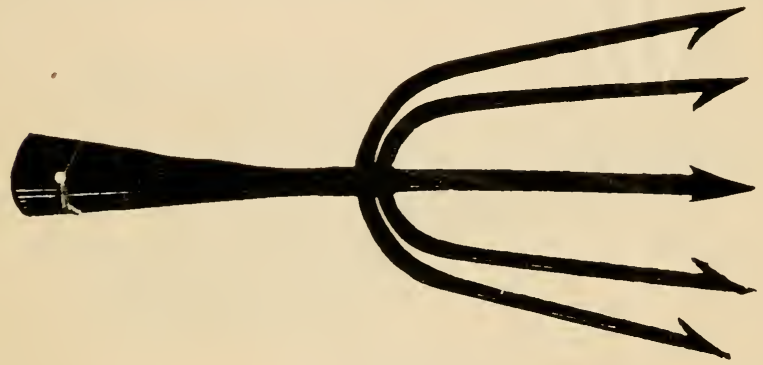

A Fish Spear.

the next. Nearly all of the large catfish are caught this way, as well as eels, and many other bottom feeding fish.

Large fish are also taken at night by spearing them from a boat, using a five-pronged spear with a long handle. A bright light is fixed in the bow of the boat so that the spearman, who stands just behind, can see the fish. The bo: a $^{+}$must be rowed slowly and quietly. This is a favorite $r$ dy of taking pickerel.

In the small streams of the East and South a method of spearing or gigging is used that is somewhat different. The spear or gig has the four square prongs set close together, and the edges of these prongs have barbs cut on them for 
about an inch back from the point. The handle is about five or six feet long and it is best to have the gig fastened to the handle by a long iron shank as it does not disturb the water so much as the chisel socket often used. The fisherman wades slowly up stream throwing the bright light from his reflecting torch down onto the bed of the stream. When a fish is seen the spear is lowered quietly to within eight or ten inches of the fish, when a quick thrust usually secures the prize. Many eels and suckers are taken this way.

Fishing through the ice in winter is practiced in northern districts, especially where pickerel abound, and this way of

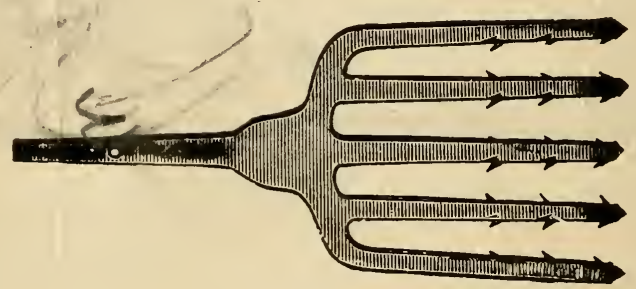

Eel or Sucker Spear.

fishing is also employed for trout, lake trout, etc. There are many styles of so-called "pickerel traps" which trip up or show a flag when a fish is hooked. The simplest of these is riade of a strip of thin board or shingle with a hole bored through near the narrow end and the line fastened at the short end. A hole is cut through the ice, the hook is baited and let down, and a round stick is thrust through the hole in the shiıgle and across the hole in the ice. When a fish takes the bait he makes a run with it and hooks himself and lis pulling on the line trips the shingle up, warning the fshernaan trat he has made a catch. The fish is then puller 
up, and the hook rebaited and set again. In this way one man may tend quite a lot of these traps.

Food fish are taken in nets and there are many kinds, each used in a different way. These are for the use of the commercial fisherman mostly, except that the gill net is sometimes used by northern hunters and woodsmen to provide whitefish and other fish for their own use, and set-nets or funnel nets are used in the East and South where it is allowed by law, for the same purpose. Gill nets are made of very fine linen twine, almost like thread, and are knit in a mesh of a suitable size to take the average run of fish. A

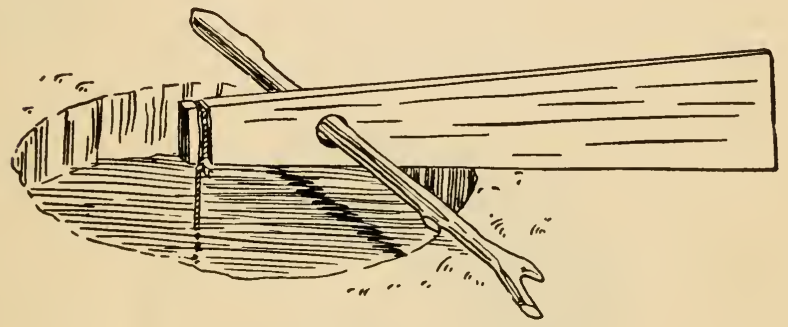

A Pickerel Trap, for Ice Fishing.

net with $1 \frac{1}{2}$-inch square mesh is the most useful for the general run of fresh water fish. The nets have floats at the top edge and weights at the bottom, and the ends are fastened with light rope or heavy cords to stakes. This keeps the net stretched and the fish run their heads through but cannot force their bodies through the mesh, and when they try to back out they get fast by the gills. White suckers may be taken this way when they go up stream in the spring to spawn. The gill net is very hard to handle as it soon gets badly tangled unless the fisherman is expert in its use, and the fish are hard to remove. 
A set net is knit in a tapering cylindrical form, closed at the small end, and a funnel knitted in the large end, so that the fish are guided into the net through the small throat of the funnel. If the net is a large one two funnels may be niade in it. Sometimes there are wings running out from the mouth. It is kept in shape by means of hoops, and is set by sinking to the bed of the stream, the wings and tail fastened to stakes. Sometimes the net is baited, but in small streams when fish are moving it is not.

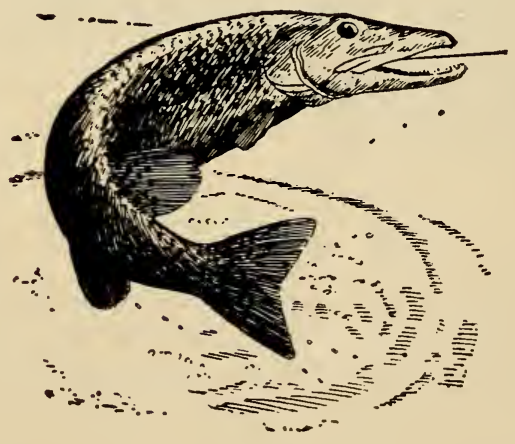




\section{CHAPTER XI.}

\section{Use of Natural Baits.}

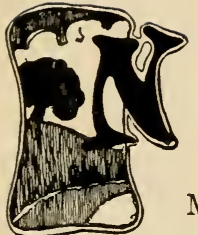

ATURAL baits are those which most anglers are accustomed to using, such baits as angleworms, minnows, frogs, grasshoppers, helgramites, grubs, salt pork, crickets and any kind of real fish-food.

Most common of all baits is the angleworm, and it is used more than any other, because it can be so easily secured, it can be used for all kinds of fish, and is accepted by all, large and small alike, no matter whether they are surface feeders or those that look for food at the bottom. The worms may be used just as taken from the ground, and are generally used in that condition, but they may be made better bait if properly prepared. Worms, to make first-class bait, should be dug a week before wanted for use, then washed and placed in damp moss in an earthen jar. The moss is washed and wrung as dry as possible and all sticks and hard objects picked out. They should be sorted out every second day and the dead or sickly ones thrown away. A few bread crumbs soaked in milk may be given them occasionally and the moss should also be changed. In a week of this treatment the worms become toughened and thoroughly emptied of earthy matter, and in this condition they make the best bait. The jar must be kept in a cool place.

There are four kinds of angleworms, and even the small boy, who fishes under the willows down at the river's bank, knows that some worms make better bait than others. In the garden you will find the black headed worm, which may 
be distinguished from others by the absence of the knot or band on the body; also by its dark color. It is a good bait and tough, so that it lasts longer than any other. A small worm of a bluish color is found under stones, and under wet and decayed leaves in damp, rich soil. It has a light colored band around the body and when kept for some time its color changes to pink. This is called the marsh wo. in and is very good for certain small fishes. The brantling is found in soil under chip dirt, and manure piles. It is of medium color and banded. It is a good bait but very soft, and does not last well. Another short, thick worm is found in the same kind of places. It is red on the back and paler beneath. It is also good when fresh, but is not a lasting bait. Another objection to worms found under manure piles is their odor, which some fish do not take kindly to, but others do not mind.

It is a common saying that the big worm will catch the big fish. There appears to be little if anything in this, but a worm that is just the right size to cover the hook when properly impaled, without crowding, is the right size, and as a rule any fish will take it, large or small. But there is a right way and a wrong way of baiting, and the way the hook is baited has much to do with its success. The best way is to stick the point of the hook into the worm about an inch or a little less from one end, taking enough hold to keep it from being torn out easily, then run the hook through the middle, and into the body near the other end, stripping it over the point of the hook a short distance so that it will stay and cover the hook, but also leave an inch of the end loose to wriggle. The point of the hook must be kept hidden for certain fish, especially for trout, for you will not catch many trout when the point of the hook shows, unless the water is swift, or the bait is kept in rapid motion. For other large mouthed fish, that take the entire bait and hook it may not matter so much. Always use a whole worm for a bait, and never more 


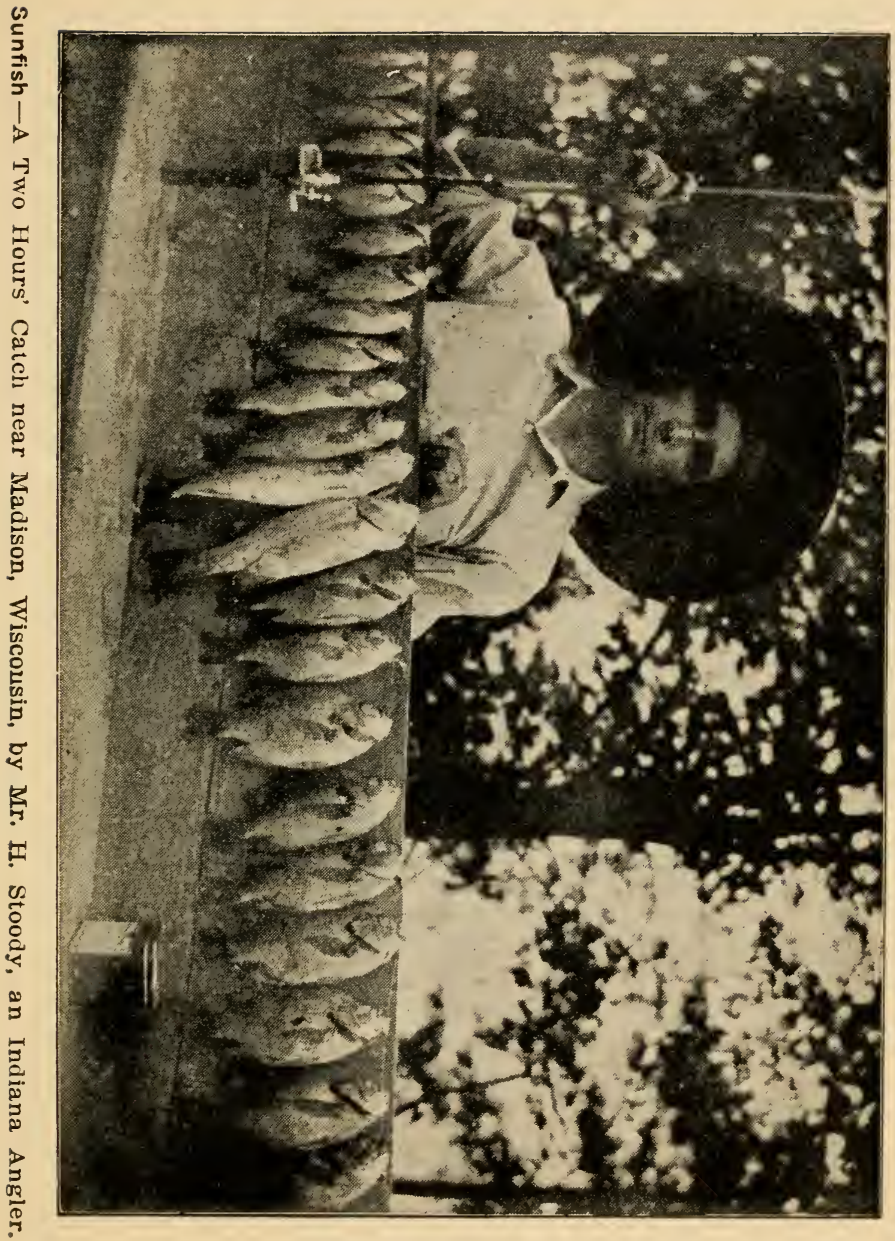


than one; also be sure to remove all little pieces of former baits. Worms are best carried in a bait box attached to a belt.

The grasshopper is another good bait, especially for surface feeding fish. Perhaps no other bait will cause a lazy old trout to rise so quickly from the depths as will a lively, kicking grasshopper, and it is an almost irresistible bait for these fish, even during the hot summer months when the water
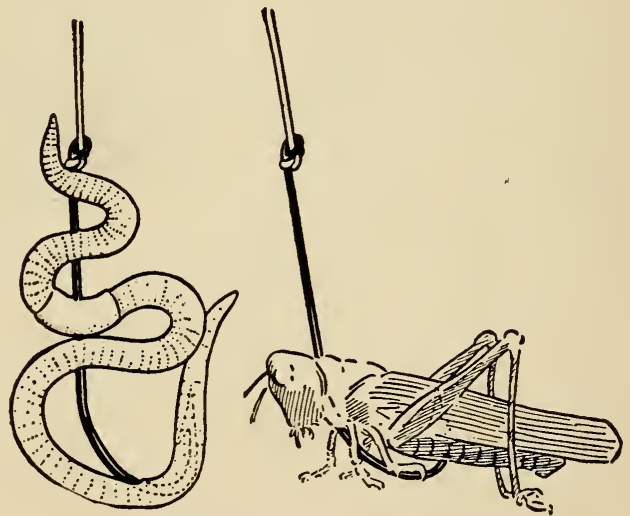

Hooks Baited with Worm and Hopper.

is clear and the fish cannot be lured in any other way. If there is a trout there, a live grasshopper cast lightly out onto the pool is almost sure to be his undoing. The hook should be entered at the joint just behind the 'hopper's head and run lengthwise of the body. To carry this bait a "hopper coop" is the proper thing.

For black bass and all of the large, voracious fish, the minnow is the favorite bait. By minnow I mean a small fish, for small fish are invariably called minnows by anglers, 
regardless of the species of fish. The small shiner, about four inches long, is the best bait, especially on dark days, as the silvery sides makes it more conspicuous. The fish should be hooked through the lips, if a single hook is used, and the hook should be put through from the under side, so that the point of the hook will be up and not so likely to catch weeds. In this way the fish will live for a number of casts and a live fish makes a more attractive bait. The small golden chubs and black chubs are hardier and live longer than the shiner, and they make good bait, but are not as good for dark days or cloudy water as the shiner. The small striped minnows, the real minnows, are very good bait also, if they can be found growing large enough, but they are very tender

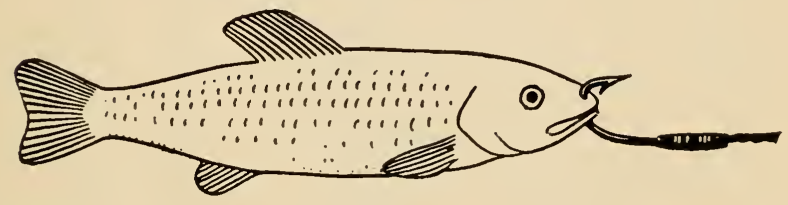

Hook Baited with Minnow.

and do not live long, so it is best to hook them through the body and use them as dead bait. A bass, in taking the minnow bait, seizes it from behind or from the side and runs some distance with it, then stops and turns the fish end about to swallow it head first. This is the time to strike. If he is stopped before this he will give a tug at the bait and should be given some slack line. The same method of baiting and hooking of the fish applies to the capture of all kinds of fish with minnow bait.

There are several rigs made for use with a dead minnow or other bait and designed to spin the bait. They are especially good for trolling for muskellunge, pike and lake trout. The best known of these is the Archer Spinner, which con- 
tains a long needle on which the bait is placed, and a pair of barbed wings or propeller blades hinged at the top, which are pressed down after the bait is on the needle, so that the barbs hold the bait in place. The hooks consist usually of a three treble gang, on gimp snell, trailing alongside the bait.

Dead minnows may be fastened on large, long-shanked hooks in such a way that they will spin, if a swivel is fastened to the hook, or directly above. The hook is run into the mouth and out at the gills, back, and hooked into the body near the tail, in such a way that the body is bent into a curved shape. This makes a good rig for casting for bass. pike, and pickerel.

Ordinarily it is an easy matter to get minnows. A baited minnow trap will usually keep an angler supplied, but often the nimnows taken in traps are too small. Some chubs and shiners mity easily be caught in the brooks with a light line and very small hooks baited with maggots or pieces of angle. worms. If you go to some quiet little pool where you can see what is going on at the bottom and not be seen yourself; it w.1l not be long until you can have a pail full. Or you can take them with a net on the very small streams, in which it is best to have a companion to drive them into the net. If you have a "live box" to keep them in, it may pay to cat:l them in spare time and keep a good supply on hand unt:l you need them. When fishing for them, carry a minnow kucket to hold the catch, and get them into the live box as soon after catching as possible. Don't handle them more than absolutely necessary.

Small frogs make good bait for all game fish from trout and bass to muskellunge. They may be used with a single hook, by inserting through the lips like baiting with a minnow, but the hook should be placed at the side of the mouth and the frog will kick around more trying to keep tack up. There are frog harnesses and frog hooks that are very good for this bait. The U-B. Frog Harness is a fine 


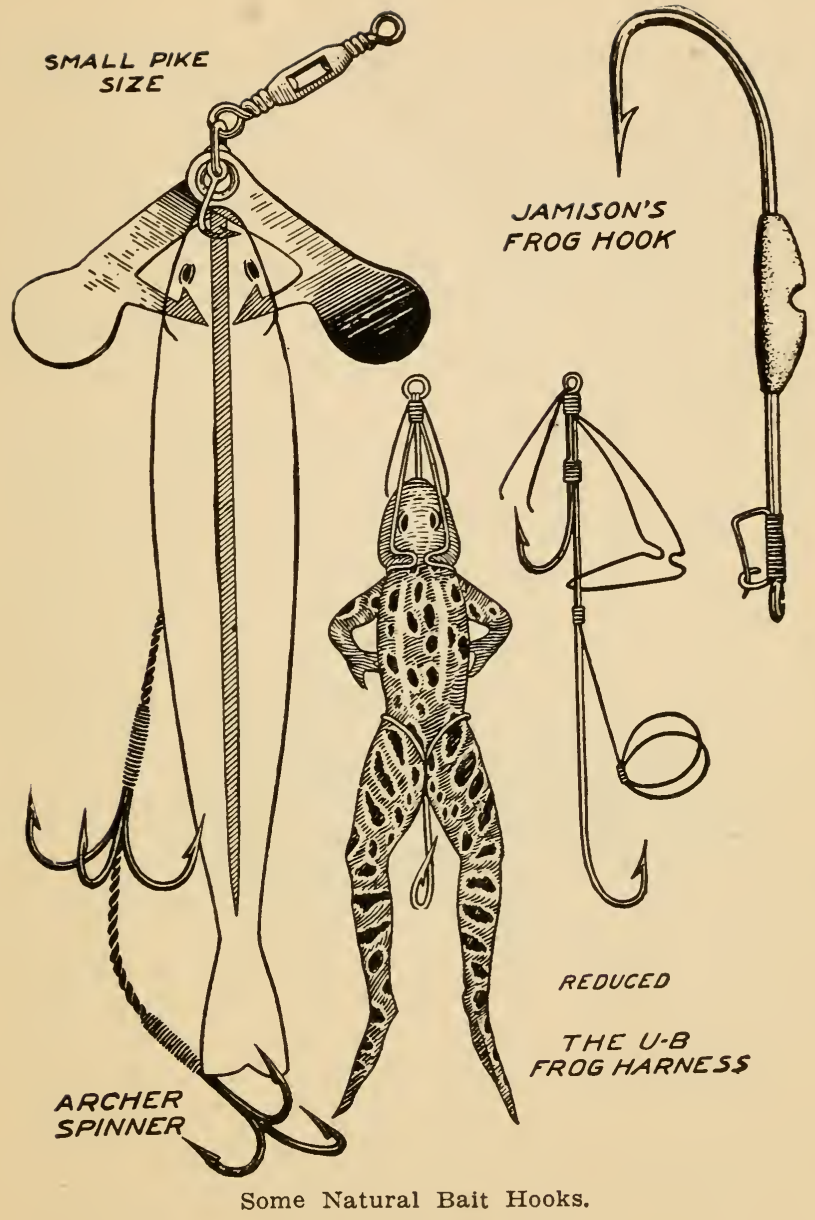


rig, so is the Jamison Frog Hook. This latter has a small nose hook to hold the frog and a rubber band is put over his body, holding him close to the hook.

The dobson $\mathrm{cr}$ helgramite is an excellent bait for many kinds of fish. It is an ugly creature and is found under stures in the stream. In swift streams they are easily captured by turning stones and holding a minnow net or one of mosquito netting below the stone, when the current will carry the helgramites into the net. They should be hooked by starting the hook under the hard shell near the head and out at the other edge.

Crickets are not used much but make good bass bait sometimes. They are used the same way as the grasshopper.

Crawfish are a common bait, used for still fishing. They are best at the time they have shed the shell, and in this condition they may be hooked through the body, but at other times they should be hooked through the tail. Bass are fond of crawfish. The "fish" may be captured by turning the stones, or by using a net. There are different kinds of crawfish and they live in all kinds of waters where conditions are very different, therefore a best way of catching them cannot be given.

A bait that is quite a favorite for bass and large trout is a strip of fat, salt pork, cut in the shape of the letter V, with the hook through the small end. Another form is a tapering strip with cuts in the edges, making it appear to have fins or legs when drawn through the water. The Cooper Weedless Porker is a weedless hook described elsewhere, made specially for pork bait fishing.

Caterpillars and other like creatures are sometimes used successfully. The grub is also used but $I$ have never found it a very taking bait. The white wood worm found in down timber is a good bait, but soft and easily pulled from the hook. The legs of a large frog, skinned, are a good bait. For still fishing, especially for catfish, liver is very good bait, 
but it is also soft, and very attractive to crawfish. Small balls of dough, sometimes half baked, and fresh bread worked into a paste are used for carp. The flesh of the fresh water clam or mussel is a good bait for carp and other fish. Directions for using these baits are not necessary.

The popular baits for salt-water fishing are bloodworms, sandworms, sand eels, shrimps, shedder crabs, clams, menhaden (a species of small fish), fiddlers and rock crabs, killies (another species of small fish), etc. These baits are used about the same way as the fresh water kinds described.

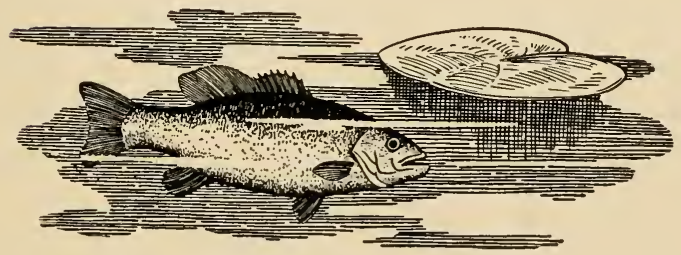




\section{CHAPTER XII.}

\section{Handling The Hooked Fish.}

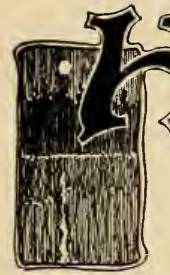

OLDING the fish after it is hooked, and successfully tiring it out so that it can be landed, is the subject that is not given enough attention by writers on angling, for the novice will often get as many strikes as the veteran fisherman, sometimes more, but if he does not know how to "play" the fish under all conditions he will lose many, and it is a regrettable fact that it is invariably the big one that gets away.

The manner of hooking the fish is usually a quick twitch of the rod, being a movement of the wrist and forearm only, but this depends on the kind of fishing, for in still fishing the fish either hook themselves or the act of hooking and lifting from the water is all in one movement. When reeling in an artificial bait, using a short rod, the rod should be held at an angle of about twenty degrees. If held higher you may break the tip when you hook the fish. Even in still fishing there is no need of roughness and it is not necessary to yank the fish up into a tree-top or fling it back into the field above the bank. All that is needed is to keep a steady, taut line, and a quick twitch to set the hook, and a steady lift to draw the fish from his element is sure to yield a larger catch of fish. In still fishing the large ones are often lost by an unnecessarily hard yank on the rod, which breaks or springs the hook, or tears it out of the fish's mouth when it has not caught well.

But it is only the heavy, strong tackle used in still fish- 
fish breaks water is more easily given than followed. It is to merely lower quickly the tip of the rod when the fish leaps if the line is long, so that he will not fall on a taut line, but the line must be recovered instantly after he strikes the water. On a short line the tip of the rod should be raised a little as the fish leaps and lowered as he falls. This requires such quick action of brain and muscles that few amateurs accomplish it and sometimes it is better to simply let the natural spring of the bent rod recover the slack. If the fish is deep you can feel the slack as he rises to the surface and should reel in the line rapidly, also prepare for a leap from the water. When he goes down, lower the rod.

When fishing from a boat, if it is anchored, don't forget the rope, and when the fish goes through under the boat swing the rod to the other side and the line around the end of the boat, the same end under which the fish has gone with your line.

If you can keep this up long enough you are sure to tire out the fish sooner or later. As a rule, the larger the fish the longer it will take to tire him - this applying to fish of the same species, for some species fight harder and longer than others.

When the fish grows quiet and shows his side, he is tired and you can reel him in but must be careful in landing him. If you have no net or gaff, and the fish is not too large, you can get hold of the line with your hand, but make no quick moves, and slipping the hand down to within six inches of the fish, lift him into the boat or onto the bank by a steady, quick lift, swinging him sideways as you lift him. If you are using an artificial bait you should have the line doubled back at the end about six or eight inches, so that it will be stronger. If the fish is very large and you have neither net nor gaff you are likely to lose him, and you should never fish with light tackle unless you have a landing net or a gaff hook with you; both if you are fishing from a boat 
where large fish are caught sometimes. In using a landing net you should submerge the net and lead the fish over it, then raise the net. In gaffing a fish, if not very large, put the hook in his mouth. It is best to shoot a large pike or a muskellunge before you attempt to gaff him, using a revolver or .22 caliber rifle. Otherwise set the gaff into the underside of the body well back towards the tail.

Large sea fish are handled the same as fresh-water fish, except that being larger and stronger it is more difficult to cheek their rushes, and a large fish like the tarpon or tuna will sometimes take out several hundred yards of line before you can stop him, even though you may have a handle drag set at a heavy tension, and a leather brake pressed down with the thumb. If you have neither brake nor drag, which is unwise where big fish are found, you must have thumbstalls so that the revolving, line-wound spool of the reel will not burn your thumbs, for you must sometimes press both thumbs on the reel as hard as possible. Then sometimes when you get the fish stopped, you cannot induce him to come nearer and he may even attempt another rush. In such cases the fisherman "pumps" the fish, and slowly recovers his line, foot by foot. For this a leather belt with a rod cup for the butt of the rod, is worn. The butt of the rod is set in the cup and with both hands the angler raises the rod by main strength, drawing the fish several feet nearer, then he suddenly lowers the tip of the rod and reels in the several feet of line that he has gained. The operation is repeated again and again as long as the fish will stand for it, but when he gets tired of it he makes another run and must be pumped again. Only stout tackle, the kind used for sea fishing, will stand such use. 


\section{CHAPTER XIII.}

\section{Fishing For Black Bass.}

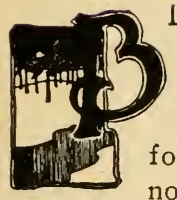

LACK bass belong to the sunfish family. There are two species, and they are known respectively as the small mouthed black bass, and the large mouthed black bass. The former is the smaller, and is found in the more northern waters, preferring the cool water of rapid streams and rock bottomed lakes. The large mouth is found in the southern and central sections of the United States, principally, and prefers quiet water, with grassy shores and muddy bottom. Throughout the central, northern and eastern parts of the country both kinds are found, the small mouth being most abundant in the rapid streams and the large mouths being found most plentifully in quiet streams and ponds. One kind or other is found from well up into eastern Canada to the Mexican border, and from the Rocky Mountains to the Atlantic Coast.

When you know what to look for the two species are easily distinguished one from the other. There is a difference in the general build, the large mouth being a heavier and chubbier fish for his length than the small mouth, and less graceful in appearance. The mouth of the large mouth variety extends a little beyond the vertical line of the eye, while that of the small mouthed species does not extend to the eye line. The eyes differ in color sometimes and those of the small mouth show considerable red while those of the other species do not, but this, like the general coloring is not infallible. The shape of the head differs in all cases, as the small mouthed species has a round forehead 
and the head of the large mouth is hollowed slightly. There is also a difference in the scales - those of the small mouth are smaller than the scales of the large mouth black bass.

The color of both varies greatly in different parts and various waters and in some the smaller species is darker, while in other places the reverse is true. The color of either may be anything from a pale greenish yellow, almost white in fact, to a very deep green or almost black. They are always darkest on the back. Either species may show transverse or longitudinal markings on the sides. The longitudinal markings are seen most frequently on the large mouthed species.

In weight the small mouth black bass runs in most waters from two to three pounds, though much larger ones are sometimes caught. In most places five pounds may be considered the maximum weight of this fish, but in certain waters they have been known to reach a weight of eleven pounds, and even more. In many places one may fish for years and never get a fish weighing over three pounds. The large mouthed black bass runs somewhat heavier in the central and northern sections, but in the South it grows to a much greater weight, and in certain waters of Florida they weigh from twelve to fifteen pounds and specimens of twenty pounds have been taken.

Black bass spawn in spring, earlier in the South than in the North. The spawning season may commence as early as March in Florida and as late as the middle of May in Canada. In Ohio most of them spawn in May and this is closed season for catching them. A black bass on the spawning bed will bite at anything that is thrown on the bed, but no true sportsman will catch a fish in spawning time.

The food of the black bass consists of all kinds of smali animal life to be found in the waters they inhabit. They eat craw-fish, small fish, helgramites, worms, bugs and insects 
of all kinds that they can get, small frogs, etc. It seems that the food of the larger ones consist mainly of small fish and frogs - a tip for the angler.
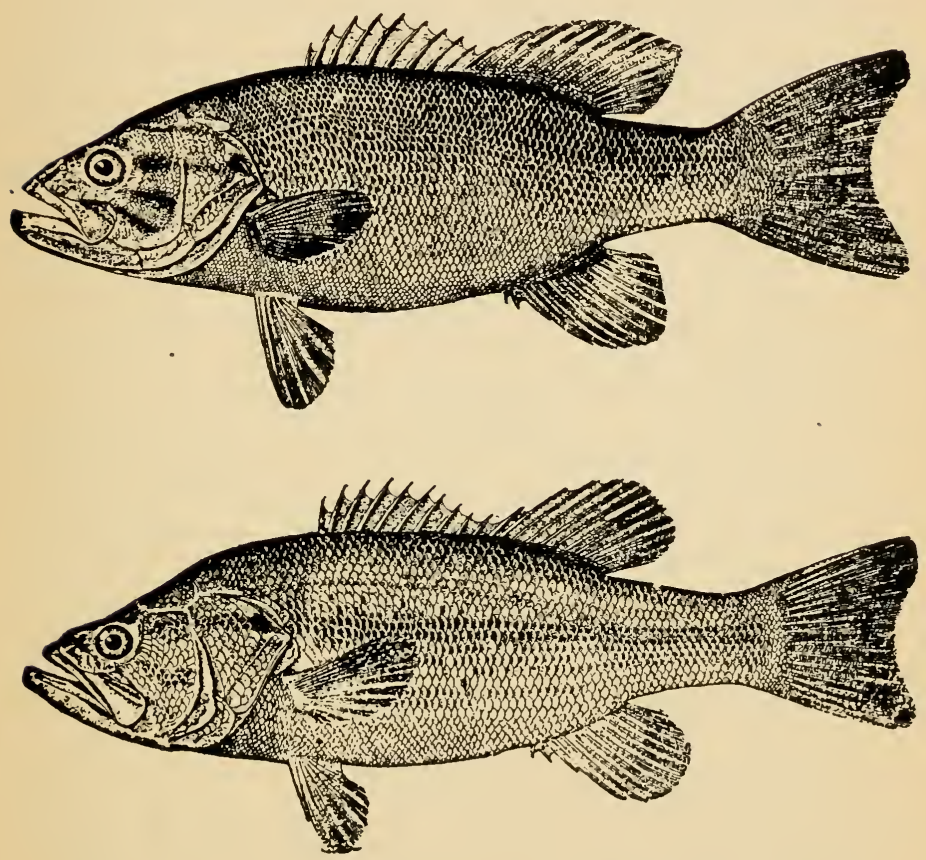

Upper-Small Mouthed Black Bass; Lower-Large Mouthed Black Bass.

There is no other game fish of so much importance as the black bass. The wide distribution of this fish and the fact that it is at home in the thickly settled part of the United 
States, makes it possible for almost everybody to be a bass fisherman if he likes, and the number of fishermen who seek this fine fish is greater perhaps than the number of devotees of all other kinds of fresh water fishing combined. In the northern half of the Mississippi valley almost every angler is a bass fisherman. The fact that so many means may be employed in capturing this fish is also very much in its favor. The small boy and the grown still-fisher get their share, the live bait fisherman and the artificial bait-caster find this fish their most worthy quarry and the fly-caster also finds that these fish take the fly well and afford a sport unrivaled in its line.

No other fish of its size can or will put up such a fight for its liberty when hooked as the black bass and this is a claim that few will dispute. And after capture too it does not take a back seat for it is a fine food fish.

Fishing with natural bait is perhaps the most common way of taking these fish, anyway it was until in recent years. Small frogs and minnows are the most taking baits for the big fellows and a fish of any size up to five inches may be used as bait. Any black bass large enough to be taken will try to eat a five inch minnow without any hesitation whatever. For this kind of fishing a bait rod of eight or eight and one-half feet, weighing about seven or eight ounces according to quality, a quadruple casting reel of the eighty yard size, a raw silk line of small size sixty or eighty yards, and a box swivel, with a No. 2 hook on a short double gut snell is about the proper tackle. For large bass of the South, or for frog casting use hooks of about $1 / 0$ size. If the fishing is about grass and lily pads, you can use a weedless hook. If you use frogs for bait, or artificial baits, you will want a much shorter and stiffer rod than for minnows and other natural baits, but the frog-casters are in the minority.

Ordinarily one will do his best fishing in morning and evening, but natural bait can be used throughout the entire 
day especially in lake fishing and on streams on cloudy days. The nice days are always best, ideal weather being bright, mediumly warm days with a light breeze and water fairly clear. Each angler, as a rule, has set ideas about weather conditions, water conditions, time of year, etc., but all rules are subject to failure in fishing. One thing is always sure though, and that is that the fish are in more shallow water early and late in the season than during the hot midsummer, when they retire to deep water if such is to be found. Black bass in lakes and deep streams are less subject to "rules" than those of shallow streams.

The favorite haunts of the small mouth bass are such spots as above and below the riffles, in little eddies beside rocks, under overhanging banks, and about the mouths of the small streams, near driftwood, etc., and these are the places to cast the bait. The minnow bait, also helgramites and other baits of this kind, are allowed to sink about halfway to the bottom, then drawn in or reeled in slowly. It is not necessary to spend much time on any such place as the bass, if he is there and inclined to bite, will do so at once. When a fish takes the bait give him time to turn it head about for swallowing, which he always does. Sometimes he starts off with it some distance before he tries to eat the fish and if stopped gives a few little tugs at the bait. If he does that, let him run a little farther when he will try to eat the bait. When he pulls strongly it is time to hook him. With other smaller baits he takes the entire bait in his mouth at the first snap and you should hook him at once. Crawfish and such bait are used mostly for stillfishing.

The same methods of fishing are used for both species. The large mouths will be found mostly in quieter water, near grass and lily pads, and sometimes lie in very shallow water among the grass or rushes.

What is fast becoming the most popular method of 
fishing for black bass is bait-casting, using the artificial baits before described.

Not much can be said of this method, other than what was given in the chapter on bait-casting. The outfit is the short bait-casting rod, same line and reel as for fishing with natural bait, and any artificial bait. The bait is cast to good looking places, and as soon as the bait strikes the water the rod is shifted to the left hand and the line reeled in, not too fast. A surface bait, one that floats, is best for the beginner, and as a rule for others also in still water; for streams the underwater bait works best, especially during midsummer. The bait should not be reeled steadily, but should be moved short distances at a time, and made to dance and wiggle on the water. Each angler has his favorite baits. Small bass will attack a large bait as quickly as a small one, and so will the large ones. They are never afraid of it and the splash of a large bait as it strikes the water will not alarm them. As a rule the largest fish are caught by artificial bait-casting. This may be because the artificial bait is used more than anything else, but more likely is because the big fellows are angered by the tantalizing movements of the artificial baits. As proof of this, a darting spoon bait, making all kinds of eccentric moves, seems to be more attractive than one that merely revolves.

Artificial baits may be used at night for bass and other fish, and are usually very successful as black bass feed mostly at night. The Moonlight Floating Baits are made specially for night fishing, being luminous, and are good for day use too.

Fly fishing for bass is popular with many anglers. It is very successful in some waters but in others bass do not take a fly well. It does not catch as many of the big fellows as the bait methods, but a two pound black bass on fly tackle makes more sport for the angler than a three pounder 
on a bait-casting outfit, and the fly fishermen are all sportsmen. There is no nicer and more enjoyable way of fishing. Bass will only take a fly when in shallow water, and it is useless to fish for them in this way at any other time. As they feed mainly at night, the best fly fishing is in early morning and late evening, and at such times they will be found on the riffles and in shallow water. Spring and early summer and early autumn are the best seasons for fly fishing. It requires considerable study for best results and the angler should learn the habits of the fish thoroughly, and study their peculiarities, and should also know the waters well. Usually the morning and evening of bright days, when there is a light breeze and the water is clear and a normal height, will yield the best catches.

The fly should be danced gently on the surface of the water and then allowed to sink and float a few inches beneath the surface for quite a distance before making another cast. Lakes should be fished from a boat, but on the streams the angler should wade, and it is generally conceded best to fisk down stream, casting out first this way and then that, to all of the good looking spots.

The fly rod is always used for this fishing, and it should not be too light a one, especially for the beginner, neither should the amateur buy an expensive rod to learn with. The reel may be either a single action click, holding eighty yards of line, or an automatic of about the same capacity. A single action reel of 100 yards capacity is even better than a smaller one. These reels will hold only about half that much size $E$ enameled silk line, which is the kind to use. A six foot double gut leader or heavy single one is best for the amateur and a single fly should be used on it. A six foot single gut leader is usually preferred by the experienced fly fisherman, and for daylight use it is better than a short one. Two flies may be used on a six foot leader. 
The angler should practice to drop his flies lightly on the water and see that the line or leader does not strike first. Keep out of sight of the fish always, and do rot splash or make more noise than is necessary. When a fish takes the fly you must hook him quickly for he learns instantly that i. is not a real insect and drops it at once. Keep the line taut so that you can hook the fish at the first move. By casting down stream you will have little trouble of this kind.

As to the flies, an old established rule is to use light and bright colored flies on dark days and in the evening, and dark or sombre flies for bright days. But there are times when this doesn't hold out well. It is a common practice to use two flies on a leader and if the fish does not take one sometimes the other is more attractive. Some one of the following list will be found good on nearly every occasion: Professor, Montreal, Coachman, Royal Coachman, Grizzly King, Parmachenee Belle, Black Hackle, Gray Hackle, Brown Hackle, Abbey, Ferguson, Ibis, Lord Baltimore, White Miller, Seth Green, Oriole, Queen of the Water, Babcock, Governor Alvord, and Silver Doctor. As before stated the brightest flies are best for dull days and the more sombre ones take best on bright days. They are tied on Nos. $2,3,4$, and 5 hooks. Nos. 4 and 5 will be best on most occasions. Either a looped or a long snelled fly will do for a tail fly, but the long snelled kind is best for a dropper fly as it can be attached without an additional snell, or length of gut.

Some may hesitate to buy a fly rod and outfit, believing that the same could not be used for any other kind of fishing, but this is a mistake, for you can use any small, light spinning bait or small casting spoon, though it is none too good for the rod to use these much. You can also use salt pork bait as mentioned elsewhere and this is a very effective bass bait. It may be skittered over the surface or used under water. 


\section{CHAPTER XIV.}

\section{Fishing For Trout and Salmon.}

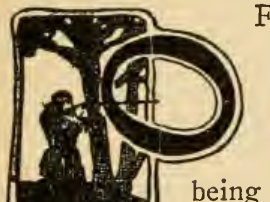

F all the North American game fishes the trouts are the most widely scattered and the most sought by those who go away from home to fish. In many ways these fish are far in the lead of all others, being the most active of all fish, good fighters,

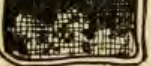
rising well to an artificial fly, a fine food fish, and the most beautiful fish that swim. I am speaking of the trouts collectively, for be it known, there are somewhere between thirty and forty species, including the introduced trouts in the United States and Canada. They, that is one species or other, are found all over the western mountain country, practically all of Canada, and all of the eastern and southern states where cool, rapid streams are found. These trouts are divided into two groups, i. e., the charrs and the salmon trouts. The latter are found naturally only in the West and the former, with the exception of the Dolly Varden, only in the East and North. But it is not the purpose of this work to go into a description and classification of each and every species - I will leave that to naturalists - what we are most interested in is the habits of the fish and the way to catch them.

Trout are found only in cool, fresh, swift-flowing streams, especially our native fishes of this order, but some of the imported ones will live in warmer water, providing it is rapid.

Most important of all the trouts is our eastern brook trout, a charr, because it is nearer home to the largest number of anglers and because of its wide distribution through- 
out the East and North, its game qualities, and the readiness with which it rises to the fly. It is the one that is best known and the fish that is usually meant when anglers speak of trout fishing. It is at home in all the moutainous parts of the eastern and southern states where it is found in the mountain streams, and in the streams and cool, clear lakes of all of eastern and central Canada and the New England States. Many of the northern ponds and lakes fairly swarm with these fish, and they are abundant in the streams of the Adirondacks, and the mountains of Pennsylvania and West Virginia.

The brook trout is a trim built fish without scales, in beautiful coloring, the back being dark brown with what are commonly known as worm track markings. The sides are a lighter color, often showing purple and rose red in parts, and rows of small bright red and yellow spots run longitudinally along the sides. The under parts are white, tinted with pink, appearing iridescent, like polished mother-of-pearl. All of the lines are exceedingly graceful. The body is very solid, having a very small cavity, and the flesh of adult specimens is a deep golden color.

The brook trout is voracious, and feeds on the surface, in mid-water, and at the bottom, but looks mostly in mid-water and on the surface for food, and very little escapes their watchful eyes.

Anything in the line of insects, worms, frogs and small fish is acceptable to the trout, and I have heard of them being caught by baiting the hook with a mouse. They take all insect life eagerly. Let a fly but touch the water in his flight across a trout pool and his doom is sealed, for like a flash of light Mr. Trout rises from the depths and his capacious jaws engulf the hapless insect. To some it may seem a mystery how the fish can get so quickly to the spot where the fly has alighted, and it is was so to me until one day as I stood on the shore of a lake looking out into 
the clear, shallow witer, I saw a large trout making lightninglike darts here and there in a zig-zag way, and then I noticed that he was following the inovements of some insect that was flying above the water; then the unlucky fly touched the surface of the water; there was a splash, and Mr. Fly was no more. And as a rule a squirming angleworm will meet the same quick end and if the trout happens to get his eye on him, and if a frog happens to stray too far from shore, or a grasshopper make a misjump and fall into the stream, they meet the same fate. To the trout "all is fish that enters the net" and I am sure that in most cases the fish does not hesitate to see what it is before he grasps it, but takes chances on it being good to eat.

The brook trout spawns in the fall. Full grown specimens will weigh from a half pound to five or six pounds, depending on the kind of water they inhabit, and the food supply. In Maine and Canada brook trout weighing over ten pounds have been taken, and in some waters four and five pounders are quite common. Being slender in build they run much longer, weight for weight, than the black bass. A trout of fifteen inches will weigh a pound and a half, and one of twenty inches will weigh about three and a half pounds. A trout two feet long will weigh about six pounds. Of course these weights are only approximate, as in some waters they are more slender than in others, just as their color varies in different waters.

Trout may be taken with artificial flies, worms, minnows, grasshoppers, crickets, grubs, small frogs and small casting spoons or even a trolling spoon. But the readiness with which they will rise to a fly and the pleasure of fishing for these gamey fish with light tackle makes fly-fishing the favorite way of taking them.

The proper outfit will depend somewhat on the waters to be fished and the size of the fish found there. On small 

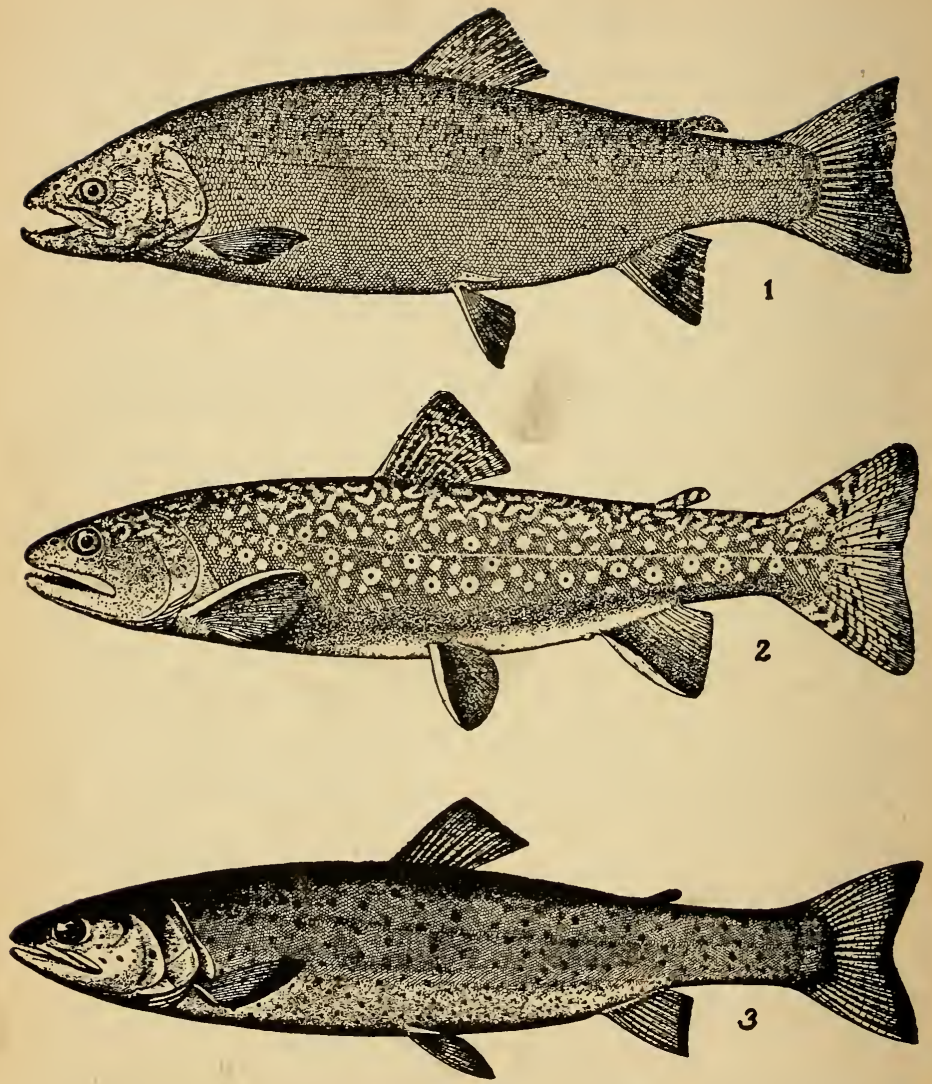

1-Steelhead Trout; 2-Eastern Brook Trout ; 3-Lake Trout 
tsreams where the fish are small and long casts are the exception the lightest and shortest fly rods may be used. For lake fishing the longer rods are best, but they should be reasonably light. For large streams where long casts must be made and where the fish are large a good weight fly rod of medium length is best. The light rod demands a light line, say size $F$ or $G$ enameled silk, and size $E$ is used for all ordinary rods, for the heavier line casts better. The leader should be of six foot length, single gut. Heavier leaders may be used in swift water than in lakes or ponds. In some parts of the East, for instance in Pennsylvania, trout are found only in small mountain streams. Here the brush overhang, and fly casting is impossible and almost unknown. Likewise, playing the fish is not practicable, and as the fish are very small, seldom more than a foot long, they are usually lifted bodily from the water. For this rather stiff fly rods and very fine lines of oiled silk or enameled silk are used. The line need not be long, and the reel is used only for lengthening and shortening the line, as required.

White leaders are commonly used, but many prefer what is known as "mist" color, a pale bluish-gray tint. In case you desire to color a white leader, you can give it a bluish color by soaking it in water to which a little common writing ink has been added, or it may be given a yellowish color by soaking in strong coffee.

Now when it comes to selecting flies, I cannot give much advice, for there are so many different patterns and the requirements are so different in the various waters. Time of year and weather conditions must also be considered. I would advise the prospective fisherman to consult some friend who is acquainted with the waters in which he is expecting to fish, and no doubt he will find some person who can tell what flies to select for those streams. They run in all colors and combinations of colors imaginable and each is known by a formiabie name. A good general rule, univer- 
sally practiced, is to use light, bright colored flies on dark days. It is mostly a matter of experiment anyway and if the fish do not rise to one kind of fly, some other kind should be tried. For use in northern waters some one of the following list will nearly always be found good, in fact the majority of anglers have only a dozen or two patterns to select from, and the most generally used flies will be found in this list:

Jungle-cock, Montreal, Parmachenee Belle, Silver Doctor, Brown Hackle, Black Hackle, Grizzly King, Coachman, Grey Hackle, March Brown, Professor, Royal Coachman, Jenny Lind, Alder, Red Ibis, Grey Palmer, Brown Palmer, Black Gnat, Red Hackle, Beaverkill, Grey Drake, and a Brown Hackle with red body.

In the northern lakes the Parmachenee Belle is usually a killer for use in the evening, late, and as the fish are actively engaged in feeding at this time, some of the largest catches are made with it. Early in the spring a common Black Hackle is often very effective for day fishing.

The smaller flies should be chosen in preference to the large ones. By the size, I mean the size of hook that the fly is tied on. Number 8 hooks are used more, perhaps, than any other, but the Nos. 10, 12 and 14 are also used by many; the smaller sizes for clear, quiet water.

The reel for trout fishing should be of a size that is claimed to hold sixty or eighty yards of line, for such a reel will hold only about half that much size $E$ enameled line. The spool should be kept well filled, as it winds faster and zeeps the line in nicer shape for casting. A single action click reel is the kind most often used but an automatic may be chosen, and it will answer admirably. A wading landing net should always be used.

When fishing, the fly should be kept in motion, always dancing lightly on the surface of the water. Watch an expert fisherman closely and you will see that his hand is apparently rembling all of the time while the fly is on the water, 


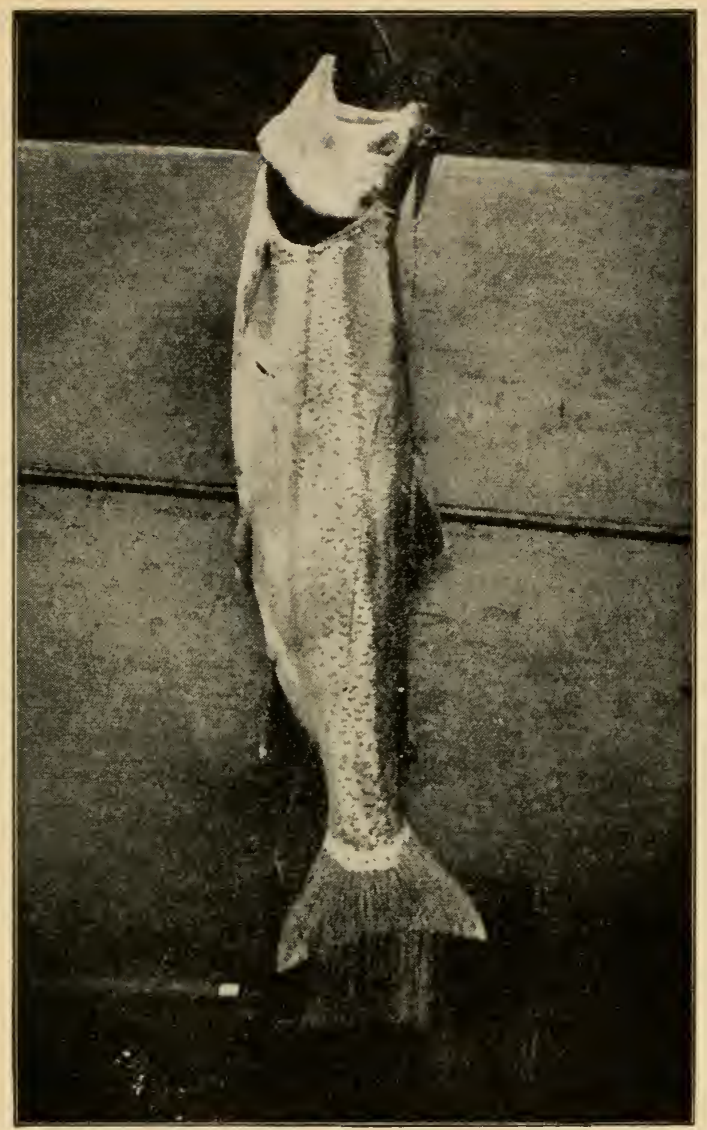

A Thirteen Pound Rainbow Trout Taken on a Spinner in Lake Okanagon, British Columbia. 
and that the motion is extended to the rod, line and fly. It is not nervousness, but a practiced art. Fish the portions nearest you first, gradually lengthening you cast and fishing the waters farther away. It is neither necessary nor advisable to fish long at any one place.

When a trout takes the fly, strike quickly. Usually, only a slight motion is needed, especially in stream fishing, but on lakes where the fish are large, a good strike is required.

Regarding the kind of fly to use, study the conditions and try the flies that your judgment tells you are right; if these fail, try others. Larger flies may be used in the spring than in summer. It is best, if possible, to talk this matter over with some person who has done considerable fishing in the waters you intend to visit. On dark days, and late in the evening, the brighter and lighter colors seem to take best.

In spring trout may be found near the surface and on the rapid streams. Later on they retire to the deeper water. In the Northern lakes they may be caught in about five or six feet of water in spring and early summer. When the water grows warm in summer, they can only be caught where the streams empty into the lakes and where springs are found along the shore. In summer they do their feeding mostly in the evening, in the shallow water, and about the mouths of streams. It is useless to fish in the northern lakes in midday, in the middle of the summer, unless you know the location of springs, and you can catch no trout when thunderstorms are brewing.

Much has been written regarding the sense of hearing of fish, but the belief is quite common among those fishermen who have given the subject a little thought, that fish do not hear. However, it is possible that they can hear a shout, or loud talking, when they are in quiet water, and it is advised that the angler make no more noise than necessary. A heavy tread or a thump on the bank is readily felt by the 
fish in the water, because of the vibration. The slightest disturbance of the water is also observed. This applies mainly to still water, for where the water is rapid, and tumbles over rocks, a little splashing in the water is not distinguished. It follows, therefore, that the angler should use care in approaching the water, and especially when nearing a quiet pool. Some anglers wade the stream, but whenever possible, the fishermen should walk the bank, especially if the pools are quiet. When wading, one should always avoid splashing. Keep out of sight of the fish, always, and avoid letting the shadow of your rod fall over the water.

Except during the mid-season when the water is low and clear, angleworms make a very attractive bait for brook trout. They should be placed on the hook in a lifelike manner so that they can cover the hook completely, or at least the point must be hidden. The same tackle is used as in fly fishing except that the fly is replaced with a snelled hook, No. 6 or 8 . My preference is the KendallSneck. Downstream fishing is the rule and the bait is carried by the current a long ways ahead of the angler. If you can see the fish the chances are very much in favor of the fish seeing you also, and when you see a fish turn slightly on its side it is watching you - no use to fish for him; come back later and keep out of sight.

Fishing with grasshoppers is a successful method in summer, when the water is very clear. They should be cast out lightly the same as a fly.

In waters that are not fished much it is the easiest thing in the world to catch trout, except in midsummer, by baiting the hook with a small piece of fat salt pork. The bait is used the same as a worm. One can also cut the pork as for bass fishing and it will be even more successful. But the point of the hook must be covered, always, unless the bait is kept in rapid motion. 
A small casting spoon is successful for large trout. It should be kept several feet beneath the surface and should be drawn slowly in spurts of about three or four feet at a time.

The methods of fishing for brook trout given here apply also to all other kinds of trout. Rainbow trout are frequently taken by trolling and lake trout are nearly always taken that way, as they are invariably found in deep water.

One of the most important of the native salmon trouts is the steelhead. It is found in the northwestern coast streams living part of the time in salt water, and spawns some in spring and others in the fall, at the heads of the streams. On very rare occasions these fish, it is said, reach a weight of twenty pounds. In shallow water the steelhead trout will rise to a fly, but the most of those caught with hook and line are taken by trolling with a spoon bait in deep water. Natural baits are also used, the favorite being salmon roe.

The German or brown trout has been introduced into this country from Europe. These fish sometimes reach a weight of fifteen pounds, but usually run from two to three when full grown. The same methods of fishing as recommended for brook trout should be employed, except that the tackle should be a little heavier. They do not rise to a fly as well as the brook trout.

The rainbow trout, of which like the others described there are a number of species, are native to the streams of the Northwest. They have also been introduced into eastern waters, and are now found in many streams of Wisconsin, Michigan, New York, and southward. In some streams they grow to a much larger size than in others, but all through they grow larger than the eastern brook trout. They are gamey fighters and are fished for in the same ways as the brook trout. In the West they are taken quite often by trolling. 
Of the eastern salmon we have the landlocked species or suananiche and the true Atlantic salmon. The ouananiche (pronounced wannaneesh) is identical with the true Atlantic salmon, except that it does not go to salt water and as a consequence does not grow so large. It usually attains a weight of two or three pounds. It is a great fighter and a fine game fish. Brook trout fly tackle is used for landlocked salmon. Dry fly fishing is said to be very successful for this fish.

The true salmon is a fish of peculiar habits. It breeds in the fresh water streams and after reaching a certain age it goes down to the ocean where it grows to a large size and takes on a different appearance, when it comes back to the streams to spawn, an Atlantic salmon. In the different stages of its growth it is known first as a parr, then as a smolt, later as a grilse and eventually it becomes a salmon. This is interesting and we would like to have more of it but it is the catching of the fish that interests the anglers most, and a lengthy discourse on the habits of the fish cannot be indulged in here. The Atlantic salmon is a beautiful fish, and a game fighter. Specimens weighing as much as eighty pounds have been taken but the usual catch runs from ten to thirty pounds. One thing I wish to mention before going farther; salmon are "killed" not caught and you seldom hear anglers talk about catching them, they invariably say "kill", These fish spawn in the sea-going rivers of Maine, New Brunswick, Nova Scotia, Quebec, Labrador, Newfoundland, and the Unorganized Territory east of Hudson Bay, commonly known is Ungava. They seldom if ever enter rivers south of Maine and the only really good fishing is in Canada and Newfoundland.

There is only one way to "kill" these fish and that is by means of the artificial fly. The outfit most often used is a salmon fly rod of greenheart or split bamboo from fifteen to seventeen feet long, about fifteen and a half or sixteen 
feet being the size most favored; a large single action click reel; a double tapered enameled silk line, size C or D, 120 yards long; a nine foot single gut leader of best quality heavy silkworm gut; and a single fly size 2 if on a single hook and size 6 if tied on double hooks. Regarding the patterns of flies, what is considered a good assortment is the
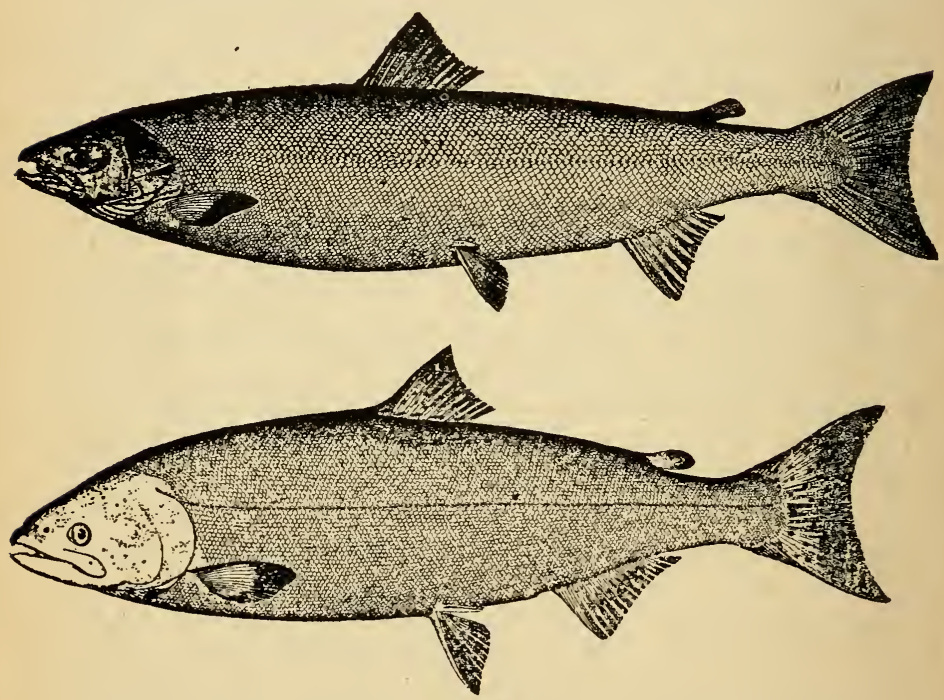

Upper-Atlantic Salmon; Lower-Quinnat Salmon (Pacific)

following: Butcher, Durham Ranger, Dusty Miller, Popham, Jock Scott, Silver Doctor and Childers. Nearly all salmon anglers will agree that this assortment is all that will be needed. In clear water use the smallest size of fly, and if the fish do not rise to a large fly they may sometimes be taken on a smaller one on the same pattern. 
The best results are had by fishing on rainy, blustery days, and on clear days it is not much use fishing except in evening and morning. Give them plenty of time and cover the water thoroughly. Work the fly continually until you are ready to retrieve the cast; then pause an instant, for sometimes a fish follows the fly some distance waiting for it to stop. In case of a rise don't strike too quickly as the salmon takes the fly when going down and not on the rise like the brook trout. If you miss a fish continue fishing on down the pool and in about fifteen minutes come back and commence casting again at the head of the pool, working down as before. It will be necessary to have a guide or other person to gaff the catch.

The Pacific salmon is a different fish and is commonly looked on as a commercial food fish. There are a number of species but the Quinnat salmon is the most important and resembles the Atlantic salmon very much, though it is quite a bit larger, sometimes reaching a weight of 100 pounds, though the average weight is about twenty. With hook and line these fish are caught mainly in the sea, as the rivers are swift and as a rule the water discolored. They do not rise well to a fly, though they can be taken in that way. The most of those caught with hook and line are taken by trolling. They are also caught by baiting with salmon roe. Good salmon fishing may be had all along the northwest coast, and especially on Vancouver Island and the salt water to the north.

Another fish which the old time naturalists classed with the salmon, but which are now considered as a separate family are the graylings. In this country there are three species, the Arctic grayling, the Montana grayling and the Michigan grayling. The latter is now extinct, or nearly so. The Arctic grayling is generally considered the parent fish, in this country, and it is thought that those of Montana and Michigan were carried south from far northern Canada 
by the ice during the glacial period. There is not any striking difference in the three species and the two southern varieties might have changed greatly since that time. Personally, I have never seen a grayling, but they are said to be beautiful fish. They are of graceful shape and have enormous brightly colored front dorsal fins. The back is gray or bluish, and lighter beneath, and when taken from the water is said to be iridescent like mother-of-pearl, showing all tints and colors. It never exceeds two pounds in weight. It is caught mostly in autumn on brook trout tackle, with the artificial fly.

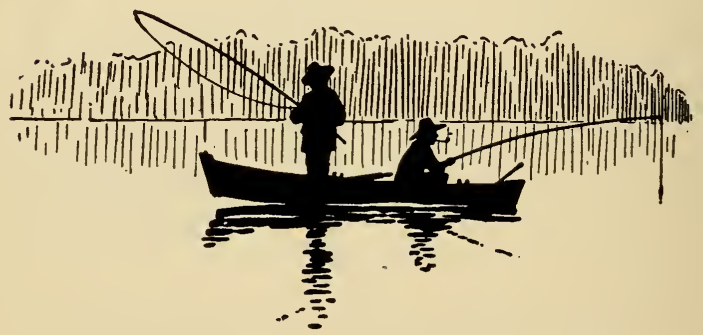




\section{CHAPTER XV.}

\section{Pike, Pickerel, Muskellunge, and Pike-Perch.}

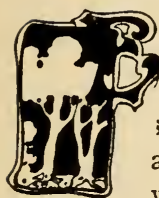

XCEPT for the last named fish in the title of this chapter, all of those named belong to one family, and resemble one another so much that frequently one is mistaken for another. The last named, the pike-perch or wall-eyed pike, does not belong to the pike family, but is included in this chapter because of its name and its general resemblance to a pike.

The pike, known in Canada sometimes by the name of jackfish, is found throughout the Great Lake region, practically all of Canada, and a part of Alaska, also in less numbers in the eastern states and upper Mississippi valley, but never south of the Ohio river. Its natural home is Canada; in parts of the dominion it is very abundant and grows to a large size. The "pike" of other parts of North America are pickerel.

The usual weight of full grown pike is about ten pounds, but it may be more or less in certain waters and in various parts of the range. Specimens of thirty pounds are sometimes taken. The color is dark gray or greenish gray on the back, lighter on the sides, and silvery white on the under parts. The sides show many irregular oblong spots lighter than the ground color. The dorsal and anal fins and tail show dark or black blotches. As on all the pikes, the dorsal and anal fins are on a vertical line. The body is long and the head is about one-fourth of the length of the fish over all. The jaws are long and armed with sharp teeth, 
for the pike is very voracious and preys on all smaller fish.

The fish are found mostly in shallow, grassy lakes and ponds. The places to look for them are over shoals and bars near the lily pads or wild rice beds. When caught on light tackle they put up a game fight, and are almost the equal of the muskellunge of the same weight.

Pike may be caught with natural or artificial bait, or by trolling. Perhaps more of them are taken by trolling with a spoon bait than in any other way. The directions given for catching muskellunge will answer very well for pike, as these two fish inhabit the same waters, their habits are much the same, and the same methods of fishing may be employed for both, in fact you are as likely to catch one as the other. The tackle for pike may be lighter throughout than for muskellunge. For bait fishing a regular bait rod, good sized multiplying reel, and good weight raw silk line should be used. The Archer Spinner with large minnow bait is an excellent lure. A plain hook, an O'Shaughnessy or Pennel, No. 3/ on a pointed piano wire is good for natural bait. If a trolling spoon is used, one having a blade about $21 / 4$ inches long is about the right size. In all cases there must be a short section of wire above the hook to keep the fish from biting the line.

The pike is not worth very much as a food fish, but is superior to such fish as carp and suckers. They are better in spring, fall and winter than in summer when the water is warm. In places where other fish are plentiful they are seldom used for food. The fish may be taken in early spring by fishing through the ice with pickerel traps, as described elsewhere.

Of the pickerel there are three species, namely, the Eastern pickerel, Western pickerel, and banded pickernl. These are the "pike" of some parts of the country. The Eastern pickerel is also called chain-pickerel and jack It 
is found in all of the eastern states, east of the Alleghanies. It resembles the pike in general appearance, but is smaller, seldom if ever growing to a greater length than two feet, and a weight exceeding eight pounds, and the average is probably three pounds. It is more slender than the pike, and the markings on the sides form a network, hence the name chain-pickerel. The ground color is brown or green, lighter in under and, as on all of the pickerels there is a dark spot below the eye. Like the pike it is voracious and feeds on fish, frogs, etc. The same methods of fishing and the same tackle may be employed as for pike.

The Western pickerel is a small fish never more than a foot long and usually less. It is found throughout the Middle West in quiet grassy waters. In all but size it resembles the Eastern pickerel. It may be caught with any light tackle, such as is used for black bass.

The banded pickerel is a small fish resembling the one described last, but is found in eastern waters. It is at home in all of the sea-going streams east of the Alleghanies, from the New England states southward.

The muskellunge, a fish known by perhaps a score of other names, all quite similar, is the largest and most important fish of the pike family. $\mathrm{He}$ is known to fishermen in general as the musky. The muskellunge is a voracious, vicious fish, feeding on all fish smaller than himself, even his own kind.

The appearance of this fish does not belie his reputed nature; he is as vicious looking as he is vicious. The head is about a fourth of the length of the body, the jaws long and the lower jaw longer and projecting beyond the upper. They are both armed with long, double-edged, dagger-like teeth. and when you catch one be sure that you don't get your hand in his mouth; he wouldn't lose an opportunity to close down on it. 


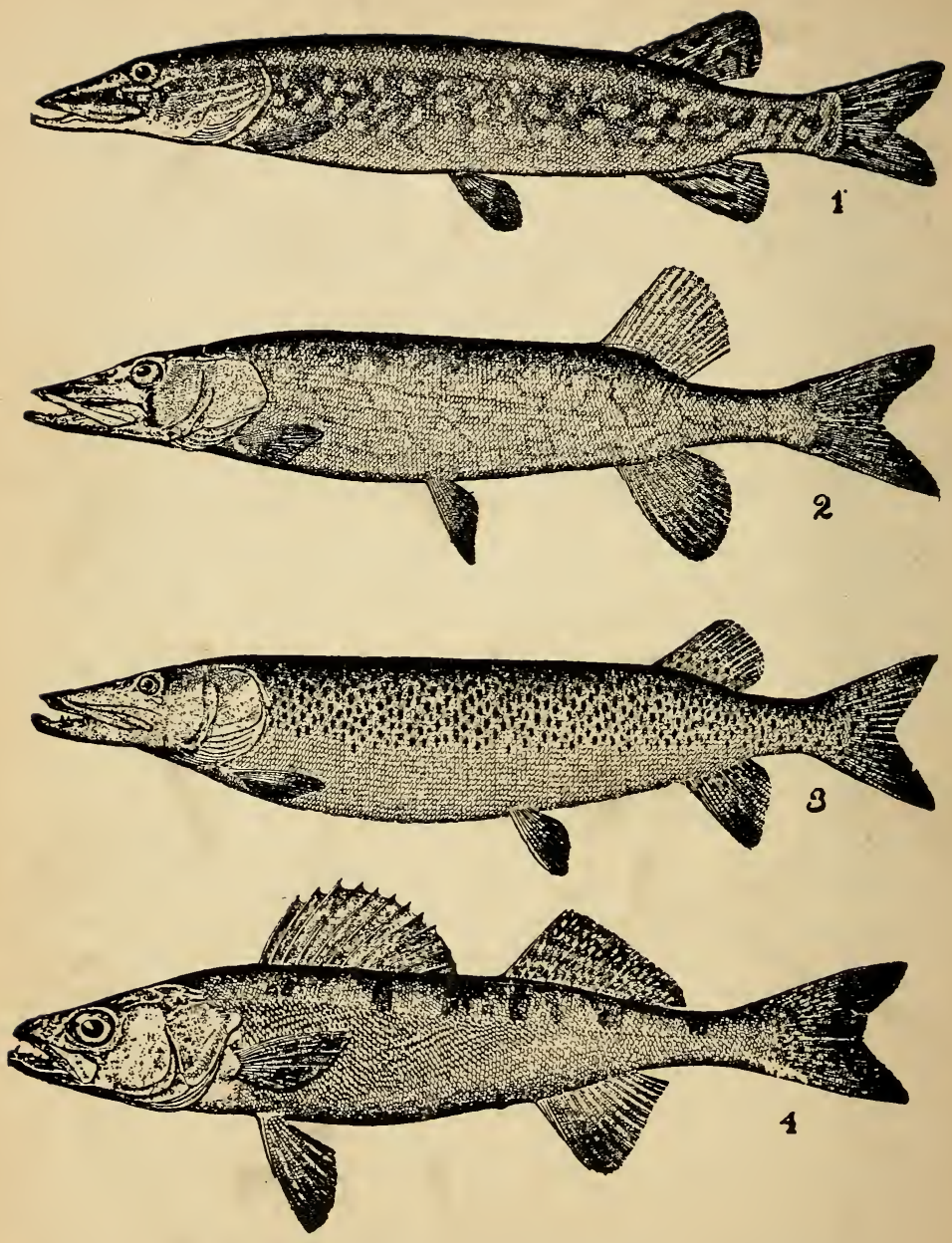

1-Pike; 2-Eastern Pickerel ; 3-Muskellunge ; 4-Pike-Perck or Wall-Eyed Pike. 
Pike, Pickerel, Muskellunge, Pike-Perch. 161

Regarding the size of this fish it is said that some have been captured that weighed as much as 100 pounds, but those over forty pounds are very rare and the usual catch weighs from fifteen to thirty pounds. Nevertheless, the musky angler is always on the lookout for the fifty pound fish.

This fish is found throughout the Great Lake region, upper Wisconsin and the adjoining parts of Canada and the St. Lawrence. It is said that they range southward into Tennessee, but if so they are knownl locally as the pike. It is in the lakes of northern Wisconsin that they appear to be most numerous.

As before said, there is apt to be confusion regarding the identity of pike, pickerel and muskellunge. But when the fish are placed side by side it will be noted that a difference exists. There is a difference in the shape of the body, the musky being deeper in the belly, and there is a difference in the spots, the muskellunge having small black spots on a lighter ground while the pike has larger light spots on the dark ground, but there is such a difference in the markings and they are sometimes so indistinct that it is best to look for a more definite distinction. By comparing a pickerel, pike, and muskellunge it will be found that the pickerel has both cheeks and gill covers completely scaled; the pike has scales on the cheek and the upper half only of the gill covers; and the muskellunge has only the upper half of both cheeks and gill covers scaled. This is the surest means of identification.

Ordinarily the fish will be found in water from five to twelve feet deep, near the weeds, water lilies and grass that grow in the water. $\mathrm{He}$ is solitary in his habits and haunts the same place daily as a rule. $\mathrm{He}$ feeds both in morning and evening but the best time to fish is in the evening, from the middle of the afternoon until dark. 
The kind of tackle to use for muskellunge depends on the way you want to fish for them. There are several ways of fishing, such as trolling with both hand line and rod, and
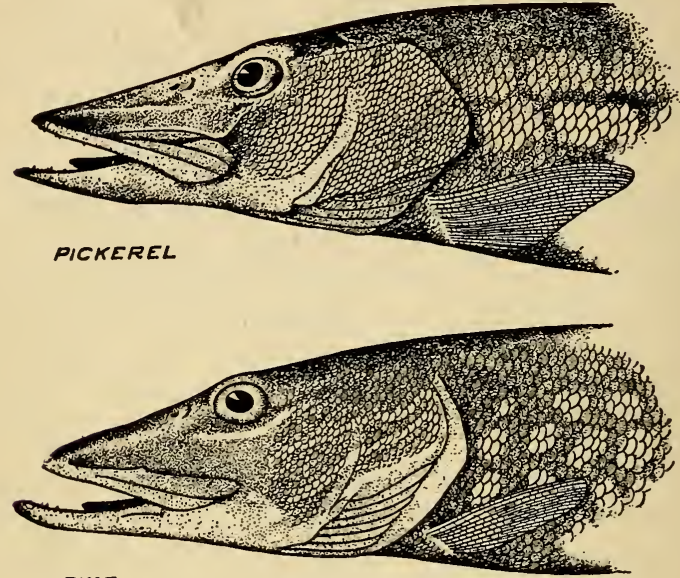

PIKE

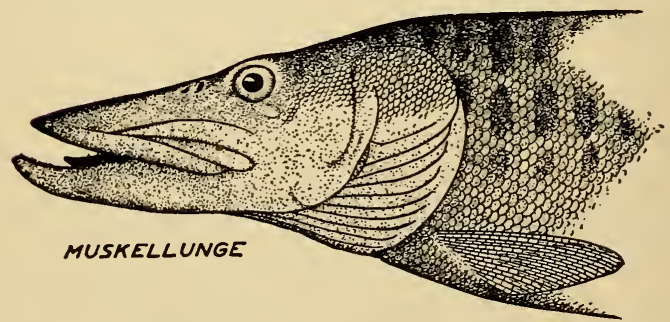

Showing Difference in Scales of Pickerel, Pike, and Muskellunge. casting, with live or artificial bait. Trolling is the method most often used, though there is more sport in bait-casting. For trolling with a hand line, strong tackle must be 
Pixe, Pickerei, Muskellunge, Pike-Perch. 163

employed. A line tested to the pull of forty pounds should be used. An excellent line for this purpose is the No. 21 Cuttyhunk, or No. 24 of the same brand, one hundred or more yards long. It should have a steel wire leader with a swivel or two on the end and a spoon bait of most any kind, large and strong. This is simply trailed behind the boat and when a musky strikes he is simply hauled in by main strength. It is productive of fish all right, but lacking in sport when compared with the use of a rod.

For trolling with a rod, a short heavy bait-catsing rod should be used. A steel bait-casting rod with trolling tip to use in place of the ordinary tip is all right, and the Bristol people make an excellent muskellunge rod, 6 feet, 6 inches long, weighing thirteen ounces. The latter is preferable if you want to try casting, and it is best if fitted with agate lined first guide and tip. The advantage of a steel rod for trolling is that the continued strain does not warp the tip. A large casting reel, the kind used for surf casting, is best. It should hold several hundred yards of line. It should be fitted with a leather brake or handle drag. The line mentioned above will do for trolling but is no good for casting and if you want to do any of this kind of fishing get a raw braided silk line, tested to a pull of thirty or forty pounds E. J. Martin's Sons make $\geqq$ fine line especially for muskys, tested to stand a strain of forty pounds. The longer your line the better as you can give that much more to the fish if need be and the more nearly full the spool of the reel provided it is not crowded, the better you can reel in a slack line. The same wire swivel and spoon are used as for hand-line fishing.

Trolling should be done over water from eight to twelve feet deep, and you should not go too fast. The rod should not be stuck out over the side of the boat, as the strain is too severe; it should stand straight out behind. You must 
have a boatman to row and help you land your fish if you want to be sure of him. A good sized sharp gaff hook is a necessity and a revolver or small rifle to shoot the fish before gaffing is a good thing to have.

For bait-casting the same rod and reel are correct, also the same bait if you like, but a live bait, fish or frog, is commonly used. The soft silk line is the only kind for this fishing. A leader of four ply twisted gut with a hook having a wire snell and barrel swivel is best. An excellent hook is the Van Vleck, size No. 4, with short chain and wire swivel. The Van Vleck hook has a double barb on the outside of the point. The bait should be a good sized frog or fair sized minnow. It should be well hooked on through the body as it is useless to try to hook it in such a way that it will live any length of time.

While there are many artificial baits that are very good, it is generally agreed that a natural bait is better and if it is used with a spinner or some arrangement is made to spin the bait, it is all the more attractive. The Archer spinner is excellent.

Much lighter tackle is used and advised by some anglers but it should be employed only by an expert. A thirty pound muskellunge puts up a tremendous fight and in bad water it may require an hour or more to bring him to gaff. You can tire him much more quickly with a heavy rod and reel than with the light kind and with light tackle there is always more danger of losing a big fish no matter how expert you are with rod and reel.

If you are using a trolling spoon or any kind of artificial bait strike instantly, as soon as the fish takes the bait, for he will drop it, at once when he finds it is not good to eat. With a natural bait on a hook give him time to swallow the bait before you strike. Give a quick, solid jerk to set the hook; then there will be something doing. 


\section{Pike, Pickerel, Muskellunge, Pike-Perch. 165}

Musky fishing is sure some sport, but it lacks the delicacy and refinement of trout fishing. But for a thrilling and savage fight no fresh water fish can equal the muskellunge. The muskellunge is good food fish, and like all of the pike family, it spawns in early spring.

The wall-eyed pike or pike perch is also known by many other names, and I fancy many of my readers would not recognize the fish were it not for the illustration and the description. It belongs to the perch family and by comparing the picture of this fish with that of the yellow perch it will be noticed that the wall-eye is simply a long, slender perch, in appearance, with less of a hump on the back and the "finger marks" not so pronounced as on the yellow perch.

The pike perch sometimes grows to a weight of ten pounds or more, but its usual weight is two or three pounds. It is a slender fish, having two dorsal fins, the forward one having olive, brown and yellow markings, and the tail has similar markings, with two sharp spines. The body color of the fish is olive or brown with yellow markings, the under parts salmon pink or yellowish. The eye is large and has a peculiar opaque appearance.

It is found throughout the Great Lakes region and Canada, down into the east-central states, in parts of Pennsylvania, Virginia and the Carolinas, and perhaps elsewhere. It is a good game and food fish. It inhabits only deep water, and in lakes will sometimes be found at a depth of twenty or thirty feet. It prefers cool water with a gravelly or rock bottom. In streams it will be found at the foot of rapids and below log jams and such places.

The tackle for this fish is the same as for bait fishing for black bass. The best bait is a minnow, but crawfish are also used. It is said that they take an artificial fly wery well, on cloudy days and in the evening, as they are mostly nocturnal in feeding habits. The fishing is in fact so much like that 
employed in the capture of black bass that the same instructions will do for both fish, except that for the wall-eye you should fish deeper, and in deeper water. The fly may be allowed to sink several feet after each cast.

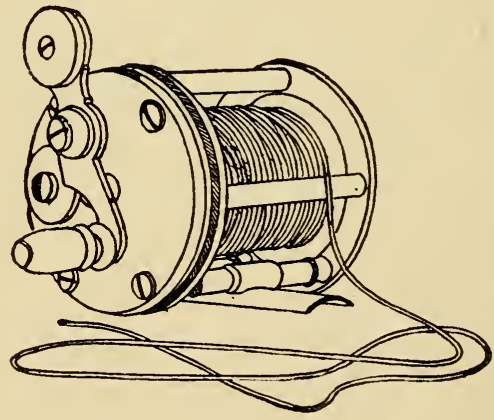




\section{CHAPTER XVI.}

\section{Sunfish, Carp, Catfish and Suckers.}

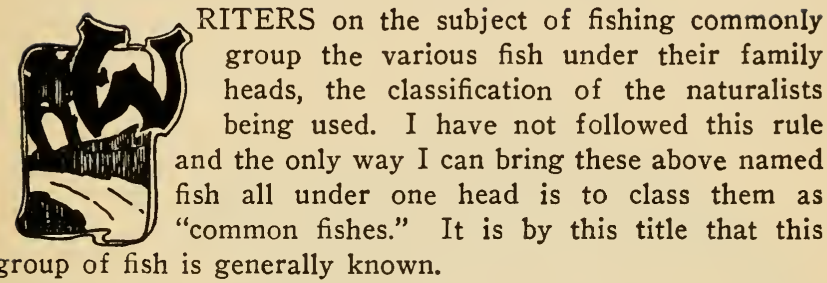

The sunfish family comprises many species. Our gamey black bass, both the large and small mouthed kinds, belong to it. The others are the rock bass, the common sunfish, the calico bass, the crappie, the blue sunfish, the long eared sunfish, the warmouth perch, etc. These are also known in localities under many other names, which is confusing. As the mode of fishing for all of these is about the same, I will first describe the fish separately and then tell how to catch them.

The common sunfish, often known as the pumpkin seed, is found throughout the Eastern States, the Great Lakes region, and the northern-central states. It is a small, flat fish, being "most as wide as long" and has many colors on its scaley sides. The predominating colors are blue and yellow, being bluish on the back and yellow or golden color beneath, the dorsal fin which is very large, being yellow with blue rays; the ear tip is black with a scarlet border, and the iris of the eye is also scarlet. It is such a common fish that almost everybody in the East who has ever done any fishing is familiar with it. It is seldom more than four or five inches 
168

Science of Fishing.

long, though it is said that it sometimes attains a length of eight inches.

The rock bass is also known as goggle-eye and red eye It is found all through the northern and central states and farther south. It looks a little like a black bass but is broader, and is much smaller, seldom weighing more than a pound and usually only half as much. It shows a number

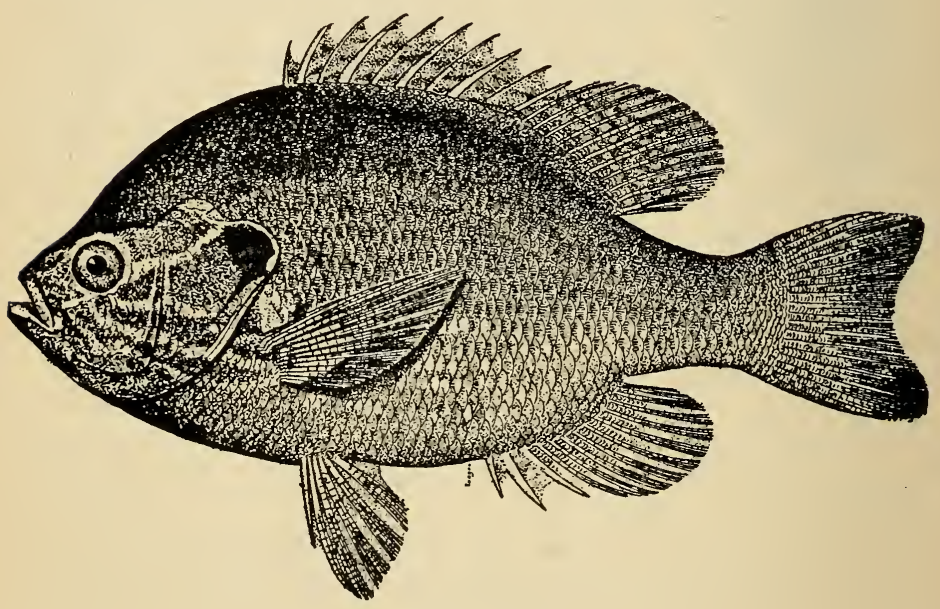

Common Sunfish.

of colors, dark olive-green and yellow predominating. The iris of the eye is red, and there is a black spot on the gill cover. Rows of small, dark spots run along the sides.

The strawberry bass or calico bass, also known as the northern crappie and many other names, is found in the region south of the Great Lakes and throughout the Missisisppi Valley; also in the streams of all of the Atlantic Coast states from New Jersey southward. It has the typical sun- 
fish shape, but has a flatter and thinner body than the others. It seldom reaches a length of more than ten inches, or a greater weight than one pound, but much larger ones are said to exist in some waters. The general color is olive-green, dark on the back and pale beneath. The sides are covered all over with dark sports; the fins are mottled.

The crappie supplants the calico bass in the south. It resembles the latter fish very much, but when specimens of each are compared a difference will be noted. The best way to distinguish them is by counting the spines in the dorsal fin (on back); the crappie has six of these and the calico bass has seven. It is also of a paler color.

The blue sunfish is found almost all over the eastern, central and southern states. In Ohio, and other of the central states, it is known as the blue-gill and in the South as blue bream and coppernosed bream. It is larger than the common sunfish and sometimes attains a weight of a pound or a pound and a half, but usually is lighter. The coloring is greenish or bluish, sometimes a slate color, lighter on the sides, and the under parts are copper colored or red. The ear cover is dark or black.

The long eared sunfish is found throughout the Mississippi Valley, and in the east coast streams; also in the Gulf States. It gets its name from the large ear flap. It has a red iris eye, in common with the other true sunfish. It is bluish on the back and orange, brown or yellow on the under parts. The ventral and anal fins (fins on under parts) are blue, and the dorsal fin is orange color with blue rays. It is about the same size as the common sunfish.

The warmouth perch is also a sunfish, and is sometimes called the black sunfish. In appearance it resembles somewhat a black bass but is broader in proportion to length, more like the rock bass. It is found in the South and also in the northern part of the Mississippi Valley. It is a dark clive-green on the back, lighter on the sides, with orange or 
red and blue spots, and greenish yellow on the under parts. It never weighs more than a pound. As a game fish it is quite a favorite and takes either a fly or natural bait.

All of the sunfish spawn in spring and early summer. The nest is made in a bed of sand or gravel in shallow water and is carefully guarded by the parent fish. After the fry make their appearance they are guarded by the male fish until several days old. Their food consists of insects, larvae, crustaceans, the fry and eggs of other fish, worms, etc.

Sunfish of nearly all kinds will rise to a fly. The best fishing is to be had in late afternoon and evening, when a light breeze is blowing. The tackle should be a light fly rod, the lighter the better, a small single action reel, smallest enameled silk line, light single gut leader, three feet long, and small trout flies.

It should be understood by all who read this book that what I describe as the "best" tackle is the kind I think best, and you may have different ideas on this subject. I would not expect anybody to buy a special fly outfit for catching sunfish, but I mean that this is what I consider most fitting, and if you have such tackle, use it, but if you have not got that kind, use what you have, for almost any kind of fish can be taken with almost any kind of tackle, if it is properly handled. You can catch sunfish with a long cane pole, a cotton line, ringed hook and bait, but will get more enjoyment out of your fishing if you have fine, light tackle to use for them. As a further illustration, large muskellunge, pike, and Atlantic salmon have been taken with a common light trout fly rod and tackle, and the large and gamey ocean fish are sometimes taken on tackle as light as that sometimes used for black bass and such fish - at the same time they are hauled in by fishermen using a heavy handline. Therefore, when I say that a rod of this kind, and that kind of a line, is the kind to use. I mean that if you have that kind, use it, or if you want to buy special tackle for that kind of 


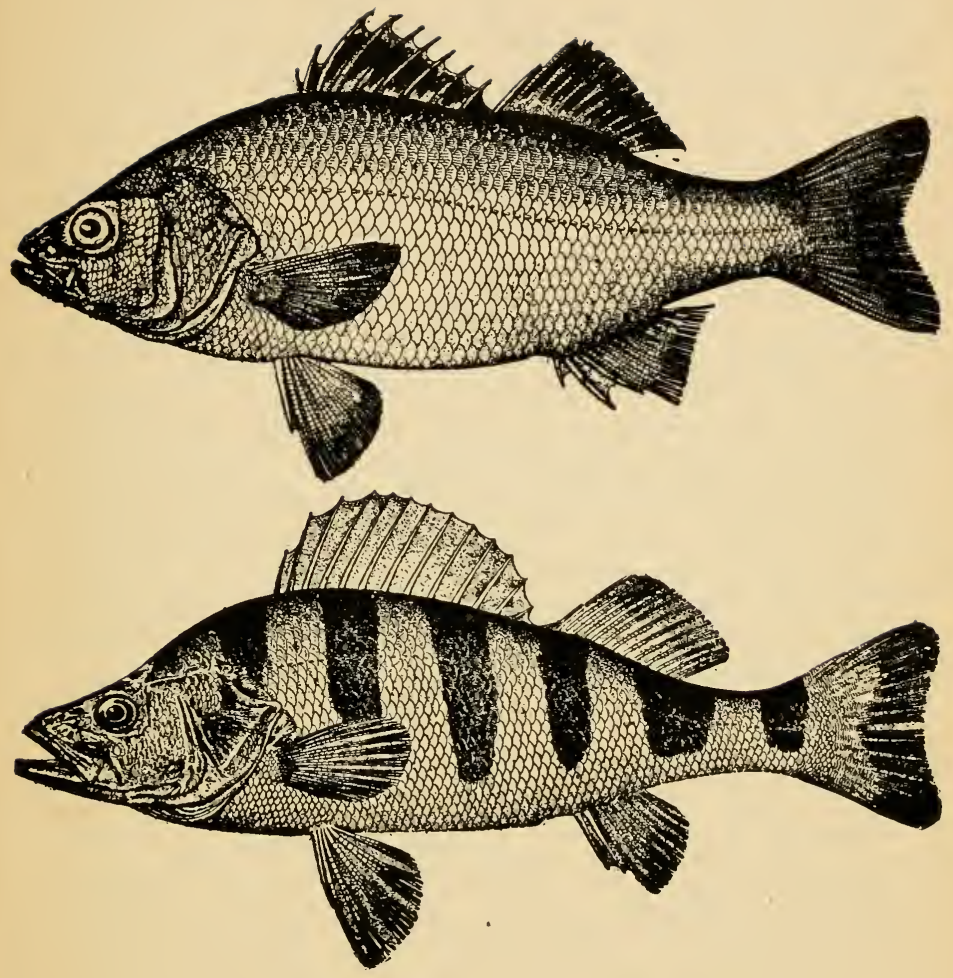

Upper-White Perch; Lower-Yellow Perch. 
fish, buy the kind described, otherwise, use what you have be content with it and enjoy your fishing, for you will not enjoy it much if you are continually thinking of some other person's fine tackle, and the common outfit that you have to use.

For bait fishing you may use the fly outfit described, and snelled hooks of size 6,8 or 10 . For the crappie you can use a No. 4 or No. 5 hook. Snelled Carlisle hooks are about the best in my opinion, and a split shot sinker should be placed on the leader, or on the line if you do not use a leader. Or you may use the lightest bait rod, with a small reel, either single action or multiplier, an undressed or an oiled silk line of small size, or the lightest twisted linen line. I would prefer a very small silk line, like the Kingfisher Special Trout line, oiled or enameled. Or you can use a native cane rod and no reel, but the same line, hooks and sinker. You will get the most sport from using the lightest tackle, and I think you will get more fish also, but you should not use an outfit that is too weak to hold a large fish of some other kind, such as a black bass for instance, for you can never be sure what you will catch. The little silk line mentioned is no thicker than a coarse button thread, but will stand a strain of ten pounds, and that is strong enough for almost any ordinary fresh water fish if it is handled in the right way.

The larger sunfish, such as rock bass and crappies, may be taken on a live minnow bait; the very small minnows with a stripe on the side, those about two inches long, are the ones to use. Hook them lightly just under the dorsal fin. Cast the bait and let it sink well down, then reel in very slowly. After all there is nothing better than the common angleworm. Use the smaller ones and bait the hook so that the worm can wiggle. Soft-shelled crawfish, or the peeled tail of a hard shelled one also makes good bait. A single gut leader should always be used, and a split buckshot for a 
sinker. I don't think it necessary to mention the various places they are likely to be found at certain times, and other such information, for the angler will soon learn this if he fishes often in the same waters, and nothing that I could tell would be of any special value.

Another very common fish is the yellow perch, or ringed perch. It is found in eastern Canada, the region immediately north of the Great Lakes, the upper Mississippi Valley, Michigan, Indiana, Ohio, and all of the states bordering on the Atlantic ocean. It is a nicely shaped fish, a little wide in proportion to length, with a high back and rather small head. The back is olive and the sides yellow, lighter beneath, and over the back and sides are some six or seven dark vertical bands, like finger prints.

The yellow perch reaches, in some waters, a weight of two pounds, though it is usually under a pound in weight. It is a gamey fish, and an excellent food fish when taken from good waters.

Perch may be caught by still fishing, with the same outfit described and recommended for sunfish. Baits are the same as for sunfish, but almost any kind of bait will do. A small casting spoon will also catch them, and sometimes they rise well to a fly.

The white perch is a sea fish, but is caught in the brackish waters on the Atlantic coast, at the river mouths| It does very well when transplanted to fresh water and sometimes ascends the streams quite a distance. It grows a little larger than the yellow perch. It is caught with the same kind of tackle and the same bait, also shrimp, shedder crab, small eel, etc.

The white bass is one of the true basses, and one of the two that live in fresh water, for most of the bass are sea fish. It is found in certain waters in the upper Mississippi Valley; also in Lake Michigan and Lake Erie. Its usual weight is about a pound, but specimens of two pounds or 
more have been taken. The fish takes a fly well and may be caught with trout fly tackle; also with bait such as for sunfish. Like sunfish, these fish go in schools, and when you find a school, or when the fish come your way you can expect good sport until they have moved on again.

The yellow bass is found only in the lower Mississippi and its tributaries. It resembles the white bass very much, and is caught in the same way, with the same kind of bait.

A fish that interests many because it is so abundant and grows to a large size, and yet is very difficult to catch, is the

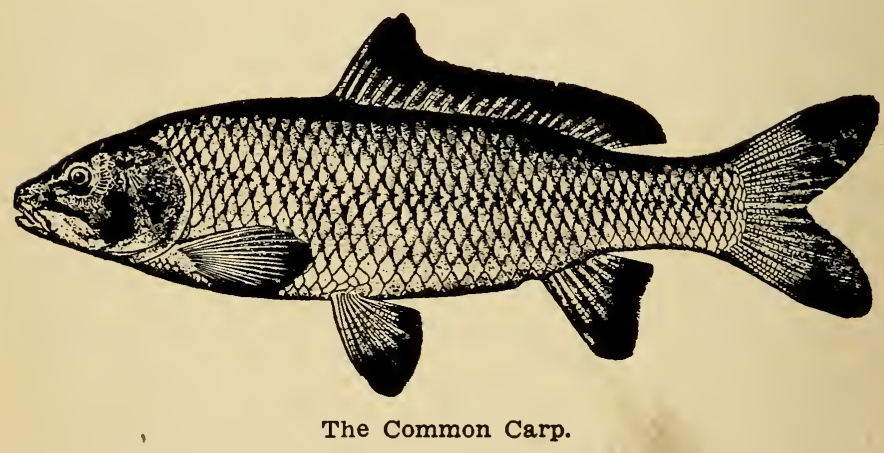

earp. They are not a good food fish, but may be eaten if properly prepared and cooked. They should be skinned so that the "muddy taste" will be removed. At the best they are a coarse and flavorless fish.

The carp is not a native of this country, but was introduced from Europe. At first it was kept only in private ponds, but it was not long in finding its way into the streams, where it increased in numbers at a rapid rate. At present it is found in the lakes and streams of almost all parts of the United States. Carp are abundant in Lake Erie and are 
netted in large numbers for the market, finding a ready sale in the Jewish quarters of the large cities.

The carp usually, when full grown, weighs five or six pounds, but specimens of ten or even fifteen pounds have been taken. The fish does best in stagnant, mud-bottomed, and weedy streams and ponds. It feeds on the bottom, in deep water usually, eating both vegetable and animal food.

The only successful way of catching carp with hook and line is by the old-time English method. A very light, but strong line is used, and a six-foot single gut leader. The hook should be very small, about 10 or 12 , and the sinker is a single split buckshot. A quill float is used. It is not necessary to have a reel, and the rod may be of common cane, but a bait rod and reel may be used. The sinker is placed about six or eight inches above the hook and the quill float so placed that the sinker will just reach the bottom when the line is stretched up. This outfit is prepared and the feeding place of the fish looked up in advance of the actual fishing, and the place is well baited the evening before to get the carp to working there. Green corn, angleworms, minced meat, bread and small dough balls are used for baiting the water, and for baiting the hook a red worm or a pill of half baked dough, or a piece of clam may be used. The hook should be well covered so that the fish cannot feel it when he takes the bait, or he will eject it. Early in the morning and late in the evening are the best times to fish for carp. Approach cautiously and drop the bait at the proper place with as little noise and disturbance of the water as possible. Then place the rod in the rests, which should also be placed there beforehand, and retire to a little distance where you can see the float and not be seen or heard by the fish. When the float goes under water go and get your fish. If you have a reel on your rod you can handle him easily, but otherwise you should have a limber cane or wood rod, so that the line 
or leader will not be so likely to break. It is well also to have a landing net or a gaff hook.

And now we come to the catfish, the homeliest fish that inhabits our fresh waters, but highly esteemed by many anglers nevertheless, and generally regarded as a good food fish if we forget out prejudice and let some other person dress and cook him.

The common bullhead or horned pout has a wide distribution, being found over all parts of the eastern half of the United States, and I understand also in parts of the West. It sometimes, though rarely, reaches a length of eighteen inches and a weight of four pounds. The usual length is from ten to fourteen inches. It is an ugly fish, having a very large flat head, a large mouth, with long streamers or barbels hanging from the jaws. It has no scales, but a tough, shiny skin like an eel. The anal fin is very large, and the pectoral fins (behind the gills) have stout, sharp spines, which make ugly wounds, and the "cat" can use them much as a boxer uses his fists. The color is brown on the back, shading to yellow on the sides and light beneath.

The bullhead loves quiet, deep water, where the bottom is muddy and he thrives best there. He seems to be more at home in warm water than in cool, and you will find him active and enjoying life when all of the other fishes are seeking the cool waters and will not take a bait. But your catfish is ever eager to take any bait that is offered to him, providing that you put it down where he can get it without rising, for though he is not particular what he eats he does not like any unnecessary exertion on his part.

To catch bullheads, all you need is a long cane rod; a line about the same length, and a light linen line will answer as well as any other; a No. 4 hook, preferably one with a long shank, as it renders extraction easier; and a small lead sinker about ten inches above the hook. If you like you may also use a cork float to tell you when the fish is biting. You 
can use only one pole, or two or three, as you like for they are "set" in rests provided on the bank. After setting the rods you can light up and take things easy until a cork goes out of sight, then haul in your fish. You needn't be afraid of hurting him and he will try his best to hurt you while you are removing the hook, so look out for his spines on the pectoral fins.

For bait you may use angleworms, soft shelled crawfish, or the tail of a shelled one, a piece of liver, a mussel, or what

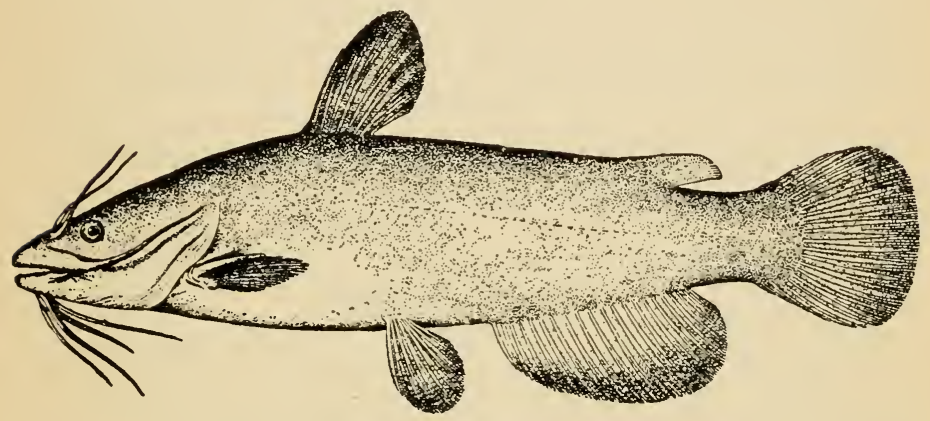

Common Catfish or Bullhead.

is probably better than anything else, a strip of fresh beef. In quiet, mud bottomed water, where weeds and lilies grow, is the best for bullheads. You can catch them at any time of day, but evening or after dark is best. It is always good after a thunder shower.

Besides the bullheads there are about thirty other kinds of catfish found in this country. The largest is the Mississippi catfish or blue cat. It is found in the Mississippi river, and others rivers of the South; also the Great Lakes. It sometimes reaches a weight of 100 pounds, or even more. 
These large ones are taken only on trot lines with large hooks baited with pieces of meat or liver.

The channel cat is a much smaller fish and though it is said to reach a weight of twenty pounds sometimes, the usual weight is five or six pounds. It is a nicer appearing fish than the other members of the family, being more slender and having a head smaller in proportion to body. The tail is forked and the anal fin is very large. It shades from dark slate on the back to white on the under side and shows a number of small black spots on the sides. It is found throughout the Mississippi Valley and the Great Lake region; also in other rivers of the Southern States. The channel cat, unlike the bullhead and other members of the catfish family, prefers running, clear, cool water, where the bottom is gravelly or stony. It is a better fish than any of the others, and takes almost any kind of natural bait, even live minnows, if they are not moved too rapidly. The tackle for this fish may be the same as for the bullhead except that line and hooks should be stronger. If desired, a black bass bait outfit can be used.

Catfish of all kinds are very tenacious of life. Fish caught in late evening will sometimes live out of water over night. It is best, though, to kill them as soon as caught more humane and they make better food. In dressing they must be skinned, and are best if soaked a few hours in salt water before cooking. Properly prepared they are very good.

Of the suckers there are many, about seventy species I am told. Of these the common white sucker is the most important. Buffalo fish and red-horse are also classed as suckers.

The white sucker is found all over the eastern and central parts of the United States and Canada. It reaches a length of twenty inches in the Great Lakes and somewhat less when found in streams, growing larger in some streams than in others. It is a smooth, cylindrical fish 


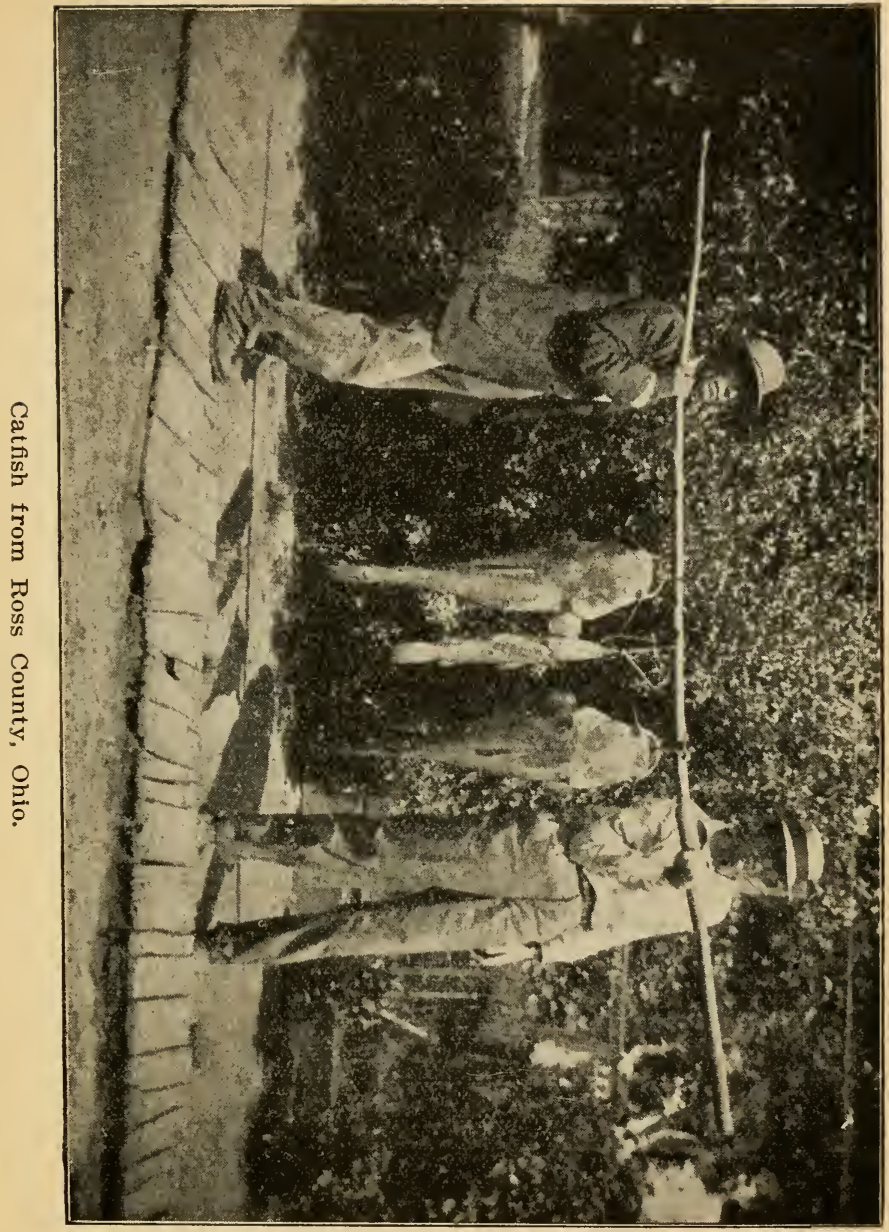


with large fins and the characteristic sucker mouth. It is gray on the back, light ashy on the sides and white beneath. The sucker spawns in spring, about May, and ascends the streams for this purpose. About the Great Lakes there is a heavy run of these fish in the streams, at that time of year. At such times they are taken in gill nets stretched across the streams, also by slipping a brass wire snare over the fish when they lie in shallow water, and by spearing. They do not take a bait at such times, nor during the summer when the water is clear, except on rare occasions. They are caught mostly in early spring when the rains raise the water and discolor it. At such times they feed in the eddies of the streams, or muddy bottom, and may be caught by still fishing with a number of rods, which are set, in the same way as for carp. The rod should be a long native cane, or a wood rod. Sometimes a slender, dead, white pine is trimmed of branches and knots and the bark, also some of the wood shaved off, making a fairly good rod, though cane is better. The smallest cuttyhunk linen line, or an oiled silk line, or a light cotton line is all right. Two or three No. 10 or 12 snelled hooks are fastened to the line near the end, being placed about ten inches apart, and a sinker weighing from a half ounce to an ounce is tied to the end of the line. It is a common practice to attach the sinker by means of a weaker line, so in case it gets caught between stones the weak string instead of the line will be broken. A cork is also used. The hooks should be baited with angleworms, well bunched, with an end hanging loose to wriggle.

Instead of using rods, some fishermen use hand lines, and by means of the sinker throw the bait out into deep water: then fasten the other end of the line somewhere on shore Before using such ligs it is best to look up the fishing laws and see whether these lines may be used lawfully, also how many may be used by one person, and how many hooks may be used on a line. 
The buffalo fish is found in the Mississippi and its branches. It grows to a weight of fifteen pounds. It is caught by still fishing with somewhat heavier tackle, baited with worms. The large mouthed buffalo is found in the Mississippi also, as well as in other large rivers of the South and central portion of the United States. It reaches a weight of fifty pounds. Heavier, stronger tackle must be used for them. The red horse is also called a mullet. It resembles the white sucker somewhat but is brown in color. Suckers are not highly esteemed as food fish but the white sucker taken from swift, hard-bottomed streams is not at all bad.

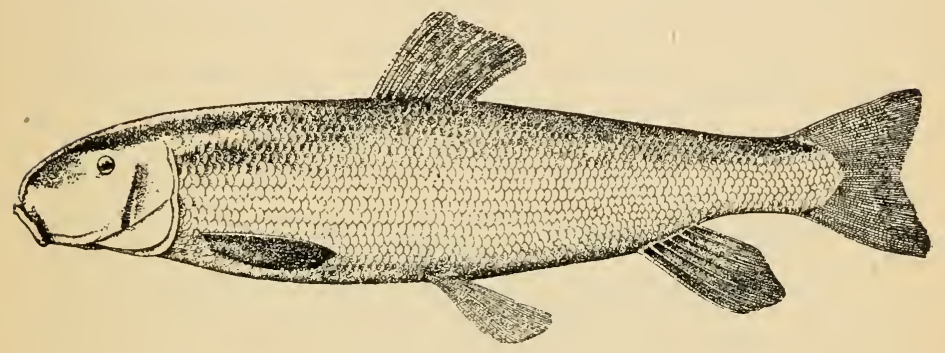

The White Sucker.

The only other bottom-feeding fish that I will mention is the eel. This is the strangest fish inhabiting fresh water and appears to be the connecting link between the fishes and something else. It is long, slender and cylindrical, usually being about two and a half feet long and only one and a half inches in diameter at the thickest part. The dorsal, anal and candal fins are all in one, commencing about the middle of the back and running clear around the tail to the under side and well forward. It has no scales, but a very tough skin. The color is slaty on the back and white beneath Some are yellow on the sides and in under. 
Contrary to the rule of sea-going fish the eel breeds in salt water and sojourns in the fresh streams in summer. They frequently go up stream 500 miles from the sea, perhaps farther. When found in clear streams they are excellent food fish.

Eels are voracious and eat all kinds of small fish, crustaceans, worms, etc. They are shy and are seldom seen by day as they retire under the stones or bore into the muddy bottom as soon as daylight appears, and do not as a rule come out again until nightfall, unless the day is dark or rainy and the water muddy, when they may be caught all day long.

The tackle mentioned for suckers is good for the eel, but only one hook, and that a larger one, about No. 1, should be used. It may be baited with a worm or a piece of fish, or any kind of raw meat, for the eel is not particular what he eats. He even eats carrion when' it can be found in the streams, and for this reason many people will not eat eels. Fish for them on the bottom in deep water. You can also catch them at night if it is dark, but not when it lightnings, and you must not build a fire. They are also taken on trot lines or short rods set from the bank, with short strong twine lines and large hooks, baited with pieces of fish. When caught the eel puts up a desperate struggle, and for his size he possesses greater strength than any other fish. It is almost impossible for a strong man to hold in his bare hands an eel weighing but a pound and a half, for he squirms, winds his body about your wrists, and kicks as no other fish can. It is best to wear a woolen or canvas glove when handling them, as they are more easily held then.

When eels return to salt water in late summer they may be taken in fish baskets built in the streams, if the laws allow it. The basket consists of a number of sloping shelves of 
Sunfish, Carp, Catpish and Suckers.

slats, which allow the water to run through but catch the fish. Wings of stones extend out on each side to guide the eels into the trap. I have known of over 400 eels being taken in one night in such a trap, when the stream was rising.

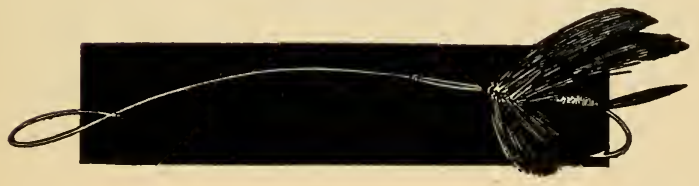




\section{CHAPTER XVII.}

\section{Fishing For Tarpon and Tuna.}

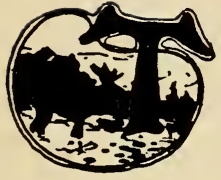

$\mathrm{HE}$ tarpon is one of the most highly prized game fish of salt water, a large fish that fights wonderfully when hooked, leaping sometimes ten feet from the water. I do not suspect that many readers of this work are tarpon fishers but if any ever have the opportunity it is a sport that is second to none, and should not be passed by without a trial.

The tarpon is found in the Gulf of Mexico and off the east coast of Florida, the most famed places being Indian River Inlet, Jupiter Inlet, North Inlet, and all the way around to Tampa Bay, and down along the west side of the Gulf to Tampico, Mexico. Tarpon move south in the fall and winter and northward in spring. They appear along the Florida coast in February, and along the Texas coast in March, but are not found in their greatest numbers until April and May. They do not take a bait until the last of May.

This fish resembles a herring somewhat in outline. It is a slender, graceful fish, and is covered with enormous silvery scales. The color on the back is a deep bluish or purplish, silvery on the sides and beneath. The dorsal and anal fins are of peculiar shape, and the tail is large and deeply notched. The average weight of the full grown fish is from 75 to 150 pounds, but it is said to reach a weight of 400 pounds and a length of eight feet.

The fish are such great fighters and there is such great sport in angling for them, that a number of tarpon clubs have been formed, and these clubs regulate the strength of tackle 
that may be used by the members. They require the use of very light tackle, and prizes are given for the record fish.

Tarpon are fished for mostly in the morning, but are also taken on moonlight nights. They are caught with mullet bait. They are taken mostly by trolling the outfit at about 75 or 100 feet behind the boat. A good boatman is a necessity.

The tackle usually employed is a one-piece rod of lancewood, split bamboo or greenheart with removable butt, double guides and agate tip. The usual length is about six feet sir inches, and the weight is about twelve or thirteen ounces for

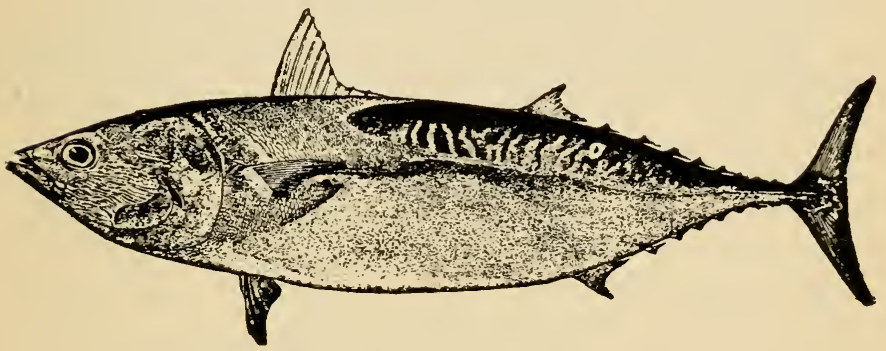

The Tuna.

the tip and about the same for the butt. Quite large tarpon have been taken on rods with a six ounce tip, and No. 9 twisted linen line, which will stand a strain of only eighteen or twenty pounds, and this is the tackle required by the Aransas Pass Tarpon Club, of Aransas Pass, Texas, but the really large tarpon are not taken on such tackle, or to be more exact they are not held by it. The standard lines are from 21 to 30 thread linen, and will stand from forty-two to sixty pounds strain. The reel must be a tarpon reel of rubber and German silver, holding 250 yards of wet line. It should have a handle drag, which is described elsewhere, 
and this should be regulated to a pull of about eight pounds. The reel should be of high quality. The hooks used should be those made for such fishing. The Van Vleck with forked barb is a favorite, and there are others of the regular pattern that are all right. A wire leader, attached to the line by a strong barrel swivel is used and the first ten feet of line should be double. It is well to make some provision for the sharks that inhabit the same water with the tarpon, and are likely to get fast. For this purpose a six inch cotton line is inserted between the leader and the hook, or the entire leader may be of cotton wound to within six inches of the hook with copper wire. The tarpon swallows the bait and is hooked deep so that the unprotected cotton is well inside his mouth but where it cannot be cut by his boney jaws. The shark, if he takes the bait, snaps right shut on the leader and will thus sever the cotton line. In case you only expect to fish a few days it is better to rent tackle, as tarpon tackle is very costly.

The bait is trolled over forty or fifty feet of water. When the bait is taken the angler should set the hook instantly. In still fishing he should let the fish run thirty or forty feet before striking. The fish must be played in the same way as a smaller fish and it is usually a desperate struggle before the fish can be brought alongside and gaffed. He makes great leaps, sometimes actually leaping into the boat, and it is not only exciting but even dangerous sometimes. $\mathrm{He}$ also sounds deep, and makes long rushes which must be checked by the reel brake, and it will be necessary to "pump" him sometimes.

The boatman must be an expert in handling a boat and must keep the stern turned towards the fish at all times. He must know all about the habits of the fish, and how to catch them, and when you bring the fish in he must know how to gaff him, and must do the gaffing.

Tarpon are no good as food and are only caught for 


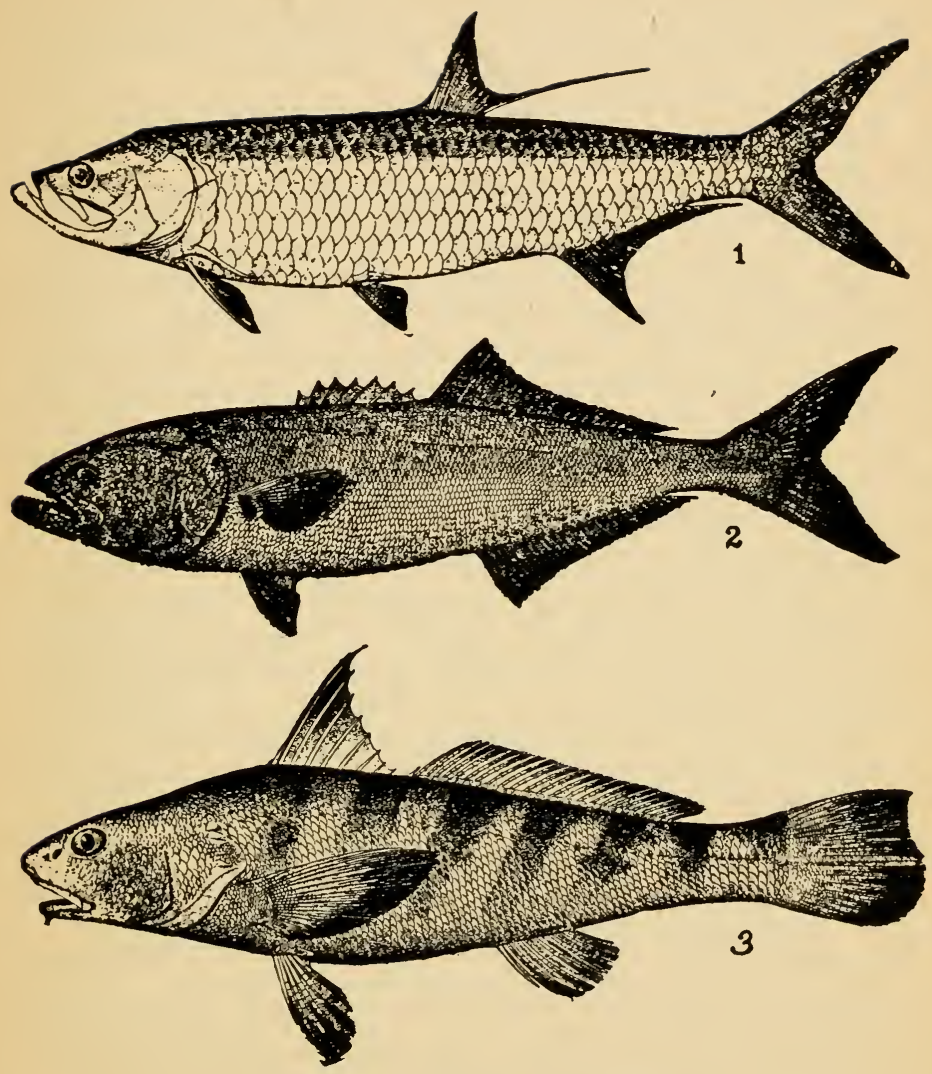

1-Tarpon; 2-Blueflsh; 3-KIng ^sh. 
the sport and to mount as trophies. The small ones are always released. To do so they are gaffed carefully under the jaw and held until the hook is extracted.

The only rival of the tarpon as a game fish, is the great leaping tuna of the California coast, near the Santa Catalina Islands. There it reaches an average weight of 150 pounds, but I don't know how heavy it really does get in the Pacific, though in the Atlantic, where it is found from New Jersey northward it reaches a weight of 1200 pounds. These monsters have never been taken with rod and line, and the record is a 680 pound fish. At Santa Catalina is the greatest sea fishing to be had anywhere in the world, and the fishing is all conducted on true sportsman's lines. There is one club known as the Three-Six Tackle Club that will not use a line heavier than a 6 thread linen, which will not stand a strain of more than fifteen pounds. It seems impossible to catch such large fish as tuna, which have such a reputation for fighting, on such tackle, and of course the large ones could not be held with it. I think the record for this tackle is a sixty pound fish. Ordinarily the same tackle is used for tuna as for tarpon. Flying fish are used for bait. The leader should be of phosphor-bronze, six feet long, and the line for ten feet should be double. The bait is cast into a school of the fish when they are chasing flying fish, and after hooking the fish it is sometimes hours before he is tired out, and the boat is towed several miles. The fishing is done from small motor-boats made specially for tuna fishing.

The Atlantic tuna or Canadian tuna, is sometimes called horse mackerel, in fact it is more often known by that name than by the name tuna. They grow to an immense size, 1200 pounds or even more, and it seems that they are the same as those found in the Pacific as regards fighting qualities, except that the largest fish of any kind are not the fiercest fighters. They are found very rarely as far south as New Jersey, and are most abundant off the coast of Nova Scotia and 
especially in St. Anne's Bay and Mira Bay, Cape Breton. These fish are seldom taken with rod and line but are harpooned. A few years ago Mr. J. K. L. Ross, writing for a certain sporting magazine said that he never knew of an Atlantic tuna being landed with rod and line, but since that time he has been fortunate enough to capture the world's record tuna taken in this way. This great fish weighed 680 pounds. I understand that he used a tuna rod of one piece and butt; a special Vom Hofe reel holding 300 yards of line, and a No. 39 linen line of that length. Mr. Ross is probably the most enthusiastic Canadian tuna fisherman living and has hooked large numbers of these fish but invariably loses them by the tackle giving way or the line being cut by the other tuna. Some of his earliest trouble of this kind was caused by the bait slipping up over the wire leader to the line, after the fish was hooked, and the other fish in their efforts to get the bait bit the line. He put an end to this trouble by fastening a short piece of wire crosswise of the leader to keep the bait from traveling off the leader and onto the unprotected line. A twelve foot leader is used and it is made of piano wire. The hook is the largest tuna hook with a six inch chain attached. If the fish is finally brought to gaff, a harpoon style gaff which has a rope attached and detaches from the handle after hooking the fish, is the kind that must be used. As such a large fish could not be taken into a boat he must be towed ashore.

Think of capturing a 680 pound fish with a line that probably would not stand a strain of more than eighty pounds! What fine handling of rod and reel must be necessary to check the rushes of such a fish on 300 yards of line! The fish will tow a boat many miles, and if allowed to have their own way will do so for days. At the very best it would take hours of work to land such a fish and the catch would not dare be allowed a minute's rest until brought to gaff. The Pacific tuna tackle would be useless here. 


\section{CHAPTER XVIII.}

\section{Fishing For Other Sea Fish.}

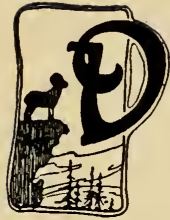

EEP sea fishing for the gamey amberjack, bluefish, weakfish, and other denizens of the deep is exciting sport and interesting to all anglers, whether they have an opportunity to indulge in it, or whether they must be content to only read of it and live in hope, and I regret that for the purpose of this work I must confine this great branch of angling to a single chapter. I can only give brief descriptions of the fish and tell in a few words how they are captured.

Many fine game fish are found off the Pacific coast. The tuna has already been described. There are several smaller tuna, good game fish, but a description of these cannot be given here. In the Pacific along the coast of California and southward is found the black sea bass or jewfish, an ocean monster running up to 800 pounds in weight. It resembles the black grouper of the eastern ocean, but is a finer fish. In appearance it is very much like a monster black bass. It is caught by still-fishing from an anchored boat in about fifty feet of water, tuna tackle being used. Albacore is used for bait. The fish puts up a great fight, but is not to be compared with the tuna.

The yellowtail of the Pacific is not the little fish known by that name along the Florida coast, but is a larger fish, running up to sixty or eighty pounds in weight. It is a splendid fighter. A light salt-water rod is used for them, and a nine thread linen line. Linen line is the only thing for ocean fishing as silk will not stand the salt water. The bait 


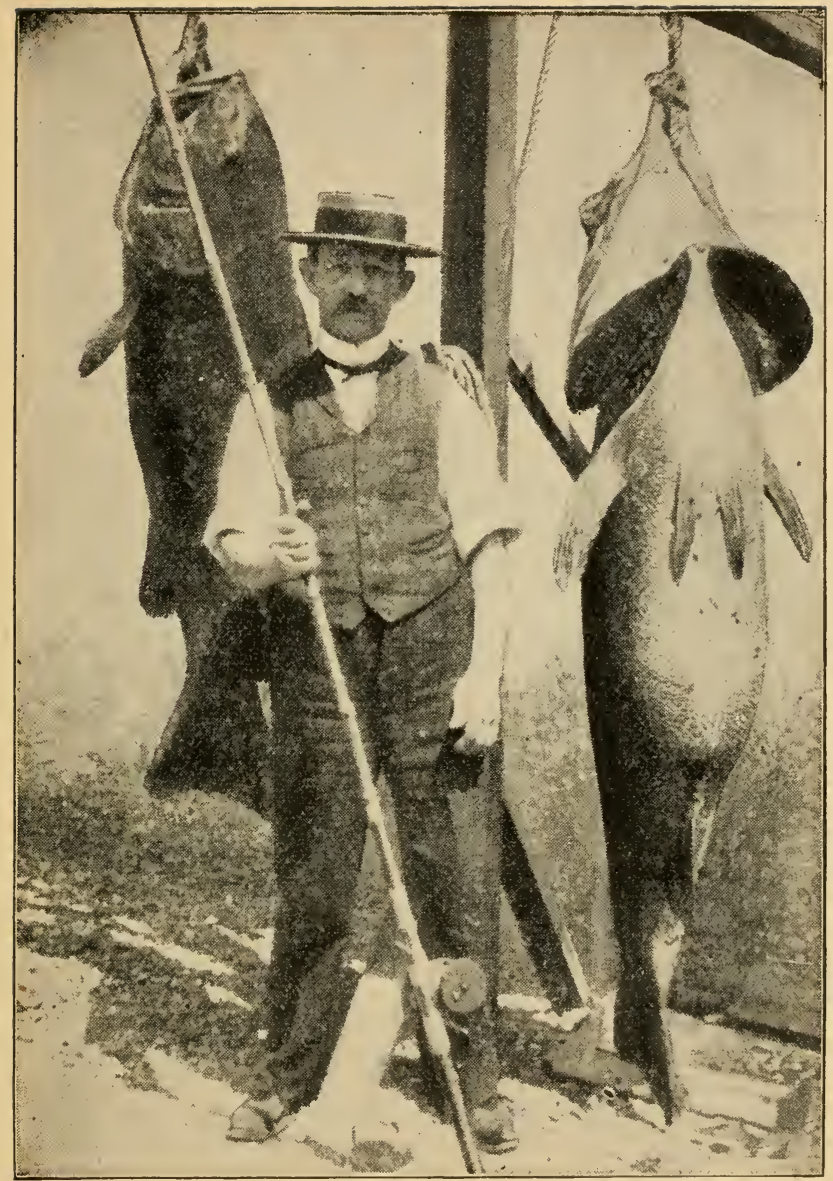

Jewfish, or Black Sea Bass, from the Pacific Coast. 
used is sardine, and it is taken with a rush that will surely break the tackle if allowance is not made for this. From seventy-five to one hundred yards of line is used, and the fish may be caught by trolling or still-fishing.

A fish found on the Florida west coast and the coast of the Carolinas, called the amberjack is very much like this western yellowtail. It reaches about the same weight and puts up a fight equal to that of a tarpon of the same weight, perhaps greater. A medium salt-water rod, good sized reel and 200 yards of line will be needed. Bait with small fish or use one of the salt-water spoon baits.

To tell what kind of tackle to use for each kind of fish when fishing near the Florida coast is not a practical way or rather it is not practical to give advice on tackle for this and for that fish. Down there one never knows what kind of fish he is going to catch, but as most of the ocean fish found there will run from twenty to eighty pounds in weight it is wise to use something that will handle these largest fish. All such fish as the black grouper, barracuda, amberjack, etc., are great fighters, and large reels equipped with long lines of suitable strength must be used. I will only mention what is considered good tackle for each fish and those who are thinking of going there can boil it all down strike an average, and select something just a little heavier. An outfit can be chosen that will answer for everything from the tarpon down.

The striped bass is one of the best game fishes found on the Atlantic coast and may be caught from Nova Scotia to the Gulf of Mexico. It sometimes reaches a weight of sixty pounds, but those taken in brackish water at the river mouths usually weigh only from three to ten pounds. It is found mostly along rocky shores. It is taken by surf casting all summer long, but the fishing is best in August and September. Shedder crab is used mostly for bait also eel tail and blood worms, but menhaden, shrimp, etc., will 
also catch them and in the South mullet is used successfully. For fishing in brackish water a regular black bass bait rod, 2

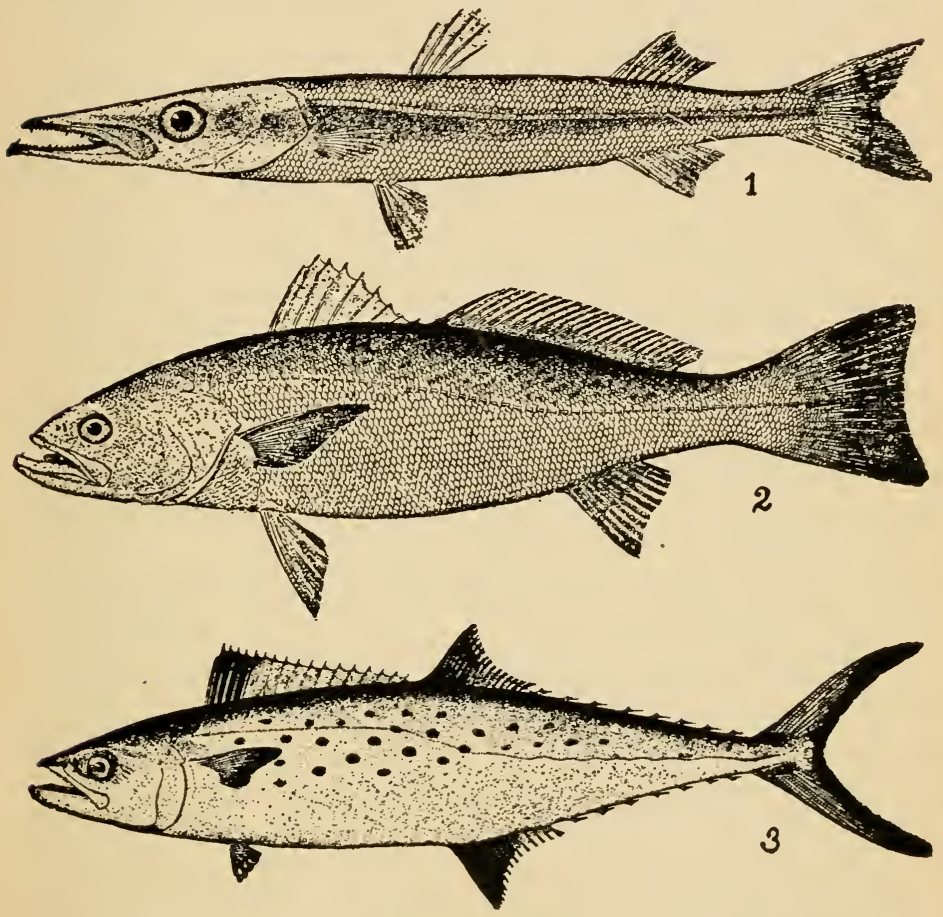

1-Barracuda ; 2-Squeteague, or Weakfish ; 3-Spanish Mackerel.

twisted linen line and a $2 / 0$ Sproat hook is commonly used. A good sized reel and a long line are always safest. The striped bass is a desperate fighter. 
The weakfish or squeteague is weak only in name. It is found all along the coast from the New England states to Florida. It grows to a weight of twelve pounds, but the usual weight is two or three pounds only. It is a surface feeder and is caught in the bays and channels mostly by trolling with the artificial squid and light tackle. It may also be taken by surf casting. The best fishing in channels is at flood tide or just before. Out in the open water the best fishing is at ebb tide. The best natural baits are shedder crab, killie, shrimp and worms. A linen line and $1 / 0$ to $3 / 0$ Sproat hooks and gut leader are the right kind of tackle. The weakfish has a soft mouth and must be played carefully. Use a landing net to get the fish into the boat. Perhaps the most successful way of taking them is by casting from an anchored boat, keeping the bait constantly in motion, as rowing is likely to frighten the fish. They are also taken by casting tin or bone squids with a hand line. They sometimes take the artificial fly. In the South a variety of this fish is called the sea-trout or spotted weakfish.

Channel bass or red drum are found from New York southward along the coast to Texas. It reaches a weight of seventy pounds, though the usual weight is from twenty to forty. It is abundant about the Carolinas and Georgia. It is taken by surf casting and by deep fishing. Light or medium salt-water rods, medium linen line and $4 / 0$ hook is about the right outfit. Shedder crab and shrimp are the most favored baits; menhaden and clam are also good. It is caught mainly in mid-summer, from July to October.

The black sea drum is found in the same waters as the channel bass. It is caught by surf casting, using clam bait. The size of this fish is about the same as channel bass.

The sheepshead is another Atlantic fish found from New England to Mexico. The average weight is about ten pounds in the North and six or eight pounds in the South, 
but it grows sometimes to a weight of eighteen or twenty pounds. It is a bottom feeder and a good food fish but not a long fighter. On light tackle it makes good sport. It frequents the shallow waters near rocky shores. A No. 2 Sproat hook, linen line, leader and regular black bass bait rod and reel is about the right thing. The large wooden reels are much used. It may be caught during flood and ebb tide from March to October on crab and clam bait.

The bluefish is the wolf of the sea as it is exceedingly voracious, preying on all kinds of fish smaller than itself. It sometimes grows to a weight of twenty-five pounds but averages about ten. It is found from Nova Scotia southward to the tropics. It may be caught on menhaden or killie bait by fishing from a boat and sometimes a grinder is attached to the side of the boat and one of the occupants grinds fish for bait, letting the minced fish fall into the water. This is called "chumming" and the minced fish attracts the bluefish to the scene. They may be caught by trolling a bone or metal squid at a lively clip. The bait must be kept in rapid motion or the fish will not take it. The squid may be cast from shore beyond the surf, using a stout linen line and a metal leader. The fish when hooked is simply hauled out onto the beach. After the squid is cast it is drawn in rapidly. For rod fishing use a light salt-water rod, and a good sized reel holding 200 yards of No. 12 linen line. Use a three foot metal leader and a 4/0 Sproat or O'Shaughnessy hook. The fish must not be allowed to get any slack line after he is hooked. Young bluefish or snappers as they are called may be caught on trout tackle and No. 4 Carlisle hook by fishing about three feet deep, keeping the bait in rapid motion. The fish run only from six to ten inches long. The best fishing is in early morning.

The red snapper is a bottom feeding fish of the South, common off the Florida coast. It frequently reaches a weight of twenty-five pounds. It is found near the rocky reefs 
and may be caught with light salt-water rod, 12 thread linen line and No. 4/0 O'Shaughnessy hook baited with crab, or shrimp or strips of shark or bluefish flesh.
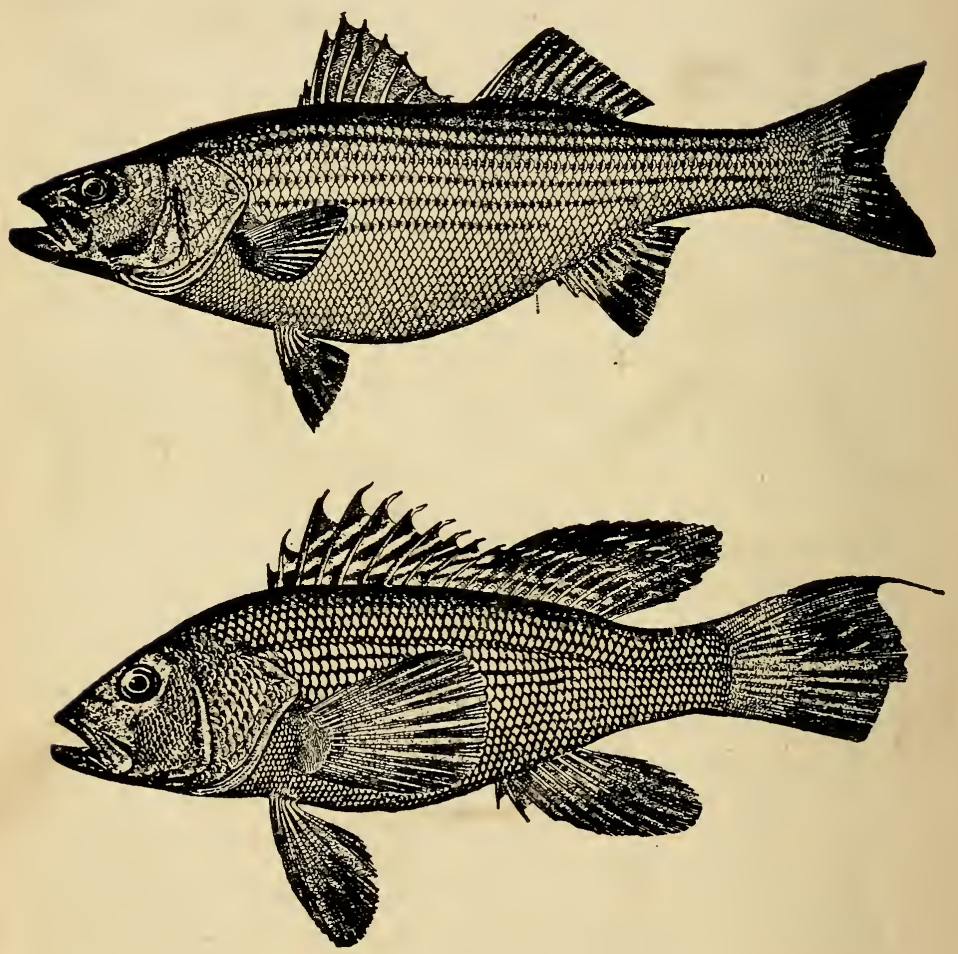

Upper - Striped Bass; Lower-Sea Bass.

The black grouper resembles the black sea bass, but it is found in the Atlantic from the Carolinas southward. It is 
caught by bottom fishing on heavy sea tackle baited with mullet and crab. It grows to a weight of 400 pounds.

The red grouper is found in the same waters. It is a bottom feeding fish reaching a weight of forty or fifty pounds. It is caught on medium tackle with crab and fish beit.

The great barracuda is a long, slender fish, reaching a length of six feet. It is found in southern waters though other species of barracuda are found as far north as the New England states. It is a surface feeding fish and is

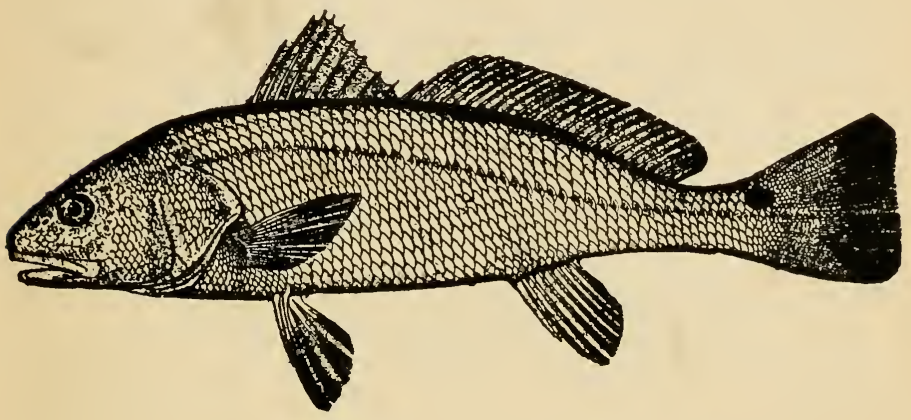

Red Drum or Channel Bass.

caught on tarpon tackle baited with mullet, or by irolling an artificial squid or a spoon bait.

A smaller game fish of the southern coast, and sometimes found as far north as Massachusettt, is the ladyfish. It weighs about two to four pounds. It is caught on a regular fresh-water bait rod or a light salt-water rod, 9 thread line, 2/0 O'Shaughnessy hook and wire leader, baited with crab or mullet.

The kingfish is caught on the same tackle, from New Jersey southward along the coast to Texas. It grows to a 
weight of twelve pounds. In northern waters the kingfish is not the same as these southern fish and does not get as large, seldom going over five pounds, and usually much smaller. For these common bass tackle may be used. The bait may be sand worm, shedder crab, shrimp or clam. The inshing is done from an anchored boat near rocky places.

The cunner is a small fish of about a half pound weight found in the North Atlantic and common on the New England coast. It is the same in salt water as the sunfish is in the streams, the delight of the boy fisherman, though despised by anglers who are after larger game as it takes the bait of any kind all too readily. Any kind of light tackle may be used for these fish.

The sea bass is found all along the coast from Massachusetts to Florida. it grows to about ten pounds, but the more common weight is from one-half pound to two pounds. It may be caught by bottom fishing near rocky reefs, baiting with clam, shedder crab or sand worms. Light salt-water tackle should be used, and a No. $1 / 0$ or $2 / 0$ hook.

The tautog is a popular bottom feeding food fish, common along the New Jersey coast, and known usually as blackfish. It is fished for from the rocks and precipitous shores, and from boats anchored near reefs. Clams, crabs and worms are used for bait. The fish weighs two or three pounds in near-shore waters, though it sometimes weighs as much as ten, and as high as twenty when caught in the open ocean. The best fishing is in April and May. The best time is during flood tide. Medium salt-water tackle and stout hooks, about No. 3 Virginia pattern, should be used for open sea fishing, and the same hook but somewhat lighter tackle may be used along shore.

A small fish called the spot or Lafayette is found in abundance all along the coast from New York southward. It seldom, if ever, goes over a pound in weight. It is a fine food fish and a good fighter. They are caught in large 
numbers in the brackish water at flood tide in spring and fall, and in less numbers during summer. A light bait rod, 9 thread linen line and No. 6 Pennell hook, with a light sinker six inches above the hook is a nice outfit for them. The hooks should be baited with small bits of clam or sand worms, and sometimes they take shedder crab. The bait should be just large enough to cover the end of the hook.

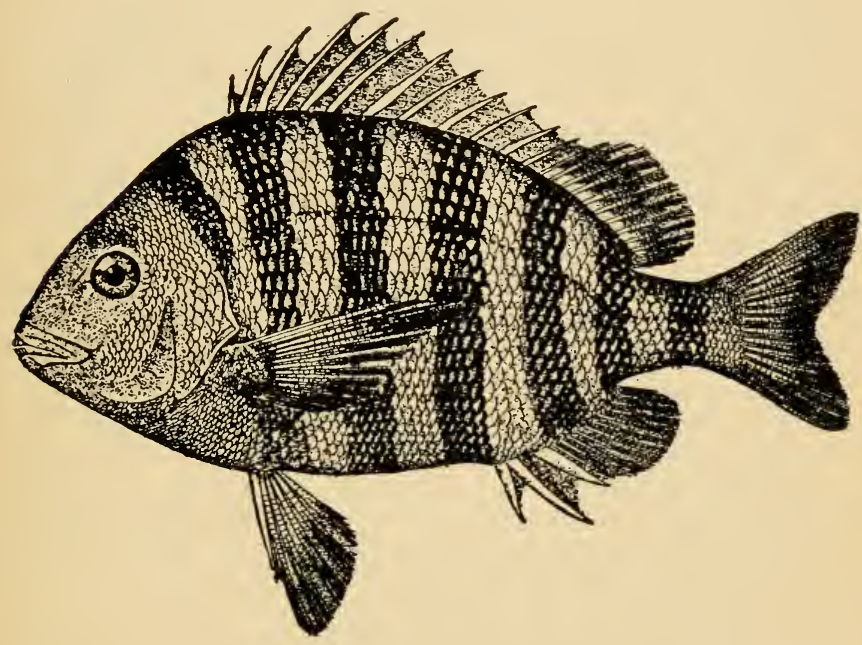

Sheepshead.

The porgy is another very common and very abundant fish, found all along the Atlantic coast. It is known also as sctip, and scuppaug. It weighs up to three pounds and is caught by bottom fishing in the channels, baiting with clam, small crabs, and sand worms. Light tackle and No. 6 hook is used. 
I might go on and speak of hundreds of other sea fish but all I could say would be of little value to anybody, as the limits of this work make very brief mention necessary. Those living near salt water know far more about saltwater fish than other people do, and if one is going there to fish he will do well to take advice from these anglers and note closely the methods employed. 


\section{CHAPTER XIX.}

\section{Making, Repairing, and Caring For Tackle.}

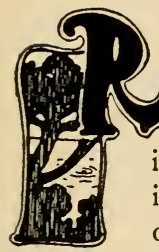

EPAIRING and caring for fishing tackle is of prime importance and by care the fine goods may be kept up for many years, and thus it becomes cheaper in the end, besides giving better satisfaction while in use. While the initial cost of fine tackle makes it necessary to dig down deep in the pocket-book it is possible for many anglers, those who are skilled in the use of tools and are careful workmen, to make much of their own tackle and thus save some of the expense, have high quality goods, and have the pleasure of making it besides.

I have, when speaking of rods, recommended the higher priced article, although I realized that many readers of this work would be unable to indulge in such luxuries. But by making your own rod you can have one equal to the highest priced article, and it will not cost more than half as much. It is possible for an angler to make a fine split bamboo rod, but it is difficult to fit the strips perfectly and at the same time keep the outside of the stick of proper dimensions, so difficult that I would not advise an amateur to try it, until he has had considerable experience in making solid wood rods. But the glued strips all ready for mounting and wrapping may be purchased so that even in this it is possible to save something.

As stated in the chapter on rods, there are three kinds of woods generally used in making fishing rods, and these are lanc:wood, gr enbeart, and bethabara. In England greenheart is the favorite rod wood, but in this country lance- 
wood is preferred by the majority of those who use solid wood rods. Bethabara is better than either in the opinion of most of those who have given the subject study, but rods of this material are more costly than those of lancewood or greenheart, therefore comparatively few bethabara rods are sold, but when buying wood from which to make a rod, the difference in cost is so little that there is no good excuse for taking anything inferior.

While I don't know what particular style of rod you are interested in, I take it that the majority would prefer to make a bait rod for the first, as it is more generally useful than any other kind, therefore I have drawn a diagram showing the measurements for a three piece bait rod which when jointed will measure about eight feet two inches. The dimensions of this rod make it very nice for all-around use. This diagram shows the three pieces in correct diameter, but very much shortened. To know how much it is shortened it is enough to state that the wood for the butt joint (A) is thirtytwo inches long and an allowance of one and a half inches for ferrule (the wood only goes to the middle of the female ferrule), will make this section measure $33 \frac{1}{2}$ inches over all. The second joint (B) measures 323 inches, and when ferrules are fitted will measure the same over all as the butt piece. It will be understood that the smaller caliber ferrules are also shorter, hence the difference in length of wood. The tip joint (C) measures 33 inches, which allows of one-half inch for the agate tip, but when finished each piece is the same length as the others.

'On the butt joint I have shown the diameter in fractions of an inch, and the spaces between measurements are four inches each. This makes the stick sixteen inches from the small end to the place where the swell of the handle begins A-1 shows the handle proper, $7 \frac{1}{2}$ inches long by 1 inch thick at its greatest diameter. Below this is a section $1 \frac{5}{8} \times \frac{3}{4}$ inch for a butt cap. A-2 is the space allotted for the reel bed. 


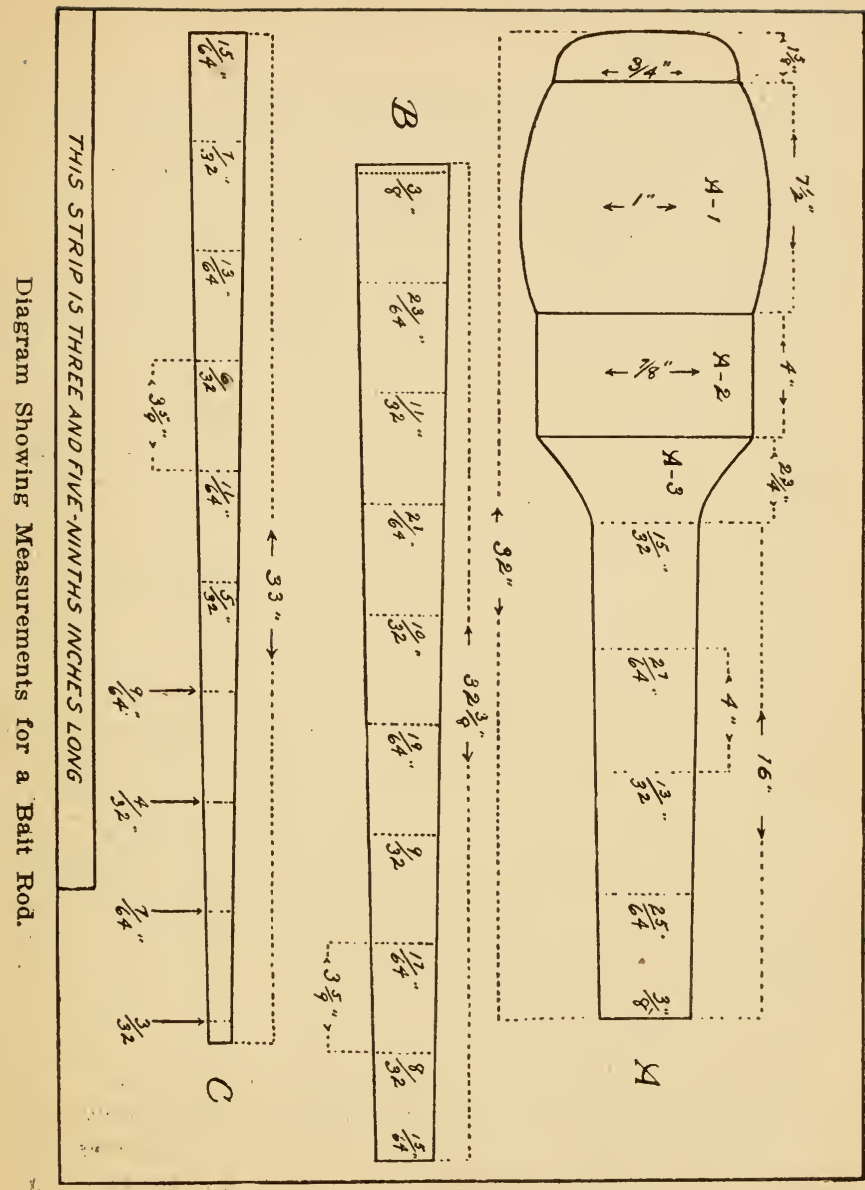


This rod is to have reel bands only, instead of a metal reel seat, and a place is hollowed out in this section for the bed of the reel. The movable band is placed farthest from the grip so that the reel is brought up close to be convenient for thumbing. This reel seat space is four inches long by $\frac{7}{8}$ inch thick. The tapered portion (A-3) is a graceful taper 23 inches long, from the diameter of the reel seat portion ( $\frac{7}{8}$ inch) to the diameter of the first measurement on the rod, or $15 / 32$ inch. This butt is to be made complete from one piece of wood, and properly finished will make a fine rod. If you don't like the hard, smooth wood grip, you can make it a trifle lighter and wind it closely and carefully with some dark colored twisted linen line, about 27 or 30 thread size. This will make a very good grip. Or you can make it still smaller, say three-fourths of an inch, and wind it with split cane, which you can buy from furniture upholsterers.

The middle joint measures $15 / 64$ inch at the small end and $3 / 8$ inch at the large end. The measurements on this joint, as well as the tip, are $35 / 9$ inches apart. Now, I realize that this is an awkward measurement and you are not likely to have any gauge that measures in unequal fractions, and to make this easy I have marked off a strip at the bottom of this diagram that measures exactly $35 / 9$ inches in length, the exact distance between these measurements on tip and second joint. The tip joint will measure $15 / 64$ inch at the heavy end and $3 / 32$ inch at the small end.

It has of:en been said that we have no native woods suitable for rod-making, that they are all too heavy, or too stiff, but I once saw a very fine fly rod, a light weight one at that, the tip and middle joint made of "juneberry," a wood found in the mountain district of the eastern states, and perhaps elsewhere. You may know this wood under somo other name, as I don't think that "juneberry" is right. It is usually more or less crooked and holds its thickness 
well, seldom grows to a greater diameter than eight inches has a rather smooth, dark bark, small leaves about like rose leaves in shape, but very smooth. It blossoms in May and later grows a small fruit, similar in appearance to a haw, but much smaller, say about like a wild cherry, first red and when ripe a sort of purple color. A wood that appears to be a dwarf variety grows in the North and is called saskatoon. This fly rod had the two upper pieces of this wood and the butt of sassafras, a strong and very light wood. Dr. Henshall recommends ash as a wood for the butt piece. White ash is very good for this and it can be procured without cost in most places, so that the only wood you will need to buy is that for the second joint and tip. For this you can purchase from any of the large fishing tackle dealers two pieces of square lancewood, four feet long, one piece $3 / 8$ inch in diameter for twenty cents, and another piece $1 / 2$ inch in diameter for twenty-five cents. Or you can get greenheart of the same sizes for twenty-five and fifty cents, respectively, or bethabara in these sizes for thirty and forty cents each. These as well as all other prices given, are only approximate and the actual cost will depend much on where you buy. If you prefer you can buy sticks already turned round and ready for finishing for about double these prices.

You will need two pairs of ferrules, the larger $3 / 8$ inch and the smaller $15 / 64$ inch. Plain, straight brass ferrules, not shouldered or welted, will cost five cents for the small size and ten cents for the larger, but you don't want these. When you go to the trouble of making a rod you want to make a good one, otherwise there is no satisfaction in making and using it, and there is certainly no saving in cost, for you can buy a cheap or medium quality rod, ready made, much cheaper than you can make it. Nickel-plated, shouldered ferrules of these sizes will cost about ten cents each. German silver shouldered ferrules will cost fifteen cents and twenty-five cents respectively. Weited ferrules (those having 
an extra thick edge to top of female ferrule) of this kind will cost five cents more each. Serrated and welted German silver ferrules, which are the finest thing you can get, will cost about thirty and forty cents, respectively.

I advise the use of German silver ferrules. They are harder and stronger than nickel-plated brass, and always look nice, while nickel plate will wear off in a few years and show the brass underneath. The welted ferrules are both handsomer and better than the plain ones, as the welt protects the edge from dents, and welted ferrules are the earmarks of a fine rod. Serrated ferrules have six long points on the end of each, and these points when covered with a wrapping, add greatly to the strength of the rod as the long points act as springs and keep the wood from being bent across a sharp edge, as it must when plain base ferrules are used. These are especially good for split bamboo rods, one of the long points fitting over each strip of bamboo, and they are easily fitted to the six-sided strip, something that is difficult with plain ferrules. What kind of ferrules you should buy for this rod I leave for you to decide, but I advise the best welted and serrated German silver ferrules. You will never regret the additional expense.

In addition to the wood and ferrules you will need for this rod you will want a $3 / 4$ inch butt cap of a material to correspond with the ferrules. If the latter are nickel-plated you will want a nickel-plated butt cap, costing about six cents, and if German silver ferrules are used, or even with nickel ones, you can use a German silver butt cap, costing twelve or fifteen cents. You must also have a set of reel bands to match the other mountings; these must be of $7 / 8$ inch size and in nickel plate will cost about ten cents; in German silver they will cost twenty-five cents.

In case you don't like to use reel bands you can fit a solid metal reel seat here. It will cost about twenty-five cents in nickel plate and sixty cents in German silver. A 
finer article with tapered hood and welted banc will cost forty cents for the nickel-plated kind and seventy-five cents for German silver. As stated before, these prices are likely to vary somewhat, depending on who you buy from and it is best to have catalogs from several dealers when making out your order. The reel bands described and recommended may be difficult to get in German silver, as few dealers carry them.

For guides you can use either the snake guides or two ring German silver tie guides. You will want seven of these and they should be of the three smallest sizes, the three nearest the tip of the smallest size, the two next of a size larger, and the next two a size larger still. Then on the butt piece, close to the ferrule you will want to mount a small adamant or imitation agate guide, and you will want a three-ring adamant tip, $3 / 32$ inch size. These guides and tip, the complete outfit, will cost in the neighborhood of sixty cents.

The other materials required are a stick of ferrule cement, costing about fifteen cents; a bottle of rod varnish, costing twenty-five cents; and two spools of winding silk at fifteen cents per spool. These may be any color desired. These are the only materials required, but if you want to keep the wrapping a nice color you will want a small quantity of white shellac to apply before varnishing. Varnishing the wrapping will darken it considerably. Also, if you use bethabara for second joint and tip and ash for the butt you must stain the latter before varnishing, as bethabara is a very dark wood and ash is white. I am not sure that you can stain it to the exact color, but advise that you see a paint store man about this staining. It doesn't matter a bit, though, whether it is the exact shade of the other wood or not.

Now, as I figure it, the material for this rod, using bethabara and ash, the latter of which you can get somewhere near home, will cost about three dollars and ten cents, 
and with fifty cents added for transportation charges, and twenty-five cents for shellac and stain; the entire cost would be three dollars and eighty-five cents, and with this material you can make a rod worth anywhere from ten dollars to fifteen dollars, and will have something to be proud of. I have made no allowance for an extra tip for this rod, but if you can stand it, you will do well to make the extra tip, for the tip joint is the most likely to break in use. This piece should be fitted with guides, but ferrule and adamant tip are not needed, as in case you break the other tip piece you can use the mountings on this one. It is true that you could also ase the guides, but the wrappings would have to be varnished and you would not only have to wait until you could find opportunity to do this work of mounting the guides, but would also have to wait for the varnish, two coats, to dry. If you have it wrapped, and guides fitted and all varnished complete, all that you need to do to make it ready for fishing in case you have an accident with the other, is to remove the ferrule and adamant tip, and place these fixtures on the extra tip. This requires only a few minutes, and it will be in condition for fishing immediately. To have this extra tip will only cost about fifty cents more.

The wood comes in square, rough strips. It is best to get them both thicker and longer than needed when finished, to work out any flaws that may appear, and I have made allowance for this. To make perfectly tapered and perfectly round sticks require careful and slow work. It is good to spend five minutes in measuring and inspecting for each minute of actual work. You will want a very sharp iron smooth plane, lightly set; a bastard-cut file, a flat millcut file; some No. 00 emery paper, and some coarser, say No. 1; a pair of outside measuring calipers that measure to 64ths. of an inch, or if you can't get this you can use plain calipers and a rule with these graduations; a small saw, a sharp pocket knife, a marking compass, and a bench 
on which to work. To hold the square sticks you will need - grooved board fastened on your bench. The groove should be such that a square stick will fit into it when placed corner down, and the easiest way to get this groove is to use two straight-edged strips of hard wood, with the two meeting edges on top planed off to a 45 -degree face, so that when placed side by side they make a sharp bottomed groove for the stick. You will also want a try-square, or what is still better, a bevel-guage. The first step is to square up your ash butt to one inch, the diameter of the handle, then find the center of each end by drawing straight lines across the end from corner to corner and where these lines cross is the center. If you can put the stick in a lathe you can turn this handle to shape with very little work, but if you don't have access to a lathe, take your compass and setting the point in the center of the end of the stick make a ocircle that just touches the edge on each flat side. Then draw a line across each corner just touching the circle and so placed that it throws an equal portion on each flat surface, and from end to end draw two perfectly straight lines on each flat side, making these lines strike the ends of the short lines drawn across the corners. If this is properly done you will have two lines lengthwise on each side of this strip, and each line will be the same distance from the edge. Now place the strip in the grooved board on the bench and carefully plane off each corner the entire length until your plane just cuts these lines. When this is done you have an octagonal shaped stick, and each of the eight sides is of the same width. Then you plane each corner down lightly and you have a stick with sixteen sides, and when these corners are carefully cut down you have an almost round stick. When the corners show very faintly it is best to use the file for cutting as a plane shaving may cut too much. 
Then on the butt make a $3 / 4$ inch circle and measure off $15 / 8$ inches, and round this portion down and round the end, and you have the butt shaped for the cap. Then you can shape the handle and the reel bed and then shape the slender part of this butt stick down, rounding it in the way described, and being very careful to make it measure exactly as shown in the diagram. This part must first be squared in a taper as shown, and then the corners planed down forming an octagon, but always keep the measurements right, and do the last rounding of corners with the

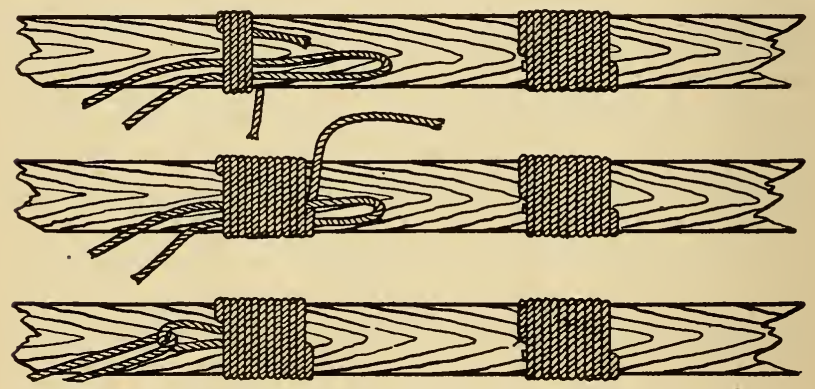

Regulation Method of wrapping a Rod.

flat file. The coarse file is used where you don't care to plane, and in shaping handle and butt, etc.

The second joint and tip must be made in the same way, by squaring the stick and bringing it to the proper measurements from end to end, then throw a circle on each end (you can't carry this out to the tip, but do it as far as practicable), then a line across each corner to form an octagon, and lines drawn with a straight-edge from end to end, then plane or file down to this line, etc.

When the sticks are shaped and rounded, smooth them down with fine sandpaper, but be very careful in this for 
sandpaper cuts fast and you only want to smooth the stick, not cut it down. It is best to not use the sandpaper on the end until you try the ferrules. When the ferrules can be put on with steady but rather heavy pressure, put the ferrules on and joint the rod up and see how one piece lines up with another.

If these are not in perfect line you must find where the trouble is, and remove the ferrule, then by use of the fine file, take a little off at the right place to relieve the strain, even though it makes the ferrule fit loosely. Then remove all ferrules, heat the end of your stick of ferrule cement and anoint the ends of the sticks, as far down as the ferrules will reach, then heat the ferrule and push it on as far as it can go. Many of the manufacturers pin the ferrules in addition to cementing, but I do not think it advisable. The cement will hold the ferrule securely, and in case you ever want to take the ferrule off, a pin is a bad thing.

After the ferruls are fitted, the tip and the reel bands are fitted and placed on (the two smallest reel bands are fastened, but the reel bed must be worked out first) and then the butt cap, after which, if the rod has not drawn crooked, give it a coat of varnish, but don't get any varnish on the metal parts, assemble the rod and hang it up by the tip to dry, but don't have it near a wall. When the varnish is dry you can wrap it with the silk thread and fasten the guides on in the same way. The guides are placed at varying distances, those nearest the tip, the smallest, being closest together. You will have to measure this off and divide it up perfectly. I might do this for you, but will leave it for you to do, for I don't want to make things too easy. See that all the guides are in perfect line with one another and with the tip. Wind them by either of the methods of winding here illustrated, waxing the thread lightly with pure white wax, and be sure that you have clean hands, and keep them clean until you are through. Examine each guide before you bind it on 
and see that the ends where the wrappings come are not sharp edged, or they will cut through the thread in time. Inen place the narrow wrappings between the guides, and over the ends of the ferrules. Here you will have to measure and space again, and it is best to make the bands of wrapping closer and wider midway between the guides, as this stiffens the wood at these places, just the same as the guides stiffen it.

I don't think it will be necessary to say much about
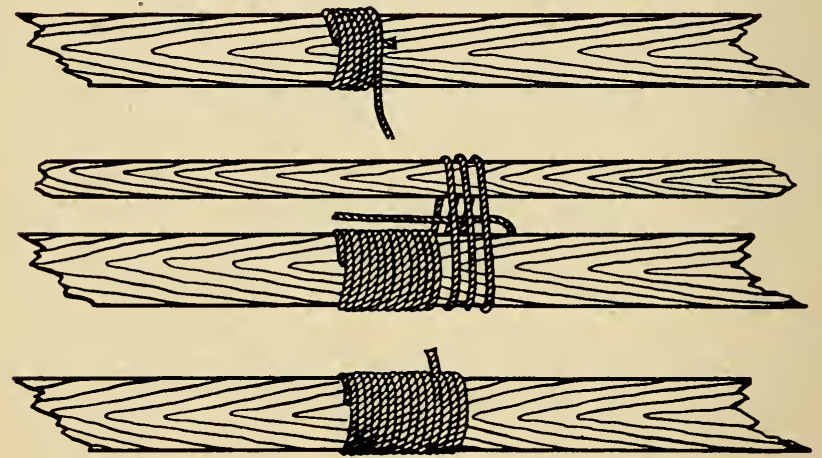

Another way to wrap a Fishing Rod.

these two ways of wrapping rods illustrated here as the pictures show it so plainly. The ends of the silk should be cut off very closely, but don't cut against the rod. The second method is best for wide wrapping as the thread cannot be drawn through under a wide wrapping if the first method is used, but the first may be used by winding to $\frac{1}{8}$ inch of the length of the wrapping before placing the small loop, and this is a very good way.

After this is finished go over each wrapping carefully with the white shellac and let this dry before you do any- 
thing more with it. When dry, give the entire rod, wrappings and all, but not the metal parts, another coat of varnish, and hang away to dry. A small varnish brush usually accompanies each bottle of varnish, but if you don't get this you must buy a small camel's hair brush. This last varnishing finishes the rod, but another coat will do no harm. Each must be perfectly dry before applying another.

When you buy fishing rod wood it is likely to be warped, especially bethabara. In such cases, before you do anything with it, just drive a small tack into the end, the center, and hang the stick up in a room, and in a few days it will be straight. If not, hang a weight on the butt and that will straighten it. Always hang your rod up after var-

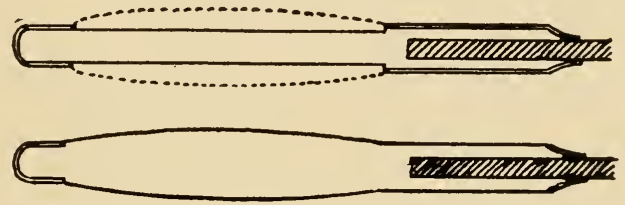

Construction of Separate Handles.

sishing and let it dry that way, and keep the room as even 2 temperature as you can. Never hang the rod near the wall while the varnish is wet.

In case you want to make the butt piece of the same kind of wood as the other joints, it is best to have this piece fitted into a handle of lighter wood. The rod should be cemented in and should be seated about four inches into the handle. In such cases the $23 / 4$ inch taper from reel seat to rod proper is omitted and a very short taper is used. This has a German silver taper fitted over it, thus hiding the joint. If you like you can get a solid metal reel seat (German silver) with a tapered end which covers the joint com. pletely and makes a very nice appearing rod. 
In regard to handles, those I described are very good, but they are all inferior to the solid cork grip. These are made by reducing the size of the handle to, say $3 / 4$ inch, and gluing on it rings of solid cork. You can make a cork handle a little thicker than a wood handle, say $11 / 8$ inch, as cork is lighter than wood. These cork rings, $1 / 4$ inch thick, may be purchased at about fifteen cents per dozen. Each one must be fastened to the other with cement and must be dried under pressure. After the glue is dry the cork may be pared down to shape with a very sharp knife, and smoothed with sandpaper.

If you want to make a split bamboo rod, as I said before, you can get the sections all glued up, in any size you want, and ready for mounting. These sticks will cost about seventy-five cents each. The butt length must be fitted into a wood handle as described.

A fly rod would be made in the same way as a bait rod, but of course the handle is somewhat different and the reel seat is below the handle. Different mountings will be needed, that is, for the handle, but a description of these with prices, will be found in the catalogs. Here are the dimensions of a fly rod that will suit the majority. Length over all $9 \frac{1}{2}$ feet; length of each joint, including ferrule, 39 inches; reel seat $11 / 16$ inch by $3 \frac{3}{4}$ inch; handle, cork, 1 inch by 5 inches; taper from cork to rod, $\frac{1}{4}$ inch long; diameter of first joint at taper, $13 / 32$ inch, at small end, $9 / 32$ inch; diameter of second joint at large end, $9 / 32$ inch; at small end, 11/64 inch; diameter of tip at large end, 11/64 inch; at small end, 5/64 inch. It should have nine bronzed steel snake guides of three or four sizes and a small agate or adamant first guide near the ferrule on the butt piece, also an agate or adamant tip. This rod will weigh about six ounces.

To get the other dimensions of the stick make two perfectly straight lines, say one-fourth of the length of each 
joint, putting them the proper distance apart at each end, and these three sets of lines will represent the three pieces of the rod. Now divide each set of lines into a number of equal length parts, say one inch, and these parts will represent corresponding parts four inches long on the respective joints of the rod. Now, if you take the measurements at each one of these inch marks, you will have the exact measurements for every four inches of the rod piece; just like I did in the diagram of the bait rod.
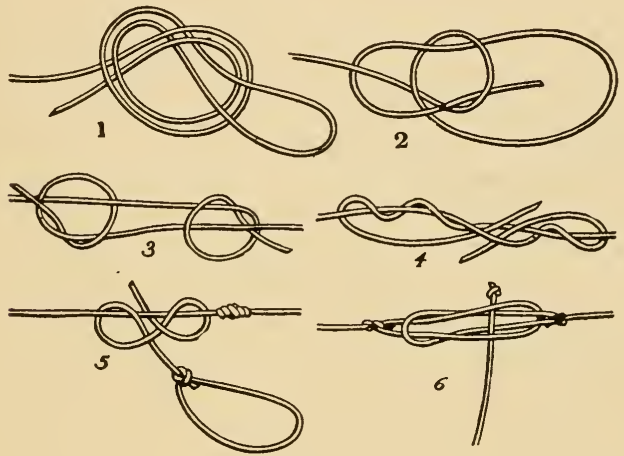

Leader Knots.

I know a man who made a very nice twelve-foot, fourpiece rod of ironwood. Ironwood is quite heavy and stiff, but he worked it down to a small diameter. He did a lot of fishing for pike and made this rod for that use. I imagine such a rod would suit a lot of fishermen who are not expert at bait-casting. Short bait-casting rods are also made of ironwood sometimes.

There is much in the way a rod is handled and cared for. I cannot say all that might be said on this subject, but 
can give a few remarks on the most important. First, don't throw your rod down, especially in sand or on stones - it is a delicate affair and deserves better treatment. Don't get the rod wet oftener than necessary. In jointing up, always put the tip and second joint together first, then attach the butt. Always take your reel off the rod when through fishing and don't put it on again until you are ready to commence fishing again. See that the several pieces of the rod are put together with the guides in perfect line. The ferrules usually have little marks to show, but don't twist one joint to bring these in line-remove it by a straight pull and replace it right. Always joint the two pieces by a straight push and separate by a straight pull. When you unjoint the rod, separate the tip and middle joint first. Wipe the ferrules with an oiled rag once in a while and they will come apart easily when you want to dismount the rod. Keep the rod on the form, generally, but in case you find a joint is warped a little, assemble the rod and hang it up by the tip a few days and it will straighten. Perhaps the ceiling of your room is not high enough, but if so, put the middle joint and tip together and hang them up. A solid wood rod should be rubbed lightly with vaseline about every six months, and then burnished with the palm of the hand until it gets hot. Before the fishing season commences, go all over your rod and examine the wrappings, and if they are frayed, rewind them. If the varnish is looking bad, revarnish it completely. If the ferrules or tip are loose, heat them a little with a match and you can remove them, then cement and replace. The reel also needs attention. Oil it once in a while, and if it is used for bait-casting oil it every day while in use, using a medium cylinder oil. For other reels some light fine oil will be all right.

After fishing, always remove your line from the reel and dry it thoroughly. Your line will last much longer if you do this. An enameled line is supposed to be perfectly water- 
proof, but it needs drying just the same, and it is not good for the reel either to put it away with a wet line on it. Too much oil in the reel may also injure the line.

Don't forget to wash out your fish basket after you get home from fishing, and hang it out to dry before it is put away. If you don't wash the basket it will have a nasty odor when you want to use it again.

If a joint of your rod sticks too tight you can reduce the size of the male ferrule by rubbing lightly with the finest emery dust, or with pumice stone, but be very careful as
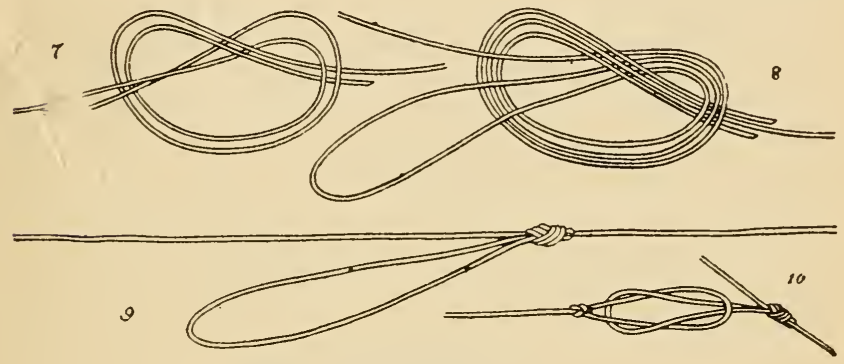

More Leader Knots.

emery dust cuts German silver rapidly. And be sure that the ferrule is really too tight before you attempt this. Ordinarily if they are oiled slightly now and then there will be no trouble whatever.

In bait fishing the line is usually the weakest part of your tackle, but in fly fishing it is the leader in which the weakness lies, therefore it should be of the finest quality. Many anglers prefer to make their own leaders. For this purpose you can buy the silkworm gut in bunches of 100 strands, in any weight from the lighest to the heaviest. This will cost from fifty cents to two dollars a bunch. 
The way to make a leader is to soak the gut several hours, usually over night, in clear water, then selecting a number of the most perfect, clear, smooth and even-thickness strands, tie them together, rejecting the bad ends, using the heaviest strand and the heaviest end of it at the line end; the next heaviest by its thickest end to this, and so on until it is long enough for your use. In the illustration of knots the first one shows the way the loop is tied in the end, but figure 2 shows a better one. Figure 3 shows a way of tying the gut strands together that was much used at one time, but

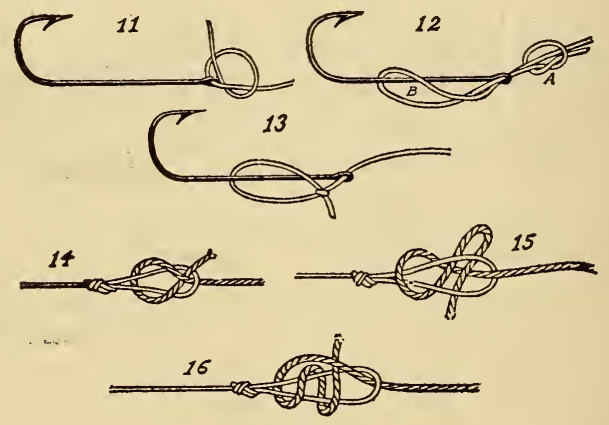

Hook and Leader Tying.

there are other methods that I think are better. Figure 4, for instance, shows a fine knot for this purpose. You must get the twists of even length at each end and then draw the knot tight by a quick jerk on the two long ends. You can make your leader in three-foot sections with loops at each end and fasten them together as in figure 6. This makes. a convenient way of attaching a dropper fly, as shown. Or you can make the leader in one length with a loop tied on as shown in figure 5 , for attaching the extra fly. The best way of all, though, I think, for tying the strands together and 
making a dropper fly loop, is shown in figures 7,8 and 9, and figure 10 shows how the dropper fly is looped on, by running the loop through the loop of the fly, then the fly through the leader loop, and drawing tight. This leader knot is as good as the twist knot shown in figure 4, and there is not so much waste, as it may be tied nearer the ends. All loose ends must be trimmed off closely after the knots are drawn perfectly tight; you can use a pair of pliers for drawing up the knots, using them on the short end of the gut only and holding the long piece in your hand. If you were to use the pliers on the long end you would injure the gut. It is not necessary to put the leader to any severe test after it is finished as this would strain it, and if it stands drawing the knots tight, and shows no imperfections in the gut, you will know that it is strong without testing. Anyway, if you test it once and it stands a five-pound strain, you don't know what it will stand the next time, but very likely it will not be so strong.

For attaching eyed flies to the leader, the latter should have no loop at the end where the fly is fastened. There are a number of knots suitable for attaching flies and hooks but figures 12 and 13 show the best ones.

Figures 14,15 and 16 show three good ways of fastening the leader to the line. These are all secure, especially 15 and 16 , so you can use safely whichever you choose.

There are many other things regarding tackle making that I would like to speak of, but I could only mention these briefly. Many of you are interested in nets of one kind or other but I could not go into details and tell how to make each kind of net used in fishing, therefore I will only tell how to tie the knots and how to go about making a net, and you can make any style you choose. A landing net can be made very easily, and will be good to try it out on.

You must make a shuttle or needle of hard wood, and it may be of either of the patterns showr in A, B and C. 
You must also have a gauge stick like figure $F$, of a width equal to one side of the squared mesh of the net you have in mind. A one-inch square mesh, which would be two-inch stretched mesh, would be one inch on each of its four sides and you would want a gauge stick one inch wide.

You will need a heavy line around the outside of your

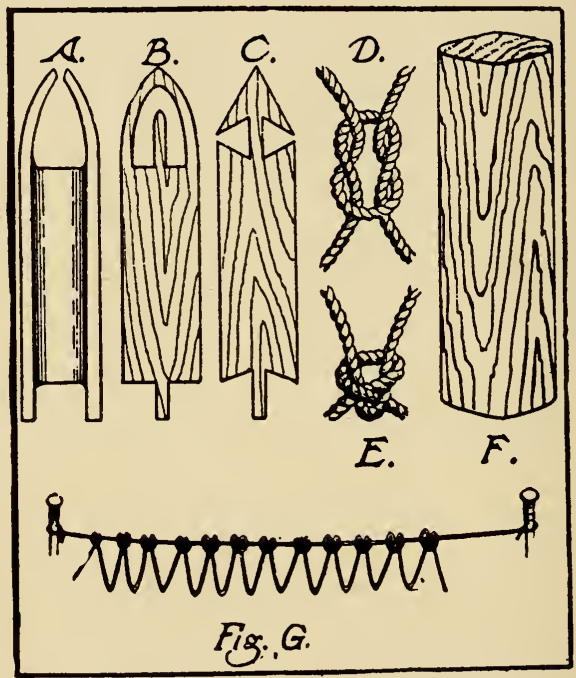

Net Knots and Needles.

net, no matter what kind you are making, so you can stretch up a line a little longer than need be for the finished article, then measure and see how many meshes will be red quired for the length. For instance, if your landing net frame measures thirty inches in circumference, and you want to make a one-inch square mesh, there will be thirty meshes 
required. This stage and the way the first round of meshes is made is shown in figure $G$. The next row fastens in these loops. Figure D shows the common square knot, but this is not the best, as it will slip if there is much strain on it; $E$ shows a better one. Figure $\mathrm{H}$ shows the way the net is tied along from mesh to mesh. A landing net can be knit right on the frame and you can tie around and around, until you get it deep enough, then tie the bottom shut square, like a

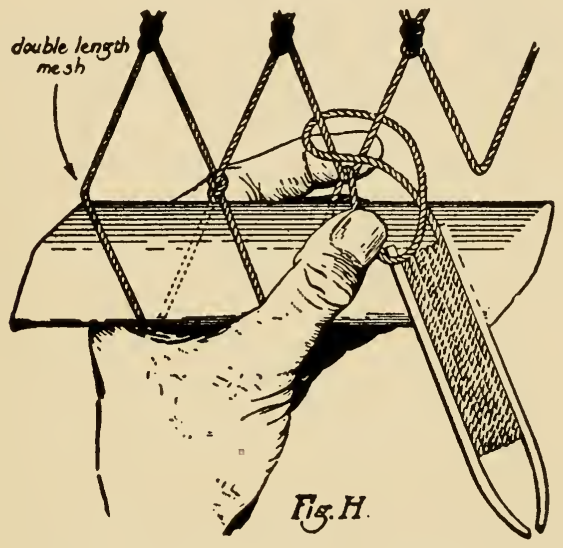

Tying the Net, end Use of Gauge stick.

bag. In knitting back and forth on a long flat net, like a seine or a gill net, tie one row of meshes from one side and the return row from the other side. Any kind of net can be made in this way.

There are many other things that an angler can make; he can make his own tackle box, his own flies, sinkers, gaff hook, and even spoon baits or plug baits. But I must leave these for the energetic ones to figure out for themselves and the others will need no instructions. 


\section{CHAPTER XX.}

\section{General Information and Advice.}

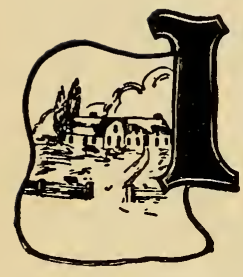

$\mathrm{N}$ writing the preceding chapters I omitted a number of little things that I meant to mention, and there are others that do not come under the caption of either of those chapters, so I will collect them all under the heading above. This advice, like all that given throughout this book, is parted with freely, for there is nothing else which I take so much pleasure in the giving of, as advice, but, while it may appear that I am talking like an authority on these subjects, it should be understood that this is only my way of saying things and my advice should not be taken too seriously without investigating elsewhere. But there are some few things on which nearly all anglers agree, and I will try to not have my advice conflict greatly with that of other writers on angling subjects.

Throughout this work when speaking of fishing tackle, it will be noted that I have recommended the higher priced goods frequently, and this is one of the subjects on which all will agree, that the highest quality is the cheapest in the end. One may economize in almost anything else with less bad effect than to practice economy in buying fishing tackle. Of course there is a limit where real worth stops and fancy finish and expensive handwork begins, just as there is a limit in the other direction, and I do not advise going beyond this limit unless you can well afford it. For instance, you can get a first-class casting reel at from five to ten dollars, ore that will last a lifetime, but if you get a cheaper one it 


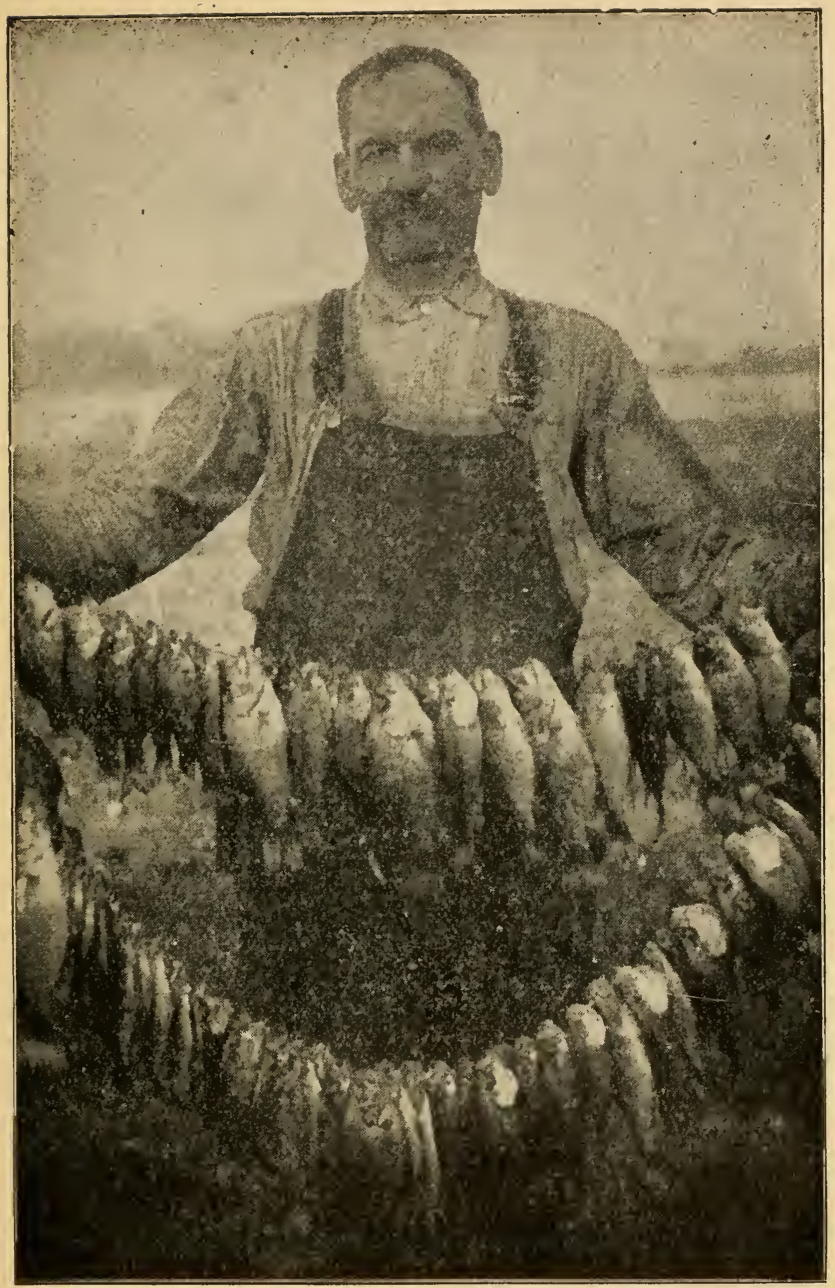

A Catch of Croppies (Strawberry Bass or Calico Bass) from Huffman Lake, Indiana. 
may be that it would wear out in five years of use, or it might not give the general satisfaction of the more costly article. Again you can get a casting reel for fifty dollars, that is a thing of beauty, and will last several lifetimes - 2 reel that you will take pride in, yet there is a difference of forty or forty-five dollars between this and the standard, medium priced reel. Now, it is for you to decide whether you should pay this high price, for to the average fisherman there would not be that much difference in the actual worth of the two. If I were a wealthy man and were buying a fishing outfit, I would buy the very best, but as it is I must be content with less costly goods. However, I will buy the best that I can afford and try to be content.

Now it is the same way in regard to rods - you may pay a high price for a name, a fine finish, and the knowledge that the rod was made by hand, for many of us cannot tell handwork from machine work in any way except by the price. Say for instance we buy a fine handmade split bam. boo rod, made of the most carefully selected stock, one that bends perfectly, has just the right action, and all that, and we lay out twenty-five or thirty hard earned dollars for it; the chances are that we have paid more than the rod is worth to us, perhaps more than its intrinsic value, and certainly more than a poor man should put into a rod. One costing eight dollars (these figures as well as others given are only approximate and for purpose of illustrating) would have done just as well for actual fishing, and unless we are rod critics we would never find anything wrong with it. It would cast perfectly, for fishing purposes at least, would balance nicely, and to all purposes would be first-class. But, then, if we go too low we get something that it is not policy to buy, a rod with the strips sawed out and not selected; as a result the grain runs across the stick in many places; the wood is female bamboo, always inferior to the male stock; there will te knots close together on two or three strips, in 
places; the ferruls are of the cheap kind, light and nickel plated; the joints do not line up well; one joint bends too much for another; it is poorly wrapped; and other faults will appear if we look far enough. Perhaps this rod has only cost two dollars, but it is not cheap at that price. The idea is that good work and good materials are bound to cost a certain amount more than poor work and poor quality goods. The best, not necessarily the best finished, is always cheapest in the long run, but the cheapest is never the best, either in start or finish, and both start and finish are usually close together. Now nobody hesitates to buy a repeating rifle for hunting big game for a few weeks in the fall, paying say fifteen or twenty dollars, perhaps more, for it. In addition he has to frequently pay for a license for hunting, which is seldom required of resident anglers, and even non-residents are not charged as much for a fishing license as for a license to hunt big game. Yet he cheerfully pays this sum for his little hunt each fall, sometimes only every second season, and yet he hesitates to put fifteen or twenty dollars into a fishing outfit that can be used on any available occasion during the entire spring, summer, and fall, a fishing kit that will give you more real sport and more for the money invested than any big game hunting outfit. Again you will pay even more than this for a shotgun, and don't expect to get a reasonably satisfactory shotgun for much less than twenty dollars, yet you hesitate to pay half that amount for a fishing rod. I think this inconsistency can be explained by the fact that there are so many cheap rods and reels offered for sale that those who have not studied the subject imagine that they can get a first-class article for a very low price, and also by the fact that many do not know what a good rod should be.

But regardless of what I have said here, there are very many to whom the initial outlay is something that simply must be considered, and they cannot go abnve a certain 
price. To such my advice is: get the best you can for the money and be content. If you cannot put more than two or three dollars into a rod, get a solid wood rod and if it is bought from a reliable dealer, you will have a good article, better than a cheap split bamboo, and something that you need not be ashamed of, either. If you take good care of it it will last many years, perhaps more years than you will be able to fish. If you cannot put more than a dollar and a half into a fly reel, you can get a really good one for that price, and if you want a multiplier you can get a good one, not a fancy one, understand, for two or three dollars. And then if you have never done much fishing, I advise that you purchase only a cheap outfit to use for a year or two, until you learn to use it properly and to take care of it. By the end of that time you will not need my advice, for you will know exactly what you want. But buy what you can afford for you will not be happy in using an outfit that cost more than you could well afford to pay.

Another thing regarding the use of high priced versus low priced goods, though not exactly under that heading, is your way of looking on and criticizing your companion's outfit. Though your own may have cost ten times as much as that of your companion, don't spoil his pleasure by speaking lightly of it, or don't in any other way let him know that you consider it inferior to yours. Better by far speak favorably of it, even though it does not so impress you, but you can surely see some good points in it, and you will make him feel better by mentioning them. Let him discover the faults himself; it will be more impressive and he will like you better.

Another thing regarding your conduct when fishing in company of others that is good to remember is that it is not a good idea to stand and watch a man play a fish and tell him to do this and do that, and then if he loses it, tell him that if he had done so and so he would not have 
lost the fish. It won't do you any good, and he will not learn any more quickly than if you had waited for a favorable opportunity to tell how you captured one of the big fellows in the past and how, by a certain move (the one that he failed to use) you succeeded in landing him, making this point entirely responsible for your success in taking the fish, and how you have remembered and used that method ever since. He will think it over and will see that this is just where he failed, and he will profit by your little story and no harm done.

Always have respect for the views of your companion. Although you may have had as much experience as he, or even more, that is no reason why you should think him wrong. Remember that anglers often see things differently, and sometimes the point at issue is of no importance as is proven by the fact that though your ideas on the subject differ, your catch of fish is the same. And even with your greater experience your friend may have learned something that you have overlooked for years.

A true sportsman does not like to see his catch suffering a slow death, and hesitates at anything else that appears cruel. He kills the captured fish at once and this is the more humane way. There is another reason why you should kill the fish as soon as they are caught - they are better for food purposes. A large fish is instantly killed by a sharp blow on the back of the head, well behind the eyes. Large hard-headed fish like muskellunge and pike should be shot.

It is a very good idea also to keep well informed on the laws regarding fishing, and see that you do not break any of them, thus keeping out of trouble and setting a good example for others. In most states it is unlawful to keep game fish under a given size, and you should remove these with as little injury as possible and return them to the water. Even if there is no such law in your state it is better to return the small ones. If all anglers would observe this 
rule there would be more large fish to catch and better sport for all.

There is always much talk among fishermen about "the big one that got away," so much indeed that the man who tells of losing a big fish is invariably put down as a prevaricator. But it is true nevertheless that it is the big fish that are lost, if I may use the word that way, for, as "Father" Izaak said, we can't lost what we haven't got. The big fish is harder to hold simply because he is big and strong and the tackle that will easily bring to hand a dozen smaller fish, may give way to the lunges of the big fellow. So you see it really is the big fish that gets away. But if anglers in general would realize that it is the successful landing of the fish rather than luring it into taking the hook, that is the real test of a good angler, there would be fewer of these tales. It is possible to land a very large fish with very light tackle, if it is rightly handled.

Before you start fishing look carefully over your tackle and see that you have not forgotten something. Be sure you take your lunch, but none of the "bottled stuff". If you smoke, don't forget your pipe and tobacco, as well as matches, for you will not enjoy your fishing so much if you forget these. If you have time look over your clothing and see that there are no buttons missing, and no holes in your pockets. Take your pocket knife, also some string, and examine your boots if you are going to wade, to see that they don't leak. These may seem like unimportant details, but really they count a great deal.

The nice appearance of your fish when you reach home and display your catch proudly to the members of the family will depend on the way you care for them after catching. The fish should be kept cool and moist, but you should not wet them after they are taken from the water and placed in the creel. The secret of it all is in so fixing the fish that they will retain the moisture on their bodies, and 
to do this there is nothing better that I know of than the long dark moss growing on the bottom of swift mountain streams, washed free of sand, wrung as dry as possible and put in the basket in such a way that it forms a thick lining. Lay the fish in this nice and straight, all on their backs, and put a layer of the moss over them. You can carry them all day and when you get home and open up the basket you will find the fish firm, cool and moist, with their pretty colors unmarred. I have been thinking of trout fishing when writing this and I realize that the greatest number of fishermen fish where this moss cannot be found. As a substitute, equally good, use large green dock leaves, a good thick lining and they will answer the same purpose. Don't use grass or fern if you can get either of these others, as these spoil the appearance of the fish. If you are on a trip of several days' duration you should dress your catch as soon as possible after catching and pack them in cool, damp moss, back down. 


\section{CHAPTER. XXI.}

\section{Commercial Fishing.}

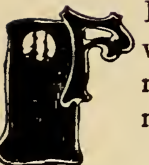

ISHING for market, or commercial fishing is a vast industry in the United States, so large that many readers of this book will look with amazement at some of the data given in this chapter.

The entire country is divided into five main divisions as follows: Atlantic Coast, Gulf of Mexico, Pacific Coast, Great Lakes and the Mississippi River and its tributaries.

The fisheries of the Atlantic Coast division empl oyed 94,281 persons, and a capital investment of over $\$ 25,000,000$, with a value of fish products caught in one year amounting to $\$ 35,475,000$. The Gulf of Mexico division employed 15,481 persons, with a catch valued at $\$ 4,825,000$. The Pacific Coast division employed 18,855 persons, with a catch valued at $\$ 6,839,000$. The Mississippi River division with 11,731 persons employed and a catch valued at $\$ 3,125,000$. The Great Lakes division with 8,533 persons employed and a catch valued at $\$ 3,767,000$.

Of the total number of persons engaged in the fishing industry of the United States in 1908, 25 per cent. were employed on fishing and transporting vessels, 73 per cent. in the shore and boat fisheries, and 2 per cent. as shoresmen, directly connected with the catching of fish. In addition to the foregoing there were 2,952 proprietors, not engaged in fishing.

The Atlantic Coast division was by far the most important in the United States, giving occupation to 66 per cent. of all the persons engaged in fishing, the Gulf of Mexico 
division next, where 11 per cent. of the total number were employed. The Pacific Coast division, and the Great Lakes division follow in the order named.

Some inland fishermen work for wages, with apparatus and board furnished; others are paid by the bushel, or according to the weight of their catch. In some coast fisheries men are given $\$ 25$ a month and board while employed, the value of the board calculated at $\$ 10$ a month.

Nearly seven-eighths of the value of fishery products of the United States are represented by 30 kinds of products. The products here considered are the following:
Alewives.
Bluefish,
Halibut,
Carp,
Catfish,
Clams,
Cod,
Crabs,
Flounders,
Haddock,
Hake,
Herring,
Lake herring,
Lake trout,
Lobster,
Mackerel,
Menhaden,
Mullets,
Mussels,
Oysters,
Pike-perches,
Pollack,
Salmon,
Shad,
Shrimp and prawn,
Snappers,
Sponges,
Squeteague,
Sturgeons,
Whale products,
Whitefish.

Alewives - One species of this fish is found in waters adjacent to the Atlantic ocean, and never found south of the Neuse River in North Carolina. It is known along the Potomac as "branch herring", on Albemarle Sound as the "big-eyed herring" and the "wall-eyed herring", in New England as "Alewife," and on the Connecticut River as "ellwife" and "ellwhop." It appears in the rivers three or four weeks earlier than the "glut herring" and the shad. The other species of alewife is found from the Carolinas to the Coast of Maine. It is known in Chesapeake Bay and Albemarle Sound as "glut herring," in the Ogeechee River as "English herring", in the St. Johns River as "her- 
ring", and in Massachusetts and during the later runs in the Rappahannock as the "blueback." This species is less abundant and less valuable as a food fish than the former. Both species average about a half pound in weight and from 8 to 10 inches in length. They are caught in nets, seines, weirs, etc., and besides being of great importance as food fish, are also used for bait. The name "alewife" is applied to the menhaden in Delaware, Maryland and Virginia. The value of the alewife catch in 1908 was $\$ 589,000$.

BLUEFISH - This fish is found on the Atlantic and the Gulf coasts. On the coasts of the New England and Middle States it is generally called "bluefish"; in Rhode Island, "horse mackerel"; south of Cape Hatteras, "skip-jack"; in North Carolina, Virginia and Maryland, "tailor" and "greenfish"; and on the Gulf of Mexico, "bluefish." The bluefish varies in weight from 1 to 20 pounds, according to the season and locality, and large numbers are caught during the summer months with nets, traps, seines and hand lines. The name "bluefish" is also improperly applied to the squeteague from southern New Jersey to Virginia, to the black sea bass at Newport and New Bedford, to the "greenfish" on the California coast south of Monterey, and the "bonito" in the markets. The value of the bluefish catch in 1908 was $\$ 506,000$.

Buffalo Fish - Under this general name are included three species; red or big-mouthed buffalo, black or mongrel buffalo, and small-mouthed or white buffalo. The fresh-water suckers, to which the name "buffalo carp" is sometimes erro. neously applied, are found in the waters of the Mississippi Valley. They frequently weigh from 30 to 40 pounds and are caught with nets and hand lines. The value of the catch yearly averages half a million dollars.

CARP - This fish, known as "German carp", is a freshwater food fish of great interest to fish culturists, and is found in ponds and streams in nearly every state in the Union. As a result of domestication several varieties have 
arisen of which the principal ones are the "scale carp", heavily scaled; the "mirror carp", with a few series of very large scales; and the "leather carp", which is scaleless. The size of the carp varies with the temperature and clearness of the water, the kind of bottom, the abundance and nature of the food supply, and in general with the conditions under which it lives. These fish live to a great age, and sometimes attain a weight of more than 40 pounds. The carp naturally thrives best in lakes, ponds and sluggish streams, seeking quiet or stagnant waters. It spawns about June. It feed largely on vegetable matter, insects and their larvae, found on aquatic vegetation, forming its principal animal food. It will, however, eat practically anything it can get into its mouth, rooting about in the mud much in the way of a pig.

The German carp product in 1908 amounted to $42,763,000$ pounds, valued at $\$ 1,135,000$. Of 38 states having fisheries of a commercial nature, 31 reported German carp. The catch of Illinois, most of which was from the Illinois River, exceeded that of all other states combined. Although carp is caught to some extent throughout the year, the largest part of the fishing is done in spring and summer. A variety of apparatus is used in taking carp, but the bulk of the catch is made with seines, fyke and hoop nets, and trammel nets.

CAtfish - The american species include the sea catfishes of the Atlantic coast, the channel cats of all the rivers east of the Rocky Mountains, the horned pout, which is widely distributed through the brooks and ponds of the states, and the diminutive mad-toms. The different varieties are distinguished by the common names of "channel cat", "blue cat", "Mississippi cat", "mud cat", "flannel mouth", "horned pout", "bullhead", "minister", "goujon", "bashaw", "gafftopsail", etc. They vary in length from 1 to 5 feet and in weight from 2 to 150 pounds, are caught by means of nets, traps, hand lines, and by jugging, and are used extensively for food. Catfish are taken in nearly all waters of the 
United States, the majority coming from the Mississippi River and its tributaries. In a canvass of 38 states all, with the exception of four New England states, reported this fish. The catches reported from Louisiana and Illinois greatly exceeded those from other states.

Clams - This term includes the hard clam, quahaug, or round clam; soft or long clam; razor clam or razor fish; surf, sea or hen clam, and various other species. Clams are bivalve mollusks largely used for food and bait, and are found on all our coasts. The clam product of the United States is valued at about $\$ 2,000,000$ annually. While the quantity of the hard-shell variety but little exceed that of the soft-shell, the value of the former is about two and a half times that of $t^{2}$ e latter.

Razor clams are reported from Washington and Massachusetts, and surf clams from New York and New Jersey. Hard clams are reported from all the Pacific coast states, from Florida and Louisiana on the Gulf of Mexico, and from all the Atlantic coast states except Maine and New Hampshire. The entire soft-clam product with the exception of a small per cent. of the total, taken in California and Oregon, is taken from the North Atlantic Coast, none being reported south of New Jersey. The clams are taken with tongs, dredges and similar apparatus.

COD - The cod is caught most extensively along the coast of the Middle States, New England, and British America, and is not taken in the Atlantic Ocean south of New Jersey. It is most plentiful on the Grand Banks and off the coast of Newfoundland and New England. The weight varies from 3 to 75 pounds. The Alaska cod is found in the Pacific Ocean from Behring sea to Oregon. On account of the length of the trips made by vessels in the Pacific coast fisheries, often extending over a period of several months, the fish taken are salted on the vessels. Massachusetts and Maine furnish the salted cod from the Atlantic 


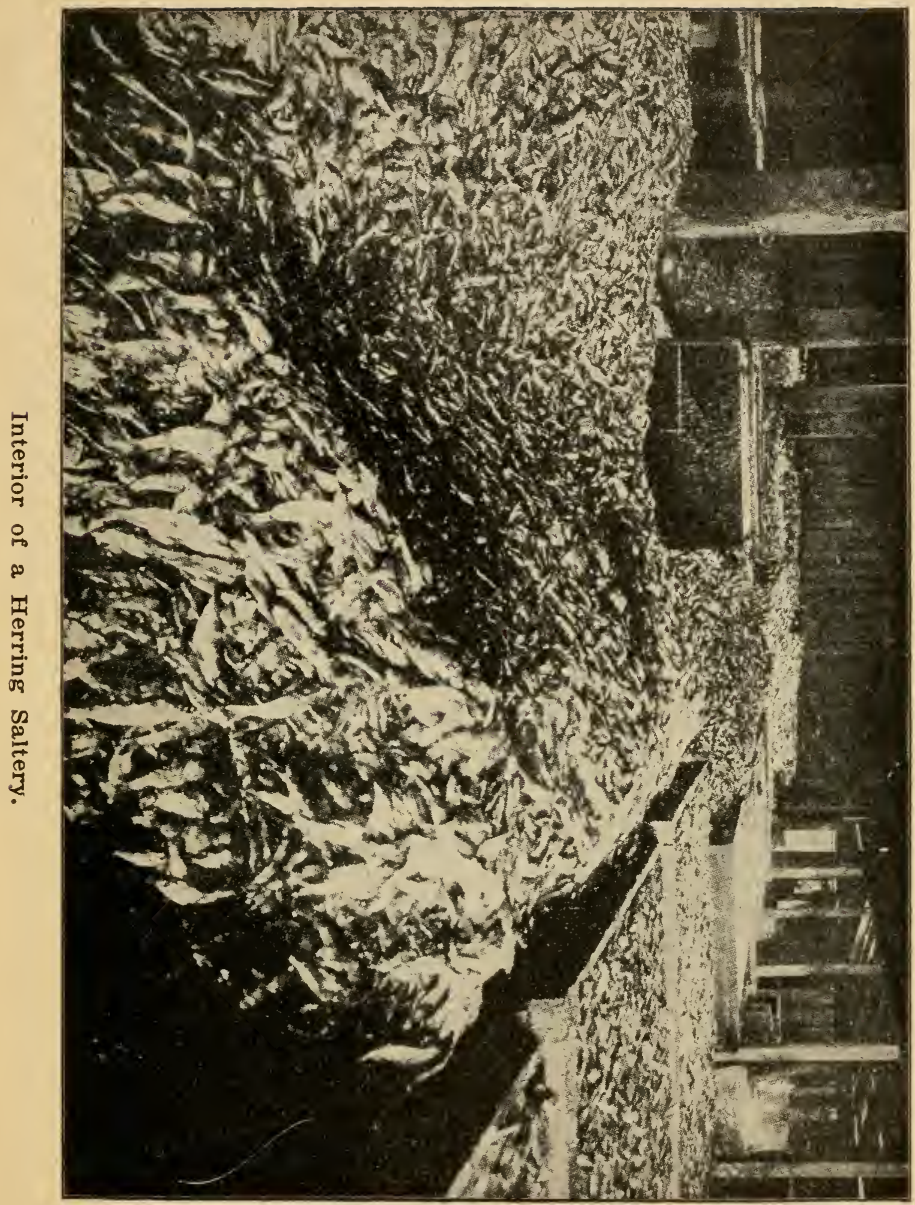


Coast. The amount salted in these two states is decreasing from year to year while the amount marketed in a fresh condition is increasing. As the cod feeds on the bottom they are taken with trawls and hand lines, though some are taken in pound nets and gill nets.

Crabs - Crabs are found along all the coasts of the United States. The different species vary much in size, habit and use. The common edible crab has names applied by catchers describing the different conditions of the shell. While shedding they are known as "comer", "buster", "peeler", and "shedder"; while growing a new shell, as "soft-shell", "paper-shell", and "buckler". Crabs are used for food, bait and fertilizer. King crabs are sold for the latter purpose. All King crabs are taken from the Atlantic Ocean, along the Middle Atlantic states, most of them from New Jersey. The most common method of taking hard crabs is with meat-baited lines, hand or set, and a dip net in which the crab is caught when hauled to the surface. Two-thirds of the soft-crab catch is taken with dredges. King crabs were formerly all caught by hand, but the great bulk are now taken in pound nets.

FLounders - The name flounder is variously applied to the flat fishes found on all the coasts of the United States, and known as "American sole", "Monterey halibut", "winter flounder", "long-finned sole", "sand dab", etc. They vary in size and shape and are sold for both food and bait. The catch is taken in weirs, nets, beam trawls and seines, and with hand lines and gaffs.

HADDOCK - The haddock is a food fish found in the Atlantic Ocean, north of the Delaware Capes; it is called "dickie" in some localities. The average weight is from 4 to 6 pounds. It is extensively used as a fresh food fish, and is also salted, pickeled and dried. The haddock is taken mostly with lines, but also with pound nets, trap nets and gill nets. 
HAKE - The species included under this head are not true hakes, but comprise different varieties of food fish found off the Atlantic Coast from Newfoundland to Cape Hatteras, which are variously known as "Old England hake", "squirrel hake", "ling", "codling", etc. The average length is from $1 \frac{1}{2}$ to 2 feet and the average weight from 3 to 8 pounds. The catch is taken principally with lines.

HALiBuT - The halibut, the largest and most valuable of the flat fishes, is found in the North Atlantic and Pacific Oceans. It is one of the largest species used for food, sometimes weighing over 300 pounds, but the average weight is from 50 to 75 pounds. Small, young fish, weighing from 10 to 20 pounds, are called "chickens", and are much sought after by epicureans. Most of the Pacific Coast catch comes from the fisheries of Washington. Most of the catch is made with lines, while some of the catch is taken with trawls.

HERRING - The herring is a very important food fish found in the North Atlantic as far south as Sandy Hook; it is never found in brackish or fresh waters. Herring weigl. from one-half to one pound and average in length about 10 inches. As a food fish they are used fresh, salted, pickled, smoked and canned. They are also used extensively for bait in the cod, haddock, halibut and hake fisheries. A large number of vessels engage in the winter herring fishery off the west coast of Newfoundland. The greater part of the catch is taken with pound nets, trap nets and weirs.

LAKE HERRING - The ciscoes, or lake herrings, are members of the whitefish family found in the Great Lakes and neighboring waters. They are caught with gill nets, pound and trap nets.

LAKE TROUT - The common lake trout is found in the Great Lakes and in the smaller lakes of the Northern States. In different localities these fish vary greatly in color, size and shape, and are known by the local names "salmon trout", "lake salmon", "black trout", "reef trout", "longe", etc. The 
"siscowet" is another species of lake trout. It is found principally in Lake Superior. Next to lake herring, lake trout is the most valuable species taken in the Great Lakes. The bulk of the lake trout catch is taken with gill nets, others with lines, pound and trap nets.

LOBSTER - The lobster, a crustacean of great economic importance, is found on the Atlantic Coast from Delaware to Labrador. It averages about 11 inches in length and about 2 pounds in weight, but the size varies with localities and seasons. It is caught in pots and traps especially constructed for the purpose.

MACKEREL - The mackerel is found in the North Atlantic south as far as Cape Hatteras. It ranges from 9 to 18 inches in length and from one-half to 3 pounds in weight, and is caught in purse seines, pound nets, weirs, gill nets, etc., and with hook and line.

MENHADEN - The menhaden is a fish of the herring family, found along the Atlantic seaboard from Maine to Florida. It is known by a great many local names, some of them being "pogy", "hard-head", "bony fish", "bunker", "cheboy", "alewife," "oldwife", "fat-back", "shiner", etc. The average weight of the menhaden is from two-thirds of a pound to one pound. They are caught in purse seines, gill nets, set nets, and weirs. Their economic importance is due mainly to the oil and guano which are produced from them; they are also used as bait for mackerel, cod, halibut, haddock and sea bass. The menhaden is the most abundant fish found anywhere in the waters of the United States and forms one of the principal fishery products. Menhaden approach the coast waters upon the advent of warm weather and remain until the water cools. They are seen as early as March in Chesapeake Bay, but not until much later in the northern waters. Purse and haul seines are the principal forms of apparatus of capture; pound nets, gill nets and trap nets are also used. 
Mussels - The black, thin-shelled, salt-water mussel is found on the Atlantic coast as far south as North Carolina and on the Pacific coast north of Monterey. The shells are used as paint holders and as ornaments.

Large quantities of another genus are sold to farmers along the New Jersey and Long Island coasts for fertilizer. The fresh-water mussels are of much value as food for animals and birds, and the shells are used in making pearl buttons. Pearl fishing was followed throughout the Mississippi Valley by the Indians and by the early settlers, in a small way, but the first excitement in recent years was in 1878 in Ohio. Since that time at regular intervals "crazes" have developed in one section or another. Among the "crazes" may be mentioned that in Wisconsin beginning in 1889 and later extending down the river; that in Arkansas in 1895 , that on the Clinch River in Tennessee in 1901, that on the Wabash in 1903, and that on the Illinois River in 1906. At the height of the excitement in Arkansas it is estimated that 10,000 persons were engaged in pearl fishing. The shells of the mussels were a waste product until the opening of the button factories. Now the shells are the important product of the industry, while pearls furnish the speculative element.

OysteR - Oysters rank first in value among all fishery products of the United States. The oyster industry is reported for every state on both the Atlantic and Pacific coasts, with the exception of New Hampshire. The greatest production is from the beds of Long Island and Chesapeake Bay.

Pike Perches - The "wall-eyed pike" is known as "glass eye", "pike perch", "yellow pike", "dory", and "blue pike" on the Great Lakes, and as "salmon", "jack", "okow", "blows fish", and "green pike" in other localities. It is an excellent food fish and sometimes reaches a weight of 20 pounds. The sauger or sandfish, which is smaller and less important 


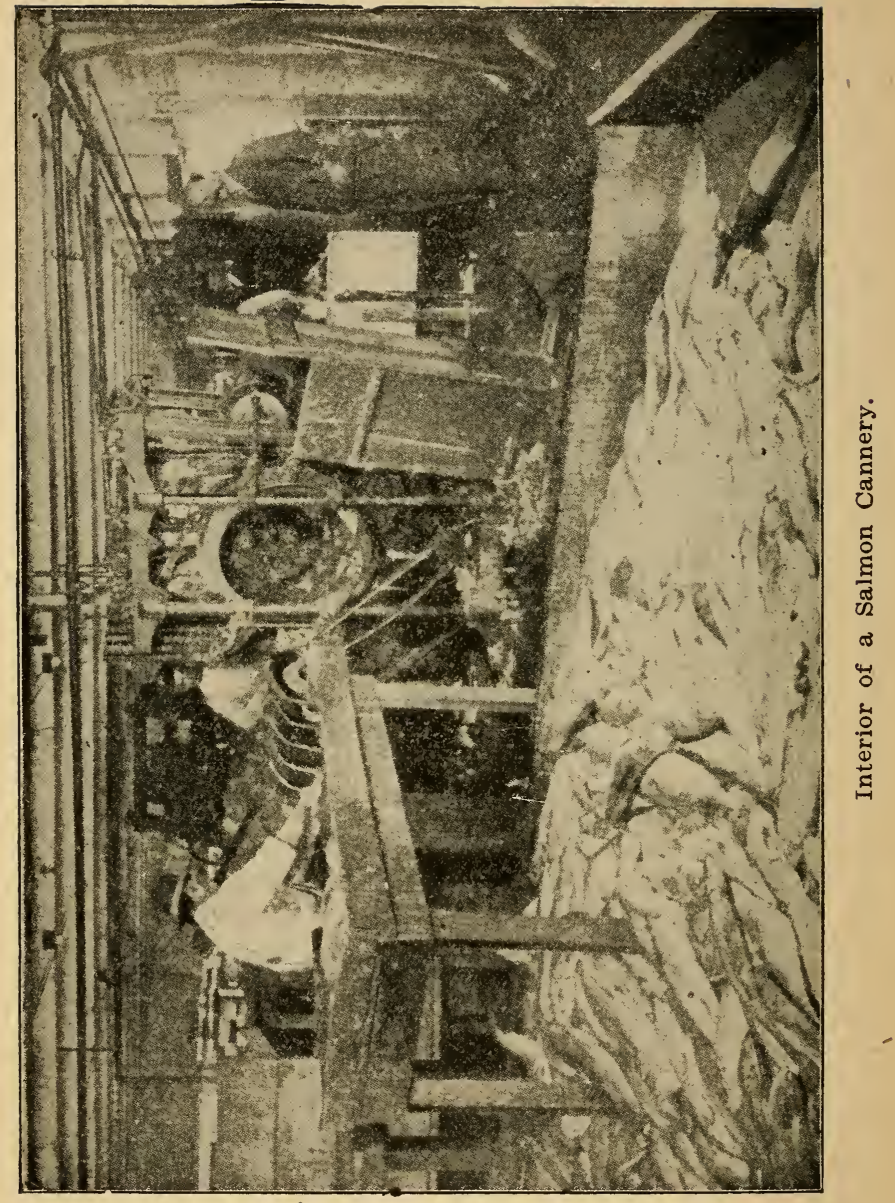


as a food fish, is especially abundant in the Great Lakes. This fish is taken principally in gill nets and pound nets.

Pollack - The pollack, a food fish of importance, is found mainly off the New England coast. It sometimes appears as far south as Virginia. The average weight is about 10 pounds. The sounds are used in the manufacture of glue, the livers are sold in large quantities for the manufacture of oil, and the tongues are cut out and sold fresh. The catch is taken principally in the vessel fisheries and the most important apparatus used are lines.

Salmon - The salmon of the Atlantic coast is found along the coast of the New England states. At different ages this fish is known as "parra", "smolts", "grilse", "kelts", and "salmon". The adults weigh from 15 to 40 pounds. The land-locked salmon, or fresh-water salmon is found, as the name implies, in fresh waters, generally land-locked. The steel-head is found in coastal streams from San Francisco northward. The blue-black salmon is found on the Pacific coast from the Columbia River northward; and the California salmon, or chinook salmon, or quinnat, is found from Monterey to Alaska. The dog salmon ranges from the Sacramento River to Behring Strait; the humpbacked salmon, or lost salmon from the Sacramento River to Alaska; and the silver salmon or white salmon is found in all rivers from the Sacramento River to Behring Strait.

Next to oysters, salmon is the most important of the fishery products. Most of the salmon catch is made on the Pacific coast.

SHAD - The common shad is found on all the coasts of the United States and in some inland waters, the most important shad fisheries being in the rivers of the Atlantic slope. The average weight is about 4 pounds and the average length about 2 feet. Among fish proper it is surpassed 
only by salmon and cod. Gill nets are the leading apparatus of capture.

Shrimp ANd PRAwN - The shrimp is a crustacean found in large numbers on all our coasts and in many inland waters. The usual length is about 2 inches, but some attain a larger size. They are caught in dip nets, purse nets, etc., and are used for food and bait. The prawn is generally larger than the shrimp, often having a length of 7 inches. The bulk of the shrimp and prawn products come from the warm western waters, and by far the largest portion from Louisiana.

SNAPPERS - The red snapper which is the most important of the snappers, is a large fish, bright red in color, and is found from Long Island southward, but in greatest abundance along the coasts of the Gulf states. The red snapper product of Florida, Alabama and Texas contribute over 90 per cent. of the total value of the snappers caught in these Gulf states. The chief fishing ground is off the west coast of Florida. As these fish habitually feed along the ground in from 10 to 40 fathoms of water, lines are only used in their capture.

SPONGE - The sponge which is of commercial value is found off the west coast of Florida.

SQUETEAGUE - The common weakfish, or squeteague is found in abundance along the Atlantic coast from Cape Cod to Florida. It averages about $2 \frac{1}{2}$ pounds in weight, but some attain a weight of 30 pounds. The spotted squeteague is found from New Jersey to Texas, and somewhat larger than the other species. The California "bluefish" and the great "white sea bass" of California are the other species of weakfish. Squeteague fishing begins in the latter part of April and lasts from six to eight weeks, until the school begins to move off into deeper and cooler waters. They are caught in pound nets, traps and weirs. 
Sturgeons - Sturgeons are found on the Atlantic and Pacific coasts and in many inland waters. The Atlantic sturgeon attains a length of from 5 to 12 feet and a weight of from 400 to 500 pounds. They are sold fresh, pickled and smoked, for food; caviar is manufactured from their eggs; the skin is made into leather; and the sounds are used in the manufacture of glue and isinglass. A valuable oil is sometimes obtained from the parts not used for food, and the refuse is used for fertilizing purposes.

WhITEFISH - Whitefish are among the most important fresh-water fishes of America. The common whitefish is the most valuable species of all, although the others are highly esteemed as food. It is found in the Great Lakes region and is known as "humpbacked", "bowbacked" and "highback" whitefish; it is also known as "Otsego bass" in the neighborhood of Otsego Lake, N. Y.

The whitefish catch is confined to the Great Lakes, Lake of the Woods, and Rainy Lake. In value it ranks fourth among the fishery products in those waters. Every state bordering on the Great Lakes share in the catch of whitefish, Michigan contributing the most. Nearly all the whitefish product is marketed fresh. Gill nets, pound and trap nets take nearly all the catch.

\section{Extent and Value of Fisheries in Canada.}

To say that Canada possesses the most extensive fisheries in the world is no exaggeration; moreover, it is safe to add that the waters in and around Canada contain the principal commercial fishes in greater abundance than the waters of any other part of the world. The extraordinary fertility of Canadian waters is abundantly proved by the fact that, apart from salmon, all the lobsters, herring, mackerel and sardines, nearly all the haddock, and many of the cod, hake, and pollack landed in Canada are taken from within its territorial waters. 
The coast line of the Atlantic provinces, from the Bay of Fundy to the Straits of Belle Isle, without taking into account the lesser bays and indentations, measures over 5000 miles; and along this great stretch are to be found innumerable natural harbors and coves, in many of which valuable fish are taken in considerable quantities with little effort.

On the Pacific coast, the province of British Columbia, owing to its immense number of islands, bays and fiords, which form safe and easily accessible harbors, has a seawashed shore of 7,000 miles.

Along this shore and within the limits of the territorial waters, there are fish and mammals in greater abundance, probably, than anywhere else in the whole world.

In addition to this immense salt-water fishing area, Canada has in its numerous lakes no less than 220,000 square miles of fresh water, abundantly stocked with many species of excellent food fishes. In this connection, it may be pointed out that the area of the distinctly Canadian waters of what are known as the Great Lakes-Superior, Huron, Erie and Ontario-forms only one-fifth part of the total area of the larger fresh-water lakes of Canada.

The fisheries of the Atlantic coast may be divided into two distinct classes: the deep-sea, and the inshore or coastal fisheries.

The deep sea fishery is pursued in vessels of from 40 to 100 tons, carrying crews of from 12 to 20 men. The fishing grounds worked on are the several banks, which lie from 20 to 90 miles off the Canadian coast. The style of fishing is that of "trawling" by hook and line. The bait used is chiefly herring, squid and capelin; and the fish taken are principally cod, haddock, hake, pollack and halibut.

The inshore or coastal fishery is carried on in small boats with crews of from two to three men; also in a class of small vessels with crews of from four to seven men. The means of capture employed by boat fishermen are gill-nets, 
hooks and lines, both hand-line and trawl, and from the shore are operated trap-nets, haul-seines and weirs. The commercial food fishes taken inshore are the cod, hake, haddock, pollack, halibut, herring, mackerel, alewife, shad, smelt, flounder and sardine. The most extensive lobster fishery known is carried on along the whole of the eastern shore of Canada, whilst excellent oyster beds exist in many parts of the Gulf of St. Lawrence; notably on the north coast of Prince-Edward Island, and in the Northumberland Straits.

The salmon fishery is, of course, the predominant one on the Pacific coast; but a very extensive halibut fishery is carried on in the northern waters of British Columbia in large, well-equipped steamers and vessels. The method of capture is by trawl-lining dories being used for setting and hauling the lines, as in the Atlantic deep-sea fishery.

Herring are in very great abundance on the Pacific coast, and provide a plentiful supply of bait for the halibut fishery.

In the inland lake fisheries, the various means of capture in use are gill-nets, pound-nets, seines, and hook-and-line to a great extent. The principal commercial fishes caught are whitefish, trout, pickerel, pike, sturgeon and fresh-water herring - the latter in the Great Lakes of Ontario only.

The total market value of all kinds of fish and fish products taken by Canadian fishermen, in both the sea and inland fisheries, during the fiscal year ended March 31, 1911, amounted to $\$ 29,965,433$.

This total is the highest yet reached in any one year in the history of the fisheries of Canada, being $\$ 336,263.32$ greater than that of the preceding year, which was a record one.

To the total, the sea fisheries contributed $\$ 26,122,596$ and the inland fisheries $\$ 3,842,837$.

In obtaining these results, there were employed 1,680 vessels and tugs, and 38,977 boats, the whole being manned by 68,610 men; while 24,978 persons were employed in the 
various canneries and fish-houses, etc., on shore, in the preparation of the fish for market. From this it will be seen that almost 100,000 people were directly employed in this great industry.

Gasoline engines are being freely used as a means of propulsion for boats in the inshore and inland fisheries. During the year under review, there were 4,588 fishing boats using such engines. The following table shows the value produced by the fisheries of each province, in its respective order of rank, with the increase or decrease as compared with the year 1909-10.

\section{Provinces.}

Nova Scotia

British Columbia ...............

New Brunswick .................

Ontario

Quebec

Manitoba

Prince Edward İland...............

Saskatchawan

Yukon

Alberta
Value

Produced. Increase. Decreáse.

$\$ 10,119,24300 \$ 2,038,13144$

$9,163,23500$

$4,134,144$ 00

$2,026,12100$

$1,692,47500$

$1,302,77900$

$1,153,70800$

172,90300

118,36500

82,46000
$\$ 1,151,52050$

542,17125

151,69200

115,96165

299,39400

43,84859

67700

10200

Totals

$\$ 29,965,43300 \$ 2,342,23651 \$ 2,005,97319$

Net Increase

$\$ 336,26332$

Nova Scotia, it will thus be seen, has again taken its place at the head of the list of fish-producing provinces, with a phenomenal increase over the previous year.

The value of the British Columbia fisheries, although it shows quite a large decrease from that of the year before, is yet $\$ 2,698,197$ ahead of that of the year 1908-9. Unfortunately, New Brunswick, Prince Edward Island and Quebec have again fallen behind.

The following table shows the relative values of the principal commercial fishes returning $\$ 100,000$ and upwards, in their order of rank for the year 1910-11, with the amount of increase or decrease when compared with the values for th: year $1909-10$. 
Kinds of Fish.

Salmon

Cod

Lobsters

Herring

Halibut

Haddock

Whitefish

Trout

Smelts

Sardines

Pickerel

Hake and cusks

Pollack

Mackerel

Pike

Clams and quahaugs......

Oysters

Alewives

Eels
Value. $\$ 7,205,871$ $5,921,248$ $3,784,099$ $2,278,842$

$1,251,839$ $1,218,759$ 983,594 825,290 797,066 539,227 508,513 508,534 405,925 400,182 330,729 383,529 198,689 137,278 110,802
Increase. Decrease.

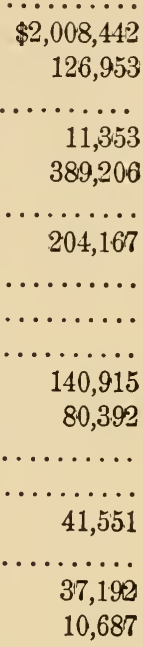

$\$ 998,653$

475,909

16,532

71,776

12,067

176,980

547,889

19,627

53,215

The foregoing table shows a phenomenal increase in the value of cod, due to the coincident of high prices with a big catch.

It is gratifying to note that there is a substantial increase in the value of lobsters over that of the previous year. The total value, however, is still considerably less than that of 1908-09.

Halibut maintains a steady increase from year to year.

A very striking falling off in the value of mackerel is recorded, the total value for $1910-11$ being not more than half the average annual value of the last twenty years. The Nova Scotia coast is almost entirely responsible for the big decrease. It is rather interesting to note in this con- 
nection that Prince Edward Island produced a value considerably in excess of that of the previous year.

It is difficult to assign a cause for such falling off in this fishery; but there can be no doubt that the means of capture in common use had a good deal to do with it. Schools of mackerel are erratic in their movements, swarming into the bays and harbours in the course of some seasons, and practically deserting them during others. In the latter event there can be only one result: namely, a diminished catch - even though the fish may be plentiful a few miles off shoreowing to the fact that the fishing is largely fixed to the shore.

a The increase in the value of oysters, which was recorded in last year's report, is more than offset by the decrease shown in the foregoing table. 


\section{CHAPTER XXII.}

\section{Distribution of Fish - Good Places.}

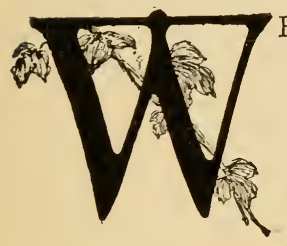

HILE an accurate knowledge of the distribution of each and every kind of fish is not essential, the angler will be interested to know approximately how far the range of certain fishes extends, and if he contemplates going to some other place where he is unacquainted, he will naturally want to know what kinds of fish he is most likely to find there. Also, if there is a vacation or a fishing trip in prospect he will want to know of the most favored localities.

It is impossible to give accurately the range of each and every species of fish for this is not known, even to naturalists. Therefore, in most cases the distribution as given can not be taken as the extreme limit of the district in which the fish is found, for sometimes some certain fish will be found in waters far removed from its natural range, and in other cases there may be a large district, embracing several states well within the boundaries of this fish's habitat, in which no such fish are found. This may be due to one or more of several causes. In many cases man has aided nature in distributing the various fishes by introducing western fishes into eastern waters, or in placing eastern fish in waters west of the Rockies, or even in bringing fish from Europe. In this way fish may become widely distributed, yet great spaces intervene. Again it is believed that various fishes were scattered over a great range during the Glacial Period, by being carried frozen in ice from far to the northward. 
It is possible too that certain fish-eating birds may carry the spawn of fishes, and often some very small stream during high water connects the heads of two different watercourses, or fish may even be carried by underground streams, but not likely any great distance.

While I have shown a map showing in general where each kind of fish is found, this is not strictly accurate and that the distribution of fishes may be better understood I will give as accurately as possible, in text, the range of each.

The small-mouthed black bass was originally found only in the region surrounding the Great Lakes, in the upper Mississippi valley, the Ohio valley, and the streams on the slopes of the southern Alleghany mountains. But the fish has been introduced into both eastern and western waters, wherever the water is reasonably cool and rapid, so that the fish is now found in all of the eastern states and some of the western ones. It is not found in the South except in the mountain streams, and I understand it does not exist farther north than the Height of Land, in Canada. The large-mouthed species is found mainly in the South, but ranges almost as far north as the small mouth, being found in the more quiet waters. One species or other is now found in every state east of the Great Plains.

On the map I have shown the sunfishes collectively, by a single character, and it should be understood that this character may mean any kind of sunfish other than the black bass.

The common sunfish or pumpkin seed is found in all of the country south of and adjoining the Great Lakes, the headwaters of the Mississippi, and all of the states lying east of the Appalachian Mountain system. The long eared sunfish is found in the same territory and also all the way down through the Mississippi valley, and on to Mexico. The blue sunfish or bluegill inhabits the entire Mississippi and Ohio valley, and the southern states. The red breast sunfish 
is found in all of the states bordering on the Atlantic, and along through the Gulf states to Louisiana. The rock bass or goggle-eye is found in New York and westward and southward throughout the Mississippi valley to Texas. The warmouth perch is found in the upper part of the Mississippi valley, and in all of the Gulf states. The Sacramento perch is found only in California. The strawberry bass or calico bass is found in the upper Mississippi river valley and eastward, then southward through the Atlantic coast states, and westward through the Gulf states. The crappie is found throughout the entire Mississippi valley, but is most abundant in the southern part. So much for the sunfish.

Of the trouts, as before said, there are many kinds, and they are scattered widely. The trout inhabits cool clear water only, and one species or other may be found in every state west of Kansas and Nebraska in the streams in or near the mountains; in all of the mountain states of the East; in the New England states and all those bordering on Canada, as well as practically all of Canada, Newfoundland and Alaska. The most common species is the brook trout; it is found in all of the New England states, New York, Pennsylvania, West Virginia, eastern Tennessee, western North Carolina, and northern Georgia, in New Brunswick, and in fact all of eastern Canada and the Great Lake region, and in Newfoundland. The cut-throat trout ranges from western Montana and northern California northward into Alaska. The rainbow trout is the most common trout on the Pacific coast and is found from northwestern Mexico northward, just how far will depend on what you call a rainbow trout, as the brook trout of the northwest is a rainbow. The rainbow has also been introduced into streams of Wisconsin, Michigan, New York, Pennsylvania, Virginia and North Carolina, also in Newfoundland. The Kansas river trout is found on the east slope of the Rockies, from the headwaters of the Kansas river to the upper Missouri in Montana. The Yellow- 


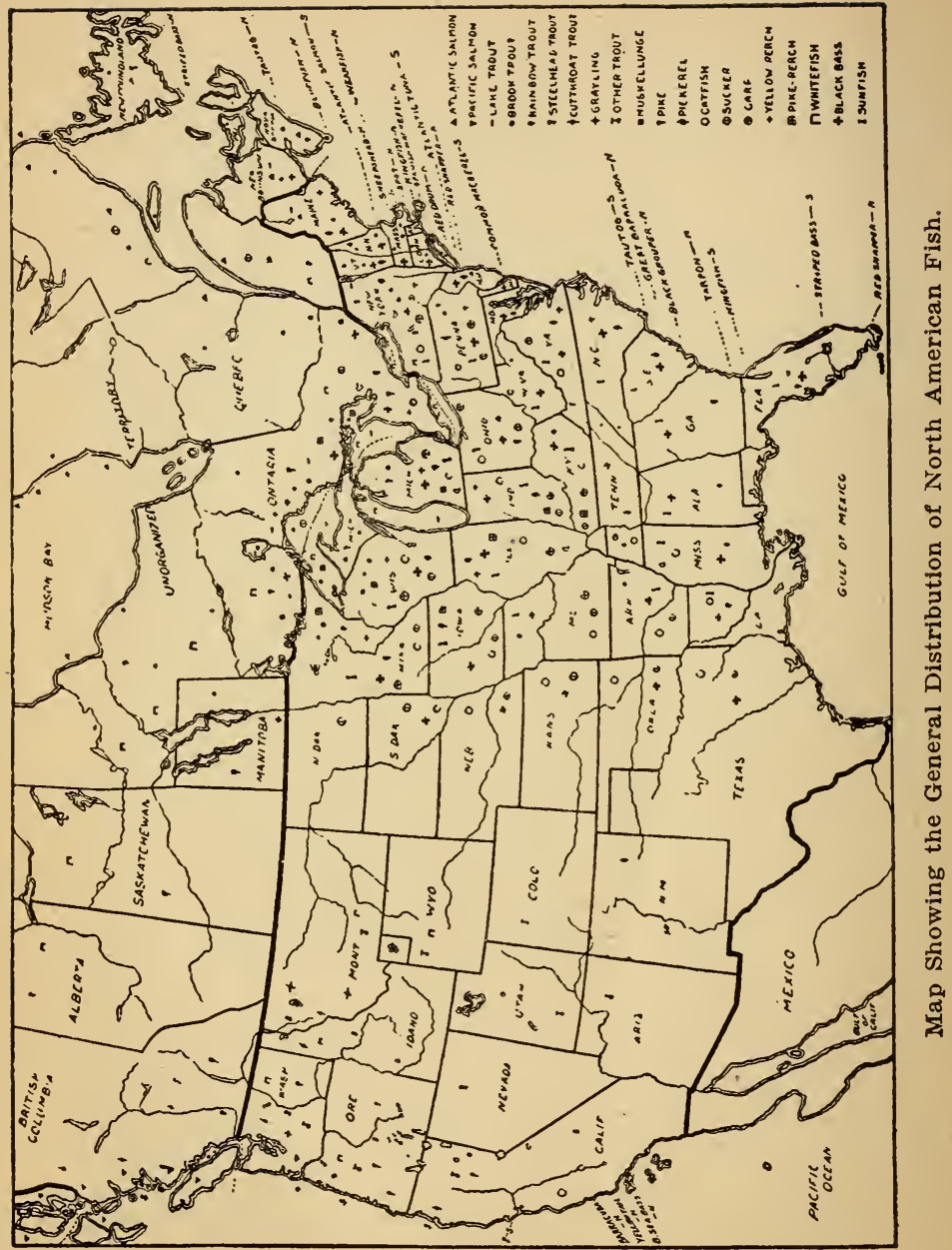


stone trout is found in northwestern Wyoming and western Montana and Idaho. The malma or dolly varden trout is found along the northwestern coast from northern California to Alaska and is caught in fresh water and in the sea. The steelhead is found, in salt water and river mouths from California northward, and spawns in the heads of the streams. It and allied species are common in British Columbia.

The true salmon of the Atlantic and Pacific are so closely related to the trouts that they might well all be called trout or all salmon, and really do, with the exception of the chars, belong to the same family. The Atlantic salmon seldom enters the streams south of Maine, and is more abundant in Canadian and Newfoundland waters. They are plentiful along the coast of Labrador and around into Hudson bay, entering the streams there in large numbers. The various Pacific ocean salmon are found all along the coast from central California northward to Behring sea and run up all of the streams to spawn.

The muskellunge and the pike inhabit the same waters, the Great Lakes, the St. Lawrence and its tributaries, certain waters of New York, and many of Michigan and Wisconsin, as well as the streams and lakes of the north side of the Great Lakes. The pike also extends northwestward into Manitoba, Saskatchewan, Alberta and the far 'northwest. The range of the eastern pickerel is from the St. Lawrence valley southward through all of the Atlantic coast states to Florida. The western pickerel inhabits all of the states of the Middle West.

The pike-perch is found in the region surrounding the Great Lakes and the upper Ohio river and its tributaries, also along near the Atlantic coast from Maryland southward. The yellow perch is more widely distributed, being found in the same range as the pike-perch and farther up along the east coast, extending through the New England states. 
The carp and the catfish are common in almost every state in the Union. All of the carp have been introduced from Europe and catfish ohave also been extended beyond their natural range by transplanting. They have been introduced into California and have thrived wonderfully. The rivers of the Middle West are probably the best streams for carp and the Illinois river is said to produce heavily of these. The south shore of Lake Erie is also a great carp producing water, and they are netted there and sent to the city markets. There are four of the New England states in which catfish are not found, but they are probably found in every other state. Illinois is said to lead in the production of this fish.

Perhaps the best districts to go to for fishing in the United States are Maine, New York, northern Michigan, Wisconsin and Minnesota, Florida, California and Washington. In Canada, which is unsurpassed as an angler's resort, the St. Lawrence river, New Brunswick, the many lakes of Ontario, and British Columbia are the most noted places. Newfoundland is noted for its salmon and trout.

Practically all of northern Maine teems with speckled trout and the many lakes and rivers offer an almost unlimited field for the angler. Very large trout are taken in some of the Maine waters, and I think that this state holds the record for large speckled trout. The Rangeley lakes, Moosehead lake, the Penobocot river, the Aroostock, are among the much visited waters, but almost any part of the state offers good fishing. Besides the speckled trout, lake trout or togue are found in some of the lakes, also landlocked salmon.

In New York there is much good fishing to be had. Some of the best bass fishing may be had there. There is good bass fishing in practically all of the waters of the central and western portions, and up in the northeastern part, in the Adirondacks, very good trout fishing is obtained. 
These mountains have many lakes and streams that are filled with trout, and some lakes contain lake trout or salmon trout as they are called there. There is also very good fishing for a varied line of fish in the group of lakes in the central part of the state. In the St. Lawrence, about the Thousand Islands, there is good black bass fishing, and muskys are also found.

Large fish are seldom taken in Pennsylvania, but small brook trout are abundant in the mountain streams. In all of the central, northern and northeastern parts good trout fishing may be had. Black bass are also found and are probably most abundant in the southeastern and northwestern parts.

Down in West Virginia there is also some good angling, perhaps the best is in the eastern part of the state, in the Greenbrier, Cheat, and Tygerts Valley rivers. where trout and bass are found.

Kentucky is full of good fishing streams. It was in this state that angling for black bass was first raised from its original level with angling for bottom fish.

Florida is an angler's Paradise. Very large black bass, the large mouthed kind, are found there, as well as many other fresh water fish. Perhaps the best region, anyway one of the best, is in Lake County. I am not speaking of the salt water fishing here, but there is no finer fishing of that kind to be had anywhere than along the Florida coast.

In Ohio black bass are found in nearly all streams, also other fish of various kinds. The most popular resorts are the artificial lakes known as Buckeye Lake, Indian Lake, Six Mile Reservior and Grand Reservior. The fish are large mouthed black bass, perch and sunfish of several kinds.

In Indiana and Illinois there are many good fishing streams and lakes, containing black bass, pike, pickerel, cat fish, carp and crappies. All in all, perhaps one stream is as good as another. 
Michigan furnishes some excellent fishing, the waters being largely stocked from the Great Lakes. Both kinds of bass are found there, also pike and muskellunge, and other fish of less note. There are so many good places that I will not attempt to name them. Good rainbow trout fishing may be had in the Au Sable and the fish grow to a large size. Brook trout are found in the Upper Peninsula and the northern part of the Lower Peninsula.

In Wisconsin we have perhaps the best muskellunge waters in the United States, the fish being found in the waters of the Mississippi system. Black bass and other fishes, such as calico bass, pickerel and perch are abundant. Trout are found in the northern part in plenty.

In Minnesota the fishing is practically the same as in Wisconsin.

Not much can be said regarding the fishing in Nebraska and Kansas except that there are black bass, catfish, etc., and several kinds of trout in the western part. In the $\mathrm{Da}$ kotas the best fishing is to be had in the eastern parts.

Western Montana and Idaho are rich in trout, and the Rocky mountain whitefish is found there also. Grayling are also found in Montana.

There is good trout fishing in Western Wyoming, fine, I should say, for the streams coming down from the Rockies are filled with these fish. Whitefish are also plentiful.

Colorado is full of fine trout streams and there are several kinds of trout found there.

In Washington and Oregon there is fine fishing as the Salmon and steelhead trout ascend all of the streams up into Idaho. There are also the western brook trout and other native fish as well as introduced kinds.

California probably gives the best trout fishing of all of the Pacific coast states, having a number of kinds of trout. There are also other fish, and the sea angling of the southwest coast is of the finest. Lake Tahoe, on the California- 
Nevada line, is a large body of very clear water, containing an abundance of Tahoe trout, which are also found in some of the other lakes.

Leaving Uncle Sam's country and going up into British Columbia, we find some of the finest fishing to be had anywhere. The best salmon fishing is found in the salt water where the waters are protected by the many islands. Perhaps the best place in the world for the Pacific salmon is in the Campbell river, on Vancouver Island. The northern lakes are stocked with whitefish and trout of many kinds abound in the inland rivers and lakes.

Trout are found also in parts of Alberta and Saskatchewan, but in these provinces as well as in Manitoba it is the whitefish that is the most important. It is not a game fish, but is a food fish of the highest rank. Pike are also found there and in the lower part of Manitoba black bass are found.

Ontario is the greatest fresh water angler's field of Canada. Here the brook trout is found in almost incredible numbers, and its trout waters, especially Nipigon river and lake are world famous. There is also excellent musky fishing in the waters adjacent to Lake Huron and black bass are also plentiful. Pike are found in many of the lakes and reach a large size. Some of the most noted waters are Nipigon, Kawartha Lakes, Muskoka Lakes, Temagami (for lake trout), Lake of Bays, the waters of the Algonquin Park, etc.

Quebec offers fine fishing also, especially in the St. Lawrence and adjacent waters. Good salmon fishing is to be had in the rivers of the north shore of the Gulf of St Lawrence.

New Brunswick is noted for its trout and salmon fishing, and is probably the same in this respect as Newfoundland. Both places are much visited by non-resident anglers. 
In this description I have not mentioned nearly all of the fish found in any state or province, nor could I mention many of the good places to visit, as a volume could be devoted to that. There are many fish that I have not mentioned, either here or in any part of this book, but I have described and told of the principal kinds, and those that I consider most important. If you learn to catch these you will have no trouble with the others. 
BOSTON PUBLIC LIBRARY

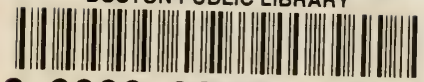

39999065613208 
$\cos$

$x_{0} 0$ 